PARADOSIS

Beiträge zur Geschicbte der altchristlicben Literatur und Theologie III

JOSEPH KASPAR STIRNIMANN

DIE PRAESCRIPTIO TERTULLIANS

IM LICHTE DES RÖMISCHEN RECHTS

UND DER THEOLOGIE 
Vorliegende Sammlung will Untersuchungen aus dem Gebiete der altchristlichen Literatur und Theologie unter dem Namen PARADOSIS vereinen. Der griechische, in der frühesten theologischen Terminologie gut beheimatete Titel wurde gewählt, um verschiedensprachigen Arbeiten Aufnahme gewähren $\mathrm{zu}$ können, ohne dadurch die Zitation umständlicher zu gestalten. Er offenbart auch eine grundsätzliche Haltung und ein Programm. Christliche Theologie wurzelt wesensgemä $\beta$ in der Vergangenheit. Nur in der lebendigen Verbundenheit mit ihr kann sie sich fortentwickeln. Jede auch noch so bescheidene Klärung der Uberlieferung und ihrer Quellen ist daher Beitrag an die Theologie der Gegenwart.

Freiburg i. d. Schweiz.

Othmar Perler. 




$$
\text { PARADOSIS }
$$

Beiträge zur Geschicbte der altchristlicben Literatur und Theologie

JOSEPH KASPAR STIRNIMANN

\section{DIE PRAESCRIPTIO TERTULLIANS IM LICHTE DES RÖMISCHEN RECHTS UND DER THEOLOGIE}


Dissertation zur Erlangung der Doktorwürde der hohen Theologischen Fakultät der Universität Freiburg in der Schweiz eingereicht und von ihr begutachtet am 15. Juni $19 ! 4$.

Mit Druckerlaubnis des Ordinariates Basel, vom 21. April 1949. 
PARENTIBUS PIISSIMIS PRIMIS FIDEI MAGISTRIS 



\section{INHALTSÜBERSICHT}

Inhaltsūbersicht . . . . . . . . . . . . . . . . vII

Literaturverzeichnis. . . . . . . . . . . . . . . IX

Verzeichnis der Abkürzungen . . . . . . . . . . . . . . XI

Einleitung. . . . . . . . . . . . . . . . . 1

ERSTER TEIL

Die praescriptio im römischen Recht

Erstes Kapitel

Der römische Zivilprozeß und seine verschiedenen praescriptiones. . . . . . . . . . . . . . . 11

1. Der FormularprozeB . . . . . . . . . . . . . . . . 12

A. Der äußere Verlauf des Formularprozesses . . . . . . . . 12

B. Die Formel im Formularprozeß, ihre Bestandteile, besonders praescriptio und exceptio . . . . . . . . . . . 14

2. Der Kognitionsprozeß . . . . . . . . . . . . . . . . 20

A. Der äußere Verlauf des Kognitionsprozesses. . . . . . . . 20

B. Die praescriptio des Kognitionsprozesses . . . . . . . . . 21

3. Die praescriptio ein mehrdeutiger Begriff . . . . . . . . . . 25

Zweites Kapitel

Die longi temporis praescriptio . . . . . . . . . . 28

1. Das Wesen der Ersitzung . . . . . . . . . . . . . . 28

2. Die ältesten Quellen der longi temporis praescriptio . . . . . 32

3. Die Voraussetzungen der longi temporis praescriptio . . . . 33

4. Die prozessuale Gestalt der longi temporis praescriptio . . . . 35

\section{ZWEITER TEIL}

Die Anwendung der praescriptio durch Tertullian

Erstes Kapitel

Analyse von De praescriptione haereticorum 15-37. . 39

1. Ankündigung des eigentlichen Ziels . . . . . . . . . 43

2. Rechtfertigung dieser Methode. . . . . . . . . . . . . 4 4́ 
3. Der Weg zum Ziel, vorgezeichnet in der Partitio. . . . . 45

4. Beantwortung der Partitio . . . . . . . . . . . . . . . 47

5. Die zwei Präskriptionen. . . . . . . . . . . . . . . . . . 50

6. Das auf Grund der 2. Präskription formulierte Kriterium und seine Anwendung. . . . . . . . . . . . . . . . . . . 5't

7. Verteidigung der Präskriptionen gegen die drei Objektionen der Häretiker . . . . . . . . . . . . . . . . . . . 57

8. Einläßliche Analyse der dritten Objektion bzw. ihrer Widerlegung $\quad 62$ A. Die vollendete Einheit des Glaubens . . . . . . . . . . 64

B. Die stete Priorität der Wahrheit vor dem Irrtum . . . . 6't

9. Die Aufforderung an die Häretiker zur Replik . . . . . . . 74

10. Letztes Argument zu Gunsten der 2. Präskription und Vergleich des römischen und afrikanischen Symbolums . . . . . 76

11. Folgerungen bezüglich der Heiligen Schrift . . . . . . . . . 79

\section{Zweites Kapitel}

Die tertullianischen Präskriptionen, im besonderen jene von praescr. haer. 21 . . . . . . . . . . . . . 82

1. Die Übereinstimmung der Präskriptionen Tertullians mit jenen des Prozesses hinsichtlich der wesentlichen Eigenschaften derselben . . . . . . . . . . . . . . . . . . . . . .

2. Die Verschiedenheit der tertullianischen und prozessualen Präskriptionen hinsichtlich des Inhaltes . . . . . . . . . . . . 92

3. Die Formulierung der zwei Präskriptionen in praescr. haer. $21 \quad 96$

4. Praescr. haer. 37 und die longi temporis praescriptio . . . . 99

A. Kap. $37 \mathrm{im}$ Zusammenhang gesehen. . . . . . . . . . . 100

B. Die juristischen Elemente in Kap. 37 . . . . . . . . . 111

5. Wie viele Präskriptionen enthält praescr. haer. ? . . . . . 127

\section{Drittes Kapitel}

Die theologische Bewertung der tertullianischen Präskriptionen . . . . . . . . . . . . . . .

1. Die tertullianischen Präskriptionen und die Forderungen der Apologetik . . . . . . . . . . . . . . . . . . . . .

2. Die 2. Präskription in praescr. haer. 21 theologisch nicht beweiskräftig. . . . . . . . . . . . . . . . . 1 149

Schlußwort . . . . . . . . . . . . . . . . 173

Stellenregister . . . . . . . . . . . . . . . 177

Personen- und Sachregister . . . . . . . . . . . . 178 


\section{LITERATURVERZEICHNIS}

I. TEIL

\section{Quellenausgaben}

Bruns C. G., Fontes juris Romani antiqui, Pars prior : Leges et Negotia, 7. Aufl., Tübingen 1909.

Krüger P. - Mommsen Th., Corpus Iuris Civilis, 2 Bde, Berlin 1932/4.

Krüger P. - Mommsen Th. - Studemund G., Collectio librorum iuris anteiustiniani, Berlin $1878 \mathrm{ff}$.

Mitteis L. - Wilcken U., Grundzüge und Chrestomathie der Papyruskunde, 2. Bd. Juristischer Teil, 1. Hälfte: Grundzüge, 2. Hälfte : Chrestomathie, Leipzig-Berlin 1912.

\section{Darstellungen und Untersuchungen}

Beck A., Römisches Recht bei Tertullian und Cyprian. Eine Studie zur frühen Kirchenrechtsgeschichte, in Schriften der Königsberger Gelehrten Gesellschaft, Geisteswissenschaftliche Klasse, 7. Jahrg., Heft 2, Halle a. d. Saale 1930.

Bethmann - Hollweg v. M. A., Der römische Civilprozeß, 3 Bde, Bonn $1864 / 6$.

BüLow O., Die Lehre von den Prozeßeinreden und Prozeßvoraussetzungen, Gießen 1868.

Girard P. F., Manuel élémentaire de Droit Romain, 8. Aufl., Paris 1929.

Jörs - Kunkel - Wenger, Römisches Recht, in Enzyklopädie der Rechtsund Staatswissenschaft II-III, 2. Aufl., Berlin 1935.

KRÜGER P., Geschichte der Quellen und Literatur des römischen Rechts, 2. Aufl., München-Leipzig 1912.

KüBLER B., Geschichte des römischen Rechts, Leipzig-Erlangen 1925.

Meyer P. M., Juristische Papyri, Erklärung von Urkunden zur Einführung in die juristische Papyruskunde, Berlin 1920.

Partsch J., Die longi temporis praescriptio im klassischen römischen Rechte, Leipzig 1906.

- Die Schriftformel im römischen Provinzialprozeß, Berlin 1905.

Wenger L., Institutionen des römischen Zivilprozeßrechts, München 1925.

N. B. Auf die übrige Literatur wird in den Anmerkungen verwiesen. 


\section{TEIL}

\section{Textausgaben}

Hoppe H., Quinti Septimi Florentis Tertulliani opera (Apologeticum) in Corpus scriptorum ecclesiasticorum latinorum, Bd. 69, Wien 1939.

Kroymann E., Q. S. F. Tertulliani opera, in CSEL Bd. 47, Wien 1906 ; Bd. 70, Wien 1942.

Öhler F., Quinti Septimii Florentis Tertulliani quae supersunt omnia, 2 Bde, Leipzig 1853/4.

Reifferscheid A. - Wissowa G., Q. S. F. Tertulliani opera, in CSEL Bd. 20, Wien 1890.

\section{Darstellungen und Untersuchungen}

Adam K., Der Kirchenbegriff Tertullians, Eine dogmengeschichtliche Studie, in Forsch. z. Christl. Literatur- und Dogmengeschichte, hrg. von A. Ehrhard und J. P. KIRsch, 6. Bd., 4. Heft, Paderborn 1907.

D'Alès A., La théologie de Tertullien, Paris 1905.

Allie J.-L., L'Argument de prescription dans le Droit romain, en Apologétique et en Théologie dogmatique, Ottawa 1940.

BARdenhewer O., Geschichte der altkirchlichen Literatur, 2. Bd. Vom Ende des zweiten Jahrhunderts bis zum Beginn des vierten Jahrhunderts $^{2}$, Freiburg i. B. 191/.

Hoppe H., Syntax und Stil des Tertullian, Leipzig 1903.

Hüntemann U., Tertulliani de praescriptione haereticorum libri analysis, Quaracchi 1924.

Koch H., Tertullian, Art. in Pauly - Wissowa - Kroll, Real-Encyclopädie der klass. Altertumswissensch. II 5 A (Stuttgart 1934) Kol. 823.

De Labriolle P., Histoire de la littérature latine chrétienne, Paris 1920.

- L'Argument de Prescription, Revue d'histoire et de littérature religieuse 11 (Paris 1906) S. 408-429, 497-514.

- - Tertullien jurisconsulte, Nouvelle Revue historique de droit français et étranger 30 (Paris 1906) S. 5-27.

LorTz J., Tertullian als Apologet, 2 Bde, Münsterische Beiträge zur Theologie, Fasz. 9-10, Münster i. W. 1927/8.

Monceaux P., Histoire littéraire de l'Afrique chrétienne, depuis les origines jusqu'à l'invasion arabe, t. I : Tertullien et les origines, Paris 1901.

Morel V., Disciplina, Le mot et l'idée représentée par lui dans les oeuvres de Tertullien, in Revue d'histoire ecclésiastique 40 (Löwen 1944/5) S. 5-46.

Teeuwen St. W. J., Sprachlicher Bedeutungswandel bei Tertullian, Ein Beitrag zum Studium der christlichen Sondersprache, Studien zur Geschichte und Kultur des Altertums, 14. Bd., 1. Heft, Paderborn 1926.

N. B. Vitton P., I concetti giuridici nelle opere di Tertulliano, Rom 1924, war unerreichbar.

Auf die übrige Literatur wird in den Anmerkungen verwiesen. 


\section{VERZEICHNIS DER ABKÜRZUNGEN}

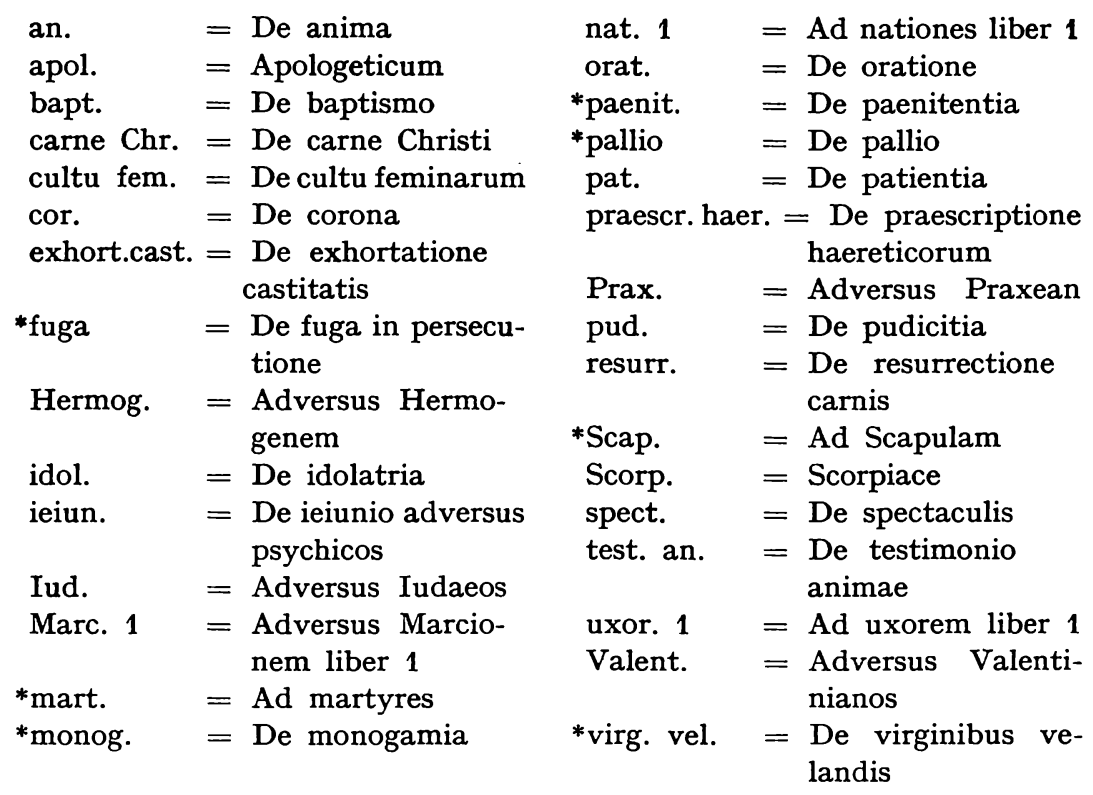

1. Tertullians Schriften werden nach der Ausgabe des Corpus scriptorum ecclesiasticorum latinorum (CSEL) zitiert, mit Ausnahme von sieben (oben mit einem * bezeichnet), die im CSEL noch nicht vorliegen und daher nach der Ausgabe von Oehler (Oe.) zitiert werden.

Die im CSEL edierten Schriften verteilen sich wie folgt auf die einzelnen Bände :

CSEL 20 ed. A. Reifferscheid et G. Wissowa (RW.) enthält: spect. orat. idol. bapt. nat. pud. test. an. ieiun. Scorp. an.

CSEL 47 ed. E. Kroymann (Kr.) enthält: $\begin{array}{ll}\text { pat. } & \text { Valent. } \\ \text { resurr. } & \text { Prax. } \\ \text { Hermog. } & \text { Marc. }\end{array}$ 
CSEL 69 ed. H. HOPPe (H.) enthält apol.

CSEL 70 ed. E. KroymanN (Kr.) enthält: praescr. haer. cor. cultu fem. carne $\mathrm{Chr}$. ux. Iud.

exhort. cast.

2. Aus dem Corpus Iuris Civilis von Justinian (ed. P. KrüGERTн. Mommsen) werden nur Digesten und Codex zitiert; z. B. :

Ulpianus dig. 48, 5. 16,6 = Digestorum liber 48, titulus 5 , lex oder fragment. 16, § 6. Der 1. Absatz der lex heißt principium (pr.) z. B. : Ulpianus dig. 49, 1, 3pr.

Dem Digesten-Zitat wird der Name des röm. Juristen vorangesetzt, dem die betr. Stelle entnommen ist, z. B. Ulpianus, Papinianus etc.

Cod. = Codex (Einteilung und Zitat wie bei Digesten). 


\section{EINLEITUNG}

Von den $z$ ahlreichen Schriften Tertullians ist von jeher keine so viel bewundert und zitiert worden wie De praescriptione haereticorum (praescr. haer.). Ein Kenner wie J. A. MöHLER hat praescr. haer. " in ihre r Anlage und Durchführung wie in ihrem Gehalte die vollendetste, geist- und wertvollste der tertullianischen Schriften "1 genannt. Die Schrift stammt ohne Zweifel aus der besten katholischen Zeit des Autors, wenn auch eine genaue Datierung unmöglich ist, denn sie hält sich frei von den Übertreibungen und Einseitigkeiten der montanistischen Periode. "Der Geist und die Durchführung des Ganzen", bemerkt ebenfalls MöHLER, " lassen überall den Katholiken erkennen. " ${ }^{2}$ Nach O. BARDENHEwer ist Tertullian " wohl nirgendwo so wie hier der Anwalt der Kirche gewesen. Wiewohl die Frucht eigenen Nachdenkens, ist sein Buch der treue Spiegel des BewuBtseins der Kirche. Er ist der Wortführer. Hinter ihm steht die gesamte Kirche " ${ }^{3}$.

Was die Eigenart und den Wert dieser Schrift Tertullians ausmacht, sind, wie der Titel derselben schon anzeigt, die darin entwickelten praescriptiones oder Prozeßeinreden. Diese, bekannt als Präskriptionsargument Tertullians, verleihen dem betreffenden Traktat eine Aktualität, die die Jahrhunderte überdauert. Praescr. haer. liest sich denn auch heute so wirklichkeitsnah wie zur Zeit ihrer Abfassung.

Unter der praescriptio, die Tertullian hier vorschwebt ist - um zur ersten Orientierung nur so viel vorauszuschicken - die Prozeßeinrede des römischen Kognitionsprozesses zu verstehen. Mit dieser Einrede, die der Richter bzw. das Gesetz in bestimmten Fällen gewährt, weist der Beklagte seinen Kläger kurzerhand $a b$, so da $B$ der Richter den eigentlichen Streit, der die beiden Parteien entzweit, überhaupt nicht zu untersuchen und abzuklären braucht.

1 Patrologie oder christliche Literärgeschichte, hrg. v. ReithmayR, 1. Bd. (Regensburg 1839) 712.

2 A. a. O. 713.

3 Geschichte der altkirchlichen Literatur 2, 2. Bd. $407 / 8$. 
Tertullian hatte die Kühnheit, dieses ausgesprochen prozeßrechtliche Institut auf die Apologetik anzuwenden. Im Streit der Katholiken und Häretiker, wer die echte christliche Lehre besitze, erhebt Tertullian im Namen der Kirche und in der Rolle des Beklagten gegen die Häretiker Prozeßeinreden - worin diese Prozeßeinreden bestehen und wie viele ihrer sind, soll im Laufe der Arbeit enthüllt werden - d. h. Tertullian beruft sich den Häretikern gegenüber auf Tatsachen, wodurch diese gleich einem Kläger im Prozeß ein für allemal abgewiesen und widerlegt werden sollen, so da $B$ ein Eingehen auf die verschiedenen Lehrstreitigkeiten gar nicht mehr nötig sei.

Nicht zuletzt hat dieses geistvolle Argument den Namen Tertullians berühmt gemacht. In den Präskriptionen hat dieser sprühende Geist der Apologetik eine ihrer schlagfertigsten Waffen geschmiedet. Die "domina mater ecclesia" - so nennt der katholische Tertullian einmal die Kirche ${ }^{1}$ - hat es ihm, dem Abtrünnigen, bis heute nicht vergessen.

So sehr nun aber auch die Präskriptionen Tertullians von jeher ungeteilte Anerkennung und Bewunderung fanden, so sind doch Bedenken an diesem noch so meisterhaften Verteidigungsmittel nicht von der Hand zu weisen. Wie läßt sich denn die Anwendung eines so ausgeprägten Rechtsbegriffes wie die praescriptio auf die Theologie rechtfertigen? Wie gelingt Tertullian überhaupt im einzelnen diese Übertragung? Hat er die prozessuale praescriptio unverändert in die Apologetik herübergenommen, oder hat er sie vielleicht je nach den besondern Ansprüchen der Apologetik umgeformt? Wie hat Tertullian sie umgeformt ? Und nicht zuletzt, wie viele Präskriptionen erhebt er in der betreffenden Schrift gegen die Häretiker, etwa nur eine, wie der Titel der Schrift glaubhaft machen könnte, oder drei, wie es bis jetzt fast allgemeine Überzeugung war, oder wenn dies falsch ist, wie viele, und wie lauten sie? Wie sind schließlich die festgestellten Präskriptionen vom theologischen Standpunkt aus zu bewerten ? Das sind Fragen von prinzipieller Bedeutung, sie rühren an die Grundlagen des Präskriptionsargumentes. Von ihrer Beantwortung hängen Wert und Berechtigung des Argumentes ab. Trotz ihrer Wichtigkeit waren diese grundlegenden Fragen bis jetzt nie Gegenstand einer eingehenden Untersuchung. P. De LABRiolle begnügt sich, in einem größern Artikel den juristischen Gedankengang von praescr. haer. zu skizzieren und eine

1 Mart. 1 (Oe. I 3). 
Geschichte des Präskriptionsargumentes zu bieten ${ }^{1}$. Die einzige gründlichere Arbeit, die bis heute über praescr. haer. vorliegt, ist die Analyse von U. Hüntemann ${ }^{2}$.

Die vorliegende Untersuchung möchte also eine Lücke ausfüllen. Sie stellt sich die Aufgabe, die Präskriptionen Tertullians vom römischen Prozeßrecht her zu beleuchten. Inwieweit hat der Apologet der praescriptio ihren prozeßrechtlichen Charakter belassen und in was hat er sie den ganz anders gearteten Erfordernissen der Theologie angepaßt ? Wie halten endlich diese theologischen Präskriptionen Tertullians einer theologischen Kritik stand?

Unsere juristisch-theologische Fragestellung gegenüber den Präskriptionen Tertullians, die, zugegeben, in erster Linie als theologisches Argument gedacht sind, ist umso berechtigter, als Tertullian heute nicht nur als Theologe, sondern auch als Jurist ernst genommen wird. Seine Schriften sind, als Ganzes oder in einzelnen Teilen, meist von einem durchaus juristischen Gedankengang getragen. Es sei nur an das Apologeticum, De corona, Adversus Hermogenem und besonders an praescr. haer. verwiesen. Durch nichts verraten jedoch die tertullianischen Schriften so deutlich die juristische Bildung ihres Verfassers, wie im Stil. Wie keines andern ist das Werk dieses Apologeten voll von juristischen Begriffen und Redensarten. Man durchblättere nur das Apologeticum oder praescr. haer. unter diesem Gesichtspunkt. Die juristischen Termini und Vergleiche fließen Tertullian ungesucht bei jeder Gelegenheit in die Feder. Le style c'est l'homme. Wie will man einen so ausgeprägt juristisch gefärbten Stil erklären, als durch eine Persönlichkeit, die juristisch durchgebildet ist, wie schon Eusebius ${ }^{3}$, und dies wohl kaum von ungefähr, berichtet, woraus sich denn auch diese ebenso reiche wie zwanglose juristische Ausdrucksweise ergibt. Trotzdem wagte noch vor Jahren S. Schlossmann, Tertullian nicht nur den Beruf eines Advokaten, sondern schlechthin jede einigermaßen

1 L'Argument de Prescription, Revue d'histoire et de littérature religieuse 11 (1906) 408-429, 497-514.

2 Tertulliani de praescriptione haereticorum libri analysis, Quaracchi 1924. Die Dissertation von J.-L. Allie, L'Argument de Prescription dans le Droit romain, en Apologétique et en Théologie dogmatique, Ottawa 1940, hat uns infolge der Zeitumstände erst lange nach Abschluß der vorliegenden Arbeit erreicht. Wir werden uns mit AllıE, soweit seine Arbeit die unsere berührt, im Verlaufe unserer Untersuchung auseinandersetzen.

3 Hist. eccl. 2, 2, 4 (ed. Ed. Schwarz, Griech. Christl. Schriftst. 9, 2. Bd.

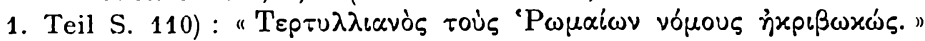


gründliche Kenntnis des römischen Rechts abzusprechen 1, wogegen P. DE LABRIOLLE in einer sachlichen Antwort seine ernsten Einwände erhob ${ }^{2}$. In neuerer Zeit dürfte indes A. BECK den Nachweis erbracht haben, daß Tertullian nicht bloß ein Schriftsteller mit einigermaßen zuverlässiger Rechtskenntnis, wenn es gut geht Advokat (Sachwalter, causidicus), sondern Rechtsgelehrter, iurisconsultus im strengen Sinn des Wortes gewesen sein muß ${ }^{3}$.

$\mathrm{Ob}$ jedoch der Apologet Tertullian mit dem gleichnamigen und gleichzeitigen römischen Juristen, aus dessen Schriften die Pandekten Justinians einiges aufgenommen haben, identisch sei, ist bis heute unentschieden und wird es wohl bleiben. Tertullian wäre, wenn der Nachweis gelänge, nicht der einzige Afrikaner unter den damaligen Leuchten der römischen Jurisprudenz. Von den beiden größten Juristen Roms, Tertullians Zeitgenossen, stammte der berühmteste, Salvius Julianus ${ }^{4}$ sicher, Aemilius Papinianus ${ }^{5}$ höchstwahrscheinlich aus Afrika ; und der juristisch gebildete und interessierte Kaiser Septimius Severus (193-211), in dessen Regierungszeit die schriftstellerische Tätigkeit Tertullians größtenteils fällt, war bekanntlich der erste Afrikaner auf dem römischen Kaiserthron. Als letzter hat A. BEck den Versuch unternommen, die Personengleichheit der beiden Tertulliane nachzuweisen, ohne jedoch zu überzeugen ${ }^{6}$; es steht nur so viel fest, daß fast nur Gründe dafür und sozusagen keine dagegen sprechen. Seither hat Hugo KocH den Stand der Frage folgenderweise zusammengefaßt : "Ob er (Tertullian) mit dem Juristen gleichen Namens ... personengleich gewesen sei, läßt sich nicht sicher entscheiden, wenn es auch sehr wahrscheinlich ist..) ${ }^{7}$

Soweit die Gründe, die eine Untersuchung der tertullianischen Präskriptionen im Lichte des römischen Rechts rechtfertigen.

1 Tertullian im Lichte der Jurisprudenz, Zeitschr. für Kirchengeschichte 27 (Gotha 1906) 251-275, 407-430.

2 Tertullien jurisconsulte, Nouvelle Revue historique de droit français et étranger 30 (1906) 5-27.

${ }^{3}$ Römisches Recht bei Tertullian und Cyprian, Eine Studie zur frühen Kirchenrechtsgeschichte (Halle a.d. Saale 1930). $124 \mathrm{ff}$.

${ }_{4}$ TH. KIPP, Geschichte der Quellen des römischen Rechts ${ }^{3}$ (Leipzig 1909)

5 A. a. O. 135 Anm. 10.

B Römisches Recht bei Tertullian und Cyprian 39/43.

7 Pauly-Wissowa-Kroll, Real-Encyclopädie der klassischen Altertumswissenschaft II 5 A (Stuttgart 1934) Kol. 823. Vgl. zur gleichen Frage J. Lorrz, Tertullian als Apologet, 2. Bd. $221 \mathrm{ff}$ und B. Altaner, Patrologie (Freiburg i. B. 1938) 86. 
Im folgenden sei eine erste Übersicht unserer Arbeit geboten. Sie zerfällt in zwei Teile, einen ersten, juristischen, und einen zweiten, theologischen.

Der erste Teil beschafft die Grundlagen. Zuerst müssen wir uns klar sein darüber, was der Terminus "praescriptio " in der römischen Rechtssprache alles bedeutet. Da nun praescriptio als prozeßrechtlicher Begriff zur Zeit Tertullians in einer dreifachen Bedeutung vorkommt, $\mathrm{mu} ß$ die praescriptio in diesen drei Bedeutungen dargestellt werden. Eine kurze Schilderung der beiden Hauptprozeßformen, innerhalb derer die jeweilige praescriptio vorkommt, wird das Verständnis derselben vervollständigen. Nach Abschluß dieser Untersuchung wird es bereits möglich, diejenige praescriptio auszuscheiden, die Tertullian für seine Präskriptionen als Vorbild diente.

Anschließend (2. Kap.) muß noch eine besondere Art der praescriptio, nämlich die longi temporis praescriptio, ausführlicher dargestellt werden, weil Kap. 37 in praescr. haer. nach dieser praescriptio zu untersuchen ist.

Der $z$ weite Teil bildet die Anwendung der im ersten Teil gewonnenen Ergebnisse auf die Präskriptionen Tertullians. Dies setzt aber eine genaue Analyse des Hauptabschnittes von praescr. haer. voraus, denn die Präskriptionen sind, wie die Analyse zeigen wird, in einen wohldurchdachten Plan eingefügt. Sie können daher auch nur aus dem Zusammenhang verstanden und dürfen nur unter Berücksichtigung des Ganzen aus diesem herausgeschält werden. Dementsprechend steht die Analyse von praescr. haer. am Anfang des zweiten Teiles (1. Kap.).

Ist die Analyse beendigt und sind die darin enthaltenen Präskriptionen ermittelt, können diese mit jener praescriptio des römischen Prozeßrechts, die Tertullian vorschwebte, endlich verglichen und auf ihre Übereinstimmung (2. Kap. 1. Abschnitt) und Verschiedenheit (2. Abschnitt) geprüft werden. Wenngleich die, wenn man so sagen darf, klassischen und in unserer gesamten Arbeit das eigentliche Interesse beanspruchenden Präskriptionen Tertullians in praescr. haer. zu suchen sind, so spannen wir in den angegebenen zwei Abschnitten den Rahmen der Untersuchung trotzdem etwas weiter, indem wir von den zahlreichen, in den übrigen Schriften Tertullians zerstreuten Anspielungen auf die praescriptio die etwas ausführlicheren Beispiele in unsern Vergleich einbeziehen. 
Je ein eigener Abschnitt wird sich noch eingehend mit der Formulierung der in praescr. haer. festgestellten Präskriptionen befassen (3. Abschnitt) und im besondern Kap. 37 nach dem Vorhandensein der longi temporis praescriptio untersuchen (4. Abschnitt). Die Lösung der Frage, wie viele Präskriptionen praescr. haer. enthalte, wird das Kapitel abschließen (5. Abschnitt).

Im dritten, letzten Kapitel dieses zweiten Teiles ist unter dem Gesichtspunkt der Theologie abzuklären, ob und wie die eigenwilligen juristisch-theologischen Präskriptionen Tertullians den besondern Ansprüchen der Apologetik gerecht werden.

Die Schrift praescr. haer., die mit ihrem Präskriptionsargument im Mittelpunkt unserer Arbeit steht, bedarf zu ihrem Verständnis keiner besondern zeitgeschichtlichen Orientierung. Wir finden darin keinen einzigen Hinweis auf ein zeitgeschichtliches Ereignis. Das ist bezeichnend für den zeitlosen, universellen Charakter dieser Schrift. Es geht hier Tertullian um nichts anderes als um den rastlosen Kampf der Wahrheit gegen die feindlichen Mächte der Lüge und der Finsternis. Dieser Kampf ist weder auf eine bestimmte Zeit noch auf einen bestimmten Ort beschränkt. Gerade deshalb möchte Tertullian der Wahrheit eine Waffe geben, die sie zu allen Zeiten und überall zu ihrer Verteidigung handhaben kann. Die Wahrheit bleibt dieselbe und unveränderliche; nur die Lüge, die Häresie ändert je nach Zeit und Ort Namen und Aussehen. So erfahren wir aus praescr. haer., daß sich die afrikanische Kirche um die Wende vom zweiten zum dritten Jahrhundert hauptsächlich gegen die Häresien eines Marcion, Valentin, Apelles, aber auch anderer weniger bedeutender Schwarmgeister zu wehren hatte.

Marcions Gestalt erregte wie wenige andere der frühen Kirchengeschichte in den letzten 20 Jahren das Interesse der Forschung ${ }^{1}$. Marcion, der im Jahre 144 aus der römischen Gemeinde ausgeschlossen wurde, ist streng genommen kein Gnostiker. Statt der phantastischen Äonenlehre und Allegorese der Gnostiker strebte er mehr praktischreligiöse Ziele an. "Marcion ... Stoicae studiosus ", so kennzeichnet Tertullian den Häresiarchen ebenso kurz wie vielsagend ${ }^{2}$. Diese praktisch-stoische Grundhaltung Marcions dürfte $u$. E. eine Erklärung dafür sein, warum seine Sonderkirche sich im römischen Reich, besonders im

1 Bibliographie bei Funk-Bihtmeyer, Kirchengeschichte, 1. Teil: Das christliche Altertum (Paderborn 1936) S. 138 Anm. 1.

2 Vgl. praescr. haer. 30 (Kr. 36). 
Osten, so erstaunlich rasch und weit ausbreitete und sich als gefährlichste Rivalin der Kirche jahrhundertelang behauptete. Marcions Lehre sagte dem nüchternen Sinn des Römers und überhaupt des einfachen Mannes mehr zu als die Phantasterien der Gnostiker. Die Lehre Marcions galt ohne Zweifel zur Zeit Tertullians auch in Afrika als der gefährlichste Feind der Kirche. Sonst würde Tertullian ihn in praescr. haer. nicht jedesmal an erster Stelle nennen ${ }^{1}$ und hätte er auch sein umfangreichstes Werk nicht gegen diesen Irrlehrer verfaßt.

Apelles, ein Schüler Marcions, lehrte in Rom und Alexandrien. Tertullian berichtet hauptsächlich von dessen obskuren Beziehungen zur

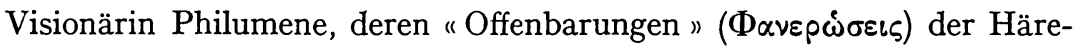
tiker niederschrieb. Tertullian läßt an der Visionärin keinen guten Faden ${ }^{2}$. Offenbar wird Apelles auf diese Weise am besten erledigt. Vielleicht war die verlorene Schrift Adversus Apelleiacos in einem ähnlichen Ton abgefaßt.

Während Marcion und Apelles streng genommen keine Gnostiker sind, gilt Valentin als einer der hervorragendsten Vertreter derselben. In ihm hat die spekulative hellenistische Gnosis ihren Höhepunkt erreicht. Tertullian nennt ihn "Valentinus, Platonicae sectator" 3 . Valentins Lehrsystem bildet ein Gemisch von platonischer Philosophie (die, nach dem Wort Tertullians zu schließen, die Grundlage des ganzen Systems gebildet haben wird), christlicher Wahrheiten, zügelloser Spekulation, Mystik und Ekstase. Eine phantastische Äonenlehre, von der Tertullian einen kleinen Querschnitt vermittelt 4, drückt der valentinischen Gnosis den Stempel auf. Die Irrlehre mochte um so gefährlicher werden, weil Valentin sich auf Theodas, einen angeblichen Schüler des hl. Paulus, berief. Die Irrlehre des hellenistischen Gnostikers verbreitete sich denn auch, von zahlreichen Schülern unterstützt, im Morgen- und Abendland. Sie muß, wie anderwärts, besonders auch die afrikanische Kirche ernsthaft gefährdet haben, weshalb Tertullian sie in einer eigenen Schrift, Adversus Valentinianos, widerlegte, in deren Einleitung er die Valentinianer "die zahlreichste Genossenschaft unter den Häretikern nennt " 5 .

1 Vgl. ebd. und praescr. haer. 33 (Kr. 41, 8).

2 Vgl. praescr. haer. 30 (Kr. 36).

3 Praescr. haer. 30 (Kr. 36, 2).

4 Vgl. praescr. haer. 33 (Kr. 42, 15).

- Adv. Valent. $1(\mathrm{Kr} .17 \%, 1)$ : "Valentiniani, frequentissimum plane collegium inter haereticos...". 

I. TEIL

Die praescriptio im römischen Recht 
1 


\section{Kapitel \\ Der römische Zivilprozeß und seine verschiedenen praescriptiones}

Die grundlegende und daher erste Aufgabe dieser Arbeit besteht darin, über den Begriff praescriptio Klarheit zu verschaffen. Da jedoch die praescriptio ein prozessualer und als solcher zudem noch mehrdeutiger Begriff ist, kann nur die Methode ein zuverlässiges Erfassen der praescriptio versprechen, die diese in ihrer Stellung und Funktion, im römischen Proze $\beta$ untersucht. Infolgedessen ergibt sich für dieses Kapitel die schon im Titel angedeutete $Z$ weiteilung: Prozeßform und praescriptio im römischen Recht.

Im voraus sei bemerkt, da $B$ uns sowohl der Proze $B$ wie die praescriptio in der Gestalt interessieren, die sich für die Zeit Tertullians feststellen läßt. Da im betreffenden Zeitabschnitt zwei Prozeßformen, der Formularprozeß $\mathrm{B}$ un der KognitionsprozeB, existierten, werden sich die folgenden Ausführungen nur mit diesen befassen. Wir beschränken uns darauf, die wesentlichsten Grundzüge und den äußern, normalen Verlauf der beiden Prozeßarten darzustellen ${ }^{1}$. Ebenso sehen wir ab von dem, was dem ProzeB vorangeht oder nachfolgt. Im Bestreben, die Darstellung der beiden Prozeßformen bei aller Kürze klar und durchsichtig zu gestalten, bedienen wir uns durchgehend derselben unmißverständlichen Bezeichnungen : Formularproze $B$ und Kognitionsproze $B$ (statt Formularverfahren und Schriftformelverfahren; Kognitionsverfahren, Beamtenverfahren, Beamtenprozeß, extraordinaria cognitio usw.).

Im Anschluß an die Darstellung der jeweiligen Prozeßform wird die zugehörige praescriptio behandelt. So nach dem FormularprozeB die praescriptio pro actore und die exceptio, welch letztere zur Zeit Tertullians zuweilen auch praescriptio genannt wird. Auf den Kogni-

1 Wir halten uns in der Hauptsache an L. WENGER, Institutionen des römischen Zivilprozeßrechts. München 1925. 
tionsproze $\beta$ folgt die Darstellung der für unsere Aufgabe besonders wichtigen praescriptio des Kognitionsprozesses.

Nachdem wir die verschiedenen praescriptiones innerhalb des betreffenden Prozeßrahmens beleuchtet haben, fassen wir diese zu einer kurzen Übersicht zusammen und ziehen, soweit dies hier schon erlaubt und möglich ist, einige Folgerungen hinsichtlich der Präskriptionen Tertullians.

Aus dem Gesagten ergibt sich folgender Plan dieses Kapitels :

1. Der Formularprozeß.

A. Der äußere Verlauf des Formularprozesses.

B. Die Formel im Formularprozeß, ihre Bestandteile, besonders die praescriptio und exceptio.

2. Der Kognitionsprozeß.

A. Der äußere Verlauf des Kognitionsprozesses.

B. Die praescriptio des Kognitionsprozesses.

3. Die praescriptio ein mehrdeutiger Begriff (Zusammenfassung).

\section{Der Formularprozeß}

\section{A. Der äußere Verlauf des Formularprozesses 1}

Der Formularprozeß ist gekennzeichnet durch seine Zweiteilung. Der Prozeß zerfällt nämlich in zwei Vorgänge, die sich vor zwei verschiedenen Personen (Prätor und Judex), an verschiedenen Orten und zu verschiedenen Zeiten abspielen. Die Prozeßwissenschaft hält die beiden Prozeßabschnitte als Verfahren in iure und als Verfahren apud iudicem auseinander. Das Verfahren in iure spielt sich ab vor dem Prätor, dem Gerichtsbeamten. Es geht hier um die Vorbereitung und Begründung des Prozesses. Das Verfahren apud iudicem läuft vor dem Privatrichter oder Geschworenen, der, vom Prätor beauftragt und bevollmächtigt, den Tatbestand untersucht, die Beweise aufnimmt und das Urteil fällt. - Für unsern $Z$ weck genügt eine Skizzierung des Prozeßverlaufes in seinen Hauptzügen.

Der Kläger lädt seinen Beklagten vor Gericht. Das ist die " in ius vocatio ". Zugleich, also schon vor dem Erscheinen vor Gericht, teilt

1 Vgl. L. Wenger, a. a. O. $90 \mathrm{ff}$. 
der Kläger dem Beklagten den Streitgegenstand, die Klage (actio) mit. Man nennt dies die außergerichtliche editio actionis.

Mit dem Erscheinen der beiden Prozeßparteien vor dem Prätor beginnt das Verfahren in iure. Hier wiederholt der Kläger die editio actionis, denn auch der Prätor muß wissen, worin der Streit besteht. Zunächst erledigt nun der Prätor einige Vorfragen, von denen es abhängt, ob der Proze $B$ weitergeführt werden kann oder nicht : vorerst muß für den Prätor feststehen, ob sein Gerichtsforum sachlich und örtlich zuständig sei; ferner vergewissert sich der Prätor darüber, ob Kläger und Beklagter Freie (status libertatis) und als solche zudem römische Bürger (status civitatis) sind. Sind diese Prozeßvoraussetzungen erfüllt, gewährt der Prätor den Prozeß (dat actionem), andernfalls verweigert er ihn (denegat actionem).

Gewährt der Prätor den Prozeß, so besteht seine nächste Aufgabe darin, für den klägerischen Anspruch die richtige Formulierung oder Formel (formula) zu bestimmen. Im Formularprozeß hat nämlich jede Klage ihre bestimmte Klageformel. Daher die Bezeichnung For mularProzeß. Die Formeln finden sich als Blankette im sog. Album des Prätors. Aus diesen wählt der Prätor diejenige Formel, die für die hic et nunc geltend gemachte Klage in Frage kommt und sowohl ihm wie den beiden Parteien genehm ist ${ }^{1}$.

Der Streit dreht sich z. B. um 100 Sesterzen, die der Kläger auf Grund eines Darlehens vom Beklagten fordert, d. h. es handelt sich um eine Darlehensklage (actio certae creditae pecuniae) ${ }^{2}$. Das Formelblankett für diese Klage lautet (zuerst wird der Judex bestimmt) :

Titius iudex esto. Si paret Numerium Negidium (Blankettnamen des Juristen Gaius für den Beklagten) Aulo Agerio (Blankettnamen für Kläger) centum dare oportere, Numerium Negidium Aulo Agerio centum condemnato, si non paret, absolvito.

An Stelle der Blankettnamen setzt der Prätor die Namen des Judex und der Parteien. Er schreibt diese Formel auf ein Wachstafeldiptychon (daher auch der Name Schriftformel) und händigt die so verfertigte Prozeßurkunde dem Kläger aus. Dieser wiederum überreicht sie dem Beklagten, der sie entgegennimmt. Durch dieses Überreichen der Prozeßurkunde von Seiten des Klägers an den Beklagten und das Ent-

1 Unter Umständen gewährt der Prätor auch eine neue, gerade für diesen Fall passende Formel, die nicht im Album steht (formula in factum).

2 Vgl. L. Wenger, a. a. O. $181 \mathrm{ff}$. 
gegennehmen derselben durch den Beklagten wird der Prozeß begründet, es wird, in der Terminologie des römischen Rechts ausgedrückt, der Akt der sog. litis contestatio, d. h. Prozeßbegründung oder Prozeßbefestigung vollzogen. Die Parteien verpflichten sich durch diesen formellen Akt ihren Streit nun vor dem Judex auszutragen und sich dem Urteil desselben zu unterwerfen. Die Prozeßurkunde wird dem Judex überreicht und damit beginnt das Verfahren apud iudicem ${ }^{1}$.

Durch die ProzeBurkunde wird der Judex (Privatrichter) über die Streitangelegenheit informiert. Zugleich erhält er aber auch bestimmte Anweisungen, unter welchen Voraussetzungen er freizusprechen bzw. zu verurteilen hat. Die Aufgabe des Judex besteht also darin, daß er untersucht, ob die Voraussetzungen für die Verurteilung des Beklagten gegeben sind oder nicht. So muB er, um auf das oben angeführte Beispiel einer Klageformel zurückzukommen, vom Kläger Aulus Agerius die Beweise dafür fordern, daß zwischen ihm und dem Beklagten Numerius Negidius einmal durch Darlehen eine Schuld von 100 Sesterzen zustande gekommen, aber noch nie beglichen worden ist. Der Beklagte, der behauptet, die Schuld sei beglichen, muß dies natürlich auch beweisen. Die hauptsächlichsten Beweisgründe sind Zeugenaussagen, in Urkunden niedergelegte Erklärungen, Augenschein, Gutachten Sachverständiger, aber auch die Aussagen der Parteien selber. In der Würdigung des Beweismaterials ist der Judex frei. Er ist an keine bestimmten Regeln gebunden, z. B. daß die Urkunde mehr Beweiswert habe als das Zeugenwort usw., wie dies im KognitionsprozeB in der Zeit nach Diokletian der Fall ist.

Ist das Beweisverfahren geschlossen, halten die Parteien, bzw. die sie vertretenden Advokaten, die letzten Wechselreden. Darauf fällt der Judex das Urteil (sententia).

\section{B. Die Formel im Formularproze $\beta$, ihre Bestandteile, besonders praescriptio und exceptio}

Es wurde oben das Blankett einer einfachen Formula als Beispiel angeführt. Es war die Formel der Darlehensklage :

"Titius iudex esto. Si paret $\mathrm{N}^{u m} \mathrm{~N}^{\mathrm{um}} \mathrm{A}^{0} \mathrm{~A}^{0}$ centum dare oportere, $\mathrm{N}^{\mathrm{um}} \mathrm{N}^{\mathrm{um}} \mathrm{A}^{0} \mathrm{~A}^{0}$ centum condemnato, si non paret, absolvito. "

1 Vgl. L. Wenger, a. a. O. $181 \mathrm{ff}$. 
Im Formularprozeß untersucht und entscheidet nicht der Prätor den Prozeß. Er hat nur die Aufgabe, den Prozeß zu gewähren und vorzubereiten. Mit der Untersuchung und Entscheidung des Streitfalles betraut und bevollmächtigt er einen Privatmann, den Judex. Mittels der Formel orientiert der Prätor den Judex über den Streitgegenstand, gibt ihm aber auch gleichzeitig Anweisung, unter welchen Bedingungen er den Beklagten zu verurteilen hat. Jede Formel hat ihre Bestandteile. Zergliedern wir obige Formel der Darlehensklage ${ }^{\mathbf{1}}$ :

"Si paret Numerium Negidium Aulo Agerio centum dare oportere." In diesem Abschnitt, intentio genannt, wird der Anspruch des Klägers Aulus Agerius formuliert; Numerius Negidius soll ihm 100 Sesterzen schuldig sein.

"condemnato". Dieser Bestandteil der Formel wird als condemnatio bezeichnet. Der Judex erhält in der intentio genaue Anweisung, unter welcher Voraussetzung er zu kondemnieren hat : nur, wenn das "centum dare oportere" wirklich vorliegt. Dies mittels der Beweisaufnahme abzuklären, darin besteht gerade die Aufgabe des Judex. Ist die Voraussetzung zur condemnatio nicht gegeben, erfolgt Freisprechung (absolutio) des Beklagten.

Die intentio und condemnatio sind die unentbehrlichen Bestandteile jeder Formel ${ }^{2}$. Bei bestimmten Klagen muß die Formel als andere Bestandteile noch aufweisen: die demonstratio, wenn der in der intentio zu wenig genau bezeichnete klägerische Anspruch noch näher bezeichnet werden muß, oder die adiudicatio; diese letztere findet sich in Formeln, die den Judex mit der Teilung einer bestimmten Sache, z. B. eines Nachlasses bevollmächtigen.

Intentio, condemnatio, demonstratio und adiudicatio werden als ordentliche Formelbestandteile bezeichnet, denn sie müssen bei bestimmten Klagen als Bestandteile in die Formel aufgenommen werden. Wir brauchen uns nicht weiter mit ihnen zu befassen. Mehr interessieren uns die zwei außerordentlichen Formelbestandteile: praescriptio und exceptio. Sie heißen außerordentliche Bestandteile, weil sie frei auf Wunsch der Parteien in die Formel eingefügt werden können, wenn bestimmte Bedingungen erfüllt sind.

1 Vgl. L. Wenger, a. a. O. 132 ff, ebenso Jörs-Kunkel-Wenger, Römisches Recht, Enzyklopädie der Rechts- und Staatswissenschaft II-III, 2. Aufl. $370 \mathrm{ff}$.

2 Eine Ausnahme bilden die Feststellungsklagen, die keine condemnatio haben. Vgl. L. Wenger, a. a. O. 135. 


\section{a) Die praescriptio ${ }^{1}$.}

Die praescriptio des Formularprozesses wird, was der Name schon andeutet, in der Formel vor die intentio geschrieben. Sie wird entweder vom Kläger verlangt und dient in diesem Fall seinen Interessen (praescriptio pro actore), oder sie wird vom Beklagten gewünscht (praescriptio pro reo). Zur Zeit Tertullians existierte jedoch nur noch die praescriptio pro actore ; die praescriptio pro reo war nach dem Zeugnis des Juristen Gaius (c. 160 n. Chr.) längst zur exceptio geworden. Wir beschränken uns deshalb auf die kurze Darstellung der praescriptio pro actore.

Die praescriptio pro actore ist in ihrem Wesen ein Vorbehalt oder eine Beschränkung. Das klassische Beispiel einer praescriptio pro actore überliefert uns der Jurist Gaius : Es hat einer Anrecht auf ein Guthaben, das ihm in bestimmten Zeitabschnitten in Raten ausbezahlt werden muß. Kommt nun dieser Gläubiger in die Lage, gegen seinen Schuldner gerichtlich vorzugehen, so klagt er nur auf die fällige Rate. Er macht im voraus den Vorbehalt, daß nicht die Schuld als solche in ihrer Gesamtheit, sondern nur die verfallene Rate derselben, Gegenstand des Prozesses sei, da $\beta$ also die litis contestatio oder Prozeßbegründung nur über diese Rate vollzogen werde. Dieser Vorbehalt, diese Begrenzung des Prozeßgegenstandes wird in der Formel vor die intentio (die intentio enthält bekanntlich den klägerischen Anspruch, der eben in unserm Fall genau abgegrenzt werden soll) gesetzt und heißt deshalb prae-scriptio.

Die praescriptio pro actore hat den $Z$ weck, den Kläger vor gewissen nachteiligen Folgen zu schützen. Würde dieser nämlich das ganze Guthaben einklagen und darüber den Akt der litis contestatio, d. h. Prozeßbegründung vollziehen, so könnte er kein zweites Mal mehr klagen, wenn der Schuldner mit der Bezahlung einer spätern Rate wieder zurückhalten sollte. Denn eine Sache, ein Anspruch, über den einmal die litis contestatio vollzogen war, kann kein zweites Mal gerichtlich geltend gemacht werden; bis de eadem re ne sit actio. Hat indes der Gläubiger unter Anwendung der praescriptio nur die verfallene Rate eingeklagt und nur über diese Rate den Akt der litis contestatio vollzogen, dann steht ihm immer wieder die Möglichkeit offen, eine andere Rate desselben Guthabens, wenn nötig, gleicherweise auf dem Gerichtswege zu fordern.

1 Vgl. L. Wenger, a. a. O. $143 \mathrm{f}$. 
Aus dem Vorhergehenden dürfte klar sein, daß die praescriptio pro actore in ihrem Wesen eine Abgrenzung des klägerischen Anspruchs ist. Insofern sie den Kläger vor nachteiligen Folgen des Prozesses schützt, darf man sie auch einen Vorbehalt, eine Vorsichtsmaßregel nennen.

b) Die exceptio ${ }^{1}$.

Die exceptio ist ein Schutzmittel des Beklagten. Es kann vorkommen, daß der Beklagte die Richtigkeit der intentio, m.a.W. den klägerischen Anspruch (der ja durch die intentio ausgedrückt wird) ohne jede Ausflucht anerkennt. Die Richtigkeit der intentio zieht aber streng genommen die condemnatio nach sich. Nun beruft sich aber derselbe Beklagte gleichzeitig auf das Vorhandensein von Umständen, die ihn trotz Richtigkeit der intentio von der Verurteilung ausnehmen (exceptio!).

Um die exceptio an einem Beispiel zu erläutern, greifen wir zurück auf die oben entwickelte Formel der Darlehensklage. Nehmen wir an, Numerius Negidius anerkennt ohne Umschweife, daß er dem Aulus Agerius auf Grund eines seinerzeit gewährten Darlehens 100 Sesterzen schuldet. Der Beklagte anerkennt also die Richtigkeit der intentio. Nun macht aber Numerius Negidius anderseits geltend, daß Aulus Agerius ihm bei Gewährung des betreffenden Darlehens die Zusicherung gab, er werde die 100 Sesterzen nie auf dem Prozeßweg zurückfordern; der Gläubiger Aulus Agerius hätte in diesem Falle mit seinem Schuldner Numerius Negidius das sog. pactum de non petendo, den formlosen Schuldbefreiungsvertrag abgeschlossen. Geht nun Aulus Agerius trotzdem gerichtlich vor gegen seinen Schuldner, so gewährt das römische Recht dem Schuldner auf Grund des "pactum de non petendo " im Prozeß ein Einrederecht, d. h. der Beklagte kann die "exceptio pacti conventi " geltend machen.

Die Berufung auf eine exceptio muß vor dem Prätor, d. h. im Verfahren in iure stattfinden. Der Prätor nimmt die exceptio, wenn er sie dem Beklagten gewährt, in die Formel auf und beauftragt dadurch den Judex, nebst der intentio auch die exceptio auf ihre Richtigkeit zu prüfen. Die exceptio wird in der Formel nach der intentio eingefügt und hat die Form eines negativen Conditionalsatzes. Die Formel der Darlehensklage hat, wenn die exceptio pacti conventi eingefügt ist, folgende Gestalt :

1 Vgl. L. Wenger, a. a. O. $145 \mathrm{ff}$. 
"Titius iudex esto. Si paret Numerium Negidium Aulo Agerio centum dare oportere (= intentio), si inter Aulum Agerium et Numerium Negidium non convenit ne ea pecunia peteretur (= exceptio), Numerium Negidium Aulo Agerio centum condemnato (= condemnatio). Si non paret, absolvito."

Dieser Formel entsprechend muß der Judex, nachdem er sich von der Richtigkeit der intentio (in unserm Fall von der Tatsache des durch den Kläger an den Beklagten erfolgten und noch nicht zurückerstatteten Darlehens) überzeugt hat, auch noch die Frage prüfen, ob das vom Beklagten behauptete pactum de non petendo auch wirklich geschlossen wurde : Kann der Beklagte seine exceptio beweisen, so darf ihn der Judex trotz Richtigkeit der intentio (ist die Richtigkeit der intentio erwiesen, erfolgt die condemnatio des Beklagten) nicht verurteilen, er muß ihn absolvieren, wie ihn der Prätor in der Formel anweist. Die exceptio schützt also den Beklagten vor der sonst unvermeidlichen Verurteilung bzw. Strafe. An diese Funktion der exceptio spielt Tertullian an, wenn er - in der, wie es scheint, einzigen Stelle, wo er von der exceptio spricht - erklärt, jene, die den Herrn nicht kennen, schütze keine exceptio vor der Strafe ${ }^{1}$.

Wie der Beklagte sich mittels der exceptio gegen die intentio schützt, so kann wiederum der Kläger unter Umständen gegen die exceptio vorgehen, indem er sich auf Tatsachen beruft, die die exceptio trotz ihrer Richtigkeit entkräften. In einem solchen Fall ist ein weiterer Formelzusatz, replicatio geheißen, erfordert.

Derselbe Vorgang kann sich der replicatio gegenüber wiederholen, indem der Beklagte diese zu entkräften sucht durch eine duplicatio.

Gegen die duplicatio ist von Seiten des Klägers eine triplicatio möglich usw.

Diese Ausführungen, im besondern das Beispiel von der exceptio pacti conventi, dürften die Funktion und Gestalt der exceptio hinlänglich erläutern. Andere bekannte exceptiones sind die exceptio quod metus causa (Beklagter macht geltend, daß er bei Abschluß des fraglichen Rechtsgeschäftes unter Zwang handelte), die exceptio doli (Beklagter will überlistet worden sein), um nur diese zwei Beispiele zu erwähnen und von den verschiedenen Einteilungen der exceptio abzusehen.

1 Paenit. 5 (Oe. 1, 651) : "Cum etiam ignorantes dominum nulla exceptio tueatur ad poenam." 
Bis dahin war von der exceptio als einem Formelbestandteil die Rede. Das soll aber nicht heißen, daß "exceptio " nur einen Formelbestandteil bezeichnen könne, wenngleich dies zwar die Regel darstellt. Exceptio kann auch einen Einwand (oder Einrede) des Beklagten bezeichnen, der ebenfalls in iure, d. h. vor dem Prätor geltend gemacht werden muß, ohne jedoch vom Prätor in die Formel eingefügt zu werden. Das ist der Fall bei der exceptio fori. Die exceptio fori bezeichnet den Einwand, womit der Beklagte geltend macht, das Gericht, vor das er geladen wurde, sei für ihn örtlich oder sachlich nicht zuständig. Dieser Einwand betrifft aber die Prozeßvoraussetzungen, die zu prüfen eben Sache des Prätors und nicht des Judex ist, von deren Vorhandensein bzw. Fehlen es abhängt, ob der Prätor den Prozeß gewähren kann oder nicht. Deshalb kann die exceptio fori gar nicht in die Formel aufgenommen werden. Denn sie muß schon in iure, vor dem Prätor, nicht erst vor dem Judex entschieden werden ${ }^{1}$.

Nach diesen Ausführungen über die exceptio sei noch hingewiesen auf eine Eigenheit in der Benennung derselben, die gerade diese Arbeit interessiert. In der severischen Zeit, in die Tertullians schriftstellerische Tätigkeit fällt, bezeichnen die römischen Juristen die exceptio des Formularprozesses vereinzelt als praescriptio. So schreiben sie statt exceptio doli auch praescriptio doli, statt exceptio fori auch praescriptio fori usw. ${ }^{2}$. Hier ist aber mitnichten an die vorhin erläuterte praescriptio des Formularprozesses zu denken. Praescriptio hieß die Einrede des Beklagten im Kognitionsprozeß, der im folgenden noch zu skizzieren ist. Der Beklagte machte in dieser Einrede oder Einwendung (praescriptio geheißen) einen Tatbestand geltend, der, wenn erwiesen, den Prozeß abwies. Doch mehr darüber im folgenden. Hier genüge der Hinweis, daß die immerhin nur vereinzelte Bezeichnung praescriptio für exceptio aus dem Kognitionsprozeß stammt.

Im Hinblick auf das folgende sollen besonders zwei charakteristische Eigenheiten der exceptio festgehalten werden.

1. Die exceptio ist eine Einrede oder Einwendung, die der Beklagte in iure, d. h. vor dem Prätor geltend macht.

1 Vgl. über die exceptio fori : O. BüLow, Die Lehre von den Prozeßeinreden und Prozeßvoraussetzungen $85 \mathrm{ff}$, ferner J. PARTsch, Die longi temporis praescriptio im klassischen römischen Rechte $77 \mathrm{f}$; derselbe in Zeitschrift der Savigny-Stiftung für Rechtsgeschichte, Romanistische Abteilung 28 (1907) 444.

2 Vgl. J. PARTsch, Die longi temporis praescriptio 73 Anm. 1; O. BüLow, a. a. $\mathrm{O} .85 \mathrm{ff}$. 
2. Die exceptio wird in der Regel in der Form eines negativen Conditionalsatzes in die Formel eingefügt, außer exceptio bezeichne (und dies ist der seltenere Fall, z. B. exceptio fori) einen Einwand, über den der Prätor, nicht erst der Judex, entscheidet, so daß die Aufnahme in die Formel nicht in Frage kommt.

\section{Der KognitionsprozeB}

\section{A. Der äußere Verlauf des Kognitionsprozesses ${ }^{1}$}

Seit Augustus besitzt das römische Gerichtswesen neben dem Formularprozeß noch eine andere Prozeßform: den Kognitionsprozeß. Der Kognitionsproze $B$ ist im Unterschied zum Formularproze $B$ nicht zweigeteilt. Während sich nämlich der Formularprozeß vor zwei verschiedenen Instanzen, zuerst vor dem staatlichen Beamten (Prätor) und darauf vor einem Privatrichter abspielt, entwickelt sich im Kognitionsprozeß das ganze Prozeßgeschehen vor dem staatlichen Beamten. Als solcher funktioniert im Kognitionsprozeß nicht mehr der Prätor, sondern der Konsul, der Spezialprätor oder ein kaiserlicher Kommissär usw. Dieser staatliche Beamte begnügt sich nicht mehr damit, den Prozeß blo $B$ vorzubereiten, um dann die eigentliche Untersuchung und Entscheidung einem Privatrichter zu überlassen, sondern er übernimmt nun auch die Funktionen des Privatrichters; der Konsul oder kaiserliche Kommissär untersucht und entscheidet den Prozeß in eigener Person. Die gerichtlichen Funktionen des Staatsbeamten erweitern sich so (wenn man sie mit jenen im Formularprozeß vergleicht) zu außerordentlichen. Die cognitio des Beamten wird zur extraordinaria cognitio. Daher auch die Bezeichnung des Prozesses als extraordinaria cognitio (daher auch Kognitionsproze $B$ oder Beamtenprozeß).

Wenn aber der staatliche Beamte den ganzen Proze $B$ in eigener Person erledigt, erübrigt sich die Formel bzw. Prozeßurkunde. Denn diese dient ja im Formularprozeß nur dazu, den Privatrichter, der eben eine andere Person ist als der Prätor, über den Streitgegenstand zu orientieren und ihm die nötigen Anweisungen bezüglich der Entscheidung zu geben. Mit der Formel bzw. Prozeßurkunde fällt selbstredend auch die litis contestatio weg. Von diesen äußern Verchiedenheiten abgesehen, wickelt sich das Prozeßgeschehen äußerlich nicht viel anders

1 L. Wenger, a. a. O. $246 \mathrm{ff}$. 
ab als im Formularproze ${ }^{1}{ }^{1}$, nur da $\beta$ der Kognitionsprozeß (infolge Wegfallens von Prozeßurkunde und litis contestatio) viel freier und ungezwungener verläuft. Der Richter prüft zuerst die Prozeßvoraussetzungen, hört die beiden Parteien an, nimmt die Beweise auf usw. In der Würdigung der Beweise gilt auch hier wie im Formularprozeß das freie Ermessen des Richters. Erst seit Diokletian wird dieser allmählich an bestimmte Beweisregeln gebunden, z. B., da $B$ das Zeugnis eines hochgestellten Herrn mehr gilt als das eines gemeinen Mannes, da $B$ die Urkunde mehr Beweiswert hat als das Zeugenwort usw.

Längere Zeit existierten Kognitions- und Formularprozeß nebeneinander. Nur allmählich wurde der letzere durch den Kognitionsprozeß verdrängt. Viel schneller als in der konservativen Hauptstadt, setzte sich der Kognitionsprozeß in der Provinz durch. Hier verlieren sich die Spuren des Formularprozesses schon in der ersten Hälfte des 2. Jahrh. In Rom ist er erst um die Mitte des 3. Jahrh. ganz verschwunden ${ }^{2}$.

\section{B. Die praescriptio des Kognitionsprozesses ${ }^{3}$}

Vor allem interessiert uns am Kognitionsprozeß die sog. praescriptio. Praescriptio bedeutet in demselben jedes auf die klägerischen Behauptungen und Beweise nicht eingehende Argument, das der Beklagte im ProzeB zu seiner Verteidigung vorbringt. In den meisten Fällen beruft sich der Beklagte auf eine Verjährungs- oder Ausschlußfrist, die, weil versäumt oder nicht berücksichtigt, den Prozeß im voraus ausschließt. Es können aber auch andere prozeßhindernde Tatsachen geltend gemacht werden.

Dazu einige Beispiele :

Die unter Augustus erlassene Lex Julia de adulteriis coërcendis 4 bestimmt unter anderm, da $B$ innert 6 Monaten von der Auflösung der Ehe an wegen Ehebruch nicht geklagt werden könne ; ferner, daß jede Klage gegen den Ehebrecher nach Ablauf von 5 Jahren erlischt usw.

1 Es kommt sogar nicht selten vor, besonders in Ågypten, daß der staatliche Beamte auch im Kognitionsprozeß nur die Voruntersuchung leitet und mit der eigentlichen Untersuchung und Entscheidung einen Unterrichter (iudex pedaneus oder datus) betraut. Dieser erhält auch eine Art Prozeßurkunde wie der Judex des Formularprozesses, doch handelt es sich hier nicht mehr um eine Formel nach der Art der im Formularprozeß gebräuchlichen.

2 Vgl. L. Wenger, a. a. O. 59 und 48 Anm. 69.

3 Vgl. J. Partsch, Die longi temporis praescriptio $71 \mathrm{ff}$.

4 Vgl. zur Lex Julia de aldulteriis coërcendis Pauli-Wissowa, Realencyclopädie der klass. Altertumswisssenschaft I $432 \mathrm{ff}$. 
Der Beklagte, der sich im Prozeß auf die Mißachtung einer derartigen Vorschrift durch den Kläger berufen kann, erhebt, in der damaligen Rechtsterminologie ausgedrückt, eine praescriptio; hinsichtlich der hier angeführten zwei Vorschriften sprechen die römischen Juristen von einer praescriptio sex mensuum bzw. quinque annorum ${ }^{1}$.

Es war dem römischen Soldaten verboten, in der Garnisonsprovinz, wo er sich des Krieges wegen aufhielt (in einer andern Provinz stand ihm dies jedoch frei), Land zu erwerben. Solche Grundstücke verfielen dem Fiskus. Wenn nun ein Soldat trotz dieses Verbotes in der Garnisonsprovinz, wo er sich des Kriegsdienstes wegen aufhielt, Land erwarb, so durfte er dasselbe behalten unter der Bedingung, daß er seine Entlassung aus dem Heere nahm, ohne daß vorher über diesen Gegenstand je eine gerichtliche Untersuchung angestrengt worden war. War diese Voraussetzung erfüllt, hatte der Veteran keinen Prozeß zu befürchten; er konnte sich auf diese Bestimmung berufen, d. h. eine praescriptio erheben. Ausdrücklich erklärt aber der Jurist Macer, "huius praescriptionis commodum " komme natürlich jenem Soldaten nicht zugute, der "ignominiae causa" aus dem Heer entlassen wurde 2 .

Die lex Julia de adulteriis coërcendis erklärt jeden unter 25 Jahren für unfähig, jemand wegen Ehebruchs vor Gericht zu verklagen. Der Zuwiderhandelnde kann vom Beklagten unter Berufung auf diese Verordnung als prozeßunfähig abgewiesen werden, d. h. der Beklagte kann eine praescriptio erheben. Dagegen soll der Kläger vor Gericht Gehöi finden, wenn es sich um ein Unrecht gegen seine eigene Ehe handelt, "nec enim ulla praescriptio obicitur suam iniuriam vindicanti " ${ }^{3}$.

Gegen einen Kläger, der in seiner Klageschrift den Appellationsbeklagten nicht nennt, darf nach Ulpian vom Beklagten trotzdem keine praescriptio erhoben werden. Dasselbe solle gelten, wenn bei einer Mehrzahl von Appellationsbeklagten nur die Namen der einen im libellus angeführt, die der andern weggelassen seien. Die Beklagten, die im libellus nicht genannt seien, dürften gegen den Kläger trotzdem nicht die praescriptio geltend machen, er habe sich ihnen gegenüber, da er ihre Namen in der Apellation nicht anführe, mit dem Urteil der

1 Vgl. J. Partsch, a. a. O. 71 Anm. 1-4.

2 Macer dig. 49, 16, 13, 1: "Is autem, qui contra disciplinam agrum comparaverit, si nulla de ea re quaestione mota missionem acceperit, inquietari prohibetur. Illud constat huius praescriptionis commodum ad eos, qui ignominiae causa missi sunt, non pertinere, quod praemii loco veteranis concessum intelligitur. "

3 Ulpianus dig. 48, 5, 16, 6 . 
1. Instanz abgefunden. Denn es handle sich in einem solchen Fall nur um einen Prozeß (gegen alle Beklagten zusammen). Anders, wenn ein Urteil gegen mehrere Kläger lautete, deren Namen aber nicht alle im libellus stehen, mit dem an die höhere Instanz appelliert wird. Hier wird angenommen, daß jene nicht appellieren wollten, deren Namen nicht im libellus stehen, weshalb sie der Beklagte mit einer praescriptio abweisen kann ${ }^{1}$.

Eine besondere Art der praescriptio stellt die sog. longi temporis praescriptio dar. Gegen Ende des 2. Jahrh. n. Chr. erklärte eine nicht mehr erhaltene, doch mehrfach bezeugte kaiserliche Konstitution, daß derjenige ungestört im Besitze seines Provinzgrundstückes belassen werden müsse, der dasselbe rechtmäßig (und wahrscheinlich auch gutgläubig) erworben und 10 bzw. 20 Jahre unangefochten besessen habe. Der Besitzer, der sich über diese Erfordernisse ausweisen konnte, hatte nichts zu fürchten, mochte auch eines Tages ein Prozeß gegen ihn angestrengt werden, mochte der Kläger sogar sein Eigentumsrecht am betreffenden Grundstücke klipp und klar nachweisen. Der bisherige Besitzer berief sich auf die Bestimmungen jener kaiserlichen Konstitution, d. h. er erhob gegen seinen Kläger die longi temporis praescriptio. Konnte der Präskribent die notwendigen Beweise leisten, mußte der Richter den Kläger abweisen ${ }^{2}$.

Diese Beispiele dürften zur Genüge beweisen, wie praescriptio, besonders im Munde der spät- und nachklassischen Juristen, die Berufung des Beklagten auf eine den Proze $B$ ausschließende Vorschrift bedeutet. Es handelt sich dabei um Vorschriften verschiedenster Art ; am meisten begegnen aber solche, die eine Verjährungs- oder Ausschlußfrist zum Inhalt haben.

Der $Z$ weck dieser Präskriptionen ist aus den bisherigen Ausführungen klar: sie bezwecken die Abweisung, Verunmöglichung des Prozesses. Zu diesem Zwecke wurden sie ja auch geschaffen. Dieser

1 Ulpianus dig. 49, 1, 3 pr.-2: "Scio quaesitum, si quis non addiderit in libellis, contra quem adversarium appellet, an praescriptioni subiciatur : et puto nihil oportere praescribi. Sed illud cecidit in quaestionem, si plures habuerit adversarios et quorundam nomina libellis sint complexa, quorundam non, an aeque praescribi ei possit ab his, quorum nomina comprehensa non sunt, quasi adversus ipsos adquieverit sententiae. Et cum una causa sit, arbitror non esse praescribendum. Certe si plures hi sunt, adversus quos pronuntiatur, et quorundam nomina in libellis sint comprehensa, quorundam non, hi soli appellasse videbuntur, quorum nomina libellis sunt comprehensa."

2 Ausführlicher über die longi temporis praescriptio im folgenden 2. Kap. 
Sinn und $Z$ weck der praescriptio, den Prozeß zu ersparen, tritt denn auch schon in der sprachlichen Formulierung diesbezüglicher Gesetzestexte oft sehr klar zutage. In einem Reskript des Kaisers Caracalla vom Jahre 212 wird die praescriptio dem Prozeß gegenübergestellt, indem treffend gesagt wird, daß die praescriptio als solche den Kläger besiege, ohne $\mathrm{da} B$ der eigentliche Streitgegenstand, der zur Klage geführt hat, untersucht worden sei :

Cod. 8, 14, 5: "... si eum ..., non causa cognita, sed praescriptione superatum esse constiterit."

Mit ähnlichen Worten nennen Diokletian und Maximian als Zweck der praescriptio (hier der longi temporis praescriptio) den Ausschluß des Prozesses :

Cod. 7, 34, 3: " ... actio excluditur longi temporis praescriptione."

Denselben Gedanken drücken die Juristen aus, wenn sie sagen, mittels der praescriptio werde der Kläger abgewiesen, z. B. :

Modestin dig. 5, 2, 12 pr.: "... filius exheredatus ... praescriptione submovebitur ... summovebitur ab actione. "

Die praescriptio des Kognitionsprozesses ist an keine feste Form gebunden ${ }^{1}$. Der Kognitionsprozeß spielt sich, wie bereits betont, in ziemlich zwangloser Form ab. Was J. PARTSCH von der Art und Weise, wie die longi temporis praescriptio im Proze $B$ geltend gemacht wird, sagt, gilt für die praescriptio ganz allgemein. Der Beklagte beruft sich auf die dem Prozeß entgegenstehende Vorschrift und leistet die erforderlichen Beweise, worauf der Richter den Kläger abweist ${ }^{2}$. Das Vorbringen der praescriptio ist im Kognitionsproze $B$ der klassischen Zeit an keinen festen Zeitpunkt geknüpft ".

Einige abschließende Worte über den Sprachgebrauch "praescriptio" mögen beitragen, das Wesen der praescriptio aufzuhellen. PARTSCH hat die praescriptio des Kognitionsprozesses von der griechischen $\pi \alpha \rho \alpha \gamma \rho \alpha \varphi \eta^{\prime}$ abgeleitet 4. Prae-scriptio ist die wörtliche Übersetzung von $\pi \alpha \rho \alpha-\gamma p \alpha \varphi^{\prime}{ }^{5}$. П $\alpha \rho \alpha \gamma \rho \alpha \varphi \eta^{\prime}$ heißt im attischen Prozeß der Einwand gegen

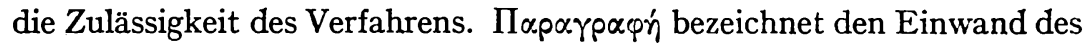
Beklagten, worin dieser noch vor dem Eingehen auf die Sache geltend

1 Vgl. J. Partsch, a. a. O. $71 \mathrm{f}$.
2 A. a. O. 68.
3 A. a. O. 68 .
4 A. a. O. $73 \mathrm{ff}$.
5 A. a. O. 74 . 
macht, daß es zu einer richterlichen Untersuchung über die klägerische

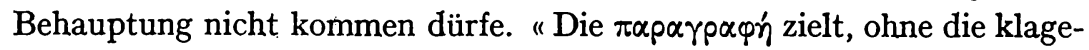
begründenden Tatsachen zu bestreiten, auf eine Einstellung oder Ablehnung des beantragten Verfahrens wegen Unzulässigkeit. " ${ }^{1}$ Durch Vermittlung der Rhetoriker dürfte dieser attische Prozeßbegriff in die römische Prozeßterminologie eingedrungen sein ${ }^{2}$. Die Juristen übernahmen die $\pi \propto \rho \alpha \gamma \rho \alpha \varphi \eta$ in der Übersetzung von praescriptio, um damit ein im römischen Prozeß ähnliches Verteidigungsmittel des Beklagten zu bezeichnen. Als praescriptio bezeichnen die Juristen seit Augustus hauptsächlich den Einwand (oder Einrede) des Beklagten im Kognitionsproze $\beta$, worin der Beklagte sich auf eine Vorschrift beruft, die, wenn bewiesen, den Prozeß ausschließt. Vereinzelt wurde auch die exceptio des Formularprozesses praescriptio genannt, wohl nur aus dem Grunde, so J. PARTSCH ${ }^{3}$, weil der Antrag des Beklagten auf Einfügung einer exceptio in die Formel prozessuale Verteidigung ist.

\section{Die praescriptio ein mehrdeutiger Begriff}

\section{(Zusammenfassung)}

Die bisherigen Ausführungen haben uns mit den beiden zur Zeit Tertullians existierenden römischen Prozeßformen und, was die vorliegende Arbeit besonders interessiert, mit dem mehrdeutigen Begriff " praescriptio " vertraut gemacht. Anschließend sollen die Abschnitte über die praescriptio herausgegriffen und zu einer klaren Übersicht $\mathrm{zu}$ sammengestellt werden.

Wir haben für die Zeit Tertullians eine dreifache praescriptio auseinanderzuhalten :

1. Die praescriptio pro actore. Wir haben sie dargestellt als eine Abgrenzung des klägerischen Anspruchs, als Vorbehalt und Vorsichtsmaßregel, als außerordentlichen Bestandteil der Formel im Formularprozeß. Diese Art der praescriptio dürfte sich in den Schriften Tertullians nicht finden.

2. Praescriptio, insofern darunter die exceptio des Formularprozesses, ebenfalls ein außerordentlicher Formelbestandteil, zu ver-

1 Ebd.

2 Vgl. J. PARTSCH, a. a. O. 75.

3 A. a. O. 76. 
stehen ist. Es ist unwahrscheinlich, daß der Terminus praescriptio, den Tertullian so oft gebraucht, einmal für exceptio steht. Die, wie es scheint, einzige Stelle im ganzen Schrifttum, wo Tertullian von der exceptio spricht ${ }^{1}$, legt eher die Vermutung nahe, daß unser Autor in den Fällen, wo er von der exceptio reden wollte, diese nicht lange unter dem Decknamen praescriptio verbergen, sondern bei ihrem unmißverständlichen Eigennamen exceptio nennen würde. Diese Vermutung erhebt sich indes zur Wahrscheinlichkeit. Wir wissen, daß die exceptio in der Regel ein Formelbestandteil ist und als solcher die Form eines negativen Conditionalsatzes hat. Wir begegnen aber in den betreffenden Stellen der tertullianischen Schriften, wo von einer praescriptio die Rede ist (wir meinen nur die ausführlicheren Stellen) keinem einzigen Gebilde dieser Art ${ }^{2}$. Aber ist vielleicht unter der tertullianischen praescriptio nicht jene exceptio des Formularprozesses zu verstehen, die sogleich vom Prätor und nicht erst vom Judex entschieden wird, jene exceptio (z. B. die exceptio fori), die einen Einwand des Beklagten bezeichnet, der nicht in die Formel aufgenommen und daher nicht nach einem festen Schema formuliert wird? Demgegenüber ist einzuwenden, da $B$ der FormularprozeB (dem die exceptio angehört) zur Zeit der schriftstellerischen Tätigkeit Tertullians (c. 195-220) in den Provinzen schon längere Zeit, nämlich seit der ersten Hälfte des 2. Jahrh., verschwunden war. Selbst in der Hauptstadt war der Formularprozeß in der Wende vom zweiten zum dritten Jahrh. ins letzte Stadium seines Bestehens eingetreten. Unter diesen Voraussetzungen ist anzunehmen, daß die exceptio um die betreffende Zeit für den gewöhnlichen, nicht juristisch gebildeten Provinzialen zu einem fast unbekannten Begriff geworden war. Praescriptio konnte folglich, als prozessualer Begriff genommen, vom Provinzialen nur noch für die Einrede des Beklagten im Kognitionsproze $B$ verstanden werden. Es scheint, daß Tertullian diesem $\mathrm{Zu}$ stand Rechnung trägt, wenn er in allen seinen Schriften nachweisbar ein einziges $\mathrm{Mal}$ auf die exceptio anspielt ${ }^{3}$, dafür aber so häufig den Ausdruck praescriptio gebraucht. Denn Tertullian wendet sich doch in seinen Schriften hauptsächlich an die Christen der Provinz und zwar Afrikas. Unter diesen Umständen scheint es ausgeschlossen, daß Tertullian in seinen zahlreichen Stellen mit praescriptio eine andere praescriptio

1 Paenit. 5 (Oe. 1, 651): "Cum etiam ignorantes dominum nulla exceptio tueatur ad poenam."

2 Siehe die Stellen mit praescriptio S. 83/5.

3 Siehe Anm. 1. 
als jene des Kognitionsprozesses vor Augen hat. Doch mehr davon im nächsten Punkt :

3. Praescriptio, insofern darunter die Einrede oder der Einwand des Beklagten im Kognitionsproze $\beta$ zu verstehen ist. Der 2. Teil dieser Arbeit ${ }^{1}$ wird den Beweis leisten, daß Tertullian in seinen zahlreichen Stellen, wo von praescriptio die Rede ist, tatsächlich die praescriptio des Kognitionsprozesses vorschwebt. Dieser Auffassung ist übrigens auch J. PARTSCH ${ }^{2}$. Ein Vergleich der tertullianischen praescriptiones mit jenen des römischen Kognitionsprozesses wird zeigen, $\mathrm{da} \beta$ Tertullian die praescriptio wohl in ihren wesentlichen, gleichbleibenden Elementen übernimmt, jedoch mit neuem Inhalt versieht.

1 Siehe S. $86 \mathrm{ff}$.

2 Vgl. J. PARTSCH, a. a. O. 76 f., wo die Eigentümlichkeiten dieser praescriptio mit Hilfe der tertullianischen Schrift praescr. haer. bzw. der darin enthaltenen Präskriptionen erläutert werden, wobei allerdings einzuwenden ist, daß PARTSCH praescr. haer. nicht gerade gründlich ansieht. Wir werden an gegebener Stelle den umgekehrten Weg einschlagen, indem wir die in der Analyse einwandfrei festgestellten Präskriptionen Tertullians mit der praescriptio des Kognitionsprozesses vergleichen und auf ihre gemeinsamen und unterschiedlichen Eigenschaften prüfen. 
2. Kapitel

\section{Die longis temporis praescriptio}

Im vorhergehenden Kapitel wurde dargelegt, wie der Begriff praescriptio zur Zeit der Severe meistens die Einrede bezeichnet, die der Beklagte im Kognitionsprozeß erhebt. Zu diesen Einreden zählt auch die longi temporis praescriptio. Nach einzelnen Autoren soll diese Einrede in Tertullians Schrift praescr. haer. enthalten sein. Unsere Arbeit wird sich deshalb im 2. Teil auch mit dieser Frage auseinandersetzen ${ }^{1}$. Doch vorerst müssen wir klare Vorstellungen von der longi temporis praescriptio gewinnen. Das ist die Aufgabe dieses Kapitels. Zuerst soll das Wesen der Ersitzung und damit der Platz und die Aufgabe der longi temporis praescriptio innerhalb des Rechtsorganismus aufgezeigt werden. Das Datum und die Zeitumstände, aus denen sie entstand, werden kurz gestreift. An zweiter Stelle seien die ältesten Quellen des Rechtsinstituts übersichtlich zusammengestellt, da wir im 2. Teil wieder auf dieselben zurückkommen werden. Der dritte Abschnitt gibt eine gedrängte Darstellung unserer Einrede. Weil der erwähnte Traktat Tertullians ums Jahr 200 herum verfaßt ist, wird es nötig sein, die longi temporis praescriptio möglichst in der Gestalt zu erfassen, die sie zu diesem Zeitpunkt aufweist. Der vierte und letzte Abschnitt orientiert über die Frage, wie die Einrede aus dem langen Besitz im Prozeß formuliert wurde.

\section{Das Wesen der Ersitzung ${ }^{2}$}

Die Rechtswissenschaft unterscheidet bekanntlich zwischen ursprünglichem (originärem) und abgeleitetem (derivativem) Eigentumserwerb.

1 Siehe unten S. $99 \mathrm{ff}$.

2 Vgl. Jörs-Kunkel-Wenger, Römisches Recht $\S 70 \mathrm{ff}$. 
Abgeleitet ist der Eigentumserwerb, wenn das Eigentum durch Rechtsgeschäft vom bisherigen Inhaber (auctor) auf den Erwerber übertragen wird.

Ursprünglich ist der Eigentumserwerb, wenn er ohne Übertragung, d. h. unabhängig von einem Vormann (auctor) erfolgt. Das Eigentum entsteht in diesem Fall für eine Person nicht auf Grund eines bereits bestehenden Rechtes eines andern (das übertragen wird), sondern unbekümmert und unabhängig von einem andern, somit erstmalig, ursprünglich. Das römische Recht kennt folgende Arten des ursprünglichen Eigentumserwerbs: Okkupation, Verbindung, Vermischung, Schatzerwerb, Fruchterwerb, Spezifikation und Ersitzung. Diese letzte interessiert uns.

Die Ersitzung ist Erwerb von Eigentum durch Zeitablauf. Nach Ablauf einer gesetzlich festgelegten Frist wird der Besitzer einer Sache, der faktisch die Stellung eines Eigentümers einnimmt, ohne es in Wirklichkeit zu sein, auch rechtlich zum Eigentümer.

Mit diesen Worten ist eine Unterscheidung angedeutet, die uns heute weniger geläufig ist, die aber für das römische Recht grundlegende Bedeutung hat: der Unterschied zwischen Besitz und Eigentum bzw. Besitzer und Eigentümer. Das römische Recht unterscheidet diese beiden Begriffe scharf und klar. Besitz (possessio) ist die tatsächliche Herrschaft über eine Sache, Eigentum (dominium, proprietas) aber die rechtliche Herrschaft über dieselbe. Für gewöhnlich wird der Besitzer auch Eigentümer einer Sache sein, aber nicht notwendig. Es kann einer eine Sache besitzen, ohne zugleich ihr Eigentümer zu sein, wie auch umgekehrt. Der Pächter eines Grundstückes z. B. ist nur Besitzer (possessor) desselben, der Verpächter ist sein Eigentümer (dominus).

Es kann sich nun ergeben, daß einer sich in guten Treuen für den Eigentü mer einer Sache, z. B. eines Grundstückes, hält und allgemein als solcher gilt, aber in Wirklichkeit, d. h. vor dem Rechte, ist er nur Besitzer. Das ist nach römischem Recht z. B. der Fall, wenn der Vormann (auctor), von dem die Sache erworben wurde, gar nicht Eigentümer derselben war und infolgedessen auch gar kein Eigentum an der betreffenden Sache übertragen konnte. Was will nun der gegenwärtige, gutgläubige Besitzer der Sache, z. B. eines Grundstückes, unternehmen, wenn sich nach Jahr und Tag plötzlich der rechtmäßige Eigentümer meldet? Er wird sich vergeblich auf seinen anerkannten Rechtstitel z. B. Kauf oder Erbschaft berufen, wenn der andere sich als Eigentümer 
auszuweisen vermag. Aber auch abgesehen von einem derartigen Fall, könnte der Inhaber besonders eines Grundstückes nie wissen, ob er wirklich Eigentümer, oder vielleicht doch nur Besitzer desselben ist. Es müßte eine allgemeine Rechtsunsicherheit herrschen. Hier hat das Rechtsinstitut der Ersitzung eingegriffen. Die Ersitzung macht den nur scheinbaren Eigentümer (der also vor dem Recht in Wirklichkeit nur Besitzer ist) unter bestimmten Bedingungen zum wirklichen, d. h. rechtlich anerkannten Eigentümer ; die Ersitzung verwandelt den tatsächlichen Zustand in einen rechtlichen, m.a.W. sie verwandelt Besitz in Eigentum. Dadurch wird der sonst drohenden Rechtsunsicherheit der Boden entzogen. Der Eigentümer einer Sache hat, nachdem eine bestimmte Zeit verstrichen und gewisse Bedingungen erfüllt sind, die absolute Gewißheit, da $B$ er wirklich Eigentümer ist; keiner kann ihm mehr seine Sache entreißen, auch wenn er noch so glaubwürdige Beweise seines (eben durch Zeitablauf verwirkten) Eigentümerrechtes $\mathrm{zu}$ leisten vermag.

Das römische Recht kennt eine doppelte Ersitzungsform: die sog. usucapio für die römischen Bürger und an Sachen, die Gegenstand von Privatrechten ${ }^{1}$ sein können, und die sog. longi temporis praescriptio für die Provinzgrundstücke. Wir begegnen der usucapio schon in den Zwölftafeln (tab. VI 3), allerdings in noch recht rudimentärer Gestalt ; sie empfängt ihre endgültige Gestalt zur Zeit der klassischen Jurisprudenz.

Wie bereits angedeutet, ist die Ersitzungsform der usucapio auffällig begrenzt. Die usucapio ist begrenzt 1. hinsichtlich ihres Subjektes (oder personal), indem sie nur römischen Bürgern (und Latinern), nicht

1 Die wichtigste Einteilung des römischen Sachenrechts ist nach den um 161 n. Chr. verfaßten Institutionen $(2,1)$ des Juristen Gaius: res in patrimonio = Sachen, die Gegenstand von Privatrechten sein können; und res extra patrimonium = Sachen, die nie Gegenstand von Privatrechten sein können. $\mathrm{Zu}$ diesen letzteren zählen :

a) die res divini iuris = die den Göttern geweiht oder heilig sind.

b) die res publici iuris = die dem Gemeingebrauch dienenden Sachen, wie öffentliche Straßen, Plätze usw.

c) der Provinzialboden; er gilt nach,klassischer Rechtstheorie als Staatseigentum (ager publicus) und ist deshalb des Privateigentums nicht fähig. Dem provinzialen Privatgrundbesitzer wird nur ein eigentumsähnliches Besitzund Nutzungsrecht zuerkannt. Dieses Quasieigentum war aber frei veräußerlich.

Vgl. hierzu K. v. Czyhlarz-M. San Nicolo, Lehrbuch der Institutionen des römischen Rechtes, 18. Aufl. (Wien-Leipzig 1924) 97 ff. 
aber den Nichtbürgern oder Peregrinen offen steht, und zu diesen zählen bis zur Constitutio Antoniania im Jahre 212 die meisten Provinzialen. Begrenzt ist die usucapio 2. hinsichtlich ihres Objekts, indem sie nur an Sachen möglich ist, die des zivilen Privateigentums fähig sind. Folglich gilt sie nicht an Grundstücken der Provinz, weil der Provinzboden Eigentum des römischen Volkes (ager publicus) ist. Aus dieser zweifachen Begrenzung der usucapio ergibt sich die Notwendigkeit einer Ersitzungsform, die für Nichtbürger und Provinzialgrundstücke Geltung hat. Diese Ersitzungsform wurde, sehr wahrscheinlich im letzten Jahrzehnt des 2. Jahrh. n. Chr., unter der Gestalt der sog. longi temporis praescriptio (zuweilen exceptio oder praescriptio longae possessionis genannt) eingeführt.

Das früheste Zeugnis, das wir bis heute von der longi temporis praescriptio besitzen, ist ein Reskript der Kaiser Septimius Severus und Caracalla aus dem Jahre 199 n. Chr. Die kaiserliche Konstitution, dem das neue Ersitzungsinstitut seine Entstehung verdankt, dürfte nur wenige Jahre früher erlassen worden sein. J. PARTSCH gelangt auf Grund eingehender Untersuchungen zum Schluß, daß man mit der Datierung der betreffenden Konstitution kaum über Septimius Severus zurückgehen dürfe und verlegt deshalb die Entstehung der longi temporis praescriptio in die Jahre 193-199 1. - Wir möchten den Ausführungen PARTSCHS noch folgende beifügen.

Daß Septimius Severus als der Schöpfer der longi temporis praescriptio gelten darf, dafür spricht auch die schon eingangs betonte provinziale Einstellung des Kaisers. Das neue Ersitzungsinstitut kam hauptsächlich den Provinzialen, d. h. Nichtrömern zugute. Es regelte ein Problem im Eigentumsrecht, das bestimmt schon lange brennend war und das erst durch den juristisch gebildeten und für die provinziellen Belange interessierten Kaiser Septimius Severus eine dauernde Lösung empfing. Es ist sogar denkbar, daß der Kaiser durch die Schaffung der longi temporis praescriptio in erster Linie seiner afrikanischen Heimat einen Erweis seiner besondern Huld schenken wollte. Er hat, als erster Afrikaner auf dem Kaiserthron, seine Heimat bekanntlich nicht vergessen, sondern mit seinem besondern Wohlwollen geehrt. Ist vielleicht praescr. haer. 37, wo einzelne Autoren die longi temporis praescriptio vermuten, ein leiser Widerhall auf dieses für die Provinzen so bedeutsame Ereignis?

1 Vgl. J. Partsch, Die longi temporis praescriptio $109 \mathrm{ff}$. 


\section{Die ältesten Quellen der longi temporis praescriptio ${ }^{1}$}

Im voraus sei bemerkt, $\mathrm{da} ß$ wir die longi temporis praescriptio möglichst in der Gestalt erfassen müssen, in der sie sich um 200 herum darbietet. Denn in diese Zeit fällt die Abfassung des tertullianischen Traktates praescr. haer. Nur so wird eine zuverlässige Deutung von praescr. haer. 37, wo einzelne Autoren die hier zu erläuternde ProzeBeinrede vermuten, möglich sein. Da sich nun aber die longi temporis praescriptio um 200 herum im ersten Stadium ihres Bestehens befindet, müssen wir auf die ältesten Quellen derselben zurückgreifen. Es folgt daher eine Übersicht der ältesten und wichtigsten Quellen (das genaue Datum und Inhalt der ursprünglichen Konstitution, die das Rechtsinstitut promulgierte, ist unbekannt) :

1. Ein Reskript der Kaiser Septimius Severus und Caracalla, das uns in einer doppelten Redaktion überliefert ist. Die erste Fassung datiert vom 3. Tybi des 8. Jahres (29. Dezember 199) und ist überliefert auf Papyrus Nr. 267 Berliner Griechischen Urkunden ${ }^{2}$. Die zweite Fassung datiert vom 24. Pharmuthi (19. April 200) und erscheint auf Papyrus Nr. 22 (Kol. 1, Zeile 1-9) der Straßburger Papyri ${ }^{3}$. Beide Fassungen wurden in Alexandrien erlassen. Tatsächlich ist uns durch eine Inschrift ${ }^{4}$ die Anwesenheit des Septimius Severus in Alexandrien anläßlich seiner Reise nach Ägypten noch vor dem 10. Dezember 199 bezeugt.

2. Ein Brief von Severus und Caracalla an die Leute von Tyra, abgefaßt im J. 201 und erhalten in einer Inschrift ${ }^{5}$.

3. Ein Reskript derselben Kaiser aus dem Jahre 202, das uns im Codex Justinians überliefert ist ${ }^{6}$.

1 Vgl. J. Partsch, Die longi temporis praescriptio 109 ff. und L. MitreisU. Wilcken, Grundzüge und Chrestomathie der Papyruskunde, 2. Bd. Juristischer Teil, 1. Hälfte Grundzüge S. $286 \mathrm{f}$. Nr. 87.

2 C. G. Bruns, Fontes juris Romani antiqui, Pars prior, Leges et Negotia ?,

${ }^{3}$ L. Mitreis-U. Wilcken, Grundzüge und Chrestomathie der Papyruskunde, 2. Bd. Juristischer Teil, 2. Hälfte Chrestomathie, Nr. 374.

4 Vgl. Corpus Inscriptionum Latinarum 3, 6581; ferner Pauly-Wissowa, Real-Encyclopädie der klass. Altertumswissenschaft II A 1972.

5 C. G. Bruns, a. a. O. Nr. 89.

- Cod. 7, 33, 1. 
4. Ein Prozeßprotokoll mit Entscheidung vom 13. März $207 \mathrm{n}$. Chr., mit der soeben erwähnten zweiten Redaktion des Severischen Reskriptes in Pap. Straßb. 22 (Zeile 10-24) enthalten ${ }^{1}$.

5. Ein ProzeBprotokoll vom 2. Oktober 232, das in allerdings sehr verstümmeltem Zustand in Nr. 69 (col. III, Zeile $17 \mathrm{ff}$.) der Pariser Papyri (Pap. Paris. 69 III $17 \mathrm{ff}$.) überliefert ist ${ }^{2}$.

\section{Die Voraussetzungen der longi temporis praescriptio}

Anhand der angeführten Quellen ergibt sich folgendes Bild von der ältesten Gestalt der longi temporis praescriptio. Wir befassen uns vorerst und hauptsächlich mit den Voraussetzungen, die beim Präskribenten erfordert sind :

1. gültiger Erwerbsgrund (iustus titulus),

2. Gutgläubigkeit (bona fides),

3. erfüllte Ersitzungsfrist.

1. Sowohl das Reskript der Severischen Kaiser als auch die Prozeß-

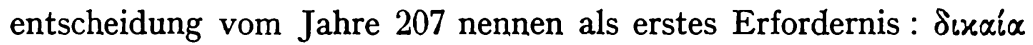
aiti $\alpha^{3}$, d. h. es ist ein gesetzlich anerkannter Erwerbsgrund (iusta causa, iustus titulus) verlangt. Der Jurist Paulus, der Konsiliar des Severus oder Caracalla, sagt mit andern Worten, der Besitz müsse einen gerechten Anfang, ein "iustum initium" haben. Als häufigster Anfang oder Erwerbsgrund begegnet in den klassischen Quellen der Kauf.

2. Nicht so eindeutig verhält es sich mit der bona fides. In einem Reskript Gordians ${ }^{5}$ vom Jahre 238 , und fortan regelmäßig, wird die Gutgläubigkeit ausdrücklich gefordert. Ob die bona fides aber auch schon vorher eine der unerläßlichen Bedingungen der longi

1 L. Mitreis-U. Wilcken, Grundzüge und Chrestomathie der Papyruskunde, 2. Bd. Juristischer Teil, 2. Hälfte Chrestomathie, Nr. 374.

${ }^{2}$ L. Mitteis - U. Wilcken, Grundzüge und Chrestomathie der Papyruskunde, 1. Bd. Historischer Teil, 2. Hälfte Chrestomathie, Nr. 11.

3 Vgl. J. Partsch, Die longi temporis praescriptio $3 \mathrm{ff}$. und Jörs-KunkelWenger, Röm. Recht § 76, 2.

4 C. G. Bruns, a. a. O. Nr. 87 Zeile 8.

5 Vgl. J. Partsch, a. a. O. $7 \mathrm{ff}$. 
temporis praescriptio ist, bleibt umstritten ${ }^{1}$. Das Reskript des Septimius Severus und Caracalla drückt sich in diesem Punkte nicht klar aus.

3. Die Ersitzungsfrist beträgt unter Gegenwärtigen (inter praesentes) 10, unter Abwesenden (inter absentes) 20 Jahre. Der klagende Eigentümer und der auf die longi temporis praescriptio sich berufende Ersitzer sind gegenwärtig, wenn sie in derselben Gemeinde (civitas), abwesend, wenn sie in verschiedenen Gemeinden ihren Wohnsitz haben.

In der Berechnung der Ersitzungsfrist darf der präskribierende Erbe die bereits vom Erblasser erfüllte Ersitzungszeit anrechnen. Dasselbe gilt in spätklassischer Zeit wahrscheinlich auch bei jedem andern gültigen Erwerbsgrund.

Der Besitz der zu präskribierenden Sache darf während der 10 bzw. 20jährigen Ersitzungsfrist nie unterbrochen worden sein. Unterbrochen wird der Besitz durch den Verlust der Sache und namentlich durch den Prozeß $\beta$ des wirklich berechtigten Eigentümers. Daher die Forderung des Reskriptes, der Besitzer müsse (innerhalb

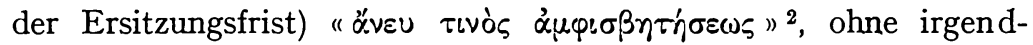
welche Belästigung geblieben sein.

Es wurde eingangs zu diesem Abschnitt erklärt, da $B$ wir die longi temporis praescriptio möglichst in ihrer anfänglichen Gestalt feststellen müssen, da Tertullian seinen Traktat um 200 herum verfaßt hat. Diesem Erfordernis entsprechend wurde in der vorangegangenen Aufzählung der Voraussetzungen bemerkt, $\mathrm{da} B$ die bona fides anfänglich vielleicht nicht verlangt war. Von Interesse ist für uns weiter, $\mathrm{da} B$ unser Rechtsinstitut seit seiner Entstehung bis zu den Jahren 215/7 höchst wahrscheinlich nur für Grundstücke galt ${ }^{3}$.

Es ist aber noch auf eine andere Eigentümlichkeit hinzuweisen, die die ursprüngliche longi temporis praescriptio kennzeichnete und deren

1 Das Erfordernis der bona fides verneinen für die ursprüngliche longi temporis praescriptio: J. PARTsch, a. a. O. 7 ff., Jörs-Kunkel-Wenger, a. a. O. $\S 76$ Anm. 4, P. M. Meyer, Juristische Papyri, Nr. 54.

Die bona fides bejahen z. B. L. Mitreis - U. WiLken, Grundzüge und Chrestomathie der Papyruskunde, 2. Bd. Juristischer Teil, 1. Hälfte Grundzüge S. $286 \mathrm{f}$. und L. Wenger, Zeitschr. der Savigny-Stiftung, romanistische Abteilung 27 (1906) $374 \mathrm{f}$.

2 C. G. Bruns, a. a. O. Nr. 87 Zeile 9.

3 Vgl. J. PARTSCH, a. a. O. 3-7. 
Feststellung für unsere $Z$ wecke von besonderm Wert sein wird. Die longi temporis praescriptio war nämlich in ihrer ursprünglichen Gestalt noch gar keine Ersitzungsform, das wurde sie erst später. Anfänglich hatte die longi temporis praescriptio nur die Funktion einer Anspruchsverwirkung, d. h. der beklagte Besitzer verweigerte dem klagenden Eigentümer (dessen Recht, Anspruch an der Sache nicht bestritten werden konnte) die Herausgabe der Sache, indem er sich auf seinen langdauernden Besitz berief. Der rechtmäßige Eigentümer hatte den seinem Eigentümerrecht widersprechenden Zustand 10 bzw. 20 Jahre schweigend mitangesehen, er hatte folglich sein Recht verwirkt. Die Funktion der longi temporis praescriptio ist also anfänglich nur die: sie schützt den beklagten Besitzer in seinem Besitz, sie macht aber den Besitzer nicht zum Eigentümer. Hierin unterscheidet sich die ursprüngliche longi temporis praescriptio hauptsächlich von der usucapio, die den Besitzer zum Eigentümer werden ließ und daher immer ein Ersitzungsinstitut war. Die longi temporis praescriptio entwickelte sich im Lauf der Zeit auch zum Ersitzungsinstitut. Wann jedoch diese Entwicklung von der bloßen Anspruchsverwirkung zur erwerbenden Ersitzung abgeschlossen war, entzieht sich einer genauern Feststellung. Kaiser Justinian (527-565), der usucapio und longi temporis praescriptio im Jahre 531 miteinander verschmolz, bemerkt nur, diese Wandlung zur Ersitzung sei vor seiner Zeit eingetreten. Diese Worte deuten auf einen ziemlich späten Zeitpunkt. Wir dürfen jedenfalls mit Sicherheit annehmen, daß die longi temporis praescriptio ums Jahr 200 herum, wo sie erst wenige Jahre existierte, noch keine Ersitzung war. Diese Feststellung wird beitragen zur Klärung der Frage, ob Tertullian in seiner um dieselbe Zeit verfaßten Schrift praescr. haer. die longi temporis praescriptio vor Augen hatte.

\section{Die prozessuale Gestalt der longi temporis praescriptio ${ }^{1}$}

Die longi temporis praescriptio ist eine Prozeßeinrede. Solange der Formularproze $ß$ noch neben dem Kognitionsprozeß existierte, konnte die Einrede aus dem langen Besitze in diesem wie jenem Verfahren auftreten. Je nachdem hatte sie eine andere Gestalt.

Im FormularprozeB erfolgte die Berufung auf den langen recht-

1 Vgl. J. Partsch, a. a. O. 66/8. 
mäßigen, während der ganzen Ersitzungsfrist unangefochtenen Besitz, durch Einfügung einer exceptio in die Formel. Utber die Form dieser exceptio sind wir im Ungewissen ${ }^{1}$.

Im Kognitionsproze $B$ war die longi temporis praescriptio eine Einrede oder Einwendung, die der Beklagte in der Verhandlung vor dem Richter geltend machte. Das Vorbringen der Einrede war im Prozeß an keinen bestimmten Zeitpunkt und keine bestimmte Form gebunden : der Beklagte berief sich auf die kaiserlichen Konstitutionen, behauptete seinen langjährigen, rechtmäßig erworbenen und unangefochtenen Besitz und leistete die notwendigen Beweise dafür.

1 Vgl. J. Partschs Vermutungen a. a. O. 67. 
II. TEIL

Die Anwendung der praescriptio durch Tertullian 



\section{Kapitel}

\section{Analyse von De praescriptione haereticorum 15-37}

Tertullians Traktat De praescriptione haereticorum (praescr. haer.) zerfällt deutlich in drei Abschnitte. Der erste umfaßt die Kap. 1-15 und stellt sich als eine weitausholende Einleitung vor, die sich der Verfasser als eine Ansprache - allocutionis praefatio ${ }^{1}$ - denkt. Der Hauptabschnitt reicht von Kap. 15-37. Die Kap. 38-44, von J.-L. AlliE eine Schmähschrift gegen die Häretiker genannt ${ }^{2}$, bilden den Schluß. Wir begnügen uns damit, die Hauptgedanken der Einleitung anzuführen. Sie handelt vom Wesen und Ursprung der Häresie im allgemeinen. Die Häresie ist in ihrem tiefsten Wesen Subjektivismus und Autonomie, eigenmächtige electio (Kap. 6). Sie ist nichts mehr als eine Lehre von Menschen und Dämonen. Daher ihre Verwandtschaft mit der heidnischen Philosophie (Kap. 7). Die Hauptwaffe der Häretiker im Kampf gegen die Kirche ist die Berufung auf die Heilige Schrift (Kap. 15). Damit beginnt der Hauptteil des gehaltvollen Traktates, der die Kap. 15-37 umfaßt und Gegenstand folgender Analyse ist.

In praescr. haer. $21^{3}$ entwickelt Tertullian seine Präskriptionen oder Prozeßeinreden. Diese sind jedoch keine isolierten Gebilde; eine eingehendere Prüfung wird im Gegenteil bestätigen, da $B$ diese Präskriptionen eingebaut sind in eine planvolle Gesamtstruktur, die die Kapitel 15-37 umfaßt. Daraus ergibt sich die Notwendigkeit, diesen ganzen Abschnitt der Analyse zu unterziehen.

$\mathrm{Daß}$ die Kap. 15-37 ein zusammenhängendes Ganzes bilden, dafür gibt uns, abgesehen vom Gedankengang, der Autor selber deutliche Anhaltspunkte. Er leitet den betreffenden Abschnitt in Kap. 15 ein mit den Worten: "Venimus igitur ad propositum." " 4 So sind wir

1 Vgl. J.-L. Allie, L'argument de praescription $72 \mathrm{ff}$.

2 Praescr. haer. 15 (Kr. 20, 2).

3 Praescr. haer. 21 (Kr. 24, 31).

${ }_{4}$ Praescr. haer. 15 (Kr. 20,1). 
denn beim Hauptthema angelangt "; und dieses heißt: "... dispici debet, cui competat possessio scripturarum, ne is admittatur ad eas, cui nullo modo competit. " ${ }^{1}$ An diese Einleitungsworte anknüpfend, beschließt der Verfasser in Kap. 37 den erwähnten Abschnitt : "... constat ratio propositi nostri definientis non esse admittendos haereticos ad ineundam de scripturis provocationem, quos sine scripturis probamus ad scripturas non pertinere. ${ }^{2}$

Das Ziel dieser Analyse : die Präskriptionen sollen aus dem $\mathrm{Zu}$ sammenhang herausgeschält und in ihrer Stellung und Bedeutung innerhalb des Gesamtplans erfaßt werden. Auch sonstige juristische Begriffe werden, soweit dies dem Zweck der Arbeit dient, berührt. Ganz besondere Aufmerksamkeit wird darauf verwendet, die innern Zusammenhänge, die große Linie des Abschnittes aufzuzeigen.

Es ist nicht leicht, die innere Struktur unseres Abschnittes, der das Kernstück von praescr. haer. ausmacht, immer klar und überzeugend aufzuhellen. Schon der dunkle und geballte Stil verhüllt oft die klare Sicht. Auch in seinen Gedankengängen bewegt sich Tertullian zuweilen in einem verwirrenden Zickzack. Bekannt ist der Ausspruch von EduARD NoRdEN : "Er (Tertullian) ist ohne Frage der schwierigste Autor in lateinischer Sprache; keiner stellt so rücksichtslose Anforderungen an den Leser ...." ${ }^{3}$

Anderseits steht aber auch fest, daß Tertullian seine Traktate nach einem wohldurchdachten Plan aufbaut 4. Die Schrift an Scapula dürfte in diesem Punkte die einzige Ausnahme bilden, da sie inmitten der Hast und Hitze der Verfolgung entstanden ist. $\mathrm{Da} \beta$ praescr. haer., bzw. der uns interessierende Abschnitt, tatsächlich nach einem bestimmten Plan verfaßt ist, dürfte die folgende Analyse bestätigen. Es möchte vielleicht die eine und andere Stelle derselben etwas gezwungen oder systematisiert anmuten. Es gibt aber zuweilen keine andere Wahl, wollen wir das Dickicht des tertullianischen Stils lichten und die darin versteckten Gedanken erfassen. Ein eventuelles Zuviel in dieser Hinsicht wird aufgewogen durch den Nutzen einer gründ-

1 Praescr. haer. 15 (Kr. 20,9).

3 Praescr. haer. 37 (Kr. 47, 3). Daß die Kap. 15-37 eine Einheit bilden und von Tertullian mit den angeführten Worten als solche gekennzeichnet werden, steht auch für J.-L. Allie a. a. O. $61 \mathrm{ff}$. fest.

3 ED. Norden, Die antike Kunstprosa (Leipzig 1898) 606.

4 Vgl. H. Kellner - G. Esser, Tertullians ausgewählte Schriften ins Deutsche übersetzt, Bibl. der Kirchenväter 2. Bd. (Kempten-München 1915) 16, 29, 302. 
lichen Analyse. Ja, eine möglichst einläßliche Analyse ist sogar sehr notwendig (und die diesbezüglichen spätern Ausführungen werden es bestätigen) hinsichtlich der nicht leichten Frage von praescr. haer. : ob und wie Terullian darin die "longi temporis praescriptio " anwendet. Die Beschäftigung mit dieser interessanten Frage ${ }^{1}$ wird es bestätigen, daß eine möglichst tief dringende Analyse nicht verlorene Mühe ist, sondern im Gegenteil die betreffende Lösung bedeutend erleichtert, wenn nicht sogar zum großen Teil überhaupt ermöglicht.

Die Analyse wird auch die herkömmliche, schon von U. HüNTEMANN 2 zurückgewiesene Auffassung widerlegen, wonach in diesem Traktat Tertullians drei Präskriptionen zu suchen wären ${ }^{3}$.

Wir berücksichtigen für unsere Arbeit die von U. HüNTEMANN veröffentlichte Analyse. Leider läßt dessen Arbeit die juristische Seite sozusagen ganz außer acht. Das hat sich zum Nachteil des sonst sehr gründlichen und wertvollen Beitrags ausgewirkt. Unter Berücksichtigung der von U. HünTEMANN gewonnenen Ergebnisse schlägt die vorliegende Analyse insofern einen neuen Weg ein, als sie praescr. haer. hauptsächlich vom juristischen Standpunkt her prüft, also vor allem die Stellung und Aufgabe der Präskriptionen in der Gesamtstruktur des Traktates aufzuhellen sich bemüht. $\mathrm{DaB}$ dieser im Lichte des römischen Rechts eingeschlagene Weg berechtigt ist, das bekräftigen die Ausführungen der Einleitung über Tertullian als Juristen ${ }^{4}$ und nicht $\mathrm{zu}$ letzt die nun folgende Analyse, bzw. ihre Ergebnisse selber.

J.-L. ALLIE unterzieht den gesamten Traktat De praescriptione haereticorum ebenfalls einer Analyse ${ }^{5}$. Doch begnügt er sich damit, die Gedanken Tertullians frei wiederzugeben. Nirgends wird versucht, die innere Struktur des Traktates, vor allem des schwierigen Abschnittes von Kap. 15-37, aufzuhellen. Der Verfasser sieht das Ziel und Ergebnis seiner Analyse darin, den Inhalt der Kap. 15-37 in eine Kette von Syllogismen $\mathrm{zu}$ fassen.

Der nun zu entfaltenden Analyse möge eine kurze, orientierende Skizze vorausgeschickt werden :

In Kap. 15 wird als das eigentliche Ziel des nun beginnenden und sich bis Kap. 36 erstreckenden Hauptabschnittes angekündigt :

1 Vgl. H. Kellner-G. Esser, Tertullians ausgew. Schr., 2. Bd. S. $27 \mathrm{ff}$.

2 Vgl. U. HüntemanN, Tertulliani de praescriptione haereticorum libri analysis, 5 .

${ }^{3}$ Siehe unten S. 127.

4 Siehe oben S. $3 / 4$.

5 Vgl. J.-L. Allie, a. a. O. $57 \mathrm{ff}$. 
"... dispici debet, cui competat possessio scripturarum ..." 1. Anschließend wird dieses Vorgehen gerechtfertigt (cc. 16-18). Die Frage nach dem rechtmäßigen Besitzer der Heiligen Schriften kann aber nur gelöst werden auf dem Umweg über eine andere : wer ist rechtmäßiger Besitzer des Offenbarungsglaubens? Denn das mündliche und schriftliche depositum fidei können nicht von einander getrennt werden. Daher wird der Weg zum oben angekündeten Ziel in Kap. 19 vorgezeichnet: vorerst muß untersucht werden, wer rechtmäßiger Besitzer des Glaubens selbst ist, zu dem die Schrift gehört (wie der Teil zum Ganzen) ; als Wegweiser für diese Untersuchung dient die Partitio : "... disputandum est, ... a quo et per quos et quando et quibus sit tradita disciplina, qua fiunt Christiani. „ ${ }^{2}$ Kap. 20 gibt Antwort auf die vier Fragen der Partitio und ergibt die Grundlage für die in Kap. 21 formulierten zwei Präskriptionen. Auf der Grundlage der zweiten Präskription ersteht das Kriterium, mittels dessen die wahre Lehre außerhalb der apostolischen Urkirchen festgestellt werden kann. Die Anwendung des Kriteriums auf die von Tertullian verteidigte Lehre der afrikanischen Christengemeinde zeugt für deren Echtheit. Vorläufig soll aber dieses Resultat suspendiert und die beiden Präskriptionen, besonders die zweite, noch gegen die drei Objektionen der Häretiker verteidigt werden. Diese drei Objektionen, bzw. deren Widerlegung, umfaßt die Kap. 22-34. Da die 3. Objektion die wichtigste und zugleich schwerste von allen ist, wird sie in einem eigenen Abschnitt analysiert. Nachdem die drei Objektionen widerlegt sind, und die beiden Präskriptionen sich somit bewährt haben, werden die Häretiker in Kap. 35 aufgefordert, nun auch ihrerseits einige Präskriptionen d.h. eine Replik vorzubringen. Nachdem diese ausbleibt, gibt Tertullian in Kap. 36 noch ein positives Argument zu Gunsten der 2. Präskription und nimmt den in Kap. 22 unterbrochenen Beweisgang für die Echtheit der afrikanischen Kirchenlehre wieder auf, indem er die Symbola der römischen und afrikanischen Kirche miteinander vergleicht. - Die mit der Partitio des 19. Kapitels eröffnete Untersuchung, wer rechtmäßiger Besitzer des Offenbarungsglaubens sei, von dem die Heilige Schrift nur einen Teil darstellt, ist hier abgeschlossen. Mit dieser Frage ist auch die andere, wer rechtmäßiger Besitzer der Heiligen Schrift sei, gelöst. Diese sich von selbst ergebenden Konsequenzen bezüglich der Heiligen Schrift zieht der Verfasser in Kap. 37.

1 Praescr. haer. 15 (Kr. 20, 9). 2 Praescr. haer. 19 (Kr. 23, 6). 
Somit ergibt sich folgender Gesamtplan :

1. Ankündigung des eigentlichen Ziels von praescr. haer. : " ... dispici debet, cui competat possessio scripturarum ... ${ }^{1}$. Kap. 15.

2. Rechtfertigung dieses Vorgehens. Kap. 16-18.

3. Der Weg zum Ziel, vorgezeichnet in der Partitio : es muß vorerst untersucht werden, "a quo et per quos et quando et quibus" die christliche Lehre als solche überliefert wurde. Kap. 19.

4. Beantwortung der Partitio. Daraus die Grundlagen für die Präskriptionen. Kap. 20.

5. Die zwei Präskriptionen. Kap. 21.

6. Das auf Grund der 2. Präskription formulierte Kriterium und seine Anwendung. Kap. 21.

7. Verteidigung der Präskriptionen gegen die drei Objektionen. Kap. 22-34.

8. Einläßliche Analyse der 3. Objektion. Kap. 27-34.

9. Aufforderung an die Häretiker zur Replik. Kap. 35.

10. Letztes Argument für die Wahrheit der zweiten Präskription und Vergleich des römischen und afrikanischen Symbolums. Kap. 36.

11. Folgerungen bezüglich der Heiligen Schrift. Kap. 37.

\section{Ankündigung des eigentlichen $Z$ iels \\ Wer ist rechtmäßiger Besitzer der Heiligen Schrift ?}

(Kap. 15)

Die wichtigste und gefährlichste Waffe der Häretiker im Kampf gegen die Katholiken ist die Heilige Schrift. Tertullian berichtet, da $B$ die Häretiker gewisse Leute schon dadurch beeindrucken, daß sie es überhaupt wagen, sich auf die Heilige Schrift zu berufen ${ }^{2}$. $\mathrm{Zu}$ welch gefährlicher Waffe muß aber die Heilige Schrift in der Hand der Häretiker, dieser Fechtmeister der Sophistik, erst werden, wenn sie dieselbe im eigentlichen Kampfe für ihre häretischen Ansichten handhaben: "die Standhaften ermüden sie, die Schwachen bringen sie zu Fall, die Mittelmäßigen (Lauen) entlassen sie mit $Z$ weifeln aus dem Kampf " 3 .

1 Siehe S. 42 Anm. 1.

2 Praescr. haer. 15 (Kr. 20, 4).

3 Praescr. haer. 15 (Kr. 20, 5) : ... firmos quidem fatigant, infirmos capiunt, medios cum scrupulo dimittunt. 
Solange der Gegner mit der gleichen Waffe kämpft, bleibt der Kampf unentschieden, wenn nicht zum Nachteil für die Katholiken, da die Häretiker die Heilige Schrift nach der ihnen eigenen, rücksichtslosen Willkür handhaben. Diese Waffe muß ihnen entwunden werden. Es soll zu diesem Zwecke untersucht werden, wer als rechtmäßiger Besitzer der Heiligen Schrift anzusehen ist, die Katholiken oder die Häretiker : "... dispici debet, cui competat possessio scripturarum ... "1. Die Untersuchung wird zu Gunsten der erstern ausfallen. Dadurch wird jeder weitere Disput mit den Häretikern im voraus überflüssig werden.

\section{Rechtfertigung dieser Methode}

$$
\text { (Kap. 16-18) }^{2}
$$

Nicht Mangel an Selbstvertrauen im Kampf mit den Häretikern, auch nicht die Absicht, die Streitfrage anders zu fassen, lassen den Autor diesen Weg einschlagen ${ }^{3}$. Er gibt für sein Vorgehen zwei triftige Gründe an :

a) Die Autorität des A postels, der verbietet, sich mit Häretikern in Disputationen einzulassen 4.

b) Die Aussichtslosigkeit einer Auseinandersetzung auf Grund der Heiligen Schrift, wie die tägliche Erfahrung beweist. Dieser Grund leuchtet umso besser ein, da uns ein Einblick gegeben wird in die Methoden der Häretiker : gewisse Bücher verwerfen sie; die, welche sie gelten lassen, entstellen sie durch eigenmächtiges Interpolieren und Streichen, um sie mit ihrer Lehre in Einklang zu bringen; wenn sie schließlich noch einige Bücher unberührt lassen, so verdrehen sie deren Sinn durch eigenmächtige Interpretation ${ }^{5}$.

Das Disputieren mit solchen Leuten erzeugt für den Disputierenden nur nutzlose Mühe und Ärger. Und derjenige, in dessen Interesse man sich in den Disput eingelassen hat, wird selber unsicher, auf welcher Seite die Wahrheit sich finde, da beide Teile auf demselben Standpunkt des Behauptens und Abstreitens stehen ${ }^{6}$.

1 Praescr. haer. 15 (Kr. 20, 9).

2 Praescr. haer. 16-18 (Kr. 21).

3 Vgl. praescr. haer. 16 (Kr. 21, 1).

4 Vgl. praescr. haer. 16 (Kr. 21, 3).

5 Vgl. praescr. haer. 17 (Kr. 21, 1).

6 Vgl. praescr. haer. 18 (Kr. 22, 1). 


\section{Der Weg zum Ziel, vorgezeichnet in der Partitio}

(Kap. 19) ${ }^{1}$

Die Ermittlung des rechtmäßigen Besitzers der Heiligen Schrift muß stattfinden innerhalb der Rangordnung, der die Heilige Schrift eingegliedert ist. Der "ordo rerum " ${ }^{2}$, wie Tertullian im Kernsatz des 19. Kapitels sagt, die Rangordnung, die Hierarchie der Dinge, weist den Weg. Die Heilige Schrift ist nicht eine isolierte und sich selbst genügende $\mathrm{Größe}$, wie die Häretiker behaupten und als was sie sie behandeln, sondern sie ist untrennbar verbunden mit der Tradition. Die Heilige Schrift als geschriebene Offenbarung bildet mit der Tradition als der mündlichen Offenbarung das untrennbare Gesamtdepositum der Offenbarungswahrheiten. Was aber die gegenseitige Rangordnung betrifft, geht die Tradition der Schrift chronologisch und logisch voran. Weil außerdem das mündliche und schriftliche Depositum von den Aposteln bei derselben Kirche deponiert wurden, braucht nur festgestellt zu werden, wer von Anfang an zum rechtmäßigen Träger des mündlichen Depositums bestellt wurde, denn derselbe ist ipso facto auch der allein rechtmäßige Inhaber des schriftlichen Depositums der Heiligen Schrift.

Tertullian ballt diese Gedanken, ganz seiner Eigenart entsprechend, in zwei gedrängte, planmäßig gebaute Sätze : “ . . ordo rerum desiderabat illud prius proponi, quod nunc solum disputandum est : quibus competat fides ipsa, cuius sunt scripturae, a quo et per quos et quando et quibus sit tradita disciplina, qua fiunt Christiani. " Denn, so folgert er : "Ubi enim apparuerit esse veritatem disciplinae et fidei Christianae, illic erit veritas et scripturarum et expositionum et omnium traditionum Christianarum. ") ${ }^{3}$

Zwischenhinein mögen einige kurze textkritische Bemerkungen Platz finden.

Entscheidend für das Verständnis der angeführten Stelle und des ihr folgenden Kapitels ist die Frage, welche Version im 1. Satz die richtige sei : "cuius sunt scripturae" oder "cuius sint scripturae".

1 Praescr. haer. 19 (Kr. 22, 1).

2 Praescr. haer. 19 (Kr. 23, 5).

3 Ebd. Vgl. zu dieser Stelle J.-L. Allie, L'argument de Prescription 63 : "La seul question qu'il (Tertullien) consent à examiner avec les Marcion et leurs émules est celle-ci : à qui appartient la vraie doctrine du Christ ? L'éclaircissement de ce point fera connaitre le possesseur légitime des Ecritures saintes et de leurs justes explications." 
Die 2. Version begegnet sozusagen in allen bisherigen Textausgaben ${ }^{1}$ und Handbüchern, die diese wichtige Stelle zitieren. Die Vermutung, "cuius sint scr." könnte die richtige Version sein, drängt sich auf den ersten Blick tatsächlich auf. "cuius sint scr. " wäre dann in einer dreigliedrigen, von "disputandum est " abhängigen Kette von Fragesätzen der mittlere. Bei genauerm Zusehn ergibt jedoch diese Lösung keinen oder nur einen verworrenen Sinn, wenn man den Zusammenhang berücksichtigt. Das Wiener Corpus ${ }^{2}$ entscheidet sich in seiner vor kurzem erfolgten Ausgabe von praescr. haer. für " cuius sunt scr. ". Diese Version kann die einzig richtige sein. Sie hat einmal das Zeugnis der vier ältesten Codices ${ }^{3}$ für sich. Sie entspricht auch dem von Tertullian häufig angewandten Satzparallelismus mit Reim ${ }^{4}$ :

disputandum est $\left\{\begin{array}{l}\text { quibus competat fides ipsa, cuius sunt scripturae. } \\ \text { a quo et per quos et quando et quibus sit tradita } \\ \text { disciplina, qua fiunt Christiani. }\end{array}\right.$

Auf " disputandum est " folgen zwei indirekte Fragesätze, denen beiderseits je ein Relativsatz entspricht. Die beiden indirekten Fragesätze gehören aber innerlich zusammen, weil sie getragen sind von den zwei Subjekten, "fides " und " disciplina ", die hier als Synonyme zu verstehen sind und daher ein zusammengehöriges Begriffspaar bilden. Das bestätigt auch der nächste Satz, wo fides und disciplina wiederum gemeinsam genannt werden: veritas fidei et disciplinae ${ }^{5}$. Somit ist der zweite

1 Es genüge, von den ältesten Textausgaben F. OeHLer, Quinti Septimii Florentis Tertulliani quae supersunt omnia, Bd. 2 (Leipzig 1854) S. 18, und von den letzten J. Martin, Quinti Septimii Florentii Tertulliani liber de praescriptione haereticorum, Florilegium patristicum, Fasz. 4 (Bonn 1930) S. 19 zu nennen.

2 A. Kroymans, Quinti Septimi Florentis Tertulliani opera, Pars III, Corpus scriptorum ecclesiasticorum latinorum, Bd. $70,23,7$.

${ }^{3}$ Codex Parisinus 1622 oder Agobardinus (9. Jahrh.).

Codex Paterniacensis 439 (11. Jahrh.).

Codex Florentinus Magliabechianus Conv. soppr. VI, 9 (15. Jahrh.).

Codex Florentinus Magliabechianus Conv. soppr. VI, 10 (15. Jahrh.).

4 Tertullian ist ein Meister des Satzparallelismus. Zahlreiche Beispiele bei H. Hoppe, Syntax und Stil des Tertullian 158/62.

5 Die vorzügliche Arbeit von V. Morel, Disciplina, Le mot et l'idée représentée par lui dans les oeuvres de Tertullian, in Revue d'histoire ecclésiastique Bd. 40 (Löwen 1944/5) 5-46, hat das Wort "disciplina" nach den vielfältigen Bedeutungen und Schattierungen, die es in den Schriften Tertullians hat, unter Berücksichtigung aller diesbezüglichen Stellen gründlich untersucht. Wenn wir von den profanen Bedeutungen absehen, bezeichnet Tertullian mit "disciplina " bald das Christentum als solches, bald die christliche Lehre unter Ausschlu $\beta$ der Glaubensregel, bald eine Glaubenslehre im besondern; in einer zweiten Grund- 
Fragesatz nur die Erweiterung oder Erklärung des ersten : der rechtmäßige Inhaber der Offenbarung soll ermittelt werden (1. indir. Fragesatz), indem untersucht wird, "a quo et per quos et quando et quibus " die Offenbarung überliefert wurde (2. indir. Fragesatz). - Für "cuius sunt scr." spricht endlich auch der Sinn und Zusammenhang. Der 2. Satz unserer Stelle unterscheidet sehr deutlich zwischen der "veritas disciplinae et fidei christianae " als der Gesamtheit der Glaubens- und Sittenlehre einerseits und der "veritas scripturarum et expositionum etc. " anderseits ${ }^{1}$. Wo das erste ist, dort findet sich auch das zweite. Soweit diese textkritischen Erwägungen.

Der rechtmäßige Inhaber des christlichen Glaubens als solchem (quibus competat fides ipsa), zu dem die Schrift gehört, wie der Teil zum Ganzen ( . . fides ..., cuius sunt scripturae $=$ Gen. poss.) soll zuerst festgestellt werden. Nur diese Frage ist vorderhand zu disputieren (... quod nunc solum disputandum est ...). Der Weg dazu ist vorgezeichnet in den 4 Punkten des 2. indir. Fragesatzes : "... a quo et per quos et quando et quibus sit tradita disciplina ... n, die für die folgende Untersuchung die Partitio abgeben. Diese Untersuchung endigt erst in Kap. 36, zu Gunsten der katholischen Lehre ${ }^{2}$. Damit ist auch die Lösung der andern Frage gegeben, wer rechtmäßiger Besitzer der Heiligen Schrift sei. Diese Folgerungen bezüglich der Heiligen Schrift zieht Tertullian in Kap. 37.

\section{Beantwortung der Partitio}

(Kap. 20) ${ }^{3}$

Kap. 20 stellt die Antwort dar für die 4 Punkte der soeben erläuterten Partitio: "a quo et per quos et quando et quibus sit tradita disciplina, qua fiunt christiani. " Kap. 20 zerfällt dement-

bedeutung die Gesetze und Gebote, seien es göttliche oder kirchliche, vereinzelt oder in ihrer Gesamtheit. Der Autor bemerkt ausdrücklich a. a. O. S. 17, da B fides und disciplina zuweilen auch synonym gebraucht werden, und er zitiert als Beispiel praesc. haer. 35 (Kr. 44, 6) u. apol. 23 (Hoppe 66, 60). Dasselbe trifft zweifelsohne auch für die uns hier interessierende Stelle in praescr. haer. $19 \mathrm{zu}$. $\mathrm{Da} \beta$ dies Morel a. a. O. S. 17 entgangen ist, erklärt sich wohl daher, daß er die Textausgabe von DE LABRIolle mit "cuius sint scripturae " benützt, den Satzparallelismus mit Reim nicht beachtet und nicht zuletzt, weil er den Satz aus dem Zusammenhang heraushebt und so die Schlüsselstellung übersieht, die dem fraglichen Satz im ganzen Traktat zukommt und dessen Sinn bestimmt, wie die Analyse eindeutig bewiesen hat.

${ }^{2}$ Siehe unten S. $76 \mathrm{ff}$.

1 Vgl. praescr. haer. 19 (Kr. 23, 8).

3 Praescr. haer. 20 (Kr. 23, 1). 
sprechend in 4 Abschnitte, die die betreffenden Punkte der Partitio klar beantworten. Die Beantwortung dieser 4 Punkte, besonders des zweiten und vierten, ergibt die Grundlage für die Präskriptionen.

a) A quo. "Christus Jesus, dominus noster." Über den Ursprung der christlichen Lehre sind sich Katholiken und Häretiker einig. Beide Parteien berufen sich auf "Christus Jesus, unsern Herrn ». Aber schon in der Frage, wer ist Christus, gehen die Meinungen auseinander. Auf diese theologischen Streitfragen läßt sich deshalb Tertullian gar nicht ein, es geht ihm vielmehr darum, eine vorläufige, gemeinsame Verhandlungsbasis zu schaffen, indem er solche Tatsachen bezüglich der Person Christi zugrunde legt, über die sich Katholiken und Häretiker einig sind, und sich bei deren Formulierung des methodischen Zweifels bedient ${ }^{1}$. Solche gemeinsame Wahrheiten sind: Christus ist eine historische Persönlichkeit (quisquis est); er ist irgendwie ein göttliches Wesen (cuiuscumque dei filius); irgendwie Gott und Mensch zugleich (cuiuscumque materiae homo et deus) ; er hat irgendwie eine Glaubenslehre vorgeschrieben (cuiuscumque fidei praeceptor) und eine Belohnung in Aussicht gestellt (cuiuscumque mercedis repromissor).

Diese Wahrheiten lassen sich, wie HünTEMANN ${ }^{2}$ bemerkt, zurückführen auf zwei :

Christi göttliche Autorität und

die Tatsache der durch ihn erfolgten Offenbarung.

Es folgen noch als unbestrittene geschichtliche Tatsachen aus dem Leben Jesu : seine Predigt vor dem Volke und seinen Jüngern, aus denen er zwölf als Apostel aussonderte, und sein an dieselben ergangener Missionsbefehl ${ }^{3}$. Damit beginnt aber schon die Antwort auf den 2. Punkt der Partitio.

b) Per quos. Durch wen gab Christus seine Offenbarung weiter? Es ist auffällig, mit welcher Präzision dieser Punkt beantwortet wird. Denn hier gehn die Ansichten der beiden Lager schon gründlich auseinander. Die Häretiker berufen sich zum Teil auf zweifelhafteste Medien. Die Anhänger des Apelles z. B. führen ihre Lehre über Apelles auf eine gewisse Philumene zurück, der sich Christus direkt geoffenbart habe und deren angebliche Offenbarungen Apelles niederschrieb.

1 Vgl. a. a. O. : "permittat dicere interim".

2 A. a. O. 30.

3 Vgl. praescr. haer. 20 (Kr. 23, 7). 
Demgegenüber betont Tertullian eindringlich, wie Christus seine Lehre einzig den Aposteln und zwar einer genau umgrenzten Zahl von Aposteln übergab und wie er nur diesen den Missionsbefehl erteilte: "... ex quibus (scil. discentibus) duodecim praecipuos lateri suo allegerat, destinatos nationibus magistros. Itaque uno eorum decusso reliquos undecim ... iussit ire ..." ${ }^{1}$. Und als sich die Apostel durch das Los als $z$ wölften den Matthias beigesellten, taten sie dies nicht eigenmächtig, sondern Kraft der Autorität einer Prophetie Davids (ein deutlicher Hieb gegen die Häretiker, die sich eigenmächtig als Apostel aufspielen) ${ }^{2}$.

c) Quando. Auch diese Frage wird mit bezeichnender Präzision beantwortet: "... bei seinem Heimgang zum Vater, nach der Auferstehung befahl Er den übrigen elf Aposteln ... $n^{3}$. Und mit Nachdruck wird von den Aposteln gesagt, daB sie sofort (statim!), nachdem sie noch den Heiligen Geist empfangen hatten, den Glauben an Christus verkündeten.

d) Quibus. Nebst dem "per quos" ist diese Frage für den Autor die wichtigste. Die Antwort ist deshalb wohlabgewogen. Sie stellt in Form und Gehalt geradezu ein kleines Kunstwerk dar.

"... Nachdem die Apostel den Glauben an Jesus Christus zuerst in Judaea bezeugt hatten ..., brachen sie von dort sofort auf über den Erdkreis und verkündeten dieselbe Glaubenslehre den Heidenvölkern. " 4 "Und so gründeten sie Gemeinden in jeder Stadt. Von diesen entliehen dann und entleihen noch täglich die übrigen Gemeinden einen Ableger des Glaubens und Samenkörner der Lehre, um Gemeinden zu werden. Und eben deshalb werden auch sie selber wieder für apostolische angesehen, weil sie Abkömmlinge apostolischer Gemeinden sind. (Denn) jede Art muß nach ihrem Ursprung bewertet werden. Deshalb sind die vielen und großen Gemeinden (im Grunde nur) eine, (nämlich) jene von den Aposteln gegründete ursprüngliche, aus der alle herstammen. Auf

1 Ebd.

2 Vgl. zu dieser Stelle praescr. haer. 30 (Kr. 38, 40), wo sogar derselbe Ausdruck : auctoritas wiederkehrt: " $\mathrm{Hi}$ (scil. haeretici), cupio, ostendant mihi, ex qua auctoritate prodierint."

3 Praescr. haer. 20 (Kr. 23, 9) : "... reliquos undecim digrediens ad patrem post resurrectionem iussit ire ..."

4 Praescr. haer. 20 (Kr. 23, 12) : "Statim igitur apostoli ... primo per Judaeam contestata fide in Jesum Christum ..., dehinc in orbem profecti eandem doctrinam eiusdem fidei nationibus promulgaverunt." 
diese Weise sind alle (Gemeinden) ursprünglich und sind alle apostolisch, weil eben alle (nur) eine bilden. Beweise für die Einheit sind die Friedensgemeinschaft, die Benennung mit Bruderschaft und die gegenseitige Gastfreundschaft ; für diese Rechte ist kein anderer Grund maßgebend als die einheitliche Überlieferung desselben Glaubens. " ${ }^{1}$

Damit ist der 4. Punkt der Partitio, wem die christliche Lehre von den Aposteln übergeben wurde, scharf beantwortet. Die Apostel übergaben sie jenen Gemeinden, denen sie noch persönlich predigten, die sie persönlich gründeten (die eigentlichen oder unmittelbar apostolischen Gemeinden). Wie diese apostolischen Urgemeinden heißen, braucht der Verfasser nicht extra zu sagen; überall, wo Christus verkündet wird, also auch in Afrika, kennt man ihre Namen : Korinth, Philippi, Ephesus, Rom usw. ${ }^{2}$. Von diesen unmittelbar apostolischen Gemeinden empfingen und empfangen bis zur Stunde die übrigen Gemeinden die Lehre (mittelbar apostolische Gemeinden).

\section{Die zwei Präskriptionen}

(Kap. 21) ${ }^{3}$

Wenn man die 4 Punkte der Partitio, a quo et per quos et quando et quibus, die in Kap. 20 beantwortet werden, miteinander vergleicht, wird klar, daß der 2. Punkt (per quos) und der 4. Punkt (quibus) die zwei wichtigsten sind. Der 2. Punkt: wem hat Christus seine Offenbarung anvertraut, bildet die Grundlage und den Ausgangspunkt für die sichere Feststellung der heute rechtmäßigen Erben der Apostel. Denn über den 1. Punkt sind sich beide Parteien einig : Christus brachte uns die Offenbarung; auf Ihn berufen sich Katholiken und Häretiker. Der 4. Punkt: an wen gaben die Apostel die Lehre Christi weiter, ist endlich das Hauptergebnis, der Angelpunkt des ganzen Streites.

1 Praescr. haer. 20 (Kr. 24, 19) : "... et perinde ecclesias apud unamquamque civitatem condiderunt. A quibus traducem fidei et semina doctrinae ceterae exinde ecclesiae mutuatae sunt et cottidie mutuantur, ut ecclesiae fiant, ac per hoc et ipsae apostolicae deputabuntur, ut suboles apostolicarum ecclesiarum. Omne genus ad originem suam censeatur necesse est. Itaque tot ac tantae ecclesiae una est illa ab apostolis prima, ex qua omnes. Sic omnes primae et apostolicae, dum una omnes. Probant unitatem communicatio pacis et appellatio fraternitatis et contesseratio hospitalitatis, quae iura non alia ratio regit quam eiusdem sacramenti una traditio."

2 Vgl. praescr. haer. 36 (Kr. 45, 6).

3 Praescr. haer. 21 (Kr. 24, 1). 
Die Antwort auf den 2. Punkt (per quos) lautet in gedrängter Form: Christus hat jene, die seine Lehre den Menschen weitergeben sollten, nach Person und Zahl genau bestimmt. Die Apostel sind daher der einzige, ausschließliche Weg, auf dem seine Offenbarung zu den Menschen gelangen konnte.

Die Antwort auf den 4. Punkt (quibus) ist kurz diese : von den Aposteln her gelangte die christliche Lehre 1. zu den Gemeinden, denen jene noch persönlich predigten und schrieben ; 2 . von diesen unmittelbar apostolischen wurde und wird sie noch immer weitergegeben an andere (mittelbar apostolische) Gemeinden.

Mit der Beantwortung der 4 Punkte der Partitio, bes. des zweiten und vierten, ist eigentlich die in Kap. 19 gestellte Frage nach dem heute (um das Jahr 200) rechtmäßigen und glaubwürdigen Besitzer der Offenbarung beantwortet: Christus hat seine Offenbarung den Aposteln anvertraut und hat diese allein mit der Verkündigung derselben beauftragt (Antwort auf 2. Punkt); die Apostel wiederum haben die Offenbarung bei jenen apostolischen Urge meinden hinterlegt (Antwort auf 4. Punkt). Der nächste Schritt ist nun der, aus diesen eindeutig gegebenen Grundlagen und Tatsachen die gewünschten Folgerungen zu ziehen :

1. Christus hat seine Offenbarung nur den Aposteln anvertraut und nur sie zur Verkündigung berufen. Daraus ergibt sich die zwanglose Folgerung : also können und dürfen nur die Apostel die Lehre Christi verkündigen. Andere, wie ein Marcion, Valentin und wie alle die Gewährsmänner der Häretiker heißen, verdienen einmal keinen Glauben (denn sie erhielten keine Offenbarung) und haben kein Recht, die Lehre Christi zu verkündigen (denn sie wurden nicht dazu berufen).

2. Die Apostel wiederum haben die ihnen anvertraute Offenbarung bei den bekannten apostolischen Urgemeinden hinterlegt. Daraus ergibt sich als Folgerung : also sind diese apostolischen Gemeinden, als einzige rechtmäßige Nachfolger der Apostel, heute allein in der Lage und sie allein haben dazu das Recht, zu entscheiden, was als Offenbarung Christi zu gelten hat und was nicht. Die Nachfolger und Gemeinden eines Marcion, Valentin usw. fallen somit außer Betracht.

Tatsächlich zieht Tertullian diese Folgerungen. Aber nicht in dieser Form, sondern in der ihm geläufigen Ausdrucksweise des rö mischen Rechtes, d.i. der Prozeßeinrede oder Präskription. 
Wir haben uns dabei zu vergegenwärtigen, da $B$ sich Tertullian die Katholiken und Häretiker als zwei Proze B parteien denkt. Die Häretiker klagen gegen die Katholiken auf Anerkennung, d. h. Echtheit ihrer ketzerischen Lehre. Sie berufen sich auf ihre Gewährsmänner, Marcion, Valentin und wie die ältern und jüngern Häupter der vielgestaltigen Sekten heißen. Tertullian als Verteidiger der katholischen Lehre und in der Rolle des Beklagten weist den "Prozeß " ab, indem er zwei Präskriptionen erhebt (der Beklagte erhebt die Präskription) :

1. Präskription : "Hinc igitur dirigimus praescriptionem (hinc $=$ auf Grund der vorangegangenen Ausführungen) :

a) si dominus Christus Jesus apostolos misit ad praedicandum (Antwort auf 2. Punkt der Partitio).

b) alios non esse recipiendos praedicatores quam Christus instituit (= Folgerung aus der Antwort des 2. Punktes).

c) quia nec alius patrem novit nisi filius et cui filius revelavit, nec aliis videtur revelasse filius quam apostolis, quos misit ad praedicandum, utique quod illis revelavit ${ }^{1} ;(=$ Beweis für die 1. Präskription. Es ist unschwer zu erkennen, daß dieser Beweis in der Hauptsache eine gedrängte Wiederholung der in Kap. 20 zum 2. Punkt [per quos] gegebenen Ausführungen darstellt).

2. Präskription : "Quid autem praedicaverint, id est quid illis Christus revelaverit, - et hic praescribam - non aliter probari debere nisi per easdem ecclesias, quas ipsi apostoli condiderunt, ipsi eis praedicando tam viva, quod aiunt, voce quam per epistolas postea. ") 2

Der Kerngedanke der beiden Prozeßeinreden ist die Apostolizität. In der ersten Einrede wird das Fundament, auf das die Apostolizität sich stützen muß, gleichsam abgegrenzt; in der zweiten wird entschieden, welche Lehre, bzw. welche Gemeinden auf diesem Fundamente der Apostel auferbaut sind, nämlich nur jene, die von den Aposteln persönlich gegründet wurden.

Über die innere und äußere Struktur dieser beiden Präskriptionen, besonders der zweiten, die nicht so klar aufgebaut ist wie die erste, sowie über die Bedeutung und den Wert derselben wird später einläßlich die Rede sein. Hier soll nur auf das eingegangen werden, was der Analyse, besonders der Aufhellung der innern Zusammenhänge, dient. Besonders dies soll hier festgehalten

\footnotetext{
1 Ebd.

2 Praescr. haer. 21 (Kr. 25, 6).
} 
sein, daß die zwei Präskriptionen in die Gesamtstruktur des Traktates planvoll eingebaut sind. - Sie führen den 2. und 4. Punkt der Partitio weiter, indem sie die zwanglos sich ergebenden Konsequenzen aus denselben ableiten. In zweiter Linie sei bemerkt, daß die zwei Präskriptionen, wenngleich jede eine vollständige und für sich abgeschlossene darstellt, doch untrennbar zusammengehören. Die erste bildet die feste Unterlage für die zweite. Die zweite baut weiter auf der ersten. Die zweite ist derart auf Gedeih und Verderb mit der ersten verbunden, daß sie mit der ersten steht und fällt. Die erste Präskription hält sich, trotz ihrer Bedeutung, mehr im Hintergrund. Die zweite dagegen steht, nachdem sie einmal formuliert ist, im Mittelpunkt des Traktates; sie fällt den endgültigen Entscheid im "Prozeß » zwischen den Katholiken und den Häretikern, indem sie bestimmt, daß allein die von den Aposteln persönlich gegründeten Gemeinden erklären dürften, was als Predigt der Apostel, bzw. Offenbarung Christi, zu gelten habe und was nicht. Die von den Häretikern vorgebrachten Einwände ${ }^{1}$ zielen letztlich darauf hin, diese zweite Präskription zu entkräften, wie denn auch umgekehrt die Widerlegung jener Einwände hauptsächlich den Zweck verfolgt, die Richtigkeit der zweiten Präskription zu erhärten. Die zweite Präskription ist der Kern von praescr. haer.

Mit der Formulierung der beiden Präskriptionen ist der Streit zwischen den Katholiken und Häretikern insofern entschieden, als nun feststeht, wer als erste Instanz die echte, unverfälschte Offenbarung besitzt: nur die von den Aposteln persönlich gegründeten Gemeinden: Rom, Korinth, Philippi usw. Tertullian spricht in der zweiten Präskription ausdrücklich nur von den unmittelbar apostolischen Gemeinden : "... non aliter probari debere nisi per easdem ecclesias, quas ipsi a postoli condiderunt, ipsi eis praedicando ... ". Er räumt den unmittelbar apostolischen Gemeinden eine Vorzugsstellung ein vor den mittelbar apostolischen. Wie scharf unser Autor zwischen diesen beiden Gruppen unterscheidet, hat Kap. 20 bewiesen und die zweite Präskription bestätigt es von neuem. Wenn nun aber lang feststeht, daß die unmittelbar apostolischen Gemeinden die wahre, unverfälschte Lehre Christi besitzen, so ist damit noch nicht erwiesen, $\mathrm{da} B$ dies auch bei den mittelbar apostolischen Gemeinden, in unserm Fall bei der afrikanischen, der Fall ist. Tertullian schreibt aber vornehmlich für die mittelbar apostolische afrikanische Kirche, die von den

1 Vgl. praescr. haer. 22-34. 
Häretikern arg bedrängt wird ${ }^{1}$. Es liegt ihm hauptsächlich daran, für die afrikanische Christengemeinde, als deren Sprecher und Anwalt er im " Prozeß " gegen die Häretiker auftritt, den Beweis zu erbringen, $\mathrm{da} B$ sie, gleich den unmittelbar apostolischen Gemeinden, die echte Lehre Christi besitzt. Er stellt zu diesem Zweck ein Kriterium auf, das Kriterium der Einheit. Dieses Kriterium ermöglicht es, mit absoluter Sicherheit festzustellen, ob eine nur mittelbar apostolische Gemeinde ebenfalls die wahre Lehre besitzt oder nicht.

\section{Das auf Grund der 2. Präskription formulierte Kriterium und seine Anwendung}

(Kap. 21) ${ }^{2}$

Tertullian führt diesen Nachweis mit der für ihn kennzeichnenden juristischen Kürze und Präzision. Wir können in seinem Beweisgang drei Stufen unterscheiden :

a) Formulierung des Kriteriums.

b) Anwendung des Kriteriums auf die afrikanische Kirche.

c) Resultat.

a) Formulierung des Kriteriums. An die zweite Präskription anschließend, formuliert Tertullian vorerst das Kriterium, anhand dessen der Nachweis möglich ist, ob eine Gemeinde die echte christliche Lehre besitzt oder nicht. Selbstverständlich handelt es sich hier um jene Gemeinden, die nicht unmittelbar apostolisch sind, überhaupt um alle Gemeinden bzw. Bekenntnisse außerhalb der von den Aposteln persönlich gegründeten Gemeinden, die Anspruch erheben, die wahre Lehre zu besitzen.

"Si haec ita sunt (zurückweisend auf die 2. Präskription) constat perinde :

1. omnem doctrinam, quae cum illis ecclesiis apostolicis matricibus et originalibus fidei conspiret, veritati deputandam, id sine dubio tenentem, quod ecclesiae ab apostolis, apostoli a Christo, Christus a deo accepit;

2. omnem vero doctrinam de mendacio praeiudicandam, quae sapiat contra veritatem ecclesiarum et apostolorum et Christi et dei. ${ }^{3}{ }^{3}$

1 Vgl. praescr. haer. 1-3.

2 Praescr. haer. 21 (Kr. 25, 11).

3 Ebd. 
Wir können dieses Kriterium als criterium unitatis bezeichnen. Die Einheit einer Gemeinde oder christlichen Genossenschaft mit den apostolischen Mutter- und Ursprungskirchen ist das untrügliche Zeugnis, der Garant für die Wahrheit ihrer Lehre. Treffend sind die beiden Ausdrücke "conspiret" als Bezeichnung der Einheit und "sapiat" als Bezeichnung des Gegensatzes.

b) Anwendung des Kriteriums. Nachdem das Kriterium formuliert ist, wird es auf die afrikanische, von Tertullian vertretene Gemeinde angewendet. "Superest ergo, ut demonstremus, an haec nostra doctrina, cuius regulam supra edidimus, de apostolorum traditione censeatur, et ex hoc ipso ceterae de mendacio veniant. communicamus cum ecclesiis apostolicis, quod nulla doctrina diversa. " ${ }^{1}$ Die afrikanische Christengemeinde steht allein in Gemeinschaft mit den unmittelbar apostolischen Gemeinden, "quod nulla doctrina diversa ". Die Gemeinschaft der afrikanischen Christengemeinde mit den apostolischen Urkirchen, zunächst Rom ${ }^{2}$, ist eine so offenkundige Tatsache, $\mathrm{da} B$ sie keines weitern Beweises bedarf. Sie ist so bekannt, wie das Ausgeschlossensein der Häretiker aus derselben Gemeinschaft bekannt ist. Daher der bündige und kurze Hinweis: "Communicamus cum ecclesiis apostolicis, quod nulla doctrina diversa. "

c) Resultat. "Hoc est testimonium veritatis. " ${ }^{3}$ Die Tatsache der Gemeinschaft mit den apostolischen Urkirchen ist für die afrikanische Christengemeinde das Zeugnis für die Wahrheit ihrer Lehre, "testimonium veritatis ". Damit ist das Ergebnis des in Form eines vollendeten Syllogismus ${ }^{4}$ geführten Beweises vermerkt.

Das " communicare cum ecclesiis apostolicis » ist das Zeugnis für die Echtheit der Lehre. Es ist hier an die dreifache Gemeinschaft der "communicatio pacis et appellatio fraternitatis et contesseratio hospitalitatis" von der in praescr. haer. $20^{5}$ die Rede ist, zu denken. Das Wesentliche dieser dreifachen Gemeinschaft liegt in der "communicatio pacis". Der Lebensnerv aber für das Bestehen der " communicatio pacis" ist die Identität der Lehre. Solange eine Geme inde in die "communicatio pacis" aufgenommen und nicht von ihr

1 Praescr. haer. 22 (Kr. 25, 1).

2 Vgl. praescr. haer. 36 (Kr. 45, 1).

3 Praescr. haer. 22 (Kr. 25, 5).

4 Die drei Glieder des Beweises (a, b, c) sind zu einem Syllogismus verkettet.

5 Praescr. haer. 20 (Kr. 2'í, 27). 
ausgeschlossen ist, hat sie implicite die Bestätigung für die Identität und daher Wahrheit ihrer Lehre. Das wußten die Häretiker gut genug. Ter tullian selbst berichtet - er war bereits erklärter Montanist - wie der Bischof von Rom im Begriffe stand, die Prophezeiungen des Montanus, der Priscilla und Maximilla anzuerkennen, um auf Grund dieser Approbation den Gemeinden von Asien und Phrygien den Frieden wieder zu gewähren und wie derselbe Bischof durch die, wie Tertullian behauptet, falschen Angaben des Praxeas über diese Propheten und ihre Gemeinden, die bereits gewährten " litterae pacis " widerrufen habe ${ }^{\mathbf{1}}$.

Die Tatsache, daß die afrikanische Christengemeinde mit den apostolischen Urkirchen die "communicatio pacis " unterhält, ist also hinlängliches Zeugnis für die Echtheit ihrer Lehre.

Hier ist der "Prozeß" im Grunde entschieden und abgeschlossen. Die Wahrheit ist auf Seiten Tertullians, bzw. der von ihm verteidigten Lehre. Wenn aber feststeht, daß die katholische Lehre allein die wahre ist, jede von ihr verschiedene Lehre folglich eine Lüge darstellt, dann er übrigt sich sofort jeder weitere Disput $z$ wischen den beiden Parteien. Die Präskription - es handelt sich hier um die zweite - hat klar und bestimmt für die apostolischen Urgemeinden, und mittels des angeschlossenen Kriteriums für die von Tertullian verteidigte afrikanische Christengemeinde entschieden. Jedes weitere Sicheinlassen in die einzelnen Lehrstreitigkeiten der Marcioniten, Valentinianer usw. ist fortan überflüssig. Der Beweis mittels der Präskription - wir denken zunächst wieder an die zweite - war zu klar und bestimmt. Eine weitere Verhandlung mit den Häretikern käme, in der Gerichtssprache ausgedrückt, einer Retraktation " gleich. Daher die dem Schluß-Satz des Syllogismus anschließenden Worte: "...tam expedita probatio (= mittels der Präskription) est, ut si statim proferatur, nihil iam sit retractandum ..." "3.

1 Vgl. Prax. 1 (Kr. 228, 5).

2 Retractare ist von Tertullian an dieser Stelle wohl sicher der Prozeßterminologie entnommen. Darauf deutet schon das unmittelbar darauf folgende : "locum interim demus diversae parti" (Kr. 26, 8). Die Häretiker werden also wie in einem Proze $B$ als Gegenpartei, diversa pars, bezeichnet. Retractare bedeutet in der Prozeßterminologie: von neuem verhandeln, besonders: neu verhandeln zu dem Zwecke, um eine frühere gerichtliche Verhandlung oder ein richterliches Urteil anzufechten. Daher besagt retractare auch : anfechten, bestreiten, seltener : widerrufen. Vgl. Heumann-Seckel, Handlexikon zu den Quellen des römischen Rechts, 9. Aufl. (Jena 1907) 517.

3 Praescr. haer. 22 (Kr. 25, 6). 
Es wird sich noch Gelegenheit bieten, einläßlich auf diesen aufschlußreichen Satz zurückzukommen ${ }^{1}$.

\section{Verteidigung der Präskriptionen gegen die drei Objektionen der Häretiker} (Kap. 22-34) ${ }^{2}$

Die Präskriptionen, zunächst die zweite, ermöglichen diesen bündigen und schlagenden $A b s c h l u ß$ des Streites. Das Kriterium ist nur eine aus der zweiten Präskription sich ergebende Folgerung und Anwendung auf die mittelbar apostolische afrikanische Kirche. Der ganze Beweis hängt also ab von der Richtigkeit der Präskriptionen, zunächst der zweiten. Wenn nun aber die beiden Präskriptionen, hauptsächlich die zweite, falsch wären ? Dann wären selbstredend auch das Kriterium und seine Anwendung wertlos und der Beweis für die Wahrheit der katholischen Lehre gar nicht erbracht.

Die beiden Präskriptionen, besonders die zweite, müssen noch die Probe bestehen gegenüber den Objektionen der Häretiker. Erst dann dürfen sie als absolut richtig und zuverlässig gelten, wenn sie den Angriffen der Gegner standgehalten haben. Dann werden sie auch die Gegner anerkennen müssen. Sie sollen also das Wort haben : " . . locum interim demus diversae parti ... ${ }^{3}$. Die Objektionen der Häretiker sind folgende drei :

1. Die Apostel haben nicht alles gewußt (cc. 22-24).

2. Die Apostel haben zwar alles gewußt, aber nicht allen alles mitgeteilt ; einiges haben sie öffentlich und der Gesamtheit, anderes im geheimen und nur wenigen anvertraut (cc. 25-26).

3. Die Apostel haben zwar die ganze Fülle der Verkündigung gekannt und haben allen den ganzen Glaubensinhalt mitgeteilt, doch haben die apostolischen Gemeinden die Lehre Christi anders aufgefaßt, als die Apostel sie verkündeten. Erst die Häretiker haben erstmals die Wahrheit gebracht (cc. 27-34).

Es wurde in der Behandlung der Präskriptionen betont, daß die Apostolizität den Kerngedanken derselben ausmacht. Wenn also die

1 Siehe unten S. $142 \mathrm{f}$.

2 Formulierung der ersten und zweiten Objektion : praescr. haer. 22 (Kr. 26, 10) und 25 (Kr. 30, 1), der dritten Objektion: praescr. haer. 27 (Kr. 33, 1).

3 Praescr. haer. 22 (Kr. 26, 8). 
Objektionen die Präskriptionen, vornehmlich die zweite, zu entkräften suchen, so greifen sie im Grunde die Apostolizität an. Die erste und zweite Objektion richten sich zunächst gegen die erste Präskription und suchen die Apostolizität gleich in ihrem Fundament zu erschüttern. Wenn die Apostel nicht alles wußten, weil sie unfähig waren, die Lehre Christi in ihrer ganzen Weite und Tiefe aufzunehmen, oder wenn sie nicht allen ohne Unterschied die ganze Offenbarung mitteilten, aus Mangel an Aufrichtigkeit, was hat dann der Ausweis jener Gemeinden, persönliche Gründungen der Apostel zu sein, noch für einen Wert? Wie viel glaubwürdiger erscheinen dann z. B. die Gemeinden eines Apelles, die vorgeben, Gott habe sich ihrem Gründer direkt, nicht auf dem Umweg über die ungebildeten und unaufrichtigen Apostel, geoffenbart. - Die dritte Objektion endlich greift direkt und ausschließlich die zweite Präskription an. Schon in ihrem ersten Stadium, als sie die christliche Lehre empfingen, haben die sog. apostolischen Urgemeinden diese falsch verstanden, die eine auf diese, die andere auf jene Weise. Also können diese Gemeinden nicht zuständig sein in der Frage, was Lehre Christi und der Apostel ist und was nicht.

Aus dem Vorhergehenden dürfte klar sein, daß zwischen der Partitio, den beiden Präskriptionen und den drei Objektionen ein Zusa mmenhang besteht. Die beiden Präskriptionen bilden die Fortsetzung des zweiten und vierten Punktes der Partitio. Die drei Objektionen wiederum entsprechen den beiden Präskriptionen:

$$
\text { Partitio Präskriptionen Objektionen }
$$

1. Punkt: a quo

2. Punkt: per quos $\longrightarrow$ 1. Präskription $\longleftarrow 1$. und 2. Objektion

3. Punkt : quando

4. Punkt : quibus $\longrightarrow 2$. Präskription $\longleftarrow 3$. Objektion

Die Häretiker sollen ganz unvoreingenommen angehört werden, so als ob der mittels Anwendung des Kriteriums gewonnene Beweis der Echtheit der afrikanischen Kirchenlehre noch gar nicht geschehen wäre : "... probatio ... ac si prolata non sit a nobis ..." ${ }^{1}$. Der bereits gewonnene Beweis ("communicamus cum ecclesiis apostolicis») wird also vorläufig suspendiert.

Es folgt vorerst die Analyse der ersten und zweiten Objektion.

Die 1. Objektion der Häretiker: die Apostel haben nicht alles

1 Praescr. haer. 22 (Kr. 25, 6). 
gewußt, weil Christus sie zu wenig unterwiesen hat: " Solent dicere, non omnia apostolos scisse ..., Christum reprehensioni inicientes, qui ... minus instructos ... apostolos miserit. ${ }^{1}$

Tertullian widerlegt diese Behauptung mit schlagenden Argumenten. "Welcher Mensch, der bei gesundem Verstand ist, kann denn glauben, irgend etwas sei denen unbekannt geblieben, die uns der Herr zu Lehrern gegeben hat, die er als unzertrennliche Gefährten in seinem Gefolge, in seinem Unterricht, in seiner Lebensgemeinschaft hatte, denen er alles Dunkle noch besonders zu erklären pflegte, indem er sagte, ihnen sei es vergönnt, Geheimnisse kennen zu lernen, die zu verstehen dem Volke nicht gegeben sei. Blieb dem Petrus etwas verborgen, welcher der Fels für den Bau der Kirche genannt wurde, der die Schlüssel des Himmelreiches erhielt und die Gewalt, im Himmel und auf Erden zu binden und zu lösen ? " 2 Tertullian erinnert weiter an den Lieblingsjünger Johannes, an die Verklärung, wo die Apostel sogar die Stimme des Vaters vernehmen durften, an die Verheißung des Heiligen Geistes, der die Apostel in alle Wahrheit einführen werde, und an die tatsächlich erfolgte Herabkunft des Heiligen Geistes ${ }^{3}$.

Die Behauptung der Häretiker, die Apostel hätten nicht alles gewußt, stützt sich mit Vorliebe auf die Person des Apostels Paulus. Petrus und seine Gefährten wurden von Paulus getadelt. Aus diesem Vorfall leiten die Häretiker ein Wenigerwissen des Petrus und seiner Gefährten im Vergleich zu Paulus ab. Tertullian verspottet vorerst die Häretiker, indem er ihnen vorwirft, daß sie doch bekanntlich die Apostelgeschichte verwerfen, und fragt sie, woher sie nun Paulus gleichwohl kennen. Dann erinnert er daran, daß Paulus wie ein gleichgestellter Bruder in die Gemeinschaft der Apostel aufgenommen wurde auf Grund des gleichen Glaubens und der gleichen Predigt; wie sie eine Teilung der Arbeit, nicht aber des Evangeliums, vorgenommen hätten. Der Tadel des Paulus gegenüber Petrus betreffe nicht die Lehre, sondern nur das Verhalten: "utique conversationis fuit vitium, non praedicationis" 4 .

1 Praescr. haer. 22 (Kr. 26, 10).

2 Praescr. haer. 22 (Kr. 26, 15) : "Quis enim integrae mentis credere potest aliquid eos ignorasse, quos magistros dominus dedit (gentibus), individuos habitos in comitatu in discipulatu in convictu, quibus obscura quaequae seorsum disserebat, illis dicens datum esse cognoscere arcana, quae populo intellegere non liceret ? Latuit aliquid Petrum aedificandae ecclesiae petram dictum, claves regni caelorum consecutum et solvendi et alligandi in caelis et in terris potestatem ?"

3 Vgl. praescr. haer. 22 (Kr. 26, 22).

4 Praescr. haer. 23 (Kr. 29, 31). 
Wir erfahren noch eine andere Begründung der Häretiker für ihre Behauptung, Paulus habe mehr gewußt als die übrigen Apostel : die Gesichte und Offenbarungen, deren Paulus gewürdigt wurde (2. Kor. 12). "Aber wenn auch Paulus, " entgegnet der Apologet, "bis in den dritten Himmel entrückt und ins Paradies versetzt, dort gewisse Dinge hörte, so kann es nicht etwas gewesen sein, das ihn für eine andere Lehre besser unterrichtet hätte; denn die Beschaffenheit jener Offenbarungen war derart, da $\beta$ sie keinem Menschen verraten wurden. "1 Tertullian schließt seine Widerlegung mit einem Dilemma: wenn nun irgendeine Häresie sich trotzdem auf diese Offenbarungen des Apostels Paulus berufe, dann habe entweder Paulus sich des Verrates eines Geheimnisses schuldig gemacht oder man müsse beweisen, daß nach Paulus noch ein anderer ins Paradies entrückt wurde, dem aber im Gegensatz zu Paulus erlaubt wurde, laut zu verkünden, wovon Paulus nicht einmal mucksen durfte ${ }^{2}$.

Die Widerlegung der ersten Objektion verfolgt, zusammengefaBt, folgendes Ziel : es soll der Beweis geleistet werden, daß alle Apostel, nicht nur Paulus, im vollen, ungeschmälerten Besitz der einen und gleichen Lehre Christi waren.

Die 2. Objektion der Häretiker: die Apostel haben zwar alles gewußt, aber nicht allen alles mitgeteilt; einiges von der Lehre Christi haben sie öffentlich und der Gesamtheit, anderes im geheimen und nur wenigen anvertraut ${ }^{3}$. Auf diese privilegierten wenigen berufen sich natürlich die Häretiker. Zur Begründung dieser Objektion führen die Häretiker die Worte des Apostels Paulus an Timotheus an : "Timotheus, hüte das Hinterlegte " 4, oder "bewahre das hinterlegte kostbare Gut " 5 , usw., als ob solche und ähnliche Ausdrücke auf eine Geheimlehre hindeuten würden.

Tertullian widerlegt auch diesen Einwand sachlich und ruhig. Christus hat seine Lehre öffentlich vorgetragen, ohne eine Hindeutung auf eine versteckte Geheimlehre. Er selbst hat den Aposteln befohlen,

1 Praescr. haer. 24 (Kr. 30, 13) : "Sed et si in tertium usque caelum ereptus Paulus et in paradisum delatus audiit quaedam illic, non possunt videri ea fuisse, quae illum in aliam doctrinam instructiorem praestarent, cum ista fuerit condicio eorum, ut nulli hominum proderentur."

2 Vgl. praescr. haer. 24 (Kr. 30, 17).

3 Vgl. praescr. haer. 25 (Kr. 30,1).

4 Praescr. haer. $25(\mathrm{Kr} .30,5):$ "... quia et hoc verbo usus est Paulus ad Timotheum : O Timothee, depositum custodi." Vgl. 1. Tim. 6, 20.

5 Praescr. haer. 25 (Kr. 25, 7) : "Bonum depositum serva." Vgl. 2. Tim. 1, 14. 
"was sie im dunkeln und geheimen gehört, am Tage und von den Dächern zu predigen ${ }^{1}{ }^{1}$ usw. So haben es die Apostel auch gehalten. Sie haben weder in den Synagogen der Juden noch auf den öffentlichen Plätzen vor den Heiden geschwiegen. Der Autor erinnert ausdrücklich an ein diesbezügliches Selbstzeugnis des Apostels im 2. Brief an Timotheus $(2,2)$ : "die Lehre, die du von mir im Beisein vieler $Z$ eugen vernommen hast ..." ". "Wie viel unbefangener ", so folgert Tertullian, "pflegten sie ganz gewiß in der Kirche zu predigen, da sie nicht einmal in den Synagogen und auf den öffentlichen Plätzen schwiegen. Ja, noch mehr, sie hätten weder die Juden bekehren noch die Heiden bewegen können, wenn sie ihnen das, was von ihnen geglaubt werden sollte, nicht der Reihe nach auseinandergelegt hätten. Noch weniger hätten sie den bereits gläubigen Gemeinden etwas unterschlagen, um es einigen wenigen andern besonders anzuvertrauen. $)^{3}$ Und wenn die Apostel einiges sozusagen privat und unter sich verhandelten, so sei darunter sicher nicht eine andere Lehre als die öffentlich vorgetragene zu verstehen, als ob sie in der Kirche und in der Herberge einen verschiedenen Gott verkündet hätten, oder eine verschiedene Wesenheit Christi, oder eine verschiedene Auferstehung, womit Tertullian gerade auf die wesentlichsten Unterscheidungen hinweist, die Katholiken und Häretiker trennen. Die Widerlegung schließt mit dem Hinweis auf die unermüdliche Sorge der Apostel um die Einheit der Lehre. ${ }^{4}$

Zusammenfassend kann gesagt werden : es geht Tertullian in der Widerlegung der zweiten Objektion darum, den Beweis zu leisten, daß die Apostel neben der gewöhnlichen christlichen Lehre nicht noch eine Geheimlehre besaßen, die einem bevorzugten, ausgesonderten Kreis vorbehalten war, auf den sich die Häretiker berufen. Die Apostel haben, selbstverständlich mit der ihnen von Christus befohlenen Vorsicht, die ganze, ungeschmälerte Lehre Christi in aller Offentlichkeit verkündet, vor Juden und Heiden, wie viel mehr erst vor den bereits gläubig gewordenen Gemeinden.

1 Praescr. haer. 26 (Kr. 32, 6) : ، . . ipse (scil. dominus) praeceperat, si suid in tencbris et in abscondito audissent, in luce et in tectis praedicarent."

2 Praescr. haer. 25 (Kr. 31, 17) : "... quam (scil. doctrinam) audierat ab ipso, et puto palam : Coram multis, inquit, testibus."

3 Praescr. haer. 26 (Kr. 32, 15) : "... quo magis utique in ecclesia libere praedicabant qui in synagogis et in locis publicis non tacebant. Immo neque Judaeos convertere neque ethnicos inducere potuissent, nisi quod credi ab-eis volebant ordine exponerent. Multo magis iam credentibus ecclesiis nihil sub traxissent, quod aliis paucis seorsum demandarent."

4 Vgl. praescr. haer. 26 (Kr. 33, 29). 
Soweit die Analyse der Widerlegung der 1. und 2. Objektion. Die beiden Widerlegungen weisen einen einfachen, zwanglosen Gedankengang auf. Nicht so durchsichtig auf den ersten Blick erscheint die Widerlegung der 3. Objektion. Und doch erweist sich eine gründliche Analyse des betreffenden Abschnittes (Kap. 27-34) als ebenso notwendig wie lohnend, notwendig, insofern die herkömmliche Auffassung, wonach zwei Präskriptionen z. Teil in diesem Abschnitt zu suchen wären (praescriptio veritatis Kap. 20-30 und praescriptio principalitatis Kap. 31-35), einer genauen Prüfung unterzogen werden soll; lohnend, weil die Kap. 27-34 einen der gehaltvollsten Abschnitte von praescr. haer. darstellen.

\section{Einläßliche Analyse der 3. Objektion bzw. ihrer Widerlegung} (Kap. 27-34)

"Wir wollen sehen, ob nicht die Apostel (die christliche Lehre) zwar aufrichtig und vollständig verkündeten, die Gemeinden sie aber durch ihre Schuld anders aufgefaßt haben, als die Apostel sie verkündeten. " ${ }^{1}$ Als Zeugen rufen die Häretiker Paulus an, der die Galater ${ }^{2}$ und Korinther ${ }^{3}$ tadelte.

Nach einigen Widerlegungen, die mehr allgemeiner Natur sind, beginnt Tertullian die eigentliche Widerlegung. Diese stellt ein apologetisches Meisterstück dar. Jede Zeile darin verrät Tertullians Eigenart. Wir bemühen uns, hier die planmäßige innere Struktur aufzuzeigen.

Bevor wir jedoch zur eigentlichen Analyse der sehr gründlichen Widerlegung übergehen, soll noch eine Frage abgeklärt werden : welches ist für Tertullian die tiefste und letzte Erklärung dafür, daß die apostolischen Gemeinden die Apostel richtig verstanden und nicht einen Irrtum überliefert haben ? Er gibt sie, nicht ohne Grund, gleich am Anfang : der Heilige Geist. Er ist von Christus dazu gesandt und vom Vater dazu erfleht, damit er als "doctor veritatis" sich um die Gemeinde annehme und sie in die Wahrheit einführe. Der Heilige Geist ist "dei villicus, Christi vicarius" 4 . Er spricht also letztlich als Lehrer aus den Aposteln (quod ipse per apostolos praedicabat) und leitet ander-

1 Praescr. haer. 27 (Kr. 33, 3) : " ... videamus, ne forte apostoli quidem simpliciter et plene, ecclesiae autem suo vitio aliter acceperint quam apostoli proferebant. "

2 Vgl. praescr. haer. 27 (Kr. 33, 7) : Gal. 3, 1; 5, 7.

3 Vgl. praescr. haer. 27 (Kr. 3/4, 11) ; 1. Kor. 3, $1 \mathrm{ff}$.

4 Praescr. haer. 28 (Kr. 34, 5). 
seits auch die Gemeinde der Gläubigen an zur richtigen Aufnahme seiner Lehre ${ }^{1}$. Tertullian spricht hier eine Wahrheit aus, von der die Urkirche allgemein und voll lebendigen Glaubens durchdrungen war. Wohl sagt er diese Wahrheit nur so nebenbei. Es ist aber gerade eine Eigenart Tertullians, so eine Grundwahrheit in Form einer beiläufigen Floskel hinzuwerfen, damit sie um so eindringlicher wirke ${ }^{2}$. Aber auch sonst wird hier das Wirken und die Aufgabe des Heiligen Geistes mit so inhaltsvollen und dazu gehäuften Worten geschildert, da $B$ über die wahre Absicht des Verfassers kein Zweifel bleibt: " ad hoc missus, ad hoc postulatus ..., ut esset doctor veritatis»; darin besteht gerade das officium des Heiligen Geistes, "ut in veritatem deduceret " 3 .

So selbstverständlich und ausreichend nun diese Erklärung für die Katholiken bleibt, so wenig ist sie es für die Häretiker. Darum sieht Tertullian hier, wo er zu Häretikern und gegen Häretiker spricht, von ihr ab, er streift sie nur : "Also gut, nehmen wir an, alle Gemeinden haben geirrt, auch der Apostel habe sich getäuscht, indem er (jenen Gemeinden) ein gutes Zeugnis ausstellte, nehmen wir an, der Heilige Geist habe sich um keine (Gemeinde) bekümmert, um sie in die Wahrheit einzuführen, obwohl er doch von Christus dazu gesandt und vom Vater dazu erfleht war, Lehrer der Wahrheit zu sein. Nehmen wir an, er habe sein Amt als Gutsverwalter Gottes, als Stellvertreter Christi vernachlässigt, indem er zuließ, daß die apostolischen Gemeinden vorläufig (interim $=$ bis die Häretiker auftraten) das anders verstanden, anders glaubten, was er selbst durch die Apostel predigte. " 4 Tertullian sieht also ab vom Heiligen Geist, er stellt sich mit den Häretikern auf deren rein natürlichen Standpunkt und nimmt auf dieser gemeinsamen Basis den Kampf auf gegen ihre Objektion. Er hält den Häretikern zwei Tatsachen entgegen, die mit ihrer Behauptung, die apostolischen Gemeinden hätten geirrt, in unversöhnlichem Widerspruch stehen :

1 Vgl. praescr. haer. 28 (Kr. 34,6): " ... sinens ecclesias aliter interim intellegere, aliter credere ....

2 Vgl. K. AdaM, Der Kirchenbegriff Tertullians 35.

3 Praescr. haer. 28 (Kr. 34, 3). Dazu ist zu bemerken, daß Tertullian sich nicht bewußt wird, daß der Heilige Geist die Kirche durch die Bischöfe leitet und belehrt. Darüber im 3. Kap. 2. Abschn.

4 Praescr. haer. 28 (Kr. 34, 1) : "Age nunc omnes erraverint; deceptus sit et apostolus dei testimonium reddendo quibusdam; nullam respexerit spiritus sanctus, ut eam in veritatem deduceret, ad hoc missus a Christo, ad hoc postulatus de patre, ut esset doctor veritatis; neglexerit, ut aiunt, officium dei villicus, Christi vicarius, sinens ecclesias aliter interim intellegere, aliter credere quod ipse per apostolos praedicabat." 
A. Die vollendete Einheit des Glaubens, die die apostolischen Gemeinden zusammenschließt (c. 28).

B. Das Prinzip von der Priorität der Wahrheit vor dem Irrtum (cc. 29-34).

\section{A. Die vollendete Einheit des Glaubens}

(Kap. 28) ${ }^{1}$

Die "una fides" ", die die apostolischen Gemeinden wie ein Band umschließt, ist so augenscheinlich und bekannt, $\mathrm{da} B$ es gar keiner weitern Beweise bedarf. Wie bringen die Häretiker diese offenkundige Tatsache mit ihrer Behauptung in Einklang ? Der Anfang der apostolischen Gemeinden war nach ihnen der Irrtum. Nun liegt es aber im Wesen des Irrtums, daß er sich vervielfältigt. Jede der apostolischen Gemeinden hätte natürlich in ihrer Art geirrt und der Irrtum der einzelnen Gemeinden hätte jeder für sich wieder seine buntesten Abwandlungen erfahren: "Variasse debuerat error doctrinam ecclesiarum. " " Wie hätte sich da aus diesen vielgestaltigen Irrtümern eine derart einheitliche Lehre herauskristallisieren sollen ?

"Ecquid verisimile est, ut tot ac tantae (scil. ecclesiae) in unam fidem erraverint ? " 4 Die vollendete Einheit des Glaubens unter den apostolischen Gemeinden kann eben nicht anders erklärt werden, als $\mathrm{da} ß$ die apostolischen Urgemeinden die Predigt der Apostel richtig und deshalb überall als die eine und selbe verstanden und glaubten und sie auch als diese eine und selbe bis auf den heutigen Tag weitergaben. "... quod apud multos unum invenitur, non est erratum, sed traditum "). Mit diesem sentenzenartig geprägten Satz (dreifacher Reim auf - um !) zieht Tertullian gleichsam den Schlußstrich unter diese erste Erwiderung zur 3. Objektion.

\section{B. Die stete Priorität der Wahrheit vor dem Irrtum} (Kap. 29 ff.)

Die Grundlage für dieses Argument bilden die wie eine Sentenz wirkenden Worte: "Sed enim in omnibus veritas imaginem

1 Praescr. haer. 28 (Kr. 34, 7 ).

2 Praescr. haer. 28 (Kr. 34, 8). Vgl. Virg. Vel. 2 (Oe. 516) : "una nobis et illis fides, unus Deus, idem Christus, eadem spes, eadem lavacri sacramenta, semel dixerim, una ecclesia sumus."

${ }^{3}$ Praescr. haer. 28 (Kr. 34, 9).

4 Praescr. haer. 28 (Kr. 34, 7 ).

5 Praescr. haer. 28 (Kr. 35, 10). 
antecedit, post rem similitudo succedit " ${ }^{1}$ (echt tertullianisch ist das Wortspiel : antecedit, succedit). In allen Dingen geht die Wahrheit dem Abbild (dem entstellten Abbild, Trugbild, Scheinbild) vor, die Ähnlichkeit kommt nachher. Ähnlich faßt Tertullian dieses Prinzip in Marc. I $1^{2}$ : "In tantum enim haeresis deputabitur quod postea inducitur, in quantum veritas habebitur quod retro et a primordio traditum est."

Die Anwendung dieses Prinzips im Streit der Katholiken und Häretiker zerfällt in zwei Teile : im ersten wird die Berechtigung und Gültigkeit des Prinzips für die geoffenbarte Wahrheit erhärtet (c. 29 und c. 31); im zweiten Teil wird seine Richtigkeit anhand der geschichtlichen Tatsachen nachgewiesen (c. 30).

1 Praescr. haer. 29 (Kr. 35, 11). Der Satz, um den es sich hier handelt, ist ein Beispiel des Satzparallelismus mit Homoioteleuton (antecedit, post rem, succedit), den Tertullian mit großer Fertigkeit handhabt (Vgl. Ed. Norden, Die antike Kunstprosa 613 f.). Die Anwendung der genannten rhetorischen Figur ist, wie NORDEN für alle Perioden der griechischen und lateinischen Literatur nachgewiesen hat, von bestimmter Gesetzmäßigkeit beherrscht ; sie wird nie willkürlich gesetzt, sondern bleibt den gehobenen Stellen vorbehalten. Vgl. E. Norden, a. a. O. $847 \mathrm{ff}$., $861,878 \mathrm{f}$. In unserm diesbezüglichen Satz: "Sed enim in omnibus veritas ..." wird das Prinzip von der Priorität der Wahrheit vor dem Irrtum in scharfer Antithese (veritas-imago und similitudo) und einprägsamem rhythmischen Satzschluß (antecedit-sụccedit) zusammengefaßt. Der Satz steht auch an wohlberechneter Stelle : er bildet Höhepunkt und Abschlu $B$ des argumentum ex absurdis, von dem im folgenden die Rede ist; in eindrucksvoller Steigerung entfaltet sich in Kap. 29 das argumentum ex absurdis; man beachte nur das achtmalige "perperam" und siebenmalige "tot", oder die inhaltliche Steigerung, die mit der Verkündigung des Evangeliums beginnt und mit dem Martyrium schließt. Eine dreigliedrige Frage leitet endlich über zum erwähnten Satz, der den Höhepunkt bildet und das Vorangehende nochmals in formell und gedanklich durchsichtiger Klarheit zusammenfaßt.

2 Marc. 1, 1 (Kr. 292, 4). Vgl. auch praescr. haer. 35 (Kr. 45, 11) : "... hoc erit testimonium veritatis ubique occupantis principatum."

Prax. $2(\mathrm{Kr} .229,14)$ : "Hanc regulam ab initio evangelii decucurrisse, etiam ante priores quosque haereticos, nedum ante Praxean hesternum, probabit tam ipsa posteritas omnium haereticorum quam ipsa novellitas Praxeae hesterni. Quo peraeque adversus universas haereses iam hinc praeiudicatum sit id esse verum, quodcumque primum, id esse adulterum, quodcumque posterius."

Selbst der Montanist Tertullian muß der von ihm geschmähten Kirche die zeitliche Priorität zugestehen: "Wenn ich die Wahrheit sagen will, hast du (Psychiker), der du der Gaumenlust so große Zugeständnisse machst, zwar den Vorzug des Alters und rühmst dich mit Recht deiner Priorität "; ieiun. 17 (RW. $296,18)$. 
1. Teil (c. 29 und c. 31). Hier wird grundsätzlich bewiesen, daß das Prinzip von der Priorität der Wahrheit erst recht Gültigkeit hat für die geoffenbarte Wahrheit. Tertullian gibt drei Argumente:

a) Das argumentum ex absurdis (c. 29).

b) Das Zeugnis des Apostels (c. 29).

c) Die Autorität Christi (c. 31).

a) Das argumentum ex absurdis. Daß das Prinzip von der Priorität der Wahrheit erst recht für die geoffenbarte Wahrheit Geltung hat, wird zuerst negativ bewiesen, indem die Objektion der Häretiker ad absurdum geführt und so in ihrer ganzen Widersinnigkeit bloßgestellt wird. Nehmen wir mit den Häretikern an, die apostolischen Urgemeinden haben wirklich die Apostel falsch verstanden, oder die Apostel ihrerseits haben schon die Lehre Christi falsch aufgefaßt (vgl.: "Es soll nun einer nur gleich den Mut aufbringen, zu behaupten, diejenigen hätten geirrt, die (die Lehre) überlieferten (nämlich die Apostel selber ") ${ }^{1}$.

Darauf antwortet Tertullian mit dem argumentum ex absurdis: "Wie immer nun der (von den Häretikern behauptete) Irrtum entstanden ist (ob durch die Apostel oder erst durch die apostolischen Urgemeinden), so lange herrschte jedenfalls der Irrtum, als es noch keine Häresien gab. Die Wahrheit wartete auf einige Marcioniten und Valentinianer, um (endlich) befreit zu werden. ") ${ }^{2}$ Weiter wird nun die ganze Tragweite dieser Behauptung aufgezeigt: Wenn bezüglich der Lehre Christi der Irrtum früher war als die Wahrheit, "so wurde in der Zwischenzeit (interim = bis irgendeine Häresie die Wahrheit aus ihren Fesseln erlöste) ein falsches Evangelium gepredigt, wurde ein falscher Glaube geübt, wurden so viele tausend und abertausend Menschen falsch getauft, wurden so und so viele Glaubenshandlungen falsch vorgenommen usw. ... Wenn aber das alles nicht falsch und umsonst war, was soll man dann dazu sagen, daß die Angelegenheiten Gottes in Gang kamen, bevor bekannt war, welchem Gott sie angehörten, da $\beta$ es Christen gab, bevor Christus entdeckt war, da $\beta$ es Häresien gab vor der wahren Lehre. ${ }^{3}$

1 Praescr. haer. 28 (Kr. 35, 12) : "Audeat ergo aliquis dicere illos errasse, qui tradiderunt."

2 Praescr. haer. 29 (Kr. 35, 1) : "At, quoquo modo, sit erratum : tamdiu utique regnavit error, quamdiu haereses non erant. Aliquos Marcionitas et Valentinianos liberanda veritas exspectabat."

3 Praescr. haer. 29 (Kr. 35, 4) : "Interea perperam evangelizabatur, perperam credebatur; tot milia milium perperam tincta, tot opera fidei perperam 
b) Das Zeugnis des Apostels Paulus. "An eine Gemeinde, die diese Lehre besaß (die Gemeinde der Galater) steht geschrieben, oder besser, die Lehre selbst schreibt an die Gemeinde : auch wenn ein Engel vom Himmel ein anderes Evangelium verkünden sollte als wir, so sei er verflucht " (Gal. 1. 8) ${ }^{1}$. Deshalb die verächtliche Bemerkung Tertullians : es sei doch ziemlich naiv, die Häresie für das Frühere in der Lehre zu halten, gerade weil die Lehre selber vorausverkündet habe, man solle sich vor den kommenden Häresien in acht nehmen ${ }^{2}$.

Nach dem Zeugnis des Apostels schiebt Tertullian den geschichtlichen Nachweis von der zeitlichen Priorität der katholischen Lehre vor den übrigen Bekenntnissen ein, den wir der Klarheit wegen im zweiten Teil darlegen. Vorerst soll hier das dritte Argument Platz finden. Tertullian selber will es auch unmißverständlich an die beiden ersten Argumente angereiht wissen, wenn er in Kap. 31 sagt, er wolle nach dieser Abschweifung (so charakterisiert er den erwähnten Nachweis aus der Geschichte) zurückkehren zur Verteidigung der Priorität der Wahrheit und Posterität der Lüge ${ }^{3}$.

Vorher soll aber noch eine kritische Bemerkung bezüglich U. HÜNTEmanNs Analyse eingeschoben werden 4. Derselbe bezieht die einleitenden Worte des hier $z u$ behandelnden dritten Argumentes : "Sed ab excessu revertar ad principalitatem veritatis et posteritatem mendacitatis disputandam ex illius quoque parabolae patrocinio ... $)^{5}$ zurück bis auf Kap. $22^{6}$, wo es heißt: "locum interim demus diversae parti ....", genauer, bis auf das gerade vorher formulierte Kriterium (Kap. 21). Auf das "interim " des Kapitels 22 würde nach U. HÜNTEMANN wieder Bezug genommen mit den Worten "... ab excessu revertar ... " und zugleich würde das in Kap. 21 formulierte Kriterium in Kap. 31 mit andern Worten wiederholt. Daß dieser Zusammenhang zwischen dem Kriterium des 21. Kapitels und dem Argument des

ministrata etc. ... Aut si non perperam nec in vacuum, quale est, ut ante res dei currerent quam cuius dei notum esset? ante Christiani quam Christus inventus? ante haereses quam vera doctrina ?"

1 Praescr. haer. 29 (Kr. 35, 15) : "Ad eius (enim) doctrinae ecclesiam scriptum est, immo ipsa doctrina ad ecclesiam suam scribit: Et si angelus de caelo aliter evangelizaverit, citra quam nos, anathema sit." - Vgl. Gal. 1, 8.

2 Vgl. praescr. haer. 29 (Kr. 35, 13).

3 Vgl. praescr. haer. 31 (Kr. 39).

4 Vgl. Tertulliani de praescriptione haereticorum libri analysis 8 .

5 Siehe Anm. 3.

- Praescr. haer. 22 (Kr. 26, 8). 
31. Kapitels nicht besteht, ergibt sich aus folgendem: vorerst wird im Kriterium des 21. Kapitels nur gesagt, daß jede mit den apostolischen Urgemeinden übereinstimmende Lehre als Wahrheit, wie umgekehrt jede ihnen widerstrebende als Lüge gelten müsse. Kein Wort steht aber davon, daß die Lehre der apostolischen Urgemeinden gegenüber der Häresie zeitlich früher sei. Diesem Gedanken begegnen wir erstmals in der Widerlegung zur 3. Objektion in Kap. 29. Ferner reicht die nach dem Kriterium mit "locum demus interim diversae parti ..." beginnende Auseinandersetzung mit den Häretikern nicht nur bis zum Anfang des 31. Kapitels, wie U. HünTEMANN annimmt, sondern ganz eindeutig bis Kap. 34 einschließlich. Erst zu Beginn des Kapitels 35 erklärt Tertullian sämtliche Häretiker für besiegt und fordert sie zur Replik auf.

Mit den Worten "Sed ab excessu revertar ... " verweist also Tertullian bestimmt auf die beiden in Kap. 29 enthaltenen Argumente ( $a$ und $b$ ), die die Priorität der Wahrheit zum Gegenstand haben. Nach dem zweiten Argument war er - was gerade naheliegend war - abgeschweift zu einem ausführlichen Gang durch die Geschichte (c. 30). Nachdem er diesen beendigt hat, nimmt er den unterbrochenen Gedankengang wieder auf, indem er das dritte Argument, betreffend die Priorität der Wahrheit, entwickelt (c. 31).

U. Hüntemann ließ sich von einer typischen Eigenheit Tertullians in die Irre führen. Tertullian hat die Gewohnheit, ganz unvermittelt auf einen neuen Gedanken überzuspringen. "Er deutet meist nur an, verläßt einen Gedanken plötzlich, um ohne anknüpfende Partikeln zu einem andern überzuspringen, alles ein Ausfluß übersprudelnder Leidenschaftlichkeit und hastiger Genialität des Denkens. "So Ed. Norden ${ }^{1}$. Ein typisches Beispiel davon ist unser Abschnitt. Der Verfasser fällt beim Zeugnis des Apostels Paulus im Galaterbrief in seiner wie gewohnt heftigen Art aus dem Gedankengang: "Ubi tunc Marcion ... ubi Valentinus?" " Daraus entsteht dann ein ganzer geschichtlicher Exkurs, nach dessen Abschluß Tertullian selber bemerkt, er wolle nun nach dieser Abschweifung die Priorität der Wahrheit noch mittels der Parabel vom Unkraut erhärten.

Der Irrtum U. Hüntemanns enthält indes eine wertvolle Beobachtung. Zwischen dem Kriterium des 21. Kapitels und dem in Kap. 31 entfalteten Argument besteht insofern ein Zusammenhang, als das

1 Antike Kunstprosa $606 . \quad 2$ Praescr. haer. 30 (Kr. 36). 
erwähnte dritte Argument das Kriterium bestätigt und erweitert. Im dritten Argument wird nämlich mit aller Präzision erklärt, daß die wahre Lehre vor allen andern die Priorität behauptet. Nachdem dies für die Lehre der apostolischen Kirchen auch noch anhand der geschichtlichen Tatsachen nachgewiesen ist, erweist sich das Kriterium (noch besser die zweite Präskription) erst recht als wahr.

Nach diesen kritischen Bemerkungen möge nun das letzte der drei Argumente folgen :

c. Die Autorität Christi in der Parabel vom Unkraut unter dem Weizen (Matth. 13. 24-30) ${ }^{1}$. Tertullian spielt an die Auslegung bei Luk. 8.11 an, wenn er bemerkt, daß "das Wort Gottes auch sonst (oder : anderswo) mit dem Samen verglichen werde ". Die betreffende Parabel "stellt den guten Getreidesamen, als vom Herrn ausgesät, an den Anfang, und läßt das Unkraut des ertraglosen Wildhafers vom Teufel als Feind später darübergestreut werden". Die Parabel "versinnbildet so recht eigentlich die Verschiedenheit der Lehren". Der Sinn der Parabel liegt somit auf der Hand : "Aus der (zeitlichen) Reihenfolge selbst wird deutlich klar, daß nur das vom Herrn stammt und echt ist, was zuerst überliefert wurde, daß das jedoch ein Fremdkörper und eine Fälschung ist, was später hereingebracht wurde. " ${ }^{2}$

Treffend bezeichnet der Jurist Tertullian diesen letzten Satz als (Gerichts-) Sentenz ${ }^{3}$. Er klingt aber auch, besonders in seiner lat. Formulierung wie das knapp und scharf gefaßte Endurteil des Richters über zwei prozessierende Parteien. Diese sententia wirkt hier besonders eindrucksvoll, da sie sich unwillkürlich aus der Parabel des Herrn ergibt und so gewissermaßen dem Herrn selber in den Mund gelegt wird. Deshalb wird sie auch, als von der ewigen Wahrheit selbst gefällt, für immer Geltung haben, sie bleibt sozusagen inappellabel : "Diese Sentenz wird Bestand haben gegen alle wann immer auftretenden Häresien, die nie einen Standpunkt besitzen, von dem aus sie mit gutem Gewissen die Wahrheit für sich in Anspruch nehmen können. "

1 Praescr. haer. 31 (Kr. 39).

2 Praescr. haer. 31 (Kr. 39, 7) : "Ita ex ipso ordine manifestatur id esse dominicum et verum, quod sit prius traditum, id autem extraneum et falsum, quod sit posterius inmissum."

3 Vgl. praescr. haer. 31 (Kr. 39, 10).

4 Praescr. haer. 31 (Kr. 39, 10) : "Ea sententia manebit adversus posteriores quasque haereses, quibus nulla constantia ex conscientia competit ad defendamden sibi veritatem. " (Wir möchten die im Text wiedergegebene Übersetzung der umstrittenen Stelle vorlegen.) 
Mit diesen drei Argumenten ist der Beweis erbracht, daß das Prinzip von der Priorität der Wahrheit seine volle Geltung hat für den Bereich der geoffenbarten Wahrheit. Die drei Argumente gehören zusammen; sie bilden eine ansteigende Linie : zu unterst steht das argumentum ex absurdis als Argument Tertullians, es folgt das Zeugnis des Apostels, den Höhepunkt bildet die Autorität des Herrn selber.

$\mathrm{Da} B$ die Lehre der apostolischen Urkirchen allein Anspruch erheben kann auf diese zeitliche Priorität und deshalb allein als die wahre Lehre gelten kann, steht aus den drei Argumenten zur Genüge fest. Trotzdem weist Tertullian noch anhand eines geschichtlichen Überblickes ausführlich und überzeugend nach, wie alle Bekenntnisse, die die Lehre der apostolischen Gemeinden bekämpfen, ohne Ausnahme viel spätern Datums sind als die bekämpfte. Daß dieser geschichtliche Nachweis nach den drei Argumenten, streng genommen, nicht mehr nötig wäre, deutet der Verfasser selber an, wenn er ihn als eine Abschweifung kennzeichnet $(\ldots$ ab excessu revertar ...). Dieser geschichtliche Nachweis soll der Vollständigkeit wegen kurz analysiert werden im :

2. Teil (c. 30). Tertullian beweist hier die zeitliche Priorität der katholischen Lehre dadurch, daß er nachweist, wie alle von ihr abweichenden Bekenntnisse viel später entstanden sind, sei es in nicht allzuweit zurückliegender Zeit, sei es sogar in der Gegenwart. Der Reihe nach werden "die bedeutenderen und größern Anhang aufweisenden Häretiker " ${ }^{1}$, die die afrikanische Kirche bedrängen, behandelt. Ihre Posterität oder Neuheit im Vergleich zur katholischen Lehre steht fest :

a) Aus den Zeitumständen ${ }^{2}$, in denen die Gründer der verschiedenen Häresien auftraten. Was z. B. Marcion und Valentin betrifft, ist es eine bekannte Tatsache, daß sie vor nicht allzu langer Zeit gelebt haben, ungefähr zur Zeit des Antoninus und unter Papst Eleutherius. Es folgt noch eine Reihe konkreter Einzelzüge aus ihrem Leben. Um nichts älter als Marcion ist Apelles.

b) Aus den Werken der Häretiker. "Quamquam et de operibus suis, ut dixit dominus, revincuntur. ${ }^{3}$ "Denn wenn Marcion das Neue Testament vom Alten getrennt hat, so ist er später als das, was er abgetrennt hat, weil er (es) nicht trennen könnte, wenn es nicht

1 Vgl. praescr. haer. 30 (Kr. 38, 37).

2 Praescr. haer. 30.

3 Praescr. haer. 30 (Kr. 37, 29). 
(vorher) vereinigt war. Das vor der Trennung Geeinte und nachträglich Getrennte zeigt, daß der, welcher die Trennung vornahm, später ist. Ebenso beweist Valentin, $\mathrm{da} B$ das, was er anders auslegt und ohne $Z$ weifel (Tertullians Sarkasmus!) verbessert, gerade dadurch, da $B$ er verbessert, weil es vorher fehlerhaft gewesen sei, früher war (als er). " ${ }^{1}$

Nach diesen bedeutenderen Vertretern der Häresie nennt Tertullian noch zwei modernste der Gegenwart, einen Nigidius und den Maler Hermogenes, gegen den Tertullian noch eine eigene Schrift verfaßte. Eigentlich sind diese zwei Häretiker nach der Widerlegung eines Marcion, Valentin und Apelles a fortiori auch widerlegt. Denn je später eine Häresie seit den Aposteln auftritt, desto augenscheinlicher trägt sie an sich das Brandmal des Irrtums und der Lüge. Somit wäre die dritte Objektion hinreichend widerlegt und dadurch die beiden Präskriptionen, besonders die zweite, statt entkräftet (vgl. "ad infirmandam hanc praescriptionem ") erst recht bekräftigt worden. An diese Tatsache will Tertullian offenbar auf dieser ersten Station seiner Widerlegung erinnern, wenn er nun die beiden Präskriptionen dem Nigidius und Hermogenes in ihren Grundgedanken entgegenhält. Die 1. Präskription hat festgelegt und bewiesen, daß die wahre Kirche Christi nur auf dem Fundament der Apostel aufgebaut sein kann, die 2. Präskription hat den Beweis erbracht, daß nur die sog. unmittelbar apostolischen Gemeinden auf diesem Fundamente ruhen und deshalb die wahre und für die Lehre Christi und der Apostel allein zuständige Kirche sind. Das Auferbautsein auf dem Fundamente der Apostel ist der Autoritätsausweis der apostolischen Gemeinden. Diese Tatsachen spielt nun Tertullian gegen Nigidius und Hermogenes aus. Die beiden Präskriptionen gewinnen in der Anwendung auf diese beiden Häresiarchen der Gegenwart eine gesteigerte Aktualität und Überzeugungskraft. Zuerst spielt Tertullian auf den Grundgedanken der 2. Präskription an: "Ostendant mihi, ex qua auctoritate prodierint. " ${ }^{2}$ Aus der 2. Präskription steht fest, und die Widerlegung der 3. Objektion hat es bestätigt, daß die wahre Kirche nur auf dem Fundamente, der Autorität der Apostel aufgebaut sein kann. Nun mögen Nigidius und Hermogenes sich bezüglich der

1 Praescr. haer. 30 (Kr. 37, 30) : "Si enim Marcion novum testamentum a vetere separavit, posterior est eo quod separavit, quia separare non posset nisi quod unitum fuit. Unitum ergo antequam separaretur postea factum separatum posteriorem ostendit separatorem. Item Valentinus, aliter exponens et sine dubio emendans hoc nomine, quicquid emendat, ut mendosum retro, anterius fuisse demonstrat. "

2 Praescr. haer. 30 (Kr. 38, 40). 
Autorität ausweisen, von der sie ausgegangen sind. Sie können sich auf jeden Fall nicht auf die Apostel berufen. Denn, wenn schon Marcion, Valentin usw. dazu nicht in der Lage sind, wie viel weniger dann ein Nigidius und Hermogenes. Sie sind sich eben ihre eigene Autorität. Sie selber sind das Fundament ihrer Kirche. Und hier weist Tertullian auf den Grundgedanken der 1. Präskription, wo festgelegt wurde, da $B$ die Apostel allein Fundament der Kirche Christi sein können, weil sie allein (wie ihr Name schon sagt) von Christus dazu bestellt wurden. So sollen also die beiden Häresiarchen beweisen, daß auch sie, wenngleich erst heute, von Christus gesandt wurden, somit wirklich Apostel sind ; "Probent se novos apostolos esse " 1 . Selbstverständlich können sie diesen Beweis nicht leisten, sowenig wie den andern, da $B$ Christus wiederum Mensch geworden sei, um auch sie zu Aposteln zu berufen, sowenig sie sich über die den Aposteln verliehene Wunderkraft auszuweisen vermögen ${ }^{2}$.

Hier sind die Ausführungen Tertullians über das Prinzip der Priorität der Wahrheit beendigt. Die Häresien sind dadurch widerlegt, daß sie nachweisbar lange, zum Teil sogar sehr lange nach den Aposteln entstanden sind. Die apostolischen Urgemeinden allein gehen unbestritten auf die Apostel zurück. Aber wenn nun eine Häresie dem gegen sie geführten Argument ausweicht und erklärt, sie habe auch schon unter den Aposteln existiert, oder wenn vielleicht irgendwo eine solche Häresie tatsächlich existierte, deren Anfänge nachweisbar in die Tage der Apostel zurückreichten? "Ceterum si quae (scil. haereses) audent interserere se aetati apostolicae, ut ideo videantur ab apostolis traditae, quia sub apostolis fuerunt ... $n^{3}$ Aus diesen Worten ist nicht klar, ob es tatsächlich Häresien gab, die solches behaupteten, oder ob nur der Möglichkeit einer diesbezüglichen Ausflucht im voraus der Weg abgeschnitten werden soll. Wahrscheinlicher ist das letzte, denn in den folgenden Kapiteln lernen wir, außer den in Kap. 30 aufgezählten, keine neuen Häresien mehr kennen. In den Kapiteln 32-34 rechnet Tertullian mit dieser Möglichkeit ab, er führt hier auch gegen die bereits widerlegten Häresien den Hauptschlag. Die Kapitel 32-34 sollen im folgenden noch analysiert werden:

1 Praescr. haer. 30 (Kr. 38, 43).

2 Praescr. haer. 30 (Kr. 38, 1 's).

3 Praescr. haer. 32 (Kr. 39). 
Widerlegung des eventuellen Einwandes der Häretiker: wir reichen auch in die apostolische Zeit zurück (cc. 32-34) ${ }^{1}$

Die Widerlegung zerfällt in zwei Teile : im ersten fordert Tertullian von den Häretikern den Nachweis der Apostolizität des Ursprungs und der Sukzession (c. 32) ; im zweiten Teil zieht er einen ausführlichen Vergleich zwischen den von den Aposteln persönlich verurteilten Irrlehren und den modernen, zu seiner Zeit bestehenden Häresien (cc. 33-34).

1. Teil. Kap. 32. Die Häretiker werden aufgefordert, sich auszuweisen über die Apostolizität des Ursprungs : "Edant ergo origines ecclesiarum suarum " und der Sukzession : "evolvant ordinem episcoporum suorum, ita per successionem ab initio decurrentem, ut primus ille episcopus aliquem ex apostolis vel apostolicis viris, qui tamen cum apostolis perseveraverit, habuerit auctorem et antecessorem " 2 . "So weisen nämlich die apostolischen Gemeinden ihren Ursprung nach " ... z. B. Smyrna, Rom usw. ${ }^{3}$. Und in der Überzeugung, daß die Apostolizität des Ursprungs und besonders der Sukzession den entscheidenden Ausweis bilden für die Echtheit der Lehre, ruft Tertullian den Häretikern nochmals mit beißendem Spotte zu, so etwas sollten sie erfinden; was ihnen denn nach ihren Gotteslästerungen noch unerlaubt sei ? " "Sed etsi confinxerint, nihil promovebunt ". "Denn ihre Lehre wird, verglichen mit der apostolischen, durch ihre Verschiedenheit und Gegensätzlichkeit laut Zeugnis ablegen, da $B$ sie weder einen Apostel noch apostolischen Mann zum Urheber hat. " 5

2. Teil. Kap. 33-34. Hier stellt der Verfasser eine Liste jener Häresien auf, die schon unter den Aposteln existierten. "Nam et sic facilius traducentur " ${ }^{\mathbf{6}}$, nämlich die heutigen Häresien. Die Parallelen, die zwischen den Häresien der apostolischen Zeit und jenen der Zeit Tertullians bestehen, werden schlagend nachgewiesen. Zusammen-

1 Ebd.

2 Praescr. haer. 32 (Kr. 39, 4).

3 Vgl. praescr. haer. 32 (Kr. 40, 8) : "Hoc enim modo ecclesiae apostolicae census suos deferunt etc."

4 Vgl. praescr. haer. 32 (Kr. 40,13).

5 Praescr. haer. 32 (Kr. 40, 15) : "Sed etsi confinxerint, nihil promovebunt. Ipsa enim doctrina eorum cum apostolica comparata ex diversitate et contrarietate sua pronuntiabit neque apostoli alicuius auctoris esse neque apostolici..."

6 Praescr. haer. 33 (Kr. 41,3). 
fassend stellt der Verfasser fest, da $B$ die modernen Häresien sogar bedeutend weiter gehen, als die frühern zur Zeit der Apostel es wagten.

Es ist für Tertullian typisch, wenn er die Ergebnisse dieses zweiten Teils nochmals zusammenfaßt in ein schlagfertiges Dile m ma, mit dem er den Häretikern seiner Zeit siegesbewußt den entscheidenden, tödlichen Schlag versetzen will :

"Entweder sind die heutigen Häresien dieselben wie zur Zeit der Apostel; damals noch roh, hätten sie sich nur etwas verfeinert. " "Habent suam exinde damnationem " ${ }^{1}$, sie sind " nominatim " verurteilt.

"Oder es existierten damals andere; nachher sind wieder andere entstanden und haben etwas von den Ansichten jener übernommen. " ${ }^{2}$ Diese sind doppelt verurteilt :

1. durch das Urteil der Apostel. "... habendo cum eis (mit den von den Aposteln verurteilten Lehren) consortium praedicationis, habeant necesse est etiam consortium damnationis ${ }^{3}$;

2. durch ihr späteres Entstehen. Dieser Grund ist noch triftiger als der erste : "... praecedente illo fine supradicto posteritatis, quo etsi nihil de damnaticiis participarent, de aetate sola praeiudicarentur tanto magis adulterae, quanto nec ab apostolis nominatae. $)^{4}$

Dieses Dilemma zieht den Schluß-Strich unter den hier behandelten zweiten Teil. Damit ist die ausführliche Widerlegung der 3. Objektion, die mit Kap. 27 einsetzt, abgeschlossen.

\section{Die Aufforderung an die Häretiker zur Replik}

(Kap. 35) ${ }^{5}$

In Kap. 21 hatte Tertullian seine Beweisführung unterbrochen und den bereits geleisteten Beweis (communicamus cum ecclesiis apostolicis) vorläufig suspendiert. Inzwischen sollten die Häretiker ihre Objektionen vorbringen und versuchen, ob sie die zweite Präskription viel-

1 Praescr. haer. 34 (Kr. 4', 22) : "sive ergo eaedem nunc sunt aliquanto expolitiores quae sub apostolis rudes, habent suam exinde damnationem."

2 Praescr. haer. 34 (Kr. 44, 24) : "sive aliae quidem illae fuerunt, aliae autem postea obortae quiddam ex illis opinionis usurpaverunt."

3 Praescr. haer. 34 (Kr. 44, 26).

4 Praescr. haer. 34 (Kr. 44, 28).

5 Praescr. haer. 35 (Kr. 44). 
leicht entkräften könnten. Es ist ihnen nicht gelungen. Sie sind im Gegenteil "alle besiegt " ${ }^{1}$ worden. Die Präskriptionen, hauptsächlich die zweite, haben allen Angriffen standgehalten, sie sind unerschüttert. In weiterer Anlehnung an die Gesetze und Eigentümlichkeiten der Gerichtspraxis lädt nun Tertullian seine Gegner ein, auch ihrerseits mit einigen Präskriptionen nach Art der vorgebrachten zu antworten; "audeant respondere et ipsae aliquas eiusmodi praescriptiones adversus nostram disciplinam ${ }^{2}{ }^{2}$, d. h. die Häretiker werden aufgefordert zur Replik. Sie sollen beweisen, daß die Lehre der apostolischen Gemeinden, die er im Prozeß verteidigt, auch eine Häresie sei, indem sie dieselbe "eadem forma" widerlegen, in der sie selber widerlegt werden: durch Präskriptionen; zugleich sollen sie zeigen, "ubinam quaerenda sit veritas, quam apud illas non esse iam constat " 3 .

$\mathrm{Da} B$ die Häretiker diese Replik nicht führen können, ist im voraus klar. Sie verzichten darauf, d. h. sie geben sich für besiegt und anerkennen damit die Richtigkeit der beiden Präskriptionen, vorab der zweiten. Die Aufforderung zur Replik wirkt daher mehr wie eine rhetorische Figur. Die Widerlegung der drei Objektionen, vor allem der dritten, wurde aber auch so schlagend geführt, daß die Häretiker nach Tertullian mundtot gemacht sind. Dieselben Argumente, die gegen die Häretiker sprechen, zeugen für die Wahrheit der von Tertullian verfochtenen apostolischen Lehre. Die zwei wesentlichen Argumente aus der Widerlegung zur 3. Objektion werden daher noch ausdrücklich auf die katholische Lehre angewendet:

1. Das Argument von der Priorität der Wahrheit: "Posterior nostra res non est, immo omnibus prior est : hoc erit testimonium veritatis ubique occupantis principatum. " 4

2. Das Argument, wodurch der eventuelle Einwand der Häretiker, wir reichen auch in die apostolische Zeit zurück, widerlegt wird : "Apostolis non damnatur, immo defenditur : hoc erit indicium proprietatis. Quam enim non damnant, qui extraneam quamque damnarunt, suam ostendunt ideoque et defendunt. " $\overline{5}$

1 Ebd.

2 Praescr. haer. 35 (Kr. 44, 4).

3 Praescr. haer. 35 (Kr. 45, 9).

4 Praescr. haer. 35 (Kr. 45,10$)$.

5 Praescr. haer. 35 (Kr. 45, 12). 


\section{Letztes Argument zu Gunsten der zweiten Präskription und Vergleich des römischen und afrikanischen Symbolums}

(Kap. 36) ${ }^{1}$

Die Widerlegung der drei Objektionen hat die Richtigkeit der Präskriptionen, vor allem der zweiten, erhärtet. Diesem langen Abschnitt fügt nun der Autor noch ein Argument an, das, nicht absolut nötig ${ }^{2}$, dennoch sehr eindrucksvoll für die zweite Präskription zeugt. Tertullian fordert auf zu einer Rundreise durch die apostolischen Urkirchen, "apud quas ipsae adhuc cathedrae apostolorum suis locis praesident, apud quas ipsae authenticae litterae eorum recitantur, sonantes vocem et repraesentantes faciem uniuscuiusque " ${ }^{3}$. Dann zählt er sie auf, Corinth, Philippi, Ephesus, Rom. Der Zusammenhang dieses Argumentes mit der zweiten Präskription ist deutlich. Dort wird erklärt, daß nur diejenigen Gemeinden für die Frage, was Lehre der Apostel sei und was nicht, zuständig sind, die die Apostel gegründet haben, indem sie ihnen mündlich und schriftlich predigten. $\mathrm{DaB}$ diese mündliche und schriftliche Predigt wirklich an diese Gemeinden ergangen ist, dafür sind die bis zur Stunde daselbst aufbewahrten Lehrstühle und Autographa der Apostel die lebendigen Zeugen.

Der Hinweis auf diese handgreiflichen Zeugen, bzw. die Aufforderung, die erwähnten Gemeinden zu diesem Zwecke zu besuchen, erinnert an einen vom Gericht vorgenommenen Augenschein; die "authenticae litterae " der Apostel lassen an die Urkunde denken, die ebenfalls ein bekanntes Beweismittel im ProzeB bildet.

Gerade an diese "authenticae litterae " knüpft sich eine interessante Frage : versteht Tertullian darunter die ursprünglichen, von den Aposteln eigenhändig geschriebenen Briefe, die Autographa, oder will er damit nur den bis auf seine Tage unversehrt und unverfälscht überlieferten Inhalt der Apostelbriefe betonen?

Der Wortschatz der tertullianischen Schriften entstammt zum größten Teil der römischen Rechtssprache. Da nun "authenticus" einen ausgesprochenen Begriff der römischen Rechtssprache darstellt, liegt es sozusagen außer Zweifel, daß sich Tertullian auch an dieser Stelle juristisch ausdrückt. "Authenticus " bedeutet in der römischen

1 Praescr. haer. 36 (Kr. 45).

2 Der Autor bemerkt selber, daß der Beweis mehr der "curiositas" diene ; vgl. praescr. haer. 36 (Kr. 45, 1).

3 Praescr. haer. 36 (Kr. 45, 2). 
Rechtssprache: eigenhändig geschrieben, urschriftlich, im Gegensatz zu descriptus oder exemplum. So wird besonders bezüglich des Testamentes unterschieden zwischen den authenticae tabulae testamenti $=$ Urschrift, und den tabulae descriptae oder exemplum testamenti $=$ Abschrift des Originals. Das Testament gilt erst als eröffnet, wenn die Urschrift entsiegelt und geöffnet ist ${ }^{1}$.

Für die Annahme, Tertullian verstehe unter den "authenticae litterae " die eigenhändig geschriebenen Urtexte der Apostel, sprechen aber noch andere Gründe :

Die "ipsae authenticae litterae eorum " werden gemeinsam mit den "ipsae adhuc cathedrae apostolorum" genannt. Tertullian mißt also den beiden Zeugen den gleichen Beweiswert bei. Diese Beobachtung berechtigt $\mathrm{zu}$ folgendem Schluß : sind unter den "cathedrae apostolorum " die ursprünglichen, noch von den Aposteln benutzten cathedrae zu verstehen, dann dürfen auch die "authenticae litterae " als die ursprünglichen, von den Aposteln persönlich handgeschriebenen Originale gedeutet werden. Nun darf aber das erste als sicher angenommen werden. Unter den "cathedrae apostolorum " kann Tertullian nicht einfach allgemein die von den Aposteln gegründeten Bischofssitze verstehen. Vielmehr ist hier ganz offensichtlich die Rede von jenen konkreten cathedrae, von denen aus die Apostel beim Gottesdienst oder in der Unterweisung der betreffenden urchristlichen Gemeinden den Vorsitz führten. Was hätte sonst die Aufforderung des Autors, man solle die betreffenden apostolischen Urkirchen aufsuchen (percurre ecclesias apostolicas, apud quas ...), um sich an Ort und Stelle mit eigenen Augen vom Vorhandensein dieser cathedrae zu überzeugen, für einen Sinn ? Daß die Gemeinden von Korinth, Philippi, Ephesus, Rom, die anschließend genannt werden, bis heute einen Bischof haben, also Bischofssitz sind, weiß man auch in Afrika, ohne daß man die betreffenden Gemeinden aufsucht. Was hätte weiter die Bemerkung noch für einen Sinn, daß die betreffenden cathedrae bis heute "suis locis praesident ", wenn darunter nicht die ursprünglichen, aus der Apostelzeit aufbewahrten cathedrae zu verstehen sind? Die Worte, womit dies alles gesagt wird, unterstreichen noch diesen Sinn : ipsae adhuc cathedrae apostolorum. Das "adhuc » bringt das Außerordentliche an

1 Vgl. Heumann-Seckel, Handlexikon zu den Quellen des römischen Rechts 45. Ulpianus dig. 29, 3, 12: " $\mathrm{Si}$ quis fecerit testamentum et exemplum eius, exemplo quidem aperto nondum apertum est testamentum; quod si authenticum patefectum est totum, apertum." 
dieser Tatsache zum Ausdruck : bis heute, durch all die Wirrnisse von mehr als einem Jahrhundert blieben uns diese Zeugen der Apostel erhalten. Bis heute stehen sie unverrückt "suis locis", an den selben, ursprünglichen Stellen; "praesident", sie führen gleichsam noch immer den Vorsitz.

Glücklicherweise besitzen wir aber außer dem tertullianischen noch ein anderes diesbezügliches Zeugnis. Eusebius berichtet in seiner Kirchengeschichte ${ }^{1}$, in Jerusalem werde die cathedra des Apostels Jakobus, des ersten Bischofs dieser Stadt, aufbewahrt. Es ist nicht abgeklärt, woher Eusebius dies weiß, ob er die betreffende cathedra mit eigenen Augen gesehen, ob er eine allbekannte Tatsache mitteilt, oder ob er am Ende auch hier aus einem Autor schöpft. Was das letzte betrifft, fällt sicher Tertullian außer Betracht, da er in seiner Aufzählung (Kap. 36) Jerusalem nicht nennt. Somit darf man in der Mitteilung des Eusebius eine Bekräftigung des tertullianischen Zeugnisses erblicken.

Die bisherigen Überlegungen dürften zur Annahme berechtigen, daß unter "cathedrae apostolorum" die ursprünglichen, von den Aposteln benutzten und bis heute aufbewahrten cathedrae $\mathrm{zu}$ verstehen sind. Folglich ist auch bezüglich der "authenticae litterae " die entsprechende Schlußfolgerung berechtigt : " authenticae litterae " sind die von den Apsoteln eigenhändig geschriebenen Originalbriefe.

Und warum sollte man, um noch eine Überlegung an die "authenticae litterae" selber anzuknüpfen, die erwähnten apostolischen Urgemeinden aufsuchen, um sich daselbst die Briefe der Apostel zeigen zu lassen, wenn diese " authenticae litterae " nur den unverfälscht überlieferten Inhalt der Apostelbriefe bezeichneten ? Tertullian beansprucht doch sicher dieselbe textinhaltliche Unversehrtheit für die in der afrikanischen Kirche in Gebrauch stehende und auch von ihm so reichlich benuzte Heilige Schrift. Die Apostelbriefe, die in den apostolischen Urgemeinden und in den afrikanischen Kirchen beim Gottesdienst vorgelesen werden, enthalten dieselbe ununterschiedliche, ungeminderte und von keinen Interpolationen entstellte Lehre der Apostel. Aus den ehrwürdigen Originalen der Urkirchen aber glaubt man die persönliche Stimme der Apostel zu vernehmen : "sonantes vocem "; ja das eigenhändige Schriftbild oder wenigstens die Unterschrift lassen den Apostel gleichsam wieder gegenwärtig werden inmitten seiner Gemeinde, die er

1 Vgl. hist. eccl. 7, 19. 
einmal gegründet und mündlich und brieflich unterrichtet hat : " repraesentantes faciem uniuscuiusque ".

Diesen in den apostolischen Urkirchen aufbewahrten Originalen kommt im Kampf gegen die Häretiker gleich der Urschrift des Testamentes ein ganz besonderer Beweiswert zu: sie liefern (wie die cathedrae) den handgreiflichen Beweis, daß die Apostel gerade diesen Gemeinden und nur ihnen allein die geoffenbarte Wahrheit anvertraut haben, da diese Gemeinden allein die betreffenden Originale besitzen. Und um diesen Beweis geht es ja hier gerade ${ }^{1}$.

Die zweite Präskription steht nun unwiderruflich fest, folglich auch das auf ihr aufgebaute Kriterium. Die apostolischen Urgemeinden sind tatsächlich von den Aposteln gegründet und sie besitzen tatsächlich die Wahrheit. Also besitzt sie auch die afrikanische Christengemeinde, weil sie mit den apostolischen Urgemeinden, zunächst Rom, in Gemeinschaft steht. Die Gemeinschaft mit der römischen Gemeinde ist zwar hinreichender Beweis für die Identität und Echtheit der afrikanischen Kirchenlehre. Trotzdem vergleicht nun Tertullian noch die Symbola der römischen und afrikanischen Gemeinde in ihren Hauptpunkten miteinander und stellt deren Identität fest ${ }^{2}$. Es scheint, als wolle der Autor die Wahrheit der von ihm verfochtenen Lehre mit der äußersten Stringenz dartun und die letzten Ausflüchte und Bedenken der Gegner zunichte machen.

\section{Folgerungen bezüglich der Heiligen Schrift}

$$
\text { (Kap. 37) }
$$

"Dort wo sich herausstellen wird, daß die echte Glaubens- und Sittenlehre sich findet, steht in Kap. $19^{3}$, dort ist auch die echte Heilige Schrift und ihre Auslegung ... ". Es steht nun fest, daß die apostolischen Urkirchen und die mit ihnen in Gemeinschaft lebende afrikanische Gemeinde die echte Lehre Christi besitzen. Ipso facto ist also

1 Daß Tertullian in praescr. haer. 37 unter den cathedrae apostolorum und den authenticae litterae wirklich die aus der Apostelzeit stammenden cathedrae und die handschriftlichen Originale der Apostelbriefe versteht, dürfte sicher sein. Eine andere Frage ist, wie es sich damit in Wirklichkeit verhielt. Diese Frage ist umso berechtigter, da Tertullian in historischen Belangen nicht für sehr zuverlässig gilt.

2 Vgl. praescr. haer. 37 (Kr. 47).

3 Praescr. haer. 19 (Kr. 23, 8) : "Ubi enim apparuerit esse veritatem disciplinae et fidei Christianae, illic erit veritas et scripturarum et expositionem et omnium traditionum Christianarum." 
auch über die Frage entschieden, wer rechtmäßiger Besitzer der Heiligen Schrift sei : nur die apostolischen Gemeinden.

Die Konsequenz aus dieser Feststellung ist einfach : die Häretiker haben gar kein Recht, sich auf die Heilige Schrift zu berufen. Die Heilige Schrift ist gleichsam Grundbesitz der wahren Kirche. Wenn die Häretiker sich trotzdem auf die Schrift berufen, so kommt dies einer Verletzung fremder Herrschaftsrechte gleich. Das ist nun ein Gedanke, der dem Juristen Tertullian liegt. Er führt ihn deshalb weiter aus. Wie ein Besitzer sein Grundstück gegen den ungerechten Angreifer verteidigt, so verwahrt sich Tertullian gegen die widerrechtlichen Eingriffe der Häretiker auf den Grundbesitz der Heiligen Schrift.

Über die Bedeutung und den Sinn dieses interessanten Abschnittes wird noch ausführlich die Rede sein ${ }^{1}$.

Nachdem die Analyșe beendigt ist, sollen nochmals kurz die Hauptergebnisse derselben zusammengestellt werden.

Kap. 19 enthält den Schlüssel für das Verständnis des sozusagen gesamten Traktates. Hier wird erklärt, daß vorerst der Träger der Offenbarung als solcher ermittelt werden müsse. Mit der Lösung dieser Frage werde dann auch die andere entschieden, wer rechtmäßiger Inhaber der Heiligen Schrift sei.

Der größte und wichtigste Abschnitt (Kap. 20-36) leistet den Beweis, daß allein die apostolischen Gemeinden im Besitz der wahren christlichen Lehre sich befinden. Den Mittelpunkt dieses ganzen Abschnittes bilden die zwei Präskriptionen. Die Präskriptionen werden vorbereitet in der Beantwortung der Partitio (Kap. 20) ; sie knüpfen direkt an den 2. und 4. Punkt der Partitio an ; auf den Präskriptionen, zunächst der zweiten, ruht das Kriterium; gegen die Präskriptionen richten sich die drei Objektionen ; gegen die Präskriptionen ist die Replik gedacht ; zu Gunsten der zweiten Präskription wird das Argument in Kap. 36 geführt. Diese Feststellung, daß die Präskriptionen, hauptsächlich die zweite, der Angelpunkt sind, um den sich alles dreht, steht auch in Einklang mit dem Titel des Traktates, der als eigentlichen Gegenstand desselben die Präskriptionen nennt, und mit der Bemerkung des Schlußkapitels ${ }^{2}$, wo wiederum derselbe Gedanke sich findet. 
Diese Ergebnisse hinsichtlich der Analyse berichtigen auch U. HüNTEMANN : nicht das Kriterium ist das Zentrale ${ }^{1}$, sondern die Präskriptionen. Das Kriterium ist, wie mehrmals dargelegt wurde, nur eine Weiterentwicklung der 2. Präskription. Indem so die beherrschende Stellung der Präskriptionen erwiesen ist, sind auch die innern $\mathrm{Zu}$ sammenhänge des analysierten Abschnittes aufgehellt.

Entsprechend dem in Kap. 19 vorausgeschickten Prinzip zieht nun Kap. 37 aus dem Ergebnis der Kap. 20-36 die Konsequenzen bezüglich der Heiligen Schrift : sind die apostolischen Gemeinden die berufenen Träger der Offenbarung als solcher, so sind sie auch die allein rechtmäßigen Besitzer der Heiligen Schrift.

Die Analyse allein hat das Problem, wie viele Präskriptionen der Traktat enthält, sozusagen schon entschieden. Er enthält deren nur zwei (wenn wir vorläufig von Kap. 37 absehen wollen), und diese zwei sind in Kap. 21 formuliert. Dadurch ist die Theorie der drei Präskriptionen bereits durch die Analyse widerlegt, wenn wir uns auch noch eingehender mit diesen Fragen befassen werden ${ }^{2}$.

Weder ist die Erklärung an die Häretiker, die Heilige Schrift gehöre nicht ihnen, sondern den apostolischen Gemeinden (Kap. 37) eine Präskription (diese Tatsache ist gerade die Folgerung aus den zwei Präskriptionen in Kap. 21), noch ist die Erklärung, die Wahrheit sei früher als der Irrtum, eine solche. Vorerst ist zu sagen, daß das Prinzip von der Priorität der Wahrheit vor dem Irrtum nicht in den Kap. 31-35 entfaltet wird, wie es die bisherige Auffassung war ${ }^{3}$, sondern in den Kap. 29-31, wie die Analyse klar bewiesen hat. Sodann hat dieses Prinzip keinen andern Sinn, als die dritte Objektion (die die zweite Präskription entkräften sollte) zu widerlegen und dadurch die angefochtene zweite Präskription erst recht zu bestätigen. Genau genommen ist das Prinzip von der Priorität der Wahrheit in den beiden Präskriptionen bereits enthalten. Denn die Wahrheit mußte existieren, bevor sie entstellt werden konnte. Christus übergab den Aposteln die reine, ungetrübte Wahrheit (1. Präskr.), in diesem Zustande erhielten sie die apostolischen Gemeinden (2. Präskr.).

1 Vgl. U. HüntemanN, a. a. O. 11, 31, 43.

2 Siehe unten S. $127 \mathrm{ff}$.

3 Ebd. 


\section{Kapitel}

\section{Die tertullianischen Präskriptionen, im besondern jene von praescr. haer. 21}

Tertullian entfaltet seine schriftstellerische Tätigkeit, soweit wir sie kennen, ziemlich genau innerhalb der Jahre 195-220. Sie fällt somit in die Regierungszeit der Severischen Kaiser. Für die römische Jurisprudenz ist dies die Zeit der ausgehenden Klassik. Als die größten Juristen dieser Zeitspanne gelten Papinian ( $\dagger$ 212) und sein Schüler Ulpian ( $† 228$ ).

Die Tatsache, daß Tertullian seine juristische Bildung, von der seine Schriften so beredtes Zeugnis ablegen, noch in der eigentlichen Glanzzeit der klassischen Jurisprudenz empfing, die andere Tatsache, daß er sehr wahrscheinlich, wenn auch nicht absolut sicher, identisch ist mit dem Pandekten-Juristen, zwingen schon zu einem Vergleich der tertullianischen Präskription mit jener des klassischen Rechtes. Die Analyse hat bereits dazu die Vorarbeit geleistet. Sie hat die beiden Präskriptionen aus dem Text herausgeschält und zugleich ihre beherrschende Stellung im Traktat nachgewiesen. Nun soll untersucht werden, wie weit die Präskriptionen Tertullians mit jenen des Prozesses übereinstimmen und in was sie von ihrem Vorbild abweichen.

Wir haben in den Schriften Tertullians gegen 40 Stellen festgestellt, in denen praescriptio, praescribere die Bedeutung von "Einwand", " einwenden " hat $\mathbf{}$.

1 Unsere Zusammenstellung ist nicht vollständig. Wir bieten die Texte in der Reihenfolge der mutmaßlichen Abfassungszeit der einzelnen Schriften. Vgl. zur Chronologie der Schr. Tertullians A. d'Alès, La théologie de Tertullien XIII f. Stellen, wo praescriptio, praescribere den Sinn hat von Vorschrift bzw. Vorschreiben: apol. 4 (H. 12, 17) : "Et hoc sine ullo retractatu humaniore praescribitis." Marc. 4, 38 (Kr. 549, 27) : "Iusta et digna praescriptio est in omni quaestione ad propositum interrogationis pertinere debere sensum responsionis."

resurr. 19 (Kr. 51, 10) : "... incertis certiora praescribant."

bapt. 3 (RW. 202, 18) : "Huius memores pronuntiationis tamquam praescriptionis ..."

pud. 7 (RW. 230, 25) ; pud. 19 (RW. 265, 10). 
nat. 1, 3 (RW. 62, 21) : "Praescribitur enim vobis non posse crimina obicere quae neque institutum dirigit neque probatio adsignat neque sententia enumerat. "

nat. 1, 20 (RW. 93, 10) : "Quodsi praescribitur vobis errorem amare et odisse veritatem ...."

nat. 2, 1 (RW. 93, 20) : "Denique si tantam perversitatem una praescriptione discuti liceret ..."

nat. 2, 12 (RW. 120, 20) : "Tenemus compendium, in ceteros originis praescriptionem, ne per singulos evagemur."

apol. 7 (H. 18, 7) : "De vestra vobis dissimulatione praescribitur non esse quod nec ipsi audetis eruere. "

apol. 47 (H. 111, 41) : "Expedite autem praescribimus adulteris nostris illam esse regulam veritatis, quae ..."

Marc. 1, 1 (Kr. 292,6) : "Sed alius libellus hunc gradum sustinebit adversus haereticos ... quod hoc sint de praescriptione novitatis. Nunc quatenus admittenda congressio est interdum, ne compendium praescriptionis ubique advocatum diffidentiae deputetur ..."

Marc. 1, 6 (Kr. 297, 29) : " ... iustissime praescribo illi diversitati locum non esse inter eos..."

Marc. 1, 9 (Kr. 301, 10) : "Sed breviter proponam et plenissime exequar, praescribens deum ignorari nec potuisse ..."

Marc. 1, 11 (Kr. 304, 25) : "Semel enim praescriptio stabit non posse illos et deum confiteri creatorem ..."

Marc. 1, 22 (Kr. 318, 19) : "... relaxata praescriptionum defensione ..."

Marc. 2, 24 (Kr. 367, 5) : "Sic et paenitentiam apud illum (scil. Deum) prave interpretaris, quasi proinde mobilitate vel improvidentia, immo iam ex delicti recordatione paeniteat... praescribens scilicet paenitentiam confessionem sapere mali operis alicuius vel erroris. "

Marc. 3, 1 (Kr. 377, 22) : "Ceterum in praescriptionum compendiis vincit (scil. veritas)."

Marc. 3, 16 (Kr. 403, 22) : "Facienda est denique iam hinc inter nos certa ista et iusta praescriptio et utrique parti necessaria, qua determinatum sit nihil omnino commune esse debere alterius dei Christo cum Christo creatoris. "

Marc. 4, 1 (Kr. 423,9): "Quamquam tam facile est praescriptive occurrere ..." 
Marc. 4, 4 (Kr. 428, 25) : "Quis inter nos determinabit, nisi temporis ratio, ei praescribens auctoritatem, quod antiquius repperietur..."

Marc. 4, 5 (Kr. 432,9): " ... temporum ordinem posteritati falsariorum praescribentem ..."

Marc. 4, 6 (Kr. 433,6): "Hinc erit et nostra praescriptio, qua defigimus nihil Christo dei alterius commune esse debere cum creatore. "

Marc. 4, 10 (Kr. 446, 4) : "De filio hominis duplex est nostra praescriptio: neque mentiri posse Christum ... neque filium hominis constitui qui non sit natus ex homine ..."

Marc. 4, 25 (Kr. 508, 16) : " ... interveniente et hic illa praescriptione, qua facilius apud eum debeant credi maiora, apud quem minora praecedunt ..."

Marc. 5, 1 (Kr. 570, 21) : " ... in ipso gradu provocabimus praescriptionis, oportere scilicet et apostolum ... nihil docere ... secundum creatorem ..."

Marc. 5, 6 (Kr. 592, 5) : "In totum enim praescriptum a nobis erit nulla illum sententia uti potuisse eius dei ..."

Marc. 5, 19 (Kr. 642, 26) : "Soleo in praescriptione adversus haereses omnes de testimonio temporum compendium figere ..."

praescr. haer. 21 (Kr. 24, 31) : "Hinc igitur dirigimus praescriptionem..." Voller Text siehe oben S. 52. Ibid. (Kr. 25, 8) : "... et hic praescribam ..." Voller Text siehe oben S. 52.

praescr. $44(\mathrm{Kr} .58,34):$ " . . actum est nobis adversus haereses omnes certis et iustis et necessariis praescriptionibus repellendas a conlatione scripturarum." "

pat. $4(\mathrm{Kr} .6,8)$ : "Per quae in expedito et quasi in praescriptionis compendio de patientia constitutum est."

Hermog. 1 (Kr. 126, 3) : "Solemus haereticis compendii gratia de posteritate praescribere."

Hermog. 7 (Kr. 133, 20) : " ... praescribo non capere ullam diminutionem et humiliationem quod sit aeternum et innatum."

Hermog. 39 (Kr. 169, 5) : « . . et hic a lineis tuis excidisti, quibus circa personam dei usus es, praescribens deum illam non ex semetipso fecisse ..."

Iud. $13(\mathrm{Kr} .314,2)$ : "... praescribimus illis ex eisdem scripturis iam venisse Christum ..."

virg. vel. 1 (Oe. 1, 884) : " . . hoc exigere veritatem, cui nemo praescribere potest ..." 
carne Chr. 2 (Kr. 192, 32) : "Sed plenius eiusmodi praescriptionibus adversus omnes haereses alibi iam usi sumus."

carne Chr. 4 (Kr. 198, 36) : "... tua, opinor, illi censura praescriberet: "Turpe hoc deo, et indignum hoc dei filio ..."

carne Chr. 6 (Kr. 205, 29) : " ... facile est veritati etiam nihil tale adversus eos praescribenti obtinere."

carne Chr. 15 (Kr. 228, 14) : "Haec sola sufficere vice praescriptionis debuerunt ad testimonium carnis humanae..."

resurr. 2 (Kr. 26, 28) : " ... proinde et obducimus praescribendo nullum alium credendum deum praeter creatorem ..."

Scorp. 10 (RW. 168, 29) : " Haec nobis etiam ludicrum in modum certa ratio mandavit nec ullus obicem praescriptionis istius extrudet ..."

Prax. 2 (Kr. 229, 20) : "Sed salva ista praescriptione ubique tamen propter instructionem et munitionem quorundam dandus est etiam retractatibus locus ..."

Prax. 11 (Kr. 243, 22) : " ... a quibus et praescriptio nostra deducitur non posse unum atque eundem videri qui loquitur et de quo loquitur et ad quem loquitur..."

Statt uns mit den zwei Präskriptionen von praescr. haer. 21 zu begnügen, können wir mittels dieses ergiebigen Materials den vorzunehmenden Vergleich auf viel breiterer Grundlage führen und so zu einem umso überzeugenderen Resultat gelangen.

Zur Orientierung unterscheiden wir an der Präskription des Prozesses :

1. ein unveränderliches, sich stets gleich bleibendes Element, welches das Wesen der Präskription ausmacht; es besteht darin, da $\beta$ die prozessuale Präskription immer Einwand ist, der, wenn bewiesen, den Prozeß abweist;

2. ein veränderliches Element; wir können es den Inhalt der Präskription nennen, der je nach der Art derselben ein anderer ist, Berufung auf eine verflossene Frist oder sonst eine prozeßhindernde Vorschrift.

Entsprechend dieser Unterscheidung weist der erste Abschnitt nach, wie die Präskriptionen Tertullians mit denen des Prozesses in ihrem unveränderlichen, stets gleichbleibenden, also wesentlichen Element übereinstimmen. 
Der zweite Abschnitt stellt die Verschiedenheit der Präskriptionen Tertullians von jenen des Prozesses hinsichtlich des Inhaltes fest.

$\mathrm{Da}$ uns vor allem die beiden Präskriptionen von praescr. haer. 21 interessieren, wird sich ein dritter Abschnitt noch näher mit der Gestalt derselben befassen.

An vierter Stelle wird die Frage untersucht, ob in praescr. haer. die longi temporis praescriptio vorkommt.

Der fünfte und letzte Abschnitt endlich hat die Aufgabe, die Zweizahl der Präskriptionen in praescr. haer. tiefer zu begründen und zu verteidigen.

1. Die Übereinstimmung der Präskriptionen Tertullians mit jenen des Prozesses hinsichtlich der wesentlichen Eigenschaften derselben

Praescriptio bedeutet im Zeitalter der Severe in der Mehrzahl der überlieferten Stellen die Berufung des Beklagten auf eine prozeßhindernde Vorschrift ${ }^{1}$. Meist handelt es sich um die Berufung auf eine Verjährungs- oder Ausschlußfrist, die der Kläger unbenutzt verstreichen ließ, seltener um andere prozeßhindernde Tatsachen. Die praescriptio wird im Kognitionsproze $\beta$ erhoben und ist an keine feste Formulierung gebunden. - Kann der Beklagte eine praescriptio geltend machen, z. B. daß die gesetzliche Klagefrist verflossen ist, so hat er nur für die Richtigkeit dieser praescriptio das Beweismaterial zu erbringen. Dann wird der Kläger abgewiesen, auf seine Klage wird gar nicht eingegangen.

Als im rechtlichen Teil von der praescriptio die Rede war ${ }^{2}$, wurde gesagt, da $B$ auch einige exceptiones so bezeichnet werden, da $B$ dies aber nur Ausnahmen sind. In der Regel bezeichnet praescriptio nicht die exceptio, also den Einwand des Formularprozesses, sondern den Einwand, der im KognitionsprozeB erhoben wird.

$\mathrm{DaB}$ Tertullian für seine Präskriptionen die praescriptio des Kognitionsprozesses vor Augen hat, ist ganz eindeutig. Denn wie die praescriptio des Kognitionsprozesses an keine bestimmte Form gebunden ist, so weisen auch die verschiedenen Präskriptionen der tertullianischen Schriften keine feste Form auf, jede hat eine andere Gestalt. Würde sich unser Autor an die exceptio, den Einwand des Formularprozesses halten, dann müßten seine Präskriptionen eine festbleibende Form auf-

1 Siehe oben S. $21 \mathrm{ff} . \quad 2$ Siehe oben S. 19. 
weisen. Denn die in die Formel des Formularprozesses eingefügte exceptio wurde immer nach demselben unveränderten Schema des negativen Konditionalsatzes formuliert. Das ist aber bei Tertullian nie der Fall ${ }^{1}$.

Im folgenden soll gezeigt werden, wie die Präskriptionen Tertullians mit der Präskription des Kognitionsprozesses in Bezug auf die wesentlichen Eigenschaften auch tatsächlich übereinstimmen. Die Präskription ist ein Lieblingsbegriff Tertullians. Wie wir gesehen haben, begegnen wir der Präskription in seinen Schriften sehr oft. Umso leichter gestaltet sich der Vergleich. Selbstverständlich stehen dabei die zwei Präskriptionen des analysierten Abschnittes im Vordergrund unseres Interesses.

Zwei wesentliche Eigenschaften sind der prozessualen Präskription eigen :

A. sie ist ein Einwand;

B. sie verkürzt und vereinfacht den Prozeß.

A. Die Präskription ist ein Einwand, ein Entgegenhalten; sie weist den Kläger, bzw. den von ihm angestrengten Prozeß zurück. Ulpian, der berühmte Jurist und Zeitgenosse Tertullians, sagt : " . . qui tempora praefinita in ordine eiusmodi appellationum peragendo non servaverint, merito praescriptione repelluntur" ${ }^{2}$. Mehrmals verwendet Ulpian in Verbindung mit praescriptio das Verb obicere, z. B. "Praescriptiones, quae obici solent..." ${ }^{3}$ oder "...praescriptio obicitur..." 4. PARTSCH führt zahlreiche Stellen an, in denen praescriptio, praescribere an sich die Bedeutung von Einwand, einwenden, entgegenhalten hat 5 .

Tertullian versteht seine Präskriptionen unzweideutig als ein Einwenden, Entgegenhalten, Zurückschlagen, Abweisen, Verteidigen. Eine Gegenüberstellung $\mathrm{zu}$ entsprechenden Stellen aus den Schriften der zeitgenössischen Juristen wird dies am anschaulichsten illustrieren :

Ulpianus dig. 50, 5, 1, 1: qui tem- praescr. haer. 44 (Kr. 58, 33) : pora praefinita ... non servaverint, actum est nobis adversus haereses merito praescriptione repellun- omnes certis ... praescriptionitur.

bus repellendas.

1 Man vergleiche die S. 83 ff. angeführten Stellen.

2 Ulp. dig. 50, 5, 1, $1 . \quad 3$ Ulp. dig. 48, 5, 16, 7.

4 Ulp. dig. 48, 5, 16, 6; 48, 5, 2, 1; 48, 16, 7 pr.

5 Vgl. J. Partsch, Die longi temporis praescriptio 71 Anm. 7. 
Cod. 7, 33, 5:... praescriptione depelli ...

Cod. 9, 9, 32 : praescriptiones civiles ... quae occurrere ... examini consuerunt.

Papinianus dig. 8, 1, 4 pr. : per doli exceptionem occurretur ... vindicanti (die exceptio hat eine der praescriptio ähnliche Funktion, weshalb sie ja auch bisweilen praescriptio genannt wird).

Cod. 7, 34, 1: praescriptione temporis defendi.

Cod. 7, 34, 5 : praescriptione ... defendi.

Cod. 9, 9, 32 : earum (scil. praescriptionum) obice.

Ulpianus dig. 48, 5, 16, $6:$ nec enim ulla praescriptio obicitur suam iniuriam vindicanti... 7 : Praescriptiones, quae obici solent accusantibus adulterii ...

Ulpianus dig. 48, 16, 7 pr.: neque enim possunt praescriptiones ei obici.

Cod. 7, 36, 2: creditoribus ... praescriptionem opponi posse.

Sehr oft bedeutet praescriptio, praescribere, für sich genommen, Einwand, einwenden :

Modestinus dig. 44, 1, 10 : litem inferenti praescribi... posse.

Ulpianus dig. $5,1,52,3$ : dicendum est non debere praescribi ei qui petit.

Macer dig. 47, 15, 3, 1 : si reus accusatori ... praescribat ...
Marc. 4, 1 (Kr. 423, 9) : facile est praescriptive occurrere (nämlich den Antithesen Marcions).

Marc. 1, 22 (Kr. 318, 19) : relaxata praescriptionum defensione.

Scorp. 10 (RW. 168, 29) : nec ullus obicem praescriptionis istius extrudet.

Denselben Grundgedanken des Entgegenstellens enthält praescr. haer. $15(\mathrm{Kr} .20,6)$ : hunc igitur potissimum gradum (Wehr) obstruimus (es folgt die Ankündigung der Präskription).

virg. vel. 1 (Oe. 1, 884) : ... hoc exigere veritatem, cui nemo praescribere potest ...

praescr. haer. 21 (Kr. 25, 7) ... et hic praescribam ...

Iud. 13 (Kr. 314,2$)$ : praescribimus illis ex eisdem scripturis iam venisse Christum.

Hermog. 1 (Kr. 126, 3) : Solemus haereticis ... de posteritate praescribere. 
B. Zum Wesen der Präskription gehört weiter, daß sie das Prozeßverfahren vereinfacht. Sie ist recht eigentlich ein Kurzverfahren, denn sie weist, wenn bewiesen, die Prozeßklage ab. Daher die Worte Quintilians : "Cum ex praescriptione lis pendet, de ipsa re quaeri non est necesse. " ${ }^{1}$ Die Präskription allein ist Gegenstand der Erörterung ; die "ipsa res", die eigentliche Klage, die die Parteien vor Gericht geführt hat, kommt gar nicht zur Sprache. Das steht auch sehr deutlich in einem Reskript des Antoninus aus dem Jahre 212: durch die Präskription werde der Kläger besiegt, ohne daß der Streitfall gerichtlich untersucht worden sei, "non causa cognita " ${ }^{2}$.

In diesem Sinn versteht auch Tertullian seine Präskriptionen. Diese sind ihm hauptsächlich Mittel zur Abkürzung und Vereinfachung seiner Beweise im Kampf ("Proze $B$ ») mit den Ketzern. In den meisten Fällen ist dies von selbst klar. Als wollte uns jedoch der Autor ja nicht im Zweifel lassen über diese seine Absicht, bezeichnet er seine Präskriptionen mehrfach als ein " compendium ", eine Abkürzung, einen Begriff, welcher der römischen Rechtssprache geläufig war ${ }^{3}$. Einige Beispiele aus seinen Präskriptionen, vor allem den in praescr. haer. 21 entfalteten, mögen es bestätigen.

Praescr. haer. $21^{4}$, erste Präskription. Die Häretiker behaupten, die wahre Lehre Christi zu besitzen. Marcion, Valentin usw. haben ihnen, jeder in seiner Art, diese "christliche Lehre " gebracht. Dagegen erhebt Tertullian die Präskription: Christus hat diejenigen genau bestimmt, die seine Lehre den Menschen bringen sollten, d.h. er hat Apostel berufen. Folglich hat niemand außer den Aposteln das Recht, das Evangelium in erster Instanz nach Christus zu verkünden. - Ist diese Präskription wahr (das Beweismaterial ist enthalten in der Antwort auf den 2. Punkt [per quos] der Partitio), so ist jedes weitere Argument gegen Marcion und die andern Häresiarchen überflüssig. Sie sind schon dadurch widerlegt, daß sie nicht Apostel sind.

Praescr. haer. 215 , zweite Präskription. Aus der ersten Präskription steht fest, da $B$ das Apostolat der einzige, ausschließliche Weg ist, auf dem die wahre christliche Lehre zu den Menschen gelangen konnte.

1 Institutionis orat. 7, 5, 3 (ed. Ed. BonNel, 2. Bd. S. 33).

2 Cod. 8, 13, 15: "... si eum ... non causa cognita, sed praescriptione superatum esse constiterit. :

3 Vgl. "Vocabularium iurisprudentiae Romanae", Bd. 1 Kol. 840.

4 Vgl. praescr. haer. 21 (Kr. 24, 31); dazu oben S. 52.

5 Vgl. praescr. haer. 21 (Kr. 25, 6) ; dazu oben S. $52 \mathrm{f}$. 
Statt sich in Disputationen bezüglich der Lehre einzulassen, erhebt deshalb Tertullian, von der ersten Präskription ausgehend, eine zweite : unsere Kirche reicht allein in die apostolische Zeit zurück, folglich kann sie allein die wahre Lehre besitzen. - Ist diese Präskription wahr (sie wird bewiesen in der Antwort auf den 4. Punkt [quibus] der Partitio), dann erübrigt es sich, weiter mit den Häretikern zu streiten und sich in ihre Lehren einzulassen, um sie von ihrem Irrtum überzeugen zu wollen. Sie werden schneller widerlegt durch den bloßen Nachweis der Tatsache, daß sie später sind. Daß Tertullian diese Präskription als ein Abkürzungsverfahren versteht, bestätigt er zum Überfluß noch ausdrücklich im 1. Buch gegen Marcion. Mit unmißverständlichem Hinweis auf die zweite Präskription von praescr. haer. 21 sagt er : "Sed alius libellus hunc gradum sustinebit adversus haereticos, etiam sine retractatu doctrinarum revincendos, quod hoc sint de praescriptione novitatis. " ${ }^{1}$ Dem gleichen Gedanken begegnen wir wieder in praescr. haer. 21 nach der Formulierung der zweiten Präskription : "... tam expedita probatio est, ut, si statim proferatur, nihil iam sit retractandum" ${ }^{2}$; der Beweis mittels der Präskription geht so schnell (leicht, bestimmt), daß sofort, wenn sie vorgebracht wird, keine weitere Verhandlung mehr nötig ist. Auf dieselbe Präskription verweisend, erklärt der Apologet gegen Hermogenes : "Solemus haereticis compendii gratia de posteritate praescribere. " ${ }^{3}$ Marc. 5, $19{ }^{4}$ nennt die gleiche Präskription kurz ein "de testimonio temporum compendium".

Apol. $7^{5}$ befaßt sich mit den schändlichen Verbrechen, die bei den Heiden über die Christen zirkulieren. Trotz der Ungeheuerlichkeit derselben denken die Heiden aber gar nicht daran, eine gerichtliche Untersuchung anzustellen, um den wahren Tatbestand abzuklären. Gestützt auf diese Einstellung der Heiden ruft Tertullian ihnen zu : "Auf Grund eurer Nachlässigkeit wird gegen euch die Einrede erhoben, daß das gar nicht existiert, was ihr nicht einmal selber zu ermitteln wagt. " ${ }^{6} \mathrm{Es}$ er übrigt sich also im Grunde, mit den Verleumdungen der Heiden sich überhaupt auseinanderzusetzen. Die Widerlegung gestaltet sich viel kürzer und einfacher. Wir brauchen nur darauf hin-

1 Marc. 1, 1 (Kr. 292, 6).

2 Praescr. haer. 22 (Kr. 25, 6).

3 Hermog. 1 (Kr. 126, 3).

4 Marc. 5, 19 (Kr. 642, 27).

5 Vgl. apol. 7 (H. 18).

- Apol. 7 (H. 18, 7) : "De vestra vobis dissimulatione praescribitur non esse quod nec ipsi audetis eruere." 
zuweisen, wie gleichgültig die gestrenge heidnische Justiz diesen "Verbrechen " zuschaut. Das beweist genugsam, daß es sich nur um Verleumdungen handelt.

Nat. 2, $1^{1}$ spricht von der Perversitas der Heiden in ihrem Glauben an die vielen Götter. Wenn es genügte, diese Perversitas mit einer einzigen Präskription zu bekämpfen, dann möchte Tertullian gegen den Götterglauben der Heiden die Einrede erheben, daß sie selber zugeben, alle diese Götter seien von den Menschen eingesetzt worden. Diese Einrede, die sich auf eine offenkundige Tatsache, das Geständnis der Heiden selber, beruft, beweist hinlänglich, da es sich bei den heidnischen Göttern nicht um wahre existierende Wesen handeln kann, denn ein göttliches Wesen hat nie angefangen zu existieren. Wollte man sich mit dieser Präskription begnügen, wäre der heidnische Götterglaube sehr schnell und leicht widerlegt. Aber statt sich mit einer summarischen Einrede zu begnügen, will er sie einläßlich widerlegen.

Nat. 2, $12^{2}$ stellt sich die Aufgabe, nachzuweisen, wie alle heidnischen Götter nur Menschen sind. Tertullian begnügt sich, dies anhand der Götter - Genealogien für Saturn, den ältesten Gott, und seine nächsten Nachkommen darzutun. Für alle die unzähligen übrigen Götter erspart er sich den gleichen Nachweis. Er erhebt gegen sie kurzerhand eine Präskription auf Grund ihrer Abstammung. "Als Abkürzung halten wir den übrigen (Göttern) die Einrede der $\mathrm{Ab}$ stammung entgegen, um nicht zu den einzelnen abzuschweifen. " ${ }^{3}$ Ist die Präskription, daß alle übrigen Götter nur Abkömmlinge Saturns sind, richtig, und die Götter-Genealogien der Heiden bestätigen es, dann erübrigt es sich, bei jedem dieser Götter nachzuweisen, daß sie nur menschliche Wesen sind. Auf einen "Prozeß " mit den Göttern braucht man sich gar nicht einzulassen; sie werden abgewiesen durch die " praescriptio originis " 4 .

$\mathrm{Da}$ Tertullian die Präskription als ein Abkürzungsverfahren versteht, bestätigt auch treffend pat. $4^{5}$. In seiner Abhandlung über die Notwendigkeit der Geduld, betont der Verfasser, wie wir Gott Gehorsam

1 Vgl. nat. 2, 1 (RW. 93, 13). Siehe oben S. 83.

2 Vgl. nat. 2, 12 (RW. 116, 7).

3 Nat. 2, 12 (RW. 120, 20) : "Tenemus conpendium, in ceteros originis praescriptionem, ne per singulos evagemur."

4 Ebd.

5 Vgl. pat. : Kr. 5,6). 
schulden und wie Gehorsam und Geduld untrennbar miteinander verbunden sind. Der Beweis für die Notwendigkeit des Gehorsams ist also gleichzeitig der Beweis für die Notwendigkeit der Geduld. Der erste Beweis erspart den zweiten, gerade wie die Präskription einen Prozeß erspart. Daher die abschließende Bemerkung: "Per quae (= durch den Beweis der Notwendigkeit des Gehorsams) ... quasi in praescriptionis compendio ... de patientia constitutum est. " ${ }^{1}$

Marc. 3, $1^{2}$ sagt von der Wahrheit, daß sie "ceterum in praescriptionum compendiis vincit ".

Die angeführten Präskriptionen, - es sind die ausführlichsten und deutlichsten im ganzen Werk Tertullians - dürften den Beweis hinreichend leisten, in welchem Sinn Tertullian die Präskription versteht und anwendet. Er versteht sie wesentlich als Einwand, der, wenn erwiesen, eine Frage schneller entscheidet und abkürzt. Soweit deckt sich die Präskription Tertullians mit jener des Prozesses, die in ihrem tiefsten Wesen ein Einwand und ein Abkürzungsverfahren ist. Im folgenden Abschnitt wird gezeigt, in was die Präskriptionen Tertullians von ihrem Vorbild abweichen.

\section{Die Verschiedenheit der tertullianischen und prozessualen Präskriptionen hinsichtlich des Inhaltes}

Die Präskriptionen der severischen Zeit machen eine Verjährungsoder Ausschlußfrist oder sonst prozeßhindernde Tatsachen geltend. Der größere Teil der Präskriptionen beruft sich auf eine Frist, 4, 5, 10, 20 Jahre, die vom Gesetze vorgeschrieben ist. Die Präskriptionen haben somit einen bestimmten Inhalt, nach welchem sie auch benannt werden, z. B.: praescriptio quinquennii, quinquaginta dierum, quadriennii, sessionis intermissae etc. ${ }^{3}$.

Vergleichen wir die zahlreichen Präskriptionen Tertullians mit den prozessualen, so stellen wir fest, daß seine Präskriptionen einen ganz andern Inhalt aufweisen. So hält er nat. 2, $12^{4}$ den Göttern, die alle von Saturn abstammen, eine "praescriptio originis", eine Einrede, die sich auf die Abstammung beruft, entgegen. Mit deutlichem Hinweis auf die in praescr. haer. 21 entwickelte zweite Präskription

1 Pat. 4 (Kr. 6, 7).

2 Marc. 3, 1 (Kr. 377, 22).

3 Vgl. J. Partsch, Die longi temporis praescriptio 71 Anm. $1 \mathrm{ff}$.

4 Siehe oben S. 91. 
spricht Marc. 1, $1^{1}$ von einer "praescriptio novitatis". Apol. $7^{2}$ erhebt gegen die Heiden eine Einrede auf Grund ihrer Gleichgültigkeit. Marc. 1, $11^{3}$ erklärt: "Ein für alle Mal gilt die Prozeßeinrede: sie (die Marcioniten) können den Demiurgen nicht als Gott bekennen ... ". Marc. 1, 94 erklärt : "... ich erhebe die Einrede : Gott konnte weder unbekannt bleiben wegen seiner Größe, noch durfte er es wegen seiner Güte..." - Es ließen sich noch mehr solcher Stellen anführen 5 .

Diese Beispiele legen zur Genüge dar, daß Tertullian die Präskription des römischen Prozesses nur in ihrer äußern Form übernimmt. Er erfüllt die Präskription mit ganz neuem Inhalt und stellt sie in den Dienst der Apologetik. Er transponiert die Präskription des Prozesses in die Sprache der Theologie. Die juristische Präskription wird in der Hand Tertullians eine theologische Präskription.

Und wie die Präskriptionen des Kognitionsprozesses nach ihrem Inhalt benannt werden, z. B. praescriptio quadriennii oder praescriptio sessionis intermissae, so benennt Tertullian, allerdings nur ausnahmsweise (nur $2 \mathrm{Mal}$ ), seine Präskriptionen nach dem ganz eigenwilligen Inhalt derselben : die zweite Präskription in praescr. haer. 21, die im Streit gegen die Häretiker das Alter der wahren Lehre, bzw. die Neuheit der Häresien, geltend macht, bezeichnet er als "praescriptio novitatis " ${ }^{6}$; nat. $2,12^{7}$ spricht von einer "praescriptio originis".

Die Präskription ist nur ein Beispiel aus unzähligen ähnlichen. Kein kirchlicher Schriftsteller hat weder früher noch später mit dieser Vorliebe, in einem solchen Umfang und mit einer solchen Gewandtheit Begriffe und Redensarten der römischen Rechtssprache mit christlichem Inhalt erfüllt und z. Teil dauernd in der christlichen Sondersprache heimisch gemacht wie Tertullian. Ordinatio (= Bestellung zu einem Amt), ein Ausdruck der spätklassischen Juristen, wird durch ihn zum bleibenden terminus technicus für "Priesterweihe " 8 . Die

1 Siehe oben S. 83.

2 Siehe oben S. 83.

3 Marc. 1, 11 (Kr. 304, 25) : "Semel enim praescriptio stabit non posse illos et Deum confiteri creatorem et..."

4 Marc. 1, 9 (Kr. 301, 10) : "Sed breviter proponam et plenissime exequar, praescribens Deum ignorari nec potuisse nomine magnitudinis nec debuisse nomine benignitatis ..."

5 Vgl. Marc. 4, 5 (Kr. 432, 9), virg. vel. 1 (Oe. 1, 884), Hermog. 1 (Kr. 126, 3).

6 Siehe oben S. 83.

7 Siehe oben S. 83.

8 Vgl. St. W. J. Teeuwen, Sprachlicher Bedeutungswandel bei Tertullian 70. 
Rechtsausdrücke: delictum, delinquere, delictum capitale, solvere, absolvere, dimittere, remittere, ignoscere, concedere, retinere usw., um aus den zahlreichen Beispielen nur eine zusammengehörige Gruppe herauszugreifen, werden durch Tertullian zu dauernden Begriffen der kirchlichen Bußdisziplin umgeprägt ${ }^{1}$.

Dasselbe gilt von der Soldatensprache, neben der Rechtssprache die wichtigste Sprachquelle, aus der Tertullian zahlreiche Begriffe entnimmt und christianisiert.

Sehr viele Übertragungen setzten sich nicht durch ; sie blieben einmalig. So die Bezeichnung der bischöflichen Verordnung als " edictum " 2, oder des Heiligen Geistes als "advocatus " ${ }^{3}$ oder des Taufpaten als " sponsor " 4, Bürgen. Und wie verhält es sich mit "praescriptio " und "praescribere", diesen bevorzugten Begriffen unseres Autors ? Es ist zu sagen, daß die Präskription als solche nicht Gemeingut der theologischen Sprache geworden ist. Sie ist in ihrem ganzen Wesen so sehr Prozeßbegriff, daß sich dieser ihr Grundcharakter sozusagen nicht abstreifen läßt. Ein weiterer Grund ist der : sie läßt sich auf die verschiedenartigsten Fälle anwenden, wie dies die oben angeführten Präskriptionen aus den Schriften Tertullians bestätigen. Aber wo ist der Theologe, der einen derart ausgesprochen prozessualen Begriff mit der geforderten Fertigkeit handhabt ? Das konnte Tertullian, der in seinen Schriften nicht nur den Theologen, sondern auch gewandten Juristen verrät. Die Präskription ist ihm in dem Grad geläufig, daß sie ihm bei zahlreichen Gelegenheiten zwanglos in die Feder fließt.

Die Präskription als solche, in ihrer für die buntesten Fälle geeigneten Hohlform, wenn man so sagen darf, ist nicht Gemeingut der Apologetik geworden. Sie hat sich aber in einer bestimmten Anwendung, mit einem bestimmten Inhalt erfüllt (in der Rechtssprache ausgedrückt : in einem konkreten Fall) durchgesetzt. Wir meinen die zweite Präskription in praescr. haer. 21.

Die Häresien werden dort in ihrer Gesamtheit abgewiesen durch die Einrede : nur die Kirchen, die von den Aposteln persönlich gegründet wurden, dürfen Auskunft geben über den Inhalt der Apostelpredigt, eben weil sie die einzigen sind, denen die Apostel die christliche Lehre direkt, mündlich oder schriftlich, mitgeteilt haben. Aus der Tatsache,

1 A. a. O. $71 \mathrm{f}$.

2 Vgl. pud. 1 (RW. 220, 5), dazu Teeuwen, a. a. O. 70.

3 Vgl. ieiun. 13 (RW. 292, 7).

4 Vgl. bapt. 18 (RW. 216, 17), dazu TeEuwen, a. a. O. 73. 
$\mathrm{da} B$ die apostolischen Urgemeinden allein mit den Aposteln in direkten Kontakt kamen und die einzigen sind, die von jenen die Offenbarung empfingen, ergibt sich, da $\beta$ die Lehre der apostolischen Urgemeinden und aller andern Gemeinden, die mit diesen in Gemeinschaft leben, die älteste ist. Den Angriff der Häretiker auf diese Präskription, die apostolischen Urgemeinden hätten die Apostel falsch verstanden, wird von Tertullian abgewiesen mit der Berufung auf das Prinzip von der Priorität der Wahrheit vor dem Irrtum und mit dem geschichtlichen Nachweis, daß alle bestehenden Häresien aus nachapostolischer Zeit stammen. Weil diese Präskription gegenüber den Häretikern das höhere Alter der apostolischen Urgemeinden und der von ihnen verteidigten Lehre geltend macht, wird sie von Tertullian zutreffend als praescriptio novitatis ${ }^{1}$ bezeichnet, d. h. als eine Einrede, die die Häretiker widerlegt auf Grund ihrer Neuheit, ihres jüngern Alters. Das ist die einzige unter seinen vielen Präskriptionen, die Tertullian weiter ausgebaut hat und die in dieser einmaligen, praktischen Anwendung die Jahrhunderte überdauert hat. Schon Tertullian war überzeugt, daß ihm mit der praescriptio novitatis ein Meisterwurf geglückt war. Nicht umsonst stellt er sie in den Mittelpunkt eines ganzen Traktates, läßt die Objektionen der Häretiker gegen sie auftreten und fordert die Gegner siegesbewußt zur Replik gegen sie auf. Dadurch gewinnt die Präskription an Überzeugungskraft. Es ist auch kein Zufall, wenn Tertullian in seinen übrigen Schriften mindestens sieben Mal auf diese Präskription verweist ${ }^{2}$. Im 1 . Buch gegen Marcion muß er selber gestehn, daß er sich allenthalben auf diese Präskription beruft, "compendium praescriptionis ubique advocatum " ${ }^{3}$. $\mathrm{Da} B$ der Autor damit die zweite Präskription in praescr. haer. 21 meint, ist unbestritten, denn er wiederholt unter seinen vielgestaltigen Präskriptionen nur diese so oft ${ }^{4}$.

Die zweite Präskription in praescr. haer. 21 hat das Zeitver-

1 Marc. 1, 1 (Kr. 292, 8).

2 Vgl. apol. 47 (H. 111, 41).

Marc. 1, 1 (Kr. 292, 4).

Marc. 5, 19 (Kr. 642, 26).

Marc. 3, 1 (Kr. 377, 15).

Hermog. $1(126,3)$.

Marc. $4,5(\mathrm{Kr} .432,7)$.

carne Chr. 2 (Kr. 192, 32).

3 Marc. 1, 1 (Kr. 292, 9).

4 Dabei ist allerdings der Vorbehalt zu machen, daß Tertullian nur die juristische Form des Argumentes geschaffen hat. Der Inhalt des Argumentes findet sich schon bei Irenäus, der adv. haer. 3, i aus dem höhern Alter der apostol. Kirchen vor allen Häresien argumentiert. Siehe unten S. 140 Anm. 2.

Über den theologischen Gehalt der 2. Präskription und die anzubringende Korrektur siehe unten S. $149 \mathrm{ff}$. 
hältnis zwischen der wahren Lehre und den Häresien zum Inhalt. Wenn Tertullian die Präskription auf dieses Zeitverhältnis anwendet, so nähert er sich hier der gebräuchlichsten Form der juristischen Präskription. Die Mehrzahl derselben macht ja, wie gesehen, ein Zeitverhältnis, eine verflossene Frist geltend, und in dieser Gestalt muß deshalb die Präskription auch am populärsten und bekanntesten gewesen sein. Indem sich Tertullian in seiner zweiten Präskription dieser populärsten und häufigsten Form der juristischen Präskription nähert, hatte seine Schöpfung umso mehr Aussicht, durchzudringen und Gemeingut der Apologetik zu werden. Der folgende 3. Abschnitt wird sich mit dieser Präskription noch näher befassen.

\section{Die Formulierung der zwei Präskriptionen in praescr. haer. $21^{1}$}

Vom Inhalt der beiden Präskriptionen war schon mehrmals die Rede. Es erübrigt sich, noch weiter darauf einzugehen. Was uns hier noch interessiert, betrifft die Gestalt, die Formulierung der zwei betreffenden Präskriptionen.

Die Präskriptionen Tertullians entsprechen der Einrede des Kognitionsprozesses, der zum Unterschied vom Formularprozeß gekennzeichnet ist durch einen geminderten Formalismus. Die freie Ungezwungenheit, die den Kognitionsproze $B$ kennzeichnet, ist auch der darin vorgebrachten praescriptio eigen. Sie ist nämlich an keine feststehende Form gebunden ${ }^{2}$, wie dies bei der in die Formel eingefügten exceptio der Fall ist. Man durchgehe nur die beiden Prozeßprotokolle, die uns für die longi temporis praescriptio überliefert sind ", um festzustellen, wie zwanglos sich die gerichtliche Handlung selber wie auch die darin geltend gemachte praescriptio abwickeln.

Nachdem feststeht, daß die Präskriptionen Tertullians, vom Inhalt abgesehen, den Präskriptionen des Kognitionsprozesses entsprechen, nachdem weiter feststeht, daß die Präskription im Prozeß an keine feste Formulierung gebunden ist, brauchen wir auch der Form der uns interessierenden zwei Präskriptionen keine besondere Beachtung zu schenken. In der Tat hat denn auch jede von den verschiedenen Präskriptionen, die in den Schriften unseres Autors zerstreut sind, eine andere Struktur.

1 Praescr. haer. 21 (Kr. 24, 31). Text siehe oben S. 52.

2 Vgl. J. Partsch, a. a. O. 71.

3 Siehe oben S. $32(4-5)$. 
Sie stimmen alle darin überein, da $ß$ sie einen Einwand darstellen, dẹ, wenn bewiesen, irgendeine zu lösende Frage schneller entscheidet.

Unter allen tertullianischen Präskriptionen (wir meinen nur jene, die etwas mehr ausgeführt und deutlicher sind) kommt den beiden in praescr. haer. 21 allerdings eine gewisse Regelmäßigkeit zu. Aber diese erklärt sich vollständig daher, daß die beiden Präskriptionen, nach dem Zeugnis der Analyse, in einen wohldurchdachten Plan eingefügt sind. Diese zwei Präskriptionen bilden das einzige Beispiel dieser Art. Die übrigen Präskriptionen sind meist nur wie im Vorbeigehn in den Text eingestreut, oder sie erinnern an die bekannte zweite Präskription in praescr. haer. 21.

Es wurde in der Analyse ${ }^{1}$ aufgezeigt, wie die zwei darin freigelegten Präskriptionen deutlich an den 2. und 4. Punkt der Partitio anknüpfen, gleichzeitig die zwangslos sich daraus ergebenden Folgerungen ziehen und diese anschließend begründen. So besteht jede der beiden Präskriptionen aus drei Gliedern :

1. Wiederholung der Antwort auf den 2. bzw. 4. Punkt der Partitio.

2. Daraus sich ergebende Folgerung.

3. Begründung der Folgerung.

Bei der 1. Präskription liegt diese Dreigliedrigkeit auf der Hand:

a) In Kap. 20 enthaltene Antwort auf den 2. Punkt (per quos) der Partitio: "(si) dominus Christus Jesus apostolos misit ad praedicandum ".

b) Aus dieser geschichtlichen Tatsache die Folgerung: "alios non esse recipiendos praedicatores quam Christus instituit ".

c) Begründung der Präskription: "quia nec alius patrem novit nisi filius et cui filius revelavit, nec aliis videtur revelasse filius quam apostolis, quos misit ad praedicandum, utique quod illis revelavit ". Diese Begründung ist zum Teil aus derselben in Kap. 20 gegebenen Antwort auf den 2. Punkt der Partitio entnommen ${ }^{2}$.

Dieselbe Regelmäßigkeit besteht, wenn auch nicht so augenscheinlich, in der zweiten Präskription :

1 Siehe oben S. $39 \mathrm{ff}$.

2 Vgl. Matth. 11, 27: "Et nemo novit Filium, nisi Pater; neque Patrem quis novit, nisi Filius, et cui volucrit filius revelare. " - Siehe dieselbe Begründung gegen Marcion (Marc. 4, 25; Kr. 506, 1). 
a) Die Antwort auf den 4. Punkt der Partitio (quibus) lautet in Kap. 20 dahin, da $B$ die Apostel den Heiden die Glaubenslehre verkündeten und in den bedeutendsten Städten der damaligen Kulturwelt jene bekannten, ältesten heidenchristlichen Gemeinden gründeten : "... perinde ecclesias apud unamquamque civitatem condiderunt ..." ${ }^{1}$. Diese Tatsache bildet (sogar unter wörtlicher Wiederholung der zwei wichtigsten Begriffe : ecclesia und condere) die Grundlage der zweiten Präskription: (ecclesiae), "quas ipsi apostoli condiderunt ..."

b) Aus dieser Tatsache ergibt sich ohne weiteres die Folgerung : wenn feststeht, daß die Apostel Gemeinden gegründet haben, dann dürfen nur diese Gemeinden darlegen, was Lehre der Apostel, bzw. Offenbarung Christi an diese, ist. "Quid autem praedicaverint, id est quid illis Christus revelaverit, - et hic praescribam - non aliter probari debere nisi per easdem ecclesias..."

c) Es folgt, gleich wie bei der ersten Präskription, die Begründung für den Ausgangspunkt $(a)$ der Folgerung. Diese Gemeinden sind tatsächlich von den Aposteln gegründet, denn sie haben ihnen persönlich gepredigt oder geschrieben; " condiderunt, ipsi (scil. a postoli) eis praedicando tam viva, quod aiunt, voce quam per epistolas postea ». Diese Worte fassen das in Kap. 20 Gesagte kurz zusammen. Einen zusätzlichen Beweis für die Tatsache der durch die Apostel erfolgten Gründung der betreffenden Gemeinden leistet Tertullian in Kap. 36, wo auf die in den apostolischen Gemeinden bis zur Stunde aufbewahrten Lehrstühle und Autographa der Apostel hingewiesen wird.

Keine weitere Beachtung verdient die unterschiedliche Einleit ung der beiden Präskriptionen, der ersten in der Mehrzahl : "... dirigimus praescriptionem ", der zweiten in der Einzahl : "... et hic praescribam ". Tertullian wechselt den Numerus vielfach ganz wahllos. Ein treffendes Beispiel in dieser Hinsicht bieten seine zwei Bücher an seine Frau. So beginnt er gerade in der Einleitung zum ersten Buch im Singular und wechselt schon in den nächsten zwei Sätzen ganz unvermittelt in den Plural über, obwohl er deutlich nur von seiner Person spricht ${ }^{2}$.

1 Praescr. haer. 20 (Kr. 24, 19). 2 Vgl. uxor. 1, 1 (Kr. 96). 


\section{Praescr. haer. 37 und die longi temporis praescriptio}

Als erster hat J. PARTSCH in praescr. haer. die longi temporis praescriptio vermutet und zwar in Kap. $37^{1}$. Ähnlich äußert sich U. MoRICCA ${ }^{2}$. P. MoncEAUX spricht sich hierüber nicht klar aus ${ }^{3}$.

$\mathrm{Da} B$ die Einrede aus dem langen Besitz nicht in den beiden Präskriptionen von Kap. 21 noch sonst irgendwo gesucht werden muB, als einzig in Kap. 37, bestätigt schon eine Durchsicht des Traktates unter diesem Gesichtspunkt.

Für die Untersuchung der interessanten Frage, ob und wie Tertullian die longi temporis praescriptio in Kap. 37 anwendet, haben wir ein Doppeltes auseinanderzuhalten :

Erstens zieht Tertullian in Kap. 37 die Folgerungen aus dem Vorhergehenden. Nachdem die Kap. 20-36 den Beweis erbracht haben, daß die wahre christliche Lehre bei den apostolischen Gemeinden sich findet, zieht Kap. 37 (entsprechend dem in Kap. 19 aufgestellten Grundsatz : wo die echte christliche Glaubens- und Sittenlehre sich findet, dort ist auch die echte Heilige Schrift und Auslegung) die Folgerung: also findet sich auch die echte Heilige Schrift bei den apostolischen Gemeinden, sie ist deren rechtmäßiger Besitz und geht die Häretiker folglich nichts an. Nun ist aber selbstverständlich, da $B$ dieselben Argumente, die in den Kap. 20-36 bestätigen, daß die geoffenbarte Wahrheit als solche in ihrer Ganzheit sich bei den apostolischen Gemeinden findet, auch für die Heilige Schrift, den Teil dieser geoffenbarten Wahrheit, Geltung haben. Es ist deshalb nur konsequent, wenn Tertullian in Kap. 37 an die wichtigsten Argumente der Kap. 20-36 anspielt. Wollen wir also Kap. 37 in einer so schwierigen Frage wie der vorliegenden richtig deuten, so dürfen wir Kap. 37 nicht aus dem Zusammenhang reißen und kurzerhand auf das Vorhandensein der longi temporis praescriptio prüfen. Diese Methode wäre im voraus verfehlt. Vorerst müssen die innern Zusammenhänge; die Kap. 37 mit dem Vorhergehenden verknüpfen, überzeugend aufgedeckt und daraus der Sinn der einzelnen Sätze ermittelt werden. Diese für die Lösung des eigentlichen Problems grundlegende Vorarbeit besorgt der erste Teil (A) dieses Abschnittes.

1 J. Partsch, Die longi temporis praescriptio 76 u. 109.

2 U. MoRICCA, Storia della letteratura latina christiana, 1. Bd. (Turin 1923) $195 / 6$.

3 P. Monceaux, Histoire littéraire de l'Afrique chrétienne, 1. Bd. : Tertullien et les origines 304 . 
Zweitens verbindet Tertullian mit den in Kap. 37 bezüglich der Heiligen Schrift ausgesprochenen Konsequenzen, zum Teil versteckt, zum Teil mit unmißverständlicher Offenheit, juristische Vorstellungen, die deutlich an die longi temporis praescriptio erinnern. Die einzelnen juristischen Ausdrücke zu erklären und theologisch zu deuten, endlich die einzelnen Sätze auf die verschiedenen Elemente der betreffenden Prozeßeinrede zu untersuchen, stellt die Aufgabe des zweiten Teiles (B) dar.

\section{A. Kap. 37 im Zusammenhang gesehen}

Die Analyse hat den Beweis erbracht, daß Kap. 37 das Schlußglied eines planvollen theologischen Gedankenganges darstellt. Dieser soll hier noch einmal skizziert werden.

Die letzte Zuflucht der Häretiker im Kampf gegen die Katholiken bildet die Heilige Schrift. Diese muß ihnen entrissen werden. Das geschieht, indem die Besitzverhältnisse an der Heiligen Schrift ein für allemal abgeklärt werden. Dies nennt daher Tertullian in Kap. 15 das Ziel seines Traktates: "dispici debet, cui competat possessio scripturarum, ne is admittatur ad eas, cui nullo modo competit " ${ }^{1}$. Die Frage nach dem wahren Besitzer der Schrift hängt jedoch ab von einer andern: wer ist der authentische, von Christus bzw. seinen Aposteln berufene Verwalter des gesamten Offenbarungsschatzes, der christlichen Lehre als solcher, in ihrer Gesamtheit ${ }^{2}$, die anfänglich nur in mündlicher Form in den Urzeugen lebte und erst nachträglich und allmählich

1 Praescr. haer. 15 (Kr. 20,9).

2 Um Mißverständnissen vorzubeugen, vermeiden wir im ganzen Abschnitt absichtlich den Ausdruck "Tradition". Die dogmatisch wie historisch durchaus unhaltbare Berufung der Reformatoren auf die Heilige Schrift als einzige Glaubensquelle und der dadurch bedingte Kampf der Kirche für die Tradition führte zur logischen Unterscheidung zwischen Heiliger Schrift einerseits und Tradition ohne Heilige Schrift anderseits. So entstand neben dem alten, allgemeinen, ein neuer, engerer Traditionsbegriff, der der urchristlich, vorreformatorischen Theologie unbekannt war. - In vorliegender Arbeit ist nun sehr viel die Rede von der Heiligen Schrift und der Tradition, aber nicht in dem Sinn, daß die beiden einander entgegengestellt würden. Vielmehr gehören nach Tertullian, im echt urchristlichen Sinn, Schrift und Tradition (Tradition als Summe aller der Kirche anvertrauten übernatürlichen Wahrheiten genommen, ob sie nun in oder außerhalb der Schrift bezeugt seien) untrennbar zusammen. Um aber jedes Mißverständnis auszuschließen, sprechen wir statt von Tradition immer von der christlichen Lehre als solcher, in ihrer Gesamtheit. (Ưber den Traditionsbegriff vgl. A. DenefFe, Der Traditionsbegriff, Münsterische Beiträge zur Theologie, Heft 18 (Münster i. W. 1931) und J. RanfT, Tradition, Lexikon für Theologie und Kirche, Bd. 10, S. $243 \mathrm{ff}$.) 
in der Heiligen Schrift ihren zwar bedeutendsten, aber weder erschöpfenden, noch sich zu ihrem Verständnis selbst genügenden schriftlichen Niederschlag fand? Die Lehre in ihrer Gesamtheit und die Heilige Schrift gehören demnach untrennbar zusammen. Denn einerseits ist die Heilige Schrift der bedeutendste, wenn auch nicht älteste und vollständige Zeuge der Lehre, anderseits ist die Heilige Schrift zu ihrem richtigen Verständnis aufs unfehlbare Lehramt angewiesen. Die Apostel haben also die Lehre als solche, wie die Heilige Schrift, der einen und selben Kirche übergeben.

Diesen Voraussetzungen getreu, verlegt sich Tertullian nur auf die Lösung dieser Frage (nennen wir sie die Hauptfrage) : wer ist der von Christus, näherhin von den Aposteln, bestellte Verwalter der christlichen Lehre schlechthin, die apostolischen Gemeinden oder eine der zahlreichen Sekten ? Mit dieser Hauptfrage wird zugleich die (nennen wir sie Nebenfrage) nach dem rechtmäßigen Besitzer bzw. allein zuständigen Interpreten der Heiligen Schrift entschieden. "Denn dort, wo sich herausstellt, daß die echte Glaubens- und Sittenlehre (die christliche Lehre in ihrer Gesamtheit, sei sie in oder außer der Heiligen Schrift bezeugt) sich findet, dort ist auch die echte Schrift und Auslegung (derselben) ... " ${ }^{1}$ Wo das Ganze hinterlegt ist, dort ist auch der Teil.

Die Antwort auf die Hauptfrage, wem die Offenbarung als solche, in ihrer Gesamtheit, von Christus anvertraut worden sei, fällt auf Grund einer geschichtlichen Untersuchung (Kap. 20) zu Gunsten der Apostel bzw. der von diesen direkt oder indirekt abstammenden Gemeinden aus. Damit ist die Hauptfrage entschieden : ums Jahr 200 herum sind die sog. apostolischen Gemeinden, zu denen auch die von Tertullian verteidigte afrikanische Kirche gehört, die alleinigen von den Aposteln bestellten Hüter der Offenbarung. Mit dieser Feststellung ist implicite auch die Nebenfrage entschieden : wenn die apostolischen Gemeinden nachweisbar die allein von den Aposteln bestellten und bevollmächtigten Hüter der Offenbarung in ihrer Gesamtheit sind, dann sind sie gleicherweise auch die allein rechtmäßigen Besitzer der Heiligen Schrift. Vorläufig zieht jedoch der Autor diese Folgerung noch nicht; er verschiebt sie bis Kap. 37. Vorderhand will er das erste Ergebnis (die apostolischen Gemeinden sind die einzig berufenen und rechtmäßigen Verwalter des Gesamtdepositums) noch vertiefen. Das zweite Ergebnis

1 Praescr. haer. 19 (Kr. 23, 8) : "Ubi enim apparuerit esse veritatem disci- plinae et fidei christianae, illic erit veritas et scripturarum et expositionum ..." 
(folglich sind die apostolischen Gemeinden auch die allein rechtmäßigen Besitzer der Heiligen Schrift), das im ersten Ergebnis implicite enthalten ist, wird dann nur umso eindringlicher überzeugen.

Die Vertiefung des ersten Ergebnisses vollzieht sich in der Widerlegung der drei Objektionen der Häretiker (Kap. 22-34) und in den beiden Argumenten von Kap. $36^{1}$. Die Widerlegung der drei Objektionen, vor allem der dritten, erweist sich nach dem Zeugnis der Analyse von geradezu unerschöpflicher theologischer Tiefe. Man darf den betreffenden Abschnitt (Kap. 22-34), und das gilt ganz besonders von der Widerlegung der dritten Objektion (Kap. 27-34), mit Recht den gehaltvollsten des ganzen Traktates nennen. Tertullian bietet hier die ganze Tiefe und Schlagfertigkeit seiner theologischen Bildung auf, ohne sich etwa in Sophismen oder Effekthascherei zu verirren. In den Kap. 22-34 haben wir infolgedessen auch die tiefsten Argumente für die Richtigkeit des vorhin erwähnten Hauptergebnisses zu suchen, daß nämlich die heutigen apostolischen Urgemeinden und alle, die mit ihnen in Gemeinschaft leben, tatsächlich die alleinigen, authentischen, von den Aposteln bestellten Verwalter des unverfälschten Gesamtdepositums der göttlichen Offenbarung sind. Es lohnt sich im Hinblick auf Kap. 37, die drei Argumente, die mit der Widerlegung der drei Objektionen zusammenfallen, hier kurzgefaßt nochmals an uns vorüberziehen zu lassen.

1. In der Widerlegung zur ersten Objektion (Kap. 22-24) der Häretiker, nicht alle Apostel hätten die ganze christliche Lehre besessen, weil Christus sie nicht in allem unterwiesen habe, wird bewiesen, daß sich alle Apostel ohne Ausnahme im vollen und ungeschmälerten Besitz der christlichen Lehre befanden?

2. Die Widerlegung der zweiten Objektion (Kap. 25-26), die Apostel hätten wohl alles gewußt, aber nicht allen alles mitgeteilt, hält daran fest, daß die Apostel die ihnen anvertraute Lehre Christi nicht in eine offizielle, für die Offentlichkeit bestimmte Lehre, und eine für einen auserwählten Kreis bestimmte sog. Geheimlehre gespalten haben. Die Apostel haben die christliche Lehre in aller Öffentlichkeit, ganz und ungeschmälert allen verkündet, den Juden und Heiden, wie viel mehr erst den bereits gläubig gewordenen Gemeinden ${ }^{3}$.

1 Siehe oben S. $57 \mathrm{ff}$. und $76 \mathrm{ff}$.

2 Siehe oben S. $58 \mathrm{ff}$.

3 Siehe oben S. $60 \mathrm{ff}$. 
3. Die dritte Objektion (Kap. 27-34) der Häretiker machte geltend : zugegeben, daß die Apostel die ganze Fülle der Lehre kannten und diese auch allen ganz mitteilten, so behaupten wir weiter, da $\beta$ die sog. apostolischen Urgemeinden die Apostel falsch verstanden und folglich bis auf den heutigen Tag nicht die Lehre der Apostel, sondern einen Irrtum überliefert haben. Erst ein Marcion, Valentin, Apelles usw. haben erstmals die wahre, unverfälschte Lehre der Apostel gebracht. Diese Behauptung wird von Tertullian Lügen gestraft :

1. durch den Hinweis auf die vollendete Einheit des Glaubens, der die apostolischen Gemeinden umschließt, Kap. $28^{1}$;

2. durch das Prinzip von der Priorität der Wahrheit vor dem Irrtum. Am eindrücklichsten beweist es dieses letztere Argument, $\mathrm{da} B$ die Lehre der heutigen apostolischen Gemeinden in der Tat identisch ist mit der Lehre der Apostel, denn :

einerseits (a priori) steht fest, daß "die Wahrheit in allem dem Trugbild vorangeht" (Kap. 29), was für die geoffenbarte Wahrheit erhärtet wird durch das argumentum ex absurdis und das Zeugnis des Apostels (Kap. 29) sowie die Parabel vom Unkraut unter dem Weizen (Kap. 31) ${ }^{2}$;

anderseits (a posteriori) steht auf Grund geschichtlicher Tatsachen ebenso unwiderlegbar fest, daß diese Priorität der Wahrheit nur der Lehre der apostolischen Gemeinden zukommt, da diese nachweisbar viel älter ist als alle sie bekämpfenden Lehren eines Marcion, Valentin usw. (Kap. 30) ${ }^{3}$.

Durch das Prinzip von der Priorität der Wahrheit werden die Lehren eines Marcion, Valentin usw., kurz überhaupt jedes Bekenntnis, das später ist als die Lehre der apostolischen Gemeinden (und das gilt für alle Häresien zur Zeit Tertullians) schon hinlänglich als nichtapostolisch und daher als Irrtum erwiesen. Für den Fall, daß jedoch eine Häresie ihre Niederlage trotzdem noch nicht anerkennen, sondern im Gegenteil sich sogar zur Behauptung erkühnen sollte, sie reiche ebenfalls in die apostolische Zeit hinauf, führt Tertullian den Hauptschlag : er beruft sich auf die A postolizität des Ursprungs und der Sukzession. Dies ist der letzte, ausschlaggebende Beweis dafür, daß die Lehre der apostolischen Gemeinden wirklich von den Aposteln stammt und mit der Lehre der Apostel identisch ist. Die Häretiker werden nie in der

\footnotetext{
${ }^{1}$ Siehe oben S. $64 \mathrm{ff.} \quad{ }^{2}$ Siehe oben S. $64 \mathrm{ff} . \quad{ }^{3}$ Siehe oben S. $70 \mathrm{f}$.
} 
Lage sein, diesen Nachweis für ihre Lehre zu leisten. Und sollten sie die Bischofsreihen erfinden, um so für ihre Lehre die apostolische Herkunft vorzutäuschen, so wird ihre Lehre, mit der apostolischen verglichen, durch ihre Verschiedenheit und Gegensätzlichkeit laut Zeugnis ablegen gegen ihre angebliche apostolische Herkunft ${ }^{1}$.

Die drei Widerlegungen gehören zusammen. Die zweite baut auf auf der ersten, die dritte schließt die letzte Bresche im Verteidigungsring gegen die Häretiker. Die erste Widerlegung beweist, da $B$ alle Apostel im Besitz der ganzen Lehre Christi waren. Die zweite hält fest, da $B$ die Apostel die Wahrheit allen ohne Ausnahme, ganz und ungeteilt, wie sie sie empfingen, weitergaben. Die Widerlegung der dritten Objektion endlich weist nach, daß im gegenwärtigen Augenblick nur die apostolischen Gemeinden sich im Besitz der vollen und unverfälschten Lehre der Apostel befinden.

Nach diesen drei Widerlegungen und nach den beiden zusätzlichen Argumenten in Kap. $36^{2}$ steht das erste Ergebnis : die apostolischen Gemeinden sind die allein rechtmäßigen und berufenen Hüter des Gesamtdepositums der geoffenbarten Wahrheit, unwiderleglich fest. "Si haec ita se habent, ut veritas nobis adiudicetur, quicumque in ea regula incedimus, quam ecclesiae ab apostolis, apostoli a Christo, Christus a Deo tradidit. " ${ }^{3}$ Hier, in Kap. 37, ist deshalb auch der Zeitpunkt da, wo Tertullian das in diesem ersten Ergebnis implicite eingeschlossene $z$ weite Ergebnis ausdrücklich folgert : also sind die apostolischen Gemeinden auch die allein rechtmäßigen Besitzer der Heiligen Schrift : "... constat ratio propositi nostri definientis non esse admittendos haereticos ad ineundam de scripturis provocationem, quos sine scripturis probamus ad scripturas non pertinere. " 4 Die Heilige Schrift geht die Häretiker überhaupt nichts an (ad scripturas non pertinere). Und wie eine Zusammenfassung der vorangegangenen Argumente gibt der Verfasser noch einmal die Begründung : "Si enim haeretici sunt, christiani esse non possunt ... " 5 Nur die Glieder der apostolischen Kirchen besitzen die Lehre Christi als solche, ganz und ungeschmälert, und heißen deshalb mit Recht Christen. Die von der Lehre der apostolischen Kirchen abweichenden Bekenntnisse haben sich eine Auslese der christlichen Lehre zurechtgelegt, sie sind nur Ausleser,

1 Vgl. praescr. haer. 32 (Kr. 39).

2 Siche oben S. $76 \mathrm{ff}$.

3 Praescr. haer. 37 (Kr. 47, 1).

4 Praescr. haer. 37 (Kr. 47,3).

5 Praescr. haer. 37 (Kr. 47,6). 
Häretiker. Diese Auslese ist nicht mehr die Lehre Christi, sie ist ein Zerrbild derselben, als solche stammt sie nicht von Christus : "... non a Christo habendo, quod de sua electione sectati haereticorum nomine admittunt. " ${ }^{1}$ Wenn also feststeht, daß allein die apostolischen Gemeinden die ganze, ungeminderte, echte christliche Lehre besitzen, dann ist auch entschieden, wem die Heilige Schrift gehört, wer folglich die echte Heilige Schrift besitzt und wer sie richtig auszulegen imstande ist ${ }^{2}$ : nur die apostolischen Gemeinden. Die nächste Folgerung gegen die Häretiker bezüglich der Heiligen Schrift liegt auf der Hand und sie wurde von Tertullian bereits energisch ausgesprochen : die Heilige Schrift geht die Häretiker nichts an; "... quos (scil. haereticos) sine scripturis probamus ad scripturas non pertinere ${ }^{3}$.

Das Hauptanliegen von praescr. haer., nämlich die Besitzverhältnisse an der Heiligen Schrift abzuklären (vgl. Kap. 154: " dispici debet, cui competat possessio scripturarum, ne is admittatur ad eas, cui nullo modo competit ") ist hier eigentlich erfüllt. Es steht ja nun eindeutig fest, wem die Heilige Schrift gehört : niemand anderm als den apostolischen Gemeinden. Wir würden es ganz in Ordnung finden, wenn Tertullian seinen Traktat hier abschließen, bzw. die letzten, in den Kap. 38-43 enthaltenen Nebenargumente hier sofort anfügen würde. Aber weit davon entfernt, benutzt er die Gelegenheit, das aus seiner scharfsinnigen Untersuchung gewonnene Endergebnis, wonach die Heilige Schrift allein den apostolischen Gemeinden gehört, seinem Leser noch recht bildhaft einzuprägen. Und hier meldet sich nun in Tertullian spontan der Jurist. Wie könnte er, der Jurist, obige Wahrheit denn besser einhämmern als eben unter den Vorstellungen und der Sprache des Rechtes. Hat er sich also soeben noch ganz allgemein ausgedrückt : die Heilige Schrift geht die Häretiker nichts an, so geht er nun zur juristischen Terminologie über: die Häretiker gewinnen als Nichtchristen kein Recht an den christlichen Schriften, d. h. der Heiligen Schrift : "Ita non Christiani nullum ius capiunt christianarum litterarum. " 5 Wenn die Häretiker sich trotzdem auf die Heilige Schrift

1 Praescr. haer. 37 (Kr. 47, 7).

2 Vgl. praescr. haer. 19 ; dazu oben S. $45 \mathrm{ff}$.

3 Praescr. haer. 37 (Kr. 47, 5).

4 Praescr. haer. 15 (Kr. 20).

5 Praescr. haer. 37 (Kr. 47, 9). "Capere" in der Bedeutung von erwerben, bes. erwerben durch Ersitzung, ist ein ausgesprochen juristischer Terminus; vgl. Heumann-Seckel, Handlexikon 5/ f., "Vocabularium Iurisprudentiae Romanae ", Bd. 1 Kol. 616 ff. 
berufen, ja sich sogar durch Streichen, Interpolieren und eigenmächtige Interpretation an ihr vergreifen, so kommt dies einer gröblichen Verletzung fremder Rechte gleich. Um nun dieses rechtswidrige Vorgehen der Häretiker möglichst plastisch vor Augen zu führen, vergleicht Tertullian die Heilige Schrift mit einem Grundstück, in das die Häretiker gewalttätig einbrechen.

Wir lassen den betreffenden Text in praescr. haer. 37 selber sprechen :

"Ita non Christiani nullum ius capiunt Christianarum litterarum, ad quos merito dicendum est: Qui estis? quando et unde venistis ? quid in meo agitis, non mei ? quo denique, Marcion, iure silvam meam caedis ? qua licentia, Valentine, fontes meos transvertis? qua potestate, Apelles, limites meos commoves? Quid hic, ceteri, ad voluntatem vestram seminatis et pascitis ? Mea est possessio, olim possideo, prior possideo, habeo origines firmas ab ipsis auctoribus, quorum fuit res. Ego sum heres apostolorum. Sicut caverunt testamento suo, sicut fidei commiserunt, sicut adiuraverunt, ita teneo. Vos certe exheredaverunt semper et abdicaverunt ut extraneos, ut inimicos. "

Die Häretiker sind, eben weil Häretiker, nicht Christen. Sie sind ausgeschlossen aus der christlichen Gemeinschaft : "non mei ". Wenn aber die Häretiker nicht zur christlichen Familie gehören, so nehmen sie auch nicht teil an den Rechten dieser Familie, auf unsern Fall angewendet, die Häretiker haben keine Rechte am "Grundstück der Heiligen Schrift ", weil dieses den Christen gehört. Die Häretiker, die sich an der Heiligen Schrift vergreifen, schalten und walten gleichsam nach Willkür auf fremdem Grund und Boden. Denn im Hinblick auf die Verschiedenheit in der Lehre und geistigen Herkunft sind die Häretiker für die Kirche eigentlich Fremdlinge, der "Grundbesitz der Heiligen Schrift » ist für diese, so gut wie die christliche Lehre als solche, "fremder Boden ". "Qui estis, wer seid ihr, ich kenne euch nicht, quid in meo agitis, non mei ${ }^{1}$, was treibt ihr also auf meinem Besitztum,

1 Bei "non mei " ist auf die patria potestas des röm. Familienrechts zu verweisen. Suus heißt der zur jemands Familie Gehörige, der Deszendent, der unmittelbar der väterlichen Gewalt des Erblassers untersteht. Vgl. Paulus dig. 38, $10,10,3$ : "Proximiores ex adgnatis sui dicuntur". Tertullian nennt also die Häretiker in der Sprache des röm. pater familias "non mei ", nicht zu seiner Familie, d. h. zur Kirche Gehörige. Denselben Gedanken enthält praescr. haer. 12 (Kr. 17,4), wo der Apologet die Häretiker als die " extranei ", die Glaubensgenossen, als "nostri " bezeichnet: "Quis servus cibaria ab extraneo, ne dicam ab inimico domini sui sperat ?... Quaeramus ergo in nostro et a nostris et de nostro." 
nachdem ihr ja gar nicht zu meiner Familie gehört ?", so ruft ihnen Tertullian mit Recht im Namen der Kirche zu, gleich dem Besitzer, der einen frechen Eindringling zur Rede stellt und von ihm einen Ausweis fordert.

"... quando et unde venistis?" In diesen Fragen klingt das Prinzip von der Priorität der Wahrheit und das Argument der Apostolizität des Ursprungs und der Sukzession an. Die Häretiker sind viel jüngern Datums als die apostolischen Gemeinden, daher : quando ... venistis ? ; sie haben ihre Lehre und Sendung nicht von den Aposteln, sondern von den Häresiarchen, daher : unde venistis ?

Im folgenden werden die drei bekanntesten und gefährlichsten Besitzstörer, von denen im Traktat mehrmals die Rede war, genannt: Marcion, Valentin und Apelles. Ohne die bildliche Ausdrucksweise, unter der die Übergriffe der drei Häresiarchen auf die Heilige Schrift geschildert werden, zu pressen, dürfen wir doch eine Charakterisierung der drei herauslesen. Marcion wird an erster Stelle und als der gewalttätigste geschildert : "quo denique, Marcion, iure silvam meam caedis ?" Marcion hat das Alte Testament verworfen. Das Neue Testament reduzierte er auf das Lukasevangelium (abzüglich Kindheitsgeschichte) und die ersten zehn Paulusbriefe. Aus diesem zusammengeschrumpften Rest tilgte er erst noch alle alttestamentlichen Zitate oder " judaisierenden Verfälschungen ". Von allen Häretikern ist Marcion am schonungslosesten verfahren mit der Bibel; er hat nach dem treffenden Vergleich Tertullians geradezu einen Wald gefällt.

Nach Marcion wird Valentin geschildert : "qua licentia, Valentine, fontes meos transvertis ? "In Valentin hat die spekulative hellenistische Gnosis ihren Höhenpunkt erreicht. Von seiner Einstellung zur Heiligen Schrift berichtet uns Tertullian nur so viel, daß er dieselbe anders auslege und, wie er sarkastisch bemerkt, zweifellos verbessere : "Valentinus aliter exponens et sine dubio emendans ... "1 Valentin vergreift sich am Quell des göttlichen Wortes, das aus der Heiligen Schrift fließt und vom unfehlbaren Lehramt in die Bahnen der richtigen Auslegung gelenkt wird. Valentin unterlegt dem Schriftwort seine gnostischen Ideen, er lenkt es gleichsam ab in die wirren Kanäle seiner gnostischen Spekulationen. Tertullians Bild ist deshalb gar nicht so abwegig : "Mit welcher Erlaubnis leitest du meine Quellen anders, Valentin ?"2

1 Praescr. haer. 30 (Kr. 38, 34).

2 Praescr. haer. 37 (Kr. 47, 13) : "qua licentia, Valentine, fontes meos transvertis ?" 
Von Apelles endlich heißt es : " qua postetate, Apelles, limites meos commoves ? "Etwas mehr als von Valentin berichtete unser Autor in Kap. 30 über Apelles. Er betonte besonders die engen Beziehungen des Apelles mit der Visionärin und Prophetin Philumene, deren Offen-

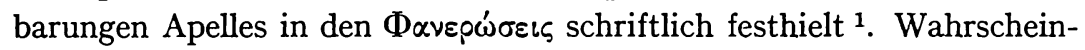

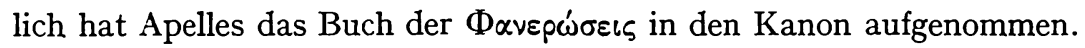
Dies könnte das Bild vom Verschieben der Grenzen, unter dem der widerrechtliche Versto $B$ des Apelles gegen den Grund und Boden der Heiligen Schrift beschrieben ist, vielleicht erklären: Apelles hat die Grenzen des Kanons verschoben.

Mit Marcion, Valentin und Apelles sind nur die bekanntesten und gefährlichsten "Besitzstörer " der Heiligen Schrift genannt. Von diesen war ja auch in den frühern Kapiteln von praescr. haer. hauptsächlich die Rede. Tertullian bemerkte in Kap. 30 über diese drei Häresiarchen : "Hos ut insigniores et frequentiores adulteros veritatis nominamus. " ${ }^{2}$ Außer diesen gebe es allerdings noch viele: "Ceterum et Nigidius nescio qui et Hermogenes et multi alii adhuc ambulant pervertentes vias domini. " ${ }^{3}$ An diese namenlose Menge der übrigen mehr oder weniger bedeutenden und bekannten Häresiarchen scheint sich der nächste Zuruf in Kap. 37 zu richten : "Quid hic, ceteri, ad voluntatem vestram seminatis et pascitis ? "Wenn das Treiben dieser Wahrheitsfälscher als ein Säen bezeichnet wird, denken wir an die Parabel vom Unkraut unter dem Weizen, auf die Tertullian sich in Kap. 31 beruft. Er spricht dort von der Häresie als dem Unkraut des ertraglosen Wildhafers, der nachträglich über den guten Getreidesamen des Gotteswortes gesät wird 4 .

Gegenüber den unter dem Bilde einer Besitzstörung geschilderten Übergriffen der Häretiker auf die Heilige Schrift macht Tertullian als Vertreter der Kirche seine Besitzerrechte geltend:

"Mea est possessio, olim possideo, prior possideo, habeo origines firmas ab ipsis auctoribus, quorum fuit res. Ego sum heres apostolorum etc. ")

Wir versuchen auch diese Sätze, getreu dem Ziele dieses 1. Teiles, vorerst so weit möglich nur aus dem Zusammenhang zu deuten. Er-

1 Vgl. praescr. haer. 30 (Kr. 37, 17).

2 Praescr. haer. 30 (Kr. 38, 37).

3 Praescr. haer. 30 (Kr. 38, 38).

4 Vgl. praescr. haer. 31 (Kr. 39, 1). 
innern wir uns wieder, daß die Argumente, die in den Kap. 22-34 die apostolischen Gemeinden als die alleinigen Inhaber der Offenbarung als solcher bekräftigen, auch für die Heilige Schrift Geltung haben. Diese Erkenntnis wird uns den Weg weisen. In der Tat spielt denn auch Tertullian in den folgenden Sätzen, die ja gerade sein ausschließliches Besitzerrecht am "Grundstück der Heiligen Schrift " beweisen sollen, wieder an jene frühern Argumente in den Kap. 22-34 an.

"Mea est possessio ", das "Grundstück der Heiligen Schrift " ist nicht euer, sondern mein Besitztum. Das soll nun bewiesen werden.

"olim possideo, prior possideo", ich, im Namen der Kirche sprechend, besitze die Heilige Schrift seit langem, längst, von alters her; und gerade weil ich sie von alters her, seit Menschengedenken besitze, besitze ich sie auch früher als ihr Häretiker, d. h. bevor ihr nur existiertet, um euch an derselben vergreifen zu können. Denn ihr seid ja bekanntlich viel spätern Datums als ich. "possideo" wird vielleicht zutreffender als historisches Praesens gedeutet : ich besa $\beta$ vor Zeiten, ich besa $B$ früher.

Die Worte " olim possideo, prior possideo " rufen mit unmißverständlicher Deutlichkeit das Prinzip von der Priorität der Wahrheit vor dem Irrtum in Erinnerung, welches in der Widerlegung der dritten Objektion (Kap. 27-34) ein Hauptargument darstellte. Es wurde dort geschichtlich nachgewiesen, daß die apostolischen Gemeinden früher existierten als alle sie bekämpfenden Sekten, was ebensosehr Zeugnis ablegt für die Wahrheit der von den apostolischen Gemeinden vertretenen Lehre, wie es alle übrigen Bekenntnisse als Irrtümer entlarvt. Wenn aber die apostolischen Gemeinden die Offenbarung als solche, in ihrer Ganzheit genommen, von jeher und zwar früher besitzen als die Häretiker, dann ipso facto auch den in der Heiligen Schrift niedergelegten Teil der Gesamtoffenbarung. Wie die Kirche also hinsichtlich der Offenbarung erklärt: ich besitze sie von jeher, lange bevor die heutigen Häretiker existierten, so berechtigt ist ihre Erklärung bezüglich der Heiligen Schrift: olim possideo, prior possideo. Das zweite ergibt sich aus dem ersten.

"habeo origines firmas ab ipsis auctoribus...". Die Vermutung liegt nahe, daß der Autor mit diesen Worten auf die Apostolizität des Ursprungs und der Sukzession anspielt, die der Apologet in Kap. 32 als endgültiges, stärkstes Argument dafür anführt, daß die apostolischen Gemeinden wirklich die ganze, unverfälschte Lehre der 
Apostel besitzen ${ }^{1}$. Nicht nur der Inhalt, schon die Formulierung weist auf Kap. 32 hin, wo die Worte stehn: "edant ergo origines ecclesiarum suarum, evolvant ordinem episcoporum suorum, ita per successionem ab initio decurrentem, ut primus ille episcopus aliquem ex apostolis vel apostolicis viris ... habuerit a uctorem et antecessorem. Hoc enim modo ecclesiae apostolicae census (= origines) suos deferunt "2. Die Apostel sind also schon in Kap. 32 mit dem der römischen Rechtssprache entlehnten Terminus auctores, d. h. Vorgänger im Rechte 3 genannt, und dies selbstverständlich im Hinblick auf die apostolischen Gemeinden, die ja von den Aposteln zu Hütern des Glaubensnachlasses bestellt wurden. $\mathrm{Da}$ Tertullian "auctor" an unserer Stelle wirklich als römisch-rechtlichen terminus technicus im angegebenen Sinn versteht, versichert er uns selber, indem er ausdrücklich beifügt : " ... auctorem et antecessorem ". Die apostolischen Gemeinden führen sich mittels ununterbrochener Bischofsreihen zurück bis auf die Apostel als ihre auctores et antecessores und beweisen so ihre Anfänge (origines) und ihre Lehre als apostolisch. Was aber für die Lehre als solche gilt, gilt ebenso sehr für die Heilige Schrift, die nur einen Teil der Lehre darstellend, von den Aposteln derselben Kirche übergeben wurde. Mit Recht erklärt daher die Kirche gegenüber den Häretikern mit Bezug auf die Heilige Schrift: meine Anfänge (origines), nämlich im Besitz der Heiligen Schrift, reichen direkt zurück auf die Rechtsvorgänger (auctores et antecessores), d.h. Apostel, denen die Sache gehörte (quorum fuit res), und von denen ich sie überkommen habe durch Erbschaft (ego sum heres apostolorum), wie gleich anschließend näher ausgeführt wird. Doch greifen diese Ausdrücke bereits ins römische Recht über; sie zu deuten, ist Aufgabe des 2. Teiles (B).

Wir dürfen übrigens mit diesem 2. Teil im folgenden sogleich beginnen. Denn die letzten, mit "Ego sum heres apostolorum " beginnenden Sätze des hier in Kap. 37 interessierenden Ausschnittes sind, wie der 2. Teil bestätigen wird, nur mehr eine juristische Weiterentfaltung des " habeo origines firmas ", dessen Grundgedanken wir bereits gedeutet haben. So ist denn die Aufgabe des 1. Teiles (A), Kap. 37 vorerst einmal aus dem Zusammenhang, d.h. Vorhergehenden zu erklären, erfüllt. Der Nachweis darf als erbracht gelten, daß hauptsächlich innerhalb des Abschnittes, der hinsichtlich der longi temporis

1 Vgl. praescr. haer. 32 (Kr. 39) und oben S. $73 \mathrm{f}$.

2 Praescr. haer. 32 (Kr. 39, 3).

3 Vgl. Heumann-Seckel, Handlexikon 43. 
praescriptio zu untersuchen ist (Ita non Christiani nullum ius capiunt ... bis ... et abdicaverunt ut extraneos, ut inimicos), sozusagen jeder Satz an frühere Ausführungen und Argumente anknüpft. So interessant diese Beobachtung an sich erscheint, sie enthüllt uns doch nur eine Selbstverständlichkeit, wenn wir - um hier wieder daran zu erinnern bedenken, daß der von Christus gebrachte Offenbarungsinhalt (traditio obiectiva) anfänglich nur mündlich in den Urzeugen existierte und als solcher den einzelnen Kirchen auch schon in seiner ungeschmälerten Ganzheit verkündigt wurde, bevor er in der Heiligen Schrift, wenn auch großenteils, so doch nicht erschöpfend, niedergelegt und denselben Gemeinden übergeben wurde. Die Apostel hatten demnach den sog. apostolischen Gemeinden bezw. den daselbst eingesetzten Bischöfen die ganze christliche Lehre übergeben, bevor sie denselben auch noch die Evangelien und Briefe schenkten. Mit Recht macht daher Tertullian dieselben Argumente, die er in den Kap. 22-34 für den Besitz der christlichen Lehre in ihrer Gesamtheit anführt, in Kap. 37 auch für den Besitz der Heiligen Schrift geltend.

\section{B. Die juristischen Elemente in Kap. 37}

Der erste Teil (A) hat versucht, Kap. 37 aus dem Zusammenhang zu deuten. Unter Zuhilfenahme der gewonnenen Ergebnisse treten wir an die eigentliche Aufgabe dieses Abschnittes: enthält Kap. 37 die longi temporis praescriptio ?

Fragen wir vorerst ganz allgemein: welches sind die allgemeinsten Indizien, die in Kap. 37 für das Vorhandensein der longi temporis praescriptio sprechen?

Zum ersten ist jedenfalls der Rah men vorhanden, innerhalb welchem die Einrede aus dem langen Besitz erhoben wird. Marcion, Valentin, Apelles und die übrigen Häretiker schalten und walten auf dem Grundstück, mit dem die Heilige Schrift verglichen wird, als ob dieses ihr Eigentum wäre. Man möchte an eine stürmische Gerichtsverhandlung denken, wenn Tertullian als Vertreter der Kirche ihnen das Widerrechtliche ihres Treibens vorhält: "Quid in meo agitis, non mei ? quo denique, Marcion, iure silvam meam caedis etc. ${ }^{1}{ }^{1}$ und wenn er, eben-

1 Im Anschluß an die "Besitzstörungen" der Häretiker sei auf das zwar verstümmelte aber für die longi temporis praescriptio doch aufschlußreiche Prozeßprotokoll in Pap. Paris. 69 verwiesen (siehe oben S. 33 [Nr. 5]). Einige Kläger aus Oberägypten stellen gegen den römischen Reiter Aurelius Serenus 
falls im Namen der Kirche, sein alleiniges Besitzerrecht am umstrittenen Grundstück geltend macht : "Mea est possessio, olim possideo, prior possideo, habeo origines firmas ab ipsis auctoribus, quorum fuit res etc. " Gerade diese letzten Sätze hören sich an wie eine Prozeßeinrede. ParTsch hat denn auch die longi temporis praescriptio gerade hier vermutet ${ }^{1}$.

Der hier fingierte Streit dreht sich um die Heilige Schrift unter dem Bilde eines durch die Häretiker verletzten Grundstückes. Dieser Umstand kann ebenfalls für die longi temporis praescriptio sprechen, denn diese war, wie ausgeführt wurde, in der ersten Zeit ihres Bestehens, also gerade zur Zeit, wo Tertullian seinen Traktat verfaßte, sehr wahrscheinlich nur auf Grundstücke anwendbar ${ }^{2}$.

Nicht unbeachtet darf weiter bleiben, daß ausdrücklich die Rede ist vom Besitz: "mea est possessio, olim possideo, prior possideo", nirgends von proprietas oder dominium. Wir wissen, daß die Einrede aus dem langen Besitz in ihrer ursprünglichen Gestalt - und das gilt ganz sicher für die Zeit der Abfassung von praescr. haer., wo diese Einrede erst wenige Jahre existierte - den Besitzer blo $B$ in seinem Besitze schützte, nicht aber zum Eigentümer der Sache machte. Tertullian gibt sich denn auch im Namen der Kirche gegenüber den Häretikern bloß als Besitzer, nicht Eigentümer der Heiligen Schrift aus.

Was nun weiter die Frage nach dem Vorhandensein der longi temporis praescriptio selber betrifft, so kann für die diesbezügliche Untersuchung nur jene Stelle in Kap. 37 in Frage kommen, wo Tertullian die Gründe anführt, die ihn als Besitzer der Heiligen Schrift bestätigen, wo er also gegen die Häretiker so etwas wie eine Prozeßeinrede erhebt :

"Mea est possessio, olim possideo, prior possideo, habeo origines firmas ab ipsis auctoribus, quorum fuit res. Ego sum heres

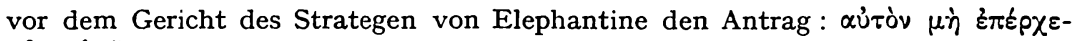
$\sigma \theta \alpha \iota \dot{\eta} \mu \tilde{i}$ (Zeile 25). J. Partsch ist der Auffassung, es handle sich hier um eine "Klage, sei es auf Unterlassung von Besitzesstörungen, die der beklagte römische Reiter, offenbar in der Behauptung, ihm stehe ein Recht an der streitigen Sache $z u$, vorgenommen hat, sei es auf Unterlassung einer Klage aus dem von ihm behaupteten dinglichen Rechte. " Vgl. J. Partsch, Die longi tem-

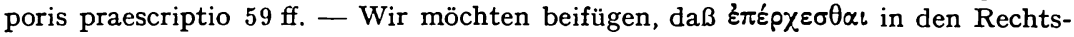
Papyri weit überwiegend in der Bedeutung von "widerrechtlich in einen Besitz eindringen" vorkommt, und dies in den mannigfachsten Abwandlungen : eindringen in Acker, Gehöft, Grund und Boden, Haus usw. Vgl. hierzu F. PReisigke, Wörterbuch der griechischen Papyrusurkunden, Bd. 1 (Berlin 1926) $536 \mathrm{f}$.

1 Vgl. J. Partsch, Die longi temporis praescriptio 76 u. 109.

${ }^{2}$ Siehe oben S. 34. 
apostolorum. Sicut caverunt testamento suo, sicut fidei commiserunt, sicut adiuraverunt, ita teneo. Vos certe exheredaverunt semper et abdicaverunt ut extraneos, ut inimicos."

Welche Elemente der longi temporis praescriptio lassen sich in diesem Abschnitt feststellen? Die Einrede aus dem langen Besitz ist die Berufung des beklagten Besitzers auf die Bestimmungen der kaiserlichen Konstitutionen, nämlich :

1. rechtsgültigen Erwerbsgrund,

2. Gutgläubigkeit,

3. erfüllte Ersitzungsfrist.

Waren diese Bestimmungen vom beklagten Besitzer erfüllt und bewiesen, wurde der Kläger vom Richter abgewiesen, mochte er auch sein Eigentümerrecht noch so einwandfrei beweisen.

Welche von diesen Voraussetzungen lassen sich nun in obiger "Prozeßeinrede" Tertullians nachweisen?

Um diese Frage zu beantworten, unterwerfen wir den betreffenden, die "Prozeßeinrede " Tertullians umfassenden Text einer genauen juristischen Analyse. Vor allem müssen natürlich die ganz eindeutig juristischen Ausdrücke : "Ego sum heres ... caverunt testamento ... fidei commiserunt ..." usw. des betreffenden Abschnittes erklärt und, soweit dies möglich ist, in ihrer Anwendung auf die Theologie gedeutet werden. Aber auch die ersten Sätze der "Prozeßeinrede ": "Mea est possessio, olim possideo, prior possideo, habeo origines firmas ab ipsis auctoribus, quorum fuit res ", müssen in diese Untersuchung einbezogen werden, obwohl sie bereits im ersten Teil (A) aus dem Zusammenhang bzw. Vorhergehenden gedeutet wurden. Denn Tertullian faßt in diesen Sätzen nicht bloß frühere Argumente (bes. Prinzip der Priorität der Wahrheit, Apostolizität des Ursprungs und der Sukzession) in gedrängtester Formulierung zusammen, sondern er verknüpft gerade mit dieser knappen Formulierung gleichzeitig juristische Vorstellungen, indem er an einzelne Bedingungen (Verfallfrist und rechtsgültigen Erwerbsgrund) der longi temporis praescriptio anspielt, wie die folgenden Untersuchungen mit großer Wahrscheinlichkeit dartun werden. Wir werden deshalb von Anfang an mit der juristischen Analyse des Textes die Frage nach den einzelnen Elementen der longi temporis praescriptio verbinden.

"Mea est possessio". Darum geht gerade der Streit: ist die Heilige Schrift wirklich Besitz der Kirche? Tertullian behauptet es. 
So wird der beklagte Besitzer zuerst ganz allgemein dem Kläger die Behauptung entgegengehalten haben, da $\beta$ das angeforderte Grundstück sein Besitz sei ${ }^{1}$. Aber diese Behauptung mußte bewiesen werden durch den Nachweis, da $B$ die Bedingungen zur Geltendmachung der longi temporis praescriptio erfüllt sind. Welche Beweise gibt Tertullian? "Olim possideo, prior possideo." Diese Worte stellen den ersten Beweis dar für die Behauptung: "mea est possessio". Das "Grundstück der Heiligen Schrift » ist mein Besitztum, denn ich besitze es seit langem, von alters her, daher auch früher als ihr Häretiker, denn ihr seid ja alle jüngern Datums als ich.

Was will nun Tertullian mit "olim possideo, prior possideo " sagen ? Auf Grund der prinzipiellen Überlegung des vorangegangenen ersten Teiles (A), wonach jene Argumente, die den apostolischen Kirchen den Besitz der christlichen Lehre in ihrer Gesamtheit bestätigen (Kap. 22-34), auch für die Heilige Schrift Geltung besitzen (Kap. 37), ferner auf Grund der im ersten Teil (A) durchgeführten Analyse der betreffenden Sätze in Kap. 37, sind wir zum Ergebnis gelangt, da 3 " olim possideo, prior possideo " das so ausführlich entwickelte Prinzip von der Priorität der Wahrheit hier in knappster Form für den Besitz der Heiligen Schrift geltend macht. Mit diesem Hauptgedanken verbindet sich nun aber allem Anschein nach die Vorstellung einer Verjährungsfrist zu Gunsten des Besitzes (possideo!) der Heiligen Schrift.

Mit " olim possideo, prior possideo " wird eine Frist geltend gemacht. Dürfen wir hier eine Nach- oder Umbildung der für die longi temporis praescriptio geforderten Frist erblicken?

Die Verfallfrist der longi temporis praescriptio beträgt 10 bzw. 20 Jahre. Sie beginnt zu laufen mit dem Augenblick des rechtsgültigen Erwerbs der betreffenden Sache. Nehmen wir nun an, der Erwerber habe sein Grundstück 50 Jahre und länger ungestört besessen, so braucht er sich im Fall eines gegen ihn angestrengten Prozesses von Rechts wegen doch nur über die letzten $10 \mathrm{bzw} .20 \mathrm{~J}$ a hre ungestörten, ununterbrochenen Besitzes auszuweisen. Wenn er sich über 50 Jahre ungestörten Besitzes auszuweisen vermag, kann dies ja einen Vorteil bedeuten, insofern eine über das gesetzliche Minimum umso weiter hinausgehende Frist (selbstverständlich neben der Erfüllung der andern Bedingungen, bes. des rechtsgültigen Erwerbsgrundes) das Recht des Beklagten auch umso eindeutiger zum Ausdruck bringt. Aber der

1 Vgl. J. Partsch, a. a. O. 68. 
Richter interessiert sich nur für die letzten $10 \mathrm{bzw}$. 20 Jahre, von der nun erfolgten Klageerhebung an rückwärts gerechnet. Hat der beklagte Besitzer die umstrittene Sache während dieser Zeitspanne unangefochten besessen (und sind auch die übrigen Bedingungen erfüllt), wird der Kläger abgewiesen. Der Erwerbsgrund, z. B. der Kauf, kann also viel weiter als bloß 10 oder 20 Jahre zurückliegen. Dieser, d. h. die Rechtsgültigkeit des Erwerbsgrundes, muß natürlich nachgewiesen werden, er mag nun noch so weit zurückliegen.

Was nun das "olim possideo, prior possideo " betrifft, kann es sich eben hier nur um eine ganz eigene, auf das "Grundstück der Heiligen Schrift " angepaßte Präskriptionsfrist handeln. Es ist zum vornherein klar, daß eine 10 oder 20jährige Frist hier nicht in Frage kommt. Denn die Kirche hat das "Grundstück der Heiligen Schrift " nicht erst vor 10 oder 20 Jahren erworben, sie besitzt dieselbe seit dem Augenblick, wo sie ihr von deren ersten Besitzern, den Aposteln, erstmalig und für immer ausgehändigt wurde, und zwar durch Testament, wie Tertullian in folgenden erklärt. Gerade diesen Gedanken scheint nun der Autor gegen die Häretiker zu betonen : die Kirche besaß die Heilige Schrift während der ganzen Zeit, die seit den Aposteln bis heute verflossen ist, also von alters her, von jeher (olim), und das schließt ipso facto ein, daß die Kirche sie auch besaß, bevor die Häretiker überhaupt existierten, um Ansprüche auf die Schrift erheben zu können (prior). Die Präskriptionsfrist wird also bis zu den Aposteln, bis zum Erwerbsgrund (Erbschaft von den Aposteln) zurück berechnet. Das ist die Frist, die für die Heilige Schrift in Frage kommt. Und gerade das soll ja bewiesen werden, daß die Heilige Schrift seit dem Augenblick, wo die Apostel sie aus den Händen gaben, sich stets im Besitz der Kirche befand.

"habeo origines firmas ab ipsis auctoribus, quorum fuit res". Der Besitzer, der den Rechtsschutz der longi temporis praescriptio für sich beansprucht, muß sich nach der Sprache der Quellen hauptsächlich über eine " $\delta$ เ $\left.\alpha i \alpha \alpha_{i} i \tau^{\prime} \alpha\right)^{1}$, einen rechtsgültigen Erwerbsgrund der zu präskribierenden Sache ausweisen. Das in den Straßburger Papyri überlieferte Prozeßprotokoll enthält statt " $\delta\left(x \alpha_{i}^{\prime} \alpha\right.$ aití " den Ausdruck

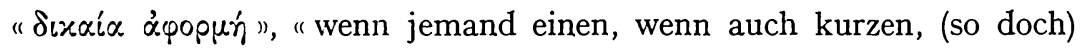
gerechten Anfang, Ausgangspunkt des Besitzes hat " ${ }^{2}$. Demselben

1 Vgl. C. G. Bruss, Fontes juris Romani antiqui, Pars prior, Leges et Negotia, Nr. 87. Zeile 8.

2 Papyrus Strassb. 22, Kol. I Zeile 20/1 (L. Mirreis, Chrestomathie der

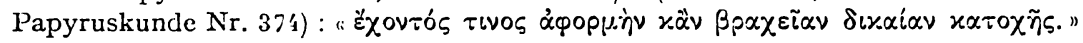


Gedanken begegnen wir beim zeitgenössischen Juristen Paulus, der den rechtsgültigen Erwerbsgrund mit "iustum initium possessionis " 1 wiedergibt. In den Konstitutionen ist das "iustum initium possessionis " sogar so häufig, daß PARTSCH zur Auffassung gelangt, der Ausdruck müsse aus jenen ältesten, nicht mehr vorhandenen Rechtsquellen stammen, die von der longi temporis praescriptio handeln ${ }^{2}$.

Unter diesen Voraussetzungen drängt sich die Vermutung auf, Tertullian gebe mit " habeo origines firmas ... " das "iustum initium "

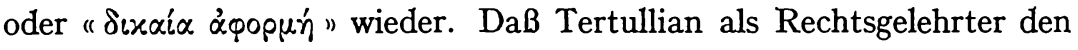
Wortlaut der ursprünglichen Konstitution, die das Rechtsinstitut der longi temporis praescriptio promulgierte, kannte, daran kann man wohl kaum zweifeln, umso weniger, wenn man bedenkt, daß die betreffende Konstitution sehr wahrscheinlich nur wenige Jahre vor der Abfassung von praescr. haer. erlassen wurde und für die Rechtsstellung der Provinzialen von großer Bedeutung war ${ }^{3}$.

Wirft vielleicht der Wortgebrauch von "origo " und "firmus " bei den zeitgenössischen Juristen mehr Licht auf unsere Frage?

"Origo" ist nicht ein eigentlich juristischer Terminus. Origo kann den originären Erwerb bezeichnen 4, der aber für unsern Fall nicht in Frage kommt, denn die apostolischen Gemeinden haben die Heilige Schrift von den Aposteln als ihren auctores, d. h. durch derivativen Erwerb erhalten. Natürlich kommt origo in den Juristenschriften auch vor in der bekannten Wendung von : originem habere, ducere, trahere ab aliquo ; so spricht der Jurist Paulus einmal von : originem trahere ex contractu ${ }^{5}$. Es ist, in Rücksicht auf das folgende (ego sum heres) denkbar, daß Tertullian sein: "habeo origines firmas ab ipsis auctoribus ... " in dem Sinn versteht : meine rechtsgültigen Anfänge im Besitz der Heiligen Schrift gehn zurück auf Erbeinsetzung durch die Apostel. Eine sichere Erklärung unserer Stelle ist aber aus dem Wortgebrauch von origo bei den Juristen nicht möglich.

"Firmus " ist der römischen Rechtssprache sehr geläufig unter der Bedeutung von " gültig ", " rechtsbeständig ", "fest " ${ }^{6}$. So finden wir in einem Reskript des Jahres 293 den Ausdruck "firmus titulus " : "im-

1 Vgl. J. Рartsch, a. a. O. 7 Anm. 4.

2 Ebd.

3 Siehe oben S. 31.

4 Vgl. Heumann-Seckel, Handlexikon 398.

5 Paulus dig. 44, 7, 11.

6 Vgl. Heunann-Seckel, a. a. O. 217. 
proba possessio firmum titulum possidendi nullum praestare potest $"{ }^{1}$. "Firmus titulus" steht hier gleichbedeutend für " iustus titulus ", oder " iusta causa ", den rechtsgültigen Erwerbsgrund. Aber schließlich ist ein solches Beispiel zu vereinzelt, um für unsere Stelle einen Schluß zu gestatten.

Folglich verhält es sich auch mit dem " habeo origines firmas " gleich, wie mit dem "olim possideo ....". Zuerst und hauptsächlich versteht Tertullian die Worte "habeo origines firmas" als eine auf die kürzeste Form gebrachte Wiederholung des Nachweises der Apostolizität des Ursprungs und der Sukzession, wie der vorhergehende erste Teil (A) glaubhaft machte. Und in zweiter Linie verbindet er damit die Vorstellung an den rechtsgültigen Erwerbsgrund. Doch lassen die Worte " habeo origines firmas " selber auf diese Vorstellung vom rechtsgültigen Erwerbsgrund nicht schließen, sie lassen diese Vorstellung höchstens vermuten. Es sind vielmehr andere Umstände, die diese Vermutung zur großen Wahrscheinlichkeit erheben. Denken wir nur an den ganzen Rahmen und die andern Gründe, die für die longi temporis praescriptio sprechen ${ }^{2}$. Den entscheidenden Anstoß aber müssen die auf « habeo origines firmas ... folgenden Sätze geben : "Ego sum heres apostolorum etc. " Hier ist ja gerade die Rede vom Erwerbsgrund, nämlich Erbschaft. Was also mit "habeo origines firmas ..." nur angedeutet wird, fände hier seinen unmißverständlichen Ausdruck.

Diese rechtsbeständigen Anfänge, oder konkret der rechtsgültige Erwerbsgrund - wenn wir "origines firmas " so übersetzen wollen von dem die Kirche ihren Besitz am "Grundstück der Heiligen Schrift " ableitet, geht zurück bis auf die Apostel. Die Apostel haben der Kirche die Schrift sozusagen testamentarisch vermacht, wie es im folgenden heißt (caverunt testamento suo). Die Apostel werden deshalb als " auctores, quorum fuit res " bezeichnet. Wer, ganz allgemein gesprochen, ein ihm zustehendes Recht auf einen andern übertragen hat, z. B. der Verkäufer, heißt in der Sprache des Rechtes auctor; der auctor ist der Vorgänger im Recht ${ }^{3}$.

"Ego sum heres apostolorum." Mit diesen Worten wird nun der Erwerbsgrund klar und deutlich genannt. Die Kirche ist Erbe der Apostel, sie besitzt die Heilige Schrift als eine von den Aposteln überkommene Erbschaft. Den Sinn dieser Worte muß uns das römische

1 Cod. 7, 32, 7.

2 Siehe oben S. $111 \mathrm{f}$.

3 Vgl. Heumann-Seckel, a. a. O. 43. 
Erbrecht erschließen ${ }^{1}$. Dieses unterscheidet zwischen Erbe (hereditas) und Vermächtnis (legatum und fidei-commissum). Während der Vermächtnisnehmer nur einzelne Vermögensgegenstände zugewendet erhält, erwirbt der Erbe das Erbgut als Ganzes und auf einmal. Der Erbe ist sog. Gesamtnachfolger des Erblassers, er tritt an dessen Stelle und übernimmt alle seine Eigentums- und Schuldverhältnisse. Wenn nun Tertullian mit seiner juristischen Bildung sich im Namen der Kirche als heres apostolorum bezeichnet, will er damit jedenfalls unterstreichen, da $\beta$ die Kirche im Besitz der Heiligen Schrift an die Stelle der Apostel getreten, daß sie dieselbe in ihrer ungeschmälerten Ganzheit, mit ihren angenehmen und weniger angenehmen Wahrheiten, gleichsam mit allen Rechten und Lasten von jenen übernommen hat, und daß sie die Heilige Schrift mit der Autorität der Apostel hütet und auslegt.

"Sicut caverunt testamento suo." Die Ausdrucksweise : " cavere testamento oder in testamento", testamentarisch oder im Testament verfügen, ist den bekanntesten klassischen und spätklassischen Juristen sehr geläufig 2. Der Satz: "Sicut caverunt testamento suo » vervollständigt den vorangehenden : "Ego sum heres apostolorum. "Wir sollen hier vernehmen, auf welche Weise die Kirche Erbe der Apostel wurde. Nach römischem Erbrecht wird einer Erbe entweder von selbst durch Geset $z$ (sog. Intestaterbfolge), oder durch letztwillige Verfügung des Erblassers, d. h. durch Testament (sog. testamentarische Erbfolge). Mit den Worten : "Sicut caverunt testamento suo " soll also offenbar hervorgehoben werden, daß es der ausdrückliche, persönliche letzte Wille der Apostel war, der die apostolischen Gemeinden in den Besitz der Lehre als solcher und damit der Heiligen Schrift einsetzte.

"... sicut fidei commiserunt ..." Das römische Recht kennt zwei Formen des Vermächtnisses: das altbekannte legatum und das jüngere, erst in der Kaiserzeit ausgebildete fideicommissum. Das Fideikommiß ${ }^{3}$ konnte, wie das Legat, schriftlich, d. h. in Testament und Kodizill (letzteres eine freiere Art letztwilliger Verfügung als das Testament), aber auch bloß mündlich errichtet werden. Das Fideikommiß ist die Bitte des Erblassers, einem Dritten etwas zuzuwenden. Eine

1 Vgl. Jörs-Kunkel-Wenger, Röm. Recht § $195 \mathrm{ff}$.

2 Vgl. "Vocabularium Iurisprudentiae Romanae", Bd. 1, 648.

3 Vgl. Jörs-Kunkel-Wenger, a. a. O. § 225 ; ferner K. CzYhlarz-M. SAN Nicolo, Lehrbuch der Institutionen des römischen Rechtes, 18. neub. Aufl. (Wien-Leipzig 1924) § 142. 
solche Bitte war ursprünglich nicht rechtsverbindlich, ihre Erfüllung war lediglich der fides des Gebetenen (Fiduziar) anvertraut, daher fidei commissum. Erst unter Augustus und seinen Nachfolgern erlangte das Fideikommiß Rechtsverbindlichkeit, indem der vom Erblasser Bedachte (Fideikommissar) gegen den Fiduziar, der seiner Verpflichtung nicht nachkam, gerichtlich vorgehen konnte.

Der Erblasser konnte jeden, der von Todes wegen etwas von ihm erhielt, mit einem Fideikommi $\beta$ belasten (d. h. ihn verpflichten, die ererbte Sache, oder einen Teil derselben, an einen Dritten weiterzugeben), also nicht blob den Testamentserben, den Intestat- oder gesetzlichen Erben, sondern auch den Legatar, ja selbst wieder den Fideikommissar und die Erben dieser Personen. So kann auf dem Wege des Fideikommisses verfügt werden, daß die vermachte Sache nach dem Tode des ersten Fideikommissars an einen zweiten, dann dritten usw. übergehen solle. Das ist z. B. der Fall beim FamilienfideikommiB, welches verfügt, daß das vermachte Vermögensstück bei einer bestimmten Familie verbleiben solle.

Tertullian spricht an unserer Stelle im Anschluß an das Testament vom Fideikommiß. Das soll wohl andeuten, daß die Apostel dieses Fideikommi $\beta$ an der Heiligen Schrift gleichsam in einem Testament, also schriftlich (eben in der Heiligen Schrift selber) und nicht nur mündlich errichtet haben. Einen viel tiefern Sinn birgt sodann das Bild vom Fideikommiß selber. Tertullian hält den Häretikern im Namen der Kirche entgegen, da $B$ die Apostel ein Fideikommi $B$ errichtet hätten, auf Grund dieses Fideikommisses besitze er die Heilige Schrift. Die Apostel haben also den Testamentserben, dem sie die Heilige Schrift vermachten, mit einem Fideikommi $B$ belastet, $d . h$. ihn verpflichtet, die Heilige Schrift wieder weiterzugeben. Wer anders ist aber dieser Testamentserbe der Apostel, als die apostolischen Gemeinden, die Kirche. Dieser Testamentserbe, die Kirche, soll die Heilige Schrift weitergeben. Die Kirche gibt sie aber auch, ausgestattet mit dem Beistand des Heiligen Geistes (vgl. hierzu Kap. 28, wo vom Wirken des Heiligen Geistes in der Kirche die Rede ist), wie die gesamte Lehre, von der ja die Schrift nur einen Teil darstellt, unversehrt an alle kommenden Generationen weiter. So hat z. B. auch die afrikanische Gemeinde, wann, wissen wir nicht genau, von ihrer römischen Mutterkirche mit der wahren Lehre auch die echte Heilige Schrift erhalten. Mehr dürfen wir in Tertullians Vergleich vom Fideikommiß wohl nicht suchen. 
"... sicut adiuraverunt ...". Dieses Wort scheint an eine Gepflogenheit des Prozeßrechtes anzuspielen. Sowohl im Formularwie Kognitionsproze $\beta$ konnte oder mußte der Kläger oder Beklagte in bestimmten Fällen das Vorhandensein bzw. Fehlen eines Tatbestandes mit einem Schwur bekräftigen. Der Schwur hatte den Wert eines Beweismittels, in bestimmten Fällen ersetzte er sogar das Urteil, d. h. er bewirkte den sofortigen Abbruch des Prozesses ${ }^{1}$. - Unsere Stelle besagt kaum etwas anderes als dies: die Apostel haben gleichsam mit einem Schwur, was wohl nur heißen will, feierlich und in aller Form, bestätigt und bekräftigt, daß die Heilige Schrift den apostolischen Gemeinden gehört. Ohne Tertullians Vergleich zu pressen, darf man hier füglich an jene nicht seltenen Stellen in den Apostelbriefen denken, wo die Apostel die Wahrheit der von ihnen verkündigten Lehre eindrücklich bezeugen und ihre Gemeinden vor den verschiedensten Irrlehren warnen. $\mathrm{Da} B$ aber die Lehre der apostolischen Gemeinden auch zur Zeit Tertullians identisch ist mit der Lehre der Apostel, dafür sollten die Kap. 20-36 gerade den Beweis erbringen. Besonders leistete hierzu Kap. 33 einen wertvollen Beitrag, wo die zahlreichen Berührungspunkte aufgezeigt werden, die die zeitgenössischen Häresien mit jenen ältesten, von den Aposteln noch persönlich verurteilten Häresien gemein haben. So bestätigen und anerkennen eigentlich die Apostel auch die Lehre der apostolischen Gemeinden des ausgehenden 2. Jahrh. feierlich und ausdrücklich als die ihrige. Wer sich aber im Besitze der echten Glaubens- und Sittenlehre befindet, der verfügt auch über die echte Heilige Schrift, um auch an dieser Stelle wieder an die im Kap. 19 ausgesprochene grundlegende und richtungweisende Wahrheit von ganz praescr. haer. zu erinnern. Wem die Apostel das eine bestätigen, den versichern sie implicite auch des andern.

"Vos certe exheredaverunt semper..." Nach dem klassischen Zivilrecht der Römer hat der paterfamilias das freie Recht, zu enterben, wen immer er will. Die Enterbung ist jedoch an bestimmte Formvorschriften gebunden : a) sie muß sich immer auf die ganze Erbschaft beziehen; $b$ ) sie muß mit bestimmten feierlichen Worten (z. B. exheres esto) angeordnet sein. Söhne müssen nominatim, also unter individueller Bezeichnung enterbt werden, sonst ist das Testament ungültig ${ }^{2}$. - Sowohl das eine wie das andere trifft im übertragenen Sinne

1 Vgl. L. Wenger, Institutionen des röm. Zivilprozeßrechts $114 \mathrm{ff}$. u. $275 \mathrm{f}$.

2 Vgl. Jörs-Kunkel-Wenger, a. a. O. $\$ 208$; ferner K. Czyhlarz, a. a. O. $\S 132$. 
für die Häretiker zu. Sie sind von den Aposteln bezüglich der gesamten Lehre enterbt, indem die Apostel die ganze, ungeteilte Lehre nur den apostolischen Gemeinden übergeben haben, wie Kap. 20 und besonders die Widerlegung der zweiten und dritten gegnerischen Objektion (Kap. 25-34) bewiesen haben. Mit der Lehre in ihrer Gesamtheit sind aber die Häretiker ipso facto auch der Heiligen Schrift enterbt. - Aber auch die letzte, für die Enterbung geltende Vorschrift paßt auf die Häretiker : sie sind von den Aposteln nominatim verurteilt und dadurch von den Erbrechten der Kirche an der Offenbarung ausgeschlossen. Erklärt doch Tertullian in seinem meisterhaften Dilemma in Kap. $34^{1}$, nachdem er in Kap. 33 die Verwandtschaft der modernen Häresien mit jenen frühern, schon von den Aposteln verurteilten nachgewiesen hat, daß die Häresien der Gegenwart von den Aposteln "in sua nominatione damnantur " ${ }^{2}$. Denn es sei (um den Gedankengang des betreffenden Dilemmas in etwas freierer Form wiederzugeben) gleichgültig, ob die Häresien der Gegenwart dieselben seien, die schon in der Apostelzeit existierten, oder ob sie in etwas verfeinerter Form erst später aufgekommen seien, Hauptsache sei die ganz offensichtliche Verwandtschaft der modernen Häresien mit jenen der Apostelzeit, wodurch sie von den Aposteln selber, eben "in sua nominatione ", verurteilt seien. Sind aber die Häretiker vom Erbe der geoffenbarten Wahrheit als solcher nominatim ausgeschlossen, dann gilt diese namentliche, individuelle Enterbung auch für die Heilige Schrift, die ja nur einen Teil der Gesamtoffenbarung ausmacht.

"... et abdicaverunt ...". Der Gedanke der exheredatio wird noch verstärkt durch die abdicatio. Die Apostel haben die Häretiker nicht nur enterbt, sie haben sich von ihnen förmlich losgesagt. "Abdicatio " bedeutet ganz allgemein ein Verhalten, durch welches sich jemand von etwas lossagt, z. B. von einem Amte, von der Erbschaft oder von der gens. Abdicatio kann aber auch die nach griechischem

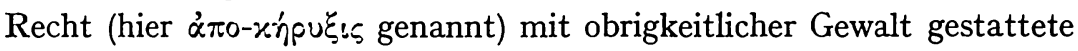
Aufkündigung der väterlichen Gewalt gegenüber ungeratenen Kindern, kurz die Verstoßung eines Kindes bezeichnen ; im römischen Recht galt diese Form der abdicatio wahrscheinlich nicht ${ }^{3}$.

Wahrscheinlicher ist, daß Tertullian das abdicare unserer Stelle im letztern, strengern Sinn versteht. Die Apostel haben den Häretikern

1 Vgl. praescr. haer. 34 (Kr. 43) und oben S. 74.

2 Praescr. haer. 34 (Kr. 44, 22).

3 Vgl. Pauly-Wissowa, Real-Encyclopädie, Bd. 1 Kol. 24. 
gleich ungeratenen Söhnen die Gewalt gekündigt, sie aus der Familiengemeinschaft der Kirche ausgestoßen (non mei!), enterbt und, wie Paulus (1. Tim. 1, 20) von Hymeneus und Alexander berichtet, dem Satan ausgeliefert.

"... ut extraneos, ut inimicos ". Die Apostel haben die Häretiker enterbt und verstoßen "ut extraneos, ut inimicos ". Das römische Erbrecht unterscheidet zwischen heredes domestici (Sohn, Tochter, gewaltunterworfene Ehefrau, Enkelkinder, ebenso testamentarisch freigelassene und zu Erben eingesetzte Sklaven) und heredes extranei, worunter alle übrigen Erben zu verstehen sind ${ }^{1}$. In der Regel setzt ein Erblasser seine nächsten Angehörigen, wenn er solche hat, zu Erben ein (heredes domestici). Dann kommen andere (heredes extranei) gar nicht in Frage. Wenn nun der Erblasser einen seiner Söhne enterbt, stellt er diesen rechtlich sozusagen auf die Stufe der extranei. Denn der enterbte Sohn geht gerade so leer aus wie die extranei, die für den Fall, wo der Erblasser Söhne hat und diese zu Erben einsetzt, als heredes nicht in Betracht kommen. - So haben die Apostel die Häretiker, ihre ehemaligen Söhne, von den Erbrechten der Kirche ausgeschlossen. Nun teilen sie, rechtlich gesehen, dasselbe Los wie die Außenstehen den (extranei), d. h. Juden und Heiden, die keinen Anteil haben an den Rechten der Kirche. Überdies sind ja die Häretiker, gleich den Juden und Heiden, die Feinde der Kirche (ut inimicos!). Ist es aber einem Erblasser je eingefallen, seinen Feind zum Erben einzusetzen ?

Fassen wir die Ergebnisse der Analyse kurz zusammen : Mit " olim possideo, prior possideo " spielt Tertullian sehr wahrscheinlich auf die Präskriptionsfrist an, mit "habeo origines firmas ... " auf den rechtsgültigen Erwerbsgrund. Während es aber mit "olim possideo, prior possideo " sein Bewenden hat, wird der Gedanke des "habeo origines firmas ..." weiter entfaltet. Denn in den Worten: "Ego sum heres apostolorum" erfahren wir den Erwerbsgrund, von dem in "habeo origines firmas " nur allgemein die Rede war. Diese Erbschaft beruht auf einem Testament, d. h. einer letztwilligen Verfügung der Apostel. Dieses Testament ist mit einem Fideikommiß belastet, $d$. $h$. die apostolischen Gemeinden müssen die Heilige Schrift weitergeben. Die Häretiker wurden von den Aposteln enterbt und verstoßen.

Wie sich aus den bisherigen Darlegungen ergibt, wird nur an zwei Bedingungen der longi temporis praescriptio angespielt, an die Frist

1 Vgl. Jörs-KunKEL-WENGER, a. a. O. $\$ 211 / 2$. 
und den Erwerbsgrund. Von einer Berufung auf die bona fides gegen die Häretiker bemerken wir nichts. Doch stellt dies keine ernsthafte Schwierigkeit dar. Es ist die Auffassung namhafter Autoritäten, da $B$ die bona fides in den ältesten Quellen der longi temporis praescriptio nicht gefordert wird, während andere erklären, sie sei schon in den ältesten Quellen im Erfordernis der " $\delta \iota \alpha^{i} \alpha \alpha \alpha_{i} \tau^{\prime} \alpha$ ) miteingeschlossen ${ }^{1}$. Es ist wohl denkbar, daß Tertullian von der bona fides schweigt, d. h. nicht auf sie anspielt, weil sie eben um 200 herum noch nicht erfordert war, und es ist ebenso denkbar, daß er in der Anspielung auf den rechtsgültigen Erwerbsgrund auch die bona fides einschließt. Ausgeschlossen ist auf jeden Fall, daß Tertullian von seiner bzw. von der Gutgläubigkeit der Kirche im Besitz der Heiligen Schrift (wie der Lehre als solcher) nicht zutiefst überzeugt gewesen wäre. Es sei nur an Kap. 31 erinnert, wo den Häretikern das gute Gewissen im Kampf für ihre Sache abgesprochen wird ${ }^{2}$.

Es besteht aber noch eine andere Schwierigkeit : besitzen die apostolischen Gemeinden die christliche Lehre als solche und folglich auch die Heilige Schrift vielleicht, juristisch ausgedrückt, a non domino ?

Es ist nämlich nicht ausgeschlossen, daß der Kläger wirklicher Eigentümer des angeforderten Grundstückes ist und daß er sein Eigentümerrecht klipp und klar nachzuweisen vermag. Trotzdem wird er vom Richter abgewiesen, wenn für den Beklagten die Bedingungen der longi temporis praescriptio erfüllt sind. Der Eigentümer hat einen widerrechtlichen Zustand so und so lange mitangesehen, ohne etwas zu unternehmen, ohne die Präskriptionsfrist mit seiner Klage zu unter-

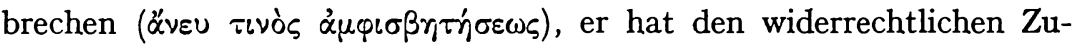
stand nach der Vorstellung des Rechtes stillschweigend anerkannt und muß ihn nun auch in Zukunft gelten lassen.

Wenden wir diese Möglichkeit auf unsern Fall an : waren vielleicht die Apostel, in der Rechtssprache ausgedrückt, in Wirklichkeit nicht Eigentümer der christlichen Lehre ? Wir denken hier an die 1. Objektion der Häretiker, die Apostel hätten nicht die ganze christliche Lehre besessen, weil Christus ihnen nicht die ganze Lehre mitgeteilt habe ${ }^{3}$. Die apostolischen Gemeinden besäßen dann ihre Lehre und damit die Heilige Schrift a non domino, d.h. sie hätten eben nicht die wahre

1 Siehe oben S. 43 Anm. 1.

2 Vgl. praescr. haer. 31 (Kr. 39, 10) und oben S. 69 Anm. 4.

3 Siehe oben S. $57 \mathrm{ff}$. 
Lehre und echte Schrift. Durch noch so gutgläubige Erbschaft und lange Besitzdauer wird aber der Irrtum nicht zur Wahrheit.

Es scheint, daß Tertullian dieser Schwierigkeit im voraus begegnen wollte, sonst würde er nicht mit so viel Nachdruck betonen, daß die Heilige Schrift den Aposteln gehörte : "... ab ipsis auctoribus, quorum fuit res." Ebenso eindrücklich wurde bei der Entfaltung des Prinzips von der Priorität der Wahrheit vor dem Irrtum bezüglich der Lehre der apostolischen Gemeinden in Kap. $35^{1}$ erklärt :

"Posterior nostra res non est... Apostolis non damnatur (scil. nostra res), immo defenditur: hoc erit indicium proprietatis (scil. apostolorum). Quam (scil. rem) enim non damnant qui extraneam quamque damnarunt, suam ostendunt ideoque et defendunt."

Das ist eine ausgesprochen juristische Terminologie. Die Lehre der Kirche wird kurz als "res " bezeichnet, ganz offensichtlich im Anschluß an das Sachenrecht. Diese Lehre wird wie eine Sache von den Aposteln als ihr Eigentum verteidigt. Proprietas, defendere, damnare sind hier ohne Zweifel der Rechtssprache entnommen.

Interessant ist nun für unsere Frage, daß der juristisch formulierte Grundgedanke voriger Stelle, die Lehre der apostolischen Gemeinden sei Eigentum der Apostel, in Kap. 37 wiederkehrt und dies sogar unter Anwendung desselben Ausdrucks "res": quorum (scil. apostolorum) fuit res. In Kap. 35 bezeichnet "res» die christliche Lehre in ihrer Gesamtheit, in der kurz darauf folgenden Stelle von Kap. 37 bezeichnet res sehr wahrscheinlich dieselbe Gesamtheit der Lehre, und nicht bloß den in der Heiligen Schrift niedergelegten Teil derselben. Denn wenn (entsprechend der schon oft betonten, grundlegenden Wahrheit in praescr. haer.) die Apostel die Lehre in ihrer Gesamtheit ihr Eigen nannten, dann ebensosehr die Heilige Schrift, in der ein großer Teil eben dieser Lehre schriftlich niedergelegt ist.

Die Apostel sind also mit aller Deutlichkeit als Eigentümer der Heiligen Schrift ausgegeben. Aus dieser Tatsache wird weiter verständlich, warum der Autor mit keinem Wort etxra bemerkt, er, d. h. die Kirche, habe die Heilige Schrift ohne jede Anfechtung, - in der Sprache

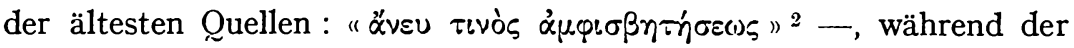

1 Praescr. haer. 35 (Kr. 45, 10).

2 C. G. Bruns, Fontes iuris Romani antiqui, Pars prior, Leges et Negotia, Nr. 87. Zeile 9. 
Präskriptionsfrist besessen. Es ist doch genugsam bekannt, wie die Häretiker der Kirche den Besitz der Wahrheit als solcher, besonders der Schrift, von jeher streitig machten.

Diese Tatsache bildet jedoch keine Schwierigkeit für die Anwendung der longi temporis praescriptio in unserm Fall. Denn nur die Anfechtung, Klage des berechtigten Eigentümers unterbrach die Präskriptionsfrist ${ }^{1}$. Es steht aber fest, daß die Apostel und nach ihnen die apostolischen Gemeinden als die allein rechtmäßigen Inhaber der Offenbarung zu gelten haben. Die Häretiker mochtẹn also die Kirche belästigen so viel sie wollten, sie konnten ihr nichts anhaben, denn die wahre Lehre ist und war nie Eigentum der Häretiker.

Aber was hat dann die Erhebung der longi temporis praescriptio gegen die Häretiker noch für einen Sinn, wenn diese der Kirche ja doch nichts anhaben können? Sie hat den und nur den Sinn, die Ansprüche der Häretiker auf die Heilige Schrift ein für allemal abzuweisen. Es sei daran erinnert, daß die Einrede aus dem langen Besitz in ihrer ursprünglichen Gestalt - und das gilt ganz sicher für die Zeit Tertullians ${ }^{2}$ - nur den, berechtigten oder unberechtigten ${ }^{3}$, Anspruch des Klägers abweist, d. h. den Beklagten in seinem Besitz schützt, nicht aber den beklagten Besitzer (wenn tatsächlich nicht dieser, sondern der Kläger Eigentümer der umstrittenen Sache ist) in den Eigentümer verwandelt. Die longi temporis praescriptio ist, kurz gesagt, zur Zeit Tertullians noch kein Ersitzungsinstitut. Diese Tatsache vereinfacht unsere Frage bedeutend. Es geht in Kap. 37 nicht um die Ersitzung der Heiligen Schrift, auch nicht um die Sicherstellung vor den vielleicht doch berechtigten Ansprüchen der Häretiker. Die Erhebung, oder besser Anspielung auf die longi temporis praescriptio in Kap. 37 hat vielmehr nur den Sinn, die Ansprüche der Häretiker, die zudem nachgewiesenermaßen unberechtigt sind (denn das ausschließliche Eigentümerrecht der Kirche an der Heiligen Schrift steht fest) ein für allemal abzuweisen. Tertullian bzw. die Kirche möchte ein für allemal Ruhe haben von ihren Belästigungen.

Abschließend sei eine möglichst gedrängte Zusammenfassung der Ergebnisse unseres zweigeteilten Abschnittes (A und B) geboten.

1 Siehe oben S. 34 (3).

2 Siehe oben S. 35.

${ }^{3}$ Ob die Ansprüche des Klägers berechtigt seien oder nicht, der Richter weist den Kläger in jedem Fall ab, wenn für den Beklagten die Bedingungen der longi temporis praescriptio erfüllt sind. 
Kap. 19 hat erklärt : es muß nur festgestellt werden, auf welcher Seite die echte christliche Glaubens- und Sittenlehre als solche sich findet; die Lösung dieser Frage entscheidet zugleich, wer als rechtmäßiger Besitzer der Heiligen Schrift zu gelten hat. Diesem Programm entsprechend wird in den Kap. 20 sowie 22-34 (eventuell auch 36) zuerst der ebenso ausführliche wie gründliche Beweis erbracht, daß die christliche Lehre als solche, gesamthaft genommen, sich auf Seiten der apostolischen Gemeinden befindet. Folglich, so schließt Kap. 37 im Anschlu $B$ an die in Kap. 19 gegebene Erklärung, gehört die Heilige Schrift ebenfalls nur den apostolischen Gemeinden. Nun ist selbstverständlich, daß dieselben Argumente, die in den Kap. 20-36 für den Besitz der christlichen Lehre in ihrer Gesamtheit geführt werden, auch für den Besitz des in der Heiligen Schrift niedergelegten Teils dieser Gesamtlehre gelten. Eine genauere Prüfung der Argumente, die in Kap. 37 für den Besitz der Heiligen Schrift in gedrängtester Form (olim possideo ... habeo origines firmas) noch einmal angeführt werden, bestätigt denn auch sozusagen mit Sicherheit, daß es sich hier nur um eine meisterhaft zusammengefaßte Wiederholung jener frühern Argumente handelt. Soweit die Ergebnisse des 1. Teiles (A).

Mit diesen kurzgefaßten Argumenten verbindet nun aber Tertullian höchst wahrscheinlich - wir möchten es nicht als sicher behaupten die Vorstellung an die Bedingungen der damals ganz jungen longi temporis praescriptio. Das Ergebnis der Untersuchungen dieses 2. Teiles (B) auf die kürzeste Formel gebracht, dürfte es sich in Kap. 37 eher um eine Anspielung auf die longi temporis praescriptio handeln, als um eine Anwendung derselben. Es geht Tertullian nicht darum, zu Gunsten des Besitzes der Heiligen Schrift ein juristisches Argument zu liefern, sondern den bereits gesicherten Beweis in das Gewand eines juristischen Argumentes zu kleiden. Vorausgesetzt, daß die longi temporis praescriptio in Kap. 37 wirklich vorliegt, was doch höchst wahrscheinlich ist, ließe sich also auch für diese praescriptio dasselbe feststellen, was für die praescriptio im allgemeinen : Tertullian erfüllt ihre äußere Form mit theologischem Inhalt. 


\section{Wie viele Präskriptionen enthält praescr. haer.?}

Fast allgemein ist die Annahme, praescr. haer. enthalte drei Präskriptionen :

praescriptio veritatis (cc. 20-30)

praescriptio principalitatis (cc. 31-35)

praescriptio proprietatis (cc. $36-40$ )

Diese Dreiteilung ist so widerspruchslos durchgedrungen, daß sie in sozusagen allen Handbüchern und Abhandlungen wiederkehrt, die sich mit praescr. haer. mehr oder weniger befassen ${ }^{1}$. O. BARDENHEWER ${ }^{2}$ nimmt auch drei Präskriptionen an, doch möchte er in denselben nur eine Abwandlung der einen "Praescriptio novitatis " sehen, von der Tertullian im Hinblick auf praescr. haer. spricht ${ }^{3}$. U. HüntemanN endlich sucht vier Präskriptionen nachzuweisen 4.

Als erster scheint U. HÜNTEMANN die Dreizahl angefochten zu haben. Nach seinen eigenen Worten war es gerade das Ziel seiner Analyse, nachzuweisen, da $\beta$ diese bekannte Dreiteilung dem Geiste Tertullians fremd ist und mit dem vom Autor festgelegten Plan nicht übereinstimmt 5 . U. HÜntemanN geht ganz von der Analyse aus. Er übersieht leider die juristische Seite des Traktates fast völlig. Neben dem Apologeticum verrät aber keine Schrift Tertullians so sehr den geübten Juristen wie praescr. haer. Das Vorgehen Hüntemanns hat sich ungünstig aus-

1 Es seien nur einige neuere Autoren, die sich mit der Frage mehr oder weniger einläßlich befassen, erwähnt:

H. Kellner, Tertullians ausgewählte Schriften ins Deutsche übersetzt, in Bibliothek der Kirchenväter, 2. Bd., neu hrg. von G. Esser (Kempten u. München 1915) S. 284.

J. Alzog, Grundriß der Patrologie, 4. Aufl. (Freiburg i. B. 1888) 181.

M. Winkler, Der Traditionsbegriff des Urchristentums bis Tertullian (München 1897) 114/125.

HI. KrHn, Patrologie, 1. Bd. (Paderborn 1904) 242.

A. D'Alès, La théologie de Tertullien (Paris 1905) 260.

K. AdAM, Der Kirchenbegriff Tertullians (Paderborn 1907) 27.

G. Rauschen, Grundriß der Patrologie, 5. Aufl. (Freiburg i. B. 1913) 78 ; dasselbe in 6. u. 7. Aufl. bes. von J. Wittig (Freiburg i. B. 1921) 70.

J. MARx, Abriß der Patrologie, 2. Aufl. (Paderborn 1919) 57.

A. Ehrhard, Die Kirche der Märtyrer, ihre Aufgaben und ihre Lcistungen (München 1932) 216.

2 Geschichte der altkirchlichen Literatur, 2. Bd. 406.

3 Vgl. Marc. 1, 1 (Kr. 292, 8).

4 Siche Anm. 5.

5 Vgl. Tertulliani de praescriptione haereticorum libri analysis 5. 
gewirkt in der Beurteilung der Aufgabe und besonders der Zahl der Präskriptionen. U. Hüntemann sieht im 21. Kap. nur eine Präskription. Nun mußte aber diese Annahme mit dem letzten Kapitel von praescr. haer. in Konflikt geraten, wo ausdrücklich von einer Mehrzahl von Präskriptionen die Rede ist. Was tut U. Hüntemann? Er bezeichnet die drei in den Kap. 41-43 enthaltenen und ganz untergeordneten Nebenargumente als drei Nebenpräskriptionen ${ }^{1}$.

Aber weder die herkömmliche Annahme von drei Präskriptionen, noch die Kompromißlösung U. Hüntemanns, der vier Präskriptionen, eine Haupt- (c. 21) und drei Nebenpräskriptionen (cc. 41-43) vorschlägt, sind haltbar.

$\mathrm{Da} B$ der Traktat mehr als eine Präskription enthält, steht außer $Z$ weifel. Den sichern Beweis liefern die Worte des letzten Kapitels: "... nunc quidem generaliter actum est nobis adversus haereses omnes certis et iustis et necessariis praescriptionibus repellendas ... ${ }^{2}$ Für die Mehrzahl zeugt auch der Titel alter Codices ${ }^{3}$, "De praescriptionibus haereticorum ". Trotzdem behielt das WienerCorpus den andern Titel "De praescriptione haer. " bei ; vermutlich wollte man den nun einmal allgemein gebräuchlich gewordenen Titel nicht mehr ändern ${ }^{4}$.

Die umstrittene Frage ist also die Festlegung der Zahl der im Traktat enthaltenen Präskriptionen.

Die Lösung der Frage kann in zwei Abschnitte geteilt werden. Der erste (A) nimmt die Kap. 20-40 zum Gegenstand der Untersuchung, der zweite Abschnitt (B) befaßt sich mit den Schluß-Kapiteln 41-43. Von den Kap. 1-14, die Tertullian als " praefatio allocutionis " 5 charakterisiert, dürfen wir absehen. $\mathrm{Da}$ darin keine Präskription zu suchen ist, darüber sind sich alle einig.

A. Kap. 20-40. Die eingangs erwähnte herkömmliche Auffassung verlegt in diesen Abschnitt drei Präskriptionen. Diese sollen sich in der Weise über den ganzen Abschnitt erstrecken, daß sie denselben in drei Teile zerlegen.

1 A. a. O. $11,32,55$.

${ }^{2}$ Praescr. haer. 44 (Kr. 58, 33).

- ${ }^{3}$ Cod. Florentinus Magliabechianus Conv. soppr. VI, 9. (15. Jahrh.) und Cod. Flor. Magliab. Conv. soppr. VI, 10 (15. Jahrh.).

4 CSEL 70, 1.

5 Praescr. haer. 15 (Kr. 20, 2). 
Vor allem dürfte die Analyse eindeutig bewiesen haben, daß die Prozeßeinreden nur in Kap. 21 formuliert werden. Kap. 20 liefert die Grundlagen für die beiden Präskriptionen. Die Kap. 22-24 umfassen die drei Objektionen der Häretiker, bzw. deren Widerlegung. Kap. 35 enthält die Aufforderung zur Replik. Kap. 36 entwickelt ein Argument, das die Richtigkeit der zweiten Präskription unterstreicht. Innerhalb der Kap. 22-36 kann keine Rede sein von einer Präskription ; dieser ganze Abschnitt hat im Gegenteil die Aufgabe, die Richtigkeit der in Kap. 21 formulierten zwei Präskriptionen, besonders der zweiten, zu verteidigen und zu bestärken. Kap. 37 endlich zieht die entsprechenden Folgerungen für die Heilige Schrift ${ }^{1}$. In den Kap. 20-36 wurde bewiesen, da $B$ der Offenbarungsnachla $\beta$ als solcher, - und dieser war in seiner ursprünglichen Form ein mündlicher -, bei den apostolischen Urkirchen hinterlegt wurde. Infolgedessen, so schließt Kap. 37, gehört auch die Heilige Schrift den apostolischen Kirchen ; die Häretiker haben kein Recht, sie zu benützen. Der Inhalt der Kap. 38-40 kann als Reflexion zu Kap. 37 bezeichnet werden:

Kap. 38 : Die Häretiker sind gezwungen, die Heilige Schrift zu fälschen, um sie ihrem jeweiligen Irrtum anzupassen.

Kap. 39 : Dasselbe geschieht bekanntlich auch bei profanen Schriften.

Kap. 40 : Der Teufel hat den Häretikern den Gedanken eingegeben, die Heilige Schrift zu fälschen.

In den Kap. 38-40 findet sich also keine Spur von einer Präskription ; es handelt sich vielmehr um Überlegungen und Ergebnisse, die sich folgern lassen dank der Richtigkeit der in Kap. 21 formulierten Präskriptionen.

Die geläufige Auffassung, die innerhalb der Kap. 20-40 eine praescriptio veritatis, principalitatis und proprietatis sieht, war nur möglich, weil man auf die Gestalt der Präskription, wie Tertullian sie anwendet, zu wenig achtete und weil man hinwegsah über die innere, übrigens durchaus logische und klare Disposition des fraglichen Abschnittes.

Die Annahme von drei Präskriptionen, die sich über den ganzen Abschnitt der Kap. 20-40 erstrecken, dürfte durch die Analyse über-

1 Da es sich in Kap. 37 nur um eine Anspielung auf die longi temporis praescriptio handeln dürfte, sehen wir in der Frage nach der Zahl der in praescr. haer. enthaltenen Präskriptionen von Kap. 37 ab. 
zeugend widerlegt sein. Die Präskriptionen sind innerhalb dieses Abschnittes einzig und allein in Kap. 21 zu suchen und sie beherrschen von dort aus den Traktat, wie es die Analyse aufgezeigt hat ${ }^{1}$. Diese Lösung bestätigt auch U. HünTEMANN, jedoch mit dem Unterschied, $\mathrm{da} \beta$ er in Kap. 21 nur eine Präskription sieht und dafür in den Kap. 41-43 noch drei Präskriptionen annimmt. Doch ist diese Auffassung, wie schon bemerkt, fast ganz zu erklären aus einer Unterschätzung des juristischen Elementes, das doch die Schriften Tertullians, wie kaum eines kirchlichen Schriftstellers, kennzeichnet, und praescr. haer. erst recht.

Wir haben uns somit noch mit dieser Auffassung HüntEmanns auseinanderzusetzen. Dies geschieht am einfachsten durch eine Zusammenstellung der drei wichtigsten Gründe, die für die $Z$ wei-Zahl der Präskriptionen im 21. Kap. zeugen.

a) Tertullian trennt die beiden Präskriptionen deutlich. Das ist schon aus ihrem Inhalt klar. Die Analyse hat gezeigt ${ }^{2}$, wie die erste der beiden Präskriptionen anknüpft an den 2. Punkt der Partitio, und daraus die Folgerung zieht; die zweite Präskription knüpft an den 4. Punkt der Partitio an. Wie Punkt 2 (per quos) und Punkt 4 (quibus), bzw. die entsprechende Beantwortung der beiden, voneinander inhaltlich verschieden sind, so gut sind die 1. und 2. Präskription voneinander inhaltlich verschieden.

b) Zum Überfluß bezeichnet der Autor jede der beiden Präskriptionen noch ausdrücklich als solche: "Hinc igitur dirigimus praescriptionem ..." und "... et hic praescribam ..." Diese Tatsache spricht nicht nur für die Zweizahl der Präskriptionen in Kap. 21, sie ist außerdem ein (wenn auch nicht entscheidendes) Argument dafür, daß wir nur in Kap. 21 Prozeßeinreden zu suchen haben. Denn im ganzen übrigen Traktat steht kein Wort von einer Präskription, außer im Schlußkapitel ${ }^{3}$, wo es sich aber nur um einen Hinweis auf die zwei Präskriptionen handelt. Und Tertullian hat doch, wie die zahlreichen diesbezüglichen Stellen in seinen Schriften bezeugen, die Gewohnheit, seine Präskriptionen ausdrücklich als solche zu bezeichnen. Präskriptionen sind der Hauptgegenstand dieses Traktates. Das zeigt schon der

1 Soweit wir sehen, ist Hilarin Felder, Apologetica sive Theologia fundamentalis, 2. Bd. (Paderborn 1923) S. 323 der einzige Autor, der die Prozeßeinreden in Kap. 21 sucht.

2 Siehe oben S. $50 \mathrm{ff}$.

3 Vgl. praescr. haer. $44(58,34)$. 
Titel an. Die ganze Aufmerksamkeit des Lesers geht so vom ersten Kapitel an auf diese angekündigten Präskriptionen. Es entspricht daher ganz dem Titel und der Absicht der Schrift, wenn die Präskriptionen so deutlich angezeigt und genannt werden. Warum sollte Tertullian die andern Präskriptionen, falls er noch mehr solche formulieren würde, nicht ebenso klar kennzeichnen und hervorheben? Er tut dies auch in den andern Schriften, wie die früher angeführten Beispiele zeigen.

c) Für die $Z$ wei-Zahl sprechen ferner die drei Objektionen. Die 1. und 2. Objektion greifen die 1. Präskription an, die 3. Objektion richtet sich gegen die zweite ${ }^{1}$.

Eine Schwierigkeit gegen die Zwei-Zahl der Präskriptionen in Kap. 21 scheinen die bald darauf folgenden Worte zu sein : " . . locum interim demus diversae parti, si quid putant ad infirmandam hanc praescriptionem movere se posse. " ${ }^{2}$ Diese Worte können anfänglich den Anschein erwecken, als ob der Autor hier bezüglich Kap. 21 nur von einer einzigen Präskription rede. Mit "hanc praescriptionem " ist aber bestimmt nur die zweite Präskription gemeint. Denn gegen die zweite Präskription geht letztlich der Kampf der drei Objektionen ${ }^{3}$. Zugegeben, da $\beta$ direkt nur die dritte, größte Objektion gegen die $z$ weite Präskription gerichtet ist, und daß die erste und zweite Objektion direkt und zunächst die erste Präskription angreifen. Aber auf dem Umweg über die erste Präskription zielen auch die Angriffe der ersten und zweiten Objektion nach der zweiten Präskription. Die Analyse hat genugsam hervorgehoben, wie die zweite Präskription die erste Präskription voraussetzt ${ }^{4}$. Wenn nun die ersten zwei Objektionen die erste Präskription zu Fall brächten, dann wäre ipso facto auch die zweite Präskription und mit ihr das Kriterium dahin. Daher kann Tertullian mit Recht sagen, daß alle drei Objektionen "hanc praescriptionem", die zweite Präskription, zu entkräften suchen.

Eine weitere Schwierigkeit gegen die Zweizahl der Präskriptionen in Kap. 21 scheint auch Marc. 5, $19^{5}$ zu bieten : "Soleo in praescriptione adversus haereses omnes de testimonio temporum compendium figere, priorem vindicans regulam nostram omni haeretica posteritate. "

1 Siehe oben S. $57 \mathrm{ff}$.

2 Praescr. haer. 22 (Kr. 26, 8).

3 Siehe oben S. $57 \mathrm{ff}$.

4 Siehe oben S. 53.

5 Marc. 5, 19 (Kr. 642, 26). 
Daß Tertullian hier praescr. haer. vor Augen hat, steht außer Zweifel. Auf Grund der Analyse ist aber ebenso klar, daß nur die 2. Präskription damit gemeint ist, dieselbe Präskription, die Marc. 1, $1^{1}$ als "praescriptio novitatis" bezeichnet.

Soweit die Ausführungen zum Abschnitt, der die Kap. 20-40 umfaßt. In einem zweiten, kürzern Teil (B) sollen noch die Kap. 41-43 einer Untersuchung unterzogen werden.

B. Kap. 41-43. U. Hüntemann sieht in den Kap. 41-43 drei NebenPräskriptionen ${ }^{2}$. Die Gründe für diese Annahme verschweigt er. Aber die Erklärung dafür dürfte in der Unterschätzung der Präskription zu suchen sein. Denn U. HÜnTEMAnN erklärt an anderer Stelle ausdrücklich, man dürfe diese äußern, von Tertullian auf die Dogmatik übertragenen juristischen Formen nicht zu sehr pressen, man müsse mehr auf ihren Inhalt sehen ${ }^{3}$. All dem ist zuzustimmen. Aber U. HüNTEMANN ist etwas zu weit gegangen. Er hat die juristische Form der Präskription zu wenig ernst genommen. Dies hat sich in seiner Analyse entsprechend ausgewirkt. Er hat im Kriterium den Mittelpunkt von praescr. haer. gesehen. In Wirklichkeit liegt aber der Mittelpunkt in den beiden Präskriptionen, aus denen das Kriterium entwickelt wird. Das beweist die Analyse, das beweist auch der Titel des Traktates, der die Präskriptionen als den eigentlichen Gegenstand und Mittelpunkt der Schrift andeutet.

Die Kap. 41-43 schildern den Mangel jeglicher Kirchenzucht bei den Häretikern :

Kap. 41 : den lockern Lebenswandel und das Fehlen einer kirchlichen Ordnung.

Kap. 42 : den schrankenlosen Subjektivismus. Unter sich in zahllose Sekten zerspalten, sind die Häresien nur einig in dem einen Ziel, die Kirche zu unterwühlen.

Kap. 43 : die Zuchtlosigkeit der Häretiker ist ein Gradmesser für den Tiefstand ihres Glaubens.

In diesen drei Kapiteln findet sich keine Spur von einem Gebilde, das einer Präskription, wie wir sie aus praescr. haer. 21 und andern

1 Vgl. Marc. 1, 1 (Kr. 292, 8).

2 Vgl. U. Hüntemann, a. a. O. 32.

3 Ebd. 
Schriften Tertullians kennen, ähnlich wäre. Es handelt sich um nichts anderes als eine Schilderung der lockern Kirchenzucht der Häretiker, welche der streng gehüteten disciplina der wahren Kirche entgegen gestellt wird. Diese Tatsachen sollen den Beweis des Hauptabschnittes, $\mathrm{da} B$ die Wahrheit sich auf Seiten der apostolischen Gemeinden findet, unterstreichen. Daher erklärt der. Verfasser nach Abschluß der betreffenden drei Kapitel : "Proinde haec pressioris apud nos testimonia disciplinae ad probationem veritatis accedunt. " ${ }^{1}$ Die Kap. 41-43 sind nicht neue Präskriptionen, sie wollen im Gegenteil nur dazu beitragen, daß die Richtigkeit der zwei bereits bewiesenen Präskriptionen noch eindringlicher und überzeugender zutage trete.

Noch ein Wort zur Auffassung, die J.-L. Allie hinsichtlich der Zahl der Präskriptionen äußert. J.-L. AllIE will in praescr. haer. vorerst eine Hauptpräskription erkennen. Er sieht sie in dem die Kap. 15-37 umfassenden Nachweis, daß die Katholiken die allein rechtmäßigen Eigentümer der Heiligen Schrift sind und in der daraus gezogenen Folgerung, die Katholiken seien nicht verpflichtet, sich mit den Häretikern auf Grund der Heiligen Schrift in eine Diskussion einzulassen ${ }^{2}$. Der Verfasser nennt dieses Argument die Präskription des Besitzes an der Heiligen Schrift und Tradition und hält sie für die grundlegende Präskription des ganzen Traktates praescr. haer. "3. Nach seinem eigenen Geständnis hat J.-L. AlliE diese Idee von den beiden holländischen Kontroverstheologen Peter und Andreas von Wallenburch übernommen 4. Nebst dieser Fundamentalpräskription, die mehr allgemeiner Natur ist, soll praescr. haer. noch eine Menge sogenannter Hilfspräskriptionen enthalten, die die Hauptpräskription tragen helfen ${ }^{5}$. Diese zweite Idee leiht der Verfasser vom Herausgeber der "Bibliothèque choisie des

1 Praescr. haer. 44 (Kr. 56, 1).

2 J.-L. Allie, L'argument de prescription 62: "Prouver que les légitimes possesseurs des saintes Lettres ne sont pas les hérétiques, mais les catholiques, et conclure de là que ceux-ci n'ont aucune obligation de discuter avec ceux-là, telle est donc, en deux mots, la prescription que Tertullian veut faire valoir dans la seconde partie de son De praescriptione 15-37."

3 A. a. O. 93 : "la prescription fondamentale de la possesion".

4 A. et P. De Wallenburch, De Praescriptionibus catholicis 1666, ed. Migne, Theologiae Cursus completus, 1. Bd. (Paris 1839) col. 923-940. Vgl. Allie, a. a. O. $138 \mathrm{ff}$.

5 Nach J.-L. Allie a. a. O. 93 wäre es verfehlt, "si l'on ne voulait entendre par prescription que l'argument général du tract tertullien, et non les $\mathrm{multiples}$ raisons subsidiaires sur lesquelles repose cet argument". 
Pères de l'Eglise ", der in praescr. haer. zehn Präskriptionen aufzählt ${ }^{1}$. J.-L. Allıe erklärt, er begnüge sich damit, aus dem Werke der Brüder von Wallenburch und des soeben genannten Herausgebers die interessantesten Präskriptionen herauszugreifen. So übernimmt er von den erstern die erwähnte Fundamentalpräskription und vom letztern «la prescription d'unité ou du consensus doctrinal, les prescriptions d'ancienneté et de nouveauté, celle de l'apostolicité " ${ }^{2}$.

Wir möchten zu diesem Vorgehen vorerst bemerken, da $\beta$ es weder den Brüdern P. u. A. von Wallenburch noch dem Herausgeber der Bibliothèque choisie darum ging, die fragliche Schrift Tertullians und die darin entwickelten Präskriptionen wissenschaftlich zu untersuchen. Beiderseits waren rein praktische Ziele maßgebend. Die Brüder von Wallenburch verfolgten mit ihrer Schrift die Widerlegung der Protestanten. Zu diesem Zweck formulierten sie die 10 angeblichen Präskriptionen, für die ihnen Tertullians praescr. haer. in großen Zügen als Vorbild diente. Die Idee des Herausgebers der Bibliothèque choisie endlich $\mathrm{muß}$ als eine ganz beiläufige Äußerung angesprochen werden, die sich in keiner Weise auf eine gründlichere, geschweige wissenschaftliche Untersuchung stützt und diesen Anspruch auch gar nicht erhebt. Angesichts dieser Tatsachen muß es als ein Fehlgriff bezeichnet werden, wenn J.-L. Allie die Ansichten dieser Autoren kritiklos übernimmt, geschweige $\mathrm{da} \mathrm{B}$ er aus den Elementen, die er beiderseits entlehnt, eine eigene Theorie zimmert, nämlich die der Fundamentalpräskription und der Hilfspräskriptionen. Der Hinweis ist überflüssig, da $\beta$ der Verfasser nur deshalb zu einer derartigen Theorie gelangt, weil er die innere Struktur der Kap. 15-37 übersieht. Unsere Textanalyse hat bewiesen, $\mathrm{da} B$ jene Argumente, die J.-L. AllıE für Präskriptionen hält, gar keine Präskriptionen sind. Was J.-L. Allie als prescription d'unité ou du consensus doctrinal (siehe praescr. haer. 28) und als prescriptions d'ancienneté et de nouveauté bezeichnet (siehe praescr. haer. $29 \mathrm{ff}$.), sind die zwei Argumente, mit denen der dritte, gegen die 2. Präskription gerichtete Einwand der Häretiker widerlegt wird ${ }^{3}$. Was er prescription d'apostolicité nennt (siehe praescr. haer. 32), bildet als Nachweis der Apostolizität des Ursprungs und der Sukzession den stärksten Rückhalt für die 2. Präskription in Kap. $21^{4}$.

1 M.-N.-S. Guillon, Bibliothèque choisie des Pères de l'Eglise grecque et latine ou Cours d'Eloquence sacrée, 3. Bd. (Paris 1824) 207/8. Vgl. Allie, a. a. O. 93 .
A. a. O. $93 \mathrm{ff}$.
${ }^{3}$ Siehc oben S. $64 \mathrm{ff}$.
4 Siehe oben S. $73 \mathrm{f}$. 


\section{Kapitel \\ Die theologische Bewertung der tertullianischen Präskriptionen}

Die praescriptio des röm. Prozeßrechts hat vorerst eine rein äußerliche, technische Seite. Man kann sie die Funktion der praescriptio nennen. Sie besteht darin, daß sie den Kläger abweist und so den Beklagten vom Prozeß befreit, wenn bestimmte Bedingungen erfüllt sind. Diese Funktion ist der praescriptio auch in ihrer Anwendung auf die Theologie, näherhin Apologetik eigen. Wie die prozessuale Präskription den Prozeß abweist, so weist auch die theologische Präskription eine Streitfrage mit den Häretikern ab. Es erhebt sich daher bei der theologischen Bewertung der tertullianischen Präskriptionen zuerst die Frage, ob und inwieweit eine solche Argumentation den Ansprüchen der Apologetik entspricht und gerecht wird. Diese erste Frage wird in einem ersten Abschnitt untersucht.

Eine andere Frage ist die nach dem Inhalt der Präskriptionen. Die praescriptio des Rechts macht eine prozeßausschließende Tatsache geltend. Tertullian hat, wie wir gesehen haben, der prozeßrechtlichen praescriptio einen theologischen Inhalt gegeben. Demzufolge stellt sich die andere Frage, ob die theologischen Präskriptionen Tertullians theologisch schlüssig seien, oder vielleicht infolge versteckter theologischer Irrtümer des Autors innerlich entwertet werden. Letzteres trifft tatsächlich zu für die 2. Präskription in praescr. haer. 21. Die diesbezügiche Untersuchung bildet den Inhalt des 2. Abschnittes dieses Kapitels .

\section{Die tertullianischen Präskriptionen und die Forderungen der Apologetik}

Die praescriptio ist ein prozessuales Institut. Praescriptio heißt die Berufung des Beklagten auf eine dem Prozeß entgegenstehende Vorschrift. In den meisten Fällen handelt es sich um eine Verjährungsoder Ausschlußfrist. 
Der Richter bzw. der Gesetzgeber weist auf Grund eines solchen prozeßhindernden Umstandes eine Streitangelegenheit (nehmen wir als Beispiel einen Adulterienprozeß) von seinem Gerichtsforum weg. Der Richter vergewissert sich nur darüber, ob die Grundlagen für die vom Beklagten vorgebrachte praescriptio (z. B. daß die Klagefrist abgelaufen ist) vorliegen und die andern Bedingungen (z. B. rechtmäßiger Erwerbsgrund und Gutgläubigkeit bei der longi temporis praescriptio) erfüllt sind. Wenn dies zutrifft, weist der Richter den Kläger ab. Er geht nicht ein auf den Streit, der die beiden Parteien vor sein Forum geführt hat. Der Streitgegenstand wird nicht geklärt und nicht entschieden. Das Unrecht, z. B. der Ehebruch, vorausgesetzt, daß er wirklich vorliegt, wird nicht bestraft, nur weil die Klage nicht innert fünf Jahren erhoben wurde. Ein Verbrechen bleibt aber ein Verbrechen, auch wenn seither fünf und mehr Jahre verflossen sind.

Wenn nun Tertullian die praescriptio auf die Theologie anwendet, heißt dies, er geht auf eine Streitfrage gar nicht ein, sondern weist sie kurzerhand mit einem Einwand, d. h. mittels einer praescriptio von sich. Die beiden praescriptiones in praescr. haer. $21^{1}$ zeigen dies deutlich.

Die zwar nicht explicite ausgesprochene, aber selbstverständliche "Klage " der Häretiker, die den beiden in praescr. haer. 21 formulierten Präskriptionen zugrunde liegt, ist folgende: wir besitzen die wahre christliche Lehre, nicht ihr apostolischen Gemeinden. Die Häretiker behaupten, ihre Lehre stelle die echte, von Christus gebrachte Offenbarung dar. Ein gemeinsamer Berührungspunkt zwischen Katholiken und Häretikern besteht insofern, als beide Parteien ihre Lehre auf Christus zurückführen ${ }^{2}$. Statt sich nun mit den Häretikern in Lehrstreitigkeiten einzulassen, erhebt Tertullian gegen diese einfach zwei eng miteinander verknüpfte, hier etwas freier wiedergegebene Präskriptionen ${ }^{3}$ :

1. Der Herr Jesus Christus hat die Apostel mit der Predigt (des Evangeliums) beauftragt. Folglich dürfen nur die als Prediger zugelassen werden, die von Christus dazu bestellt sind. Denn es kennt kein anderer den Vater als der Sohn, und wem es der Sohn geoffenbart hat, und er hat es auch augenscheinlich niemand anderm geoffenbart, als den Aposteln ...

1 Siehe oben S. 52 und $96 \mathrm{ff}$.

2 Siehe oben S. 48 (a).

3 Siehe Anm. 1. 
2. Nun haben aber die Apostel persönlich Gemeinden gegründet, indem sie selbst diesen predigten, sowohl durch das lebendige Wort, wie man sagt, als auch nachher durch Briefe. Also können nur diese Gemeinden sagen, was Lehre der Apostel bzw. Offenbarung Christi an diese ist und was nicht.

Mit diesen beiden praescriptiones weist Tertullian die Häretiker ab. Er läßt sich auf alle die mannigfachen Streitfragen und Behauptungen derselben überhaupt nicht ein.

Wir lassen zwei weitere Beispiele folgen :

Apol. $7^{1}$ kommt auf die Verbrechen zu sprechen, die den Christen von der öffentlichen Meinung zur Last gelegt werden. Bevor sich jedoch der Apologet mit diesen Verleumdungen auseinandersetzt, wendet er sich an die Adressaten seiner Schrift, d. h. an die "Spitzen der römischen Reichsregierung, die an augenfälliger und erhabenster Stelle, sozusagen auf dem höchsten Punkt der Stadt den Vorsitz führt, um Recht zu sprechen " ${ }^{2}$, an die, die "täglich, um die Gefangenen abzuurteilen, zu Gericht sitzen und die Liste der Angeklagten durch ihren Richterspruch erledigen " ${ }^{3}$. Der Apologet hält ihnen vor : "Man sagt uns dies (nämlich diese Verbrechen) beständig nach, und doch sorgt ihr nicht dafür, das gerichtlich zu ermitteln, was man uns schon so lange nachsagt. Entweder ermittelt es, wenn ihr es glaubt, oder glaubt es nicht, wenn ihr es nicht ermittelt. " Und mit geschickter Anlehnung an die Funktion der prozessualen praescriptio fährt er fort : "Auf Grund eurer Gleichgültigkeit wird gegen euch die Prozeßeinrede erhoben, da $B$ das nicht existiert, was nicht einmal ihr selber zu ermitteln wagt. ") ${ }^{4}$ Wollte man konsequent sein, brauchte man sich gegen das verleumderische Gerede der Heiden gar nicht zu verteidigen und um die Untersuchung und Abklärung des wahren Sachverhaltes überhaupt nicht zu bemühen. Die desinteressierte Haltung der heidnischen Gerichtshöfe angesichts d:eser ungeheuerlichen öffentlichen Anschuldigungen ist wie eine Prozeßeinrede zu Gunsten der Unschuld der Christen.

1 Siehe oben S. $90 \mathrm{f}$.

2 Apol. 1 (H. 1, 1) : "... vobis, Romani imperii antstites, in aperto et edito, ipso fere vertice civitatis praesidentibus ad iudicandum ..."

3 Apol. 44 (H. 103, 5) : "... qui cottidie iudicandis custodiis praesidetis, qui sententiis elogia dispungitis. "

4 Apol. 7 (H. 18, 4) : "Dicimur tamen semper, nec vos quod tamdiu dicimur eruere curatis. Ergo aut eruite, si creditis, aut nolite credere, qui non eruistis ! De vestra vobis dissimulatione praescribitur non esse quod nec ipsi audetis eruere." 
Nat. 2, $1^{1}$ setzt sich mit der Vielgötterei der Heiden auseinander. Tertullian erklärt, wenn wir seine Gedanken etwas freier wiedergeben wollen, er könne diese perversitas der Heiden bezüglich des Götterglaubens mit einer einzigen praescriptio zerschlagen. Diese praescriptio bestehe im Hinweis auf das eigene Geständnis der Heiden, alle diese zahllosen Götter seien von den Menschen erfunden, hätten also einmal (in ihrer Vorstellung) zu existieren angefangen, während doch ein göttliches Wesen keinen Anfang kenne in seiner Existenz. Das Geständnis der Heiden erübrigt also streng genommen eine einläßliche Untersuchung und Abhandlung, um die Nichtigkeit des Götterglaubens darzutun. Das Geständnis der Heiden macht sie überflüssig, wie eine praescriptio den Richter der Untersuchung und Klärung des eigentlichen Prozeßgegenstandes enthebt.

Wir können es uns ersparen, auf weitere Beispiele einzugehen, zumal oben diejenigen Stellen, wo Tertullian die praescriptio etwas weiter ausführt, bereits dargestellt wurden ${ }^{2}$. Wenn Tertullian auch oft von der praescriptio spricht, so handelt es sich doch meistens nur um eine flüchtige Anspielung auf das Wesen derselben, wobei zudem mehrmals auf die zweite Präskription in praescr. haer. 21 verwiesen wird ${ }^{3}$. Als die sozusagen klassischen Beispiele für die Übertragung der prozessualen praescriptio auf die Theologie können im gesamten überlieferten Schriftum Tertullians nur die zwei in praescr. haer. 21 entwickelten Präskriptionen, und von diesen hauptsächlich die zweite, die sog. praescriptio novitatis ${ }^{4}$, gelten. Deshalb war zwecks Aufhellung der tertullianischen praescriptio an erster Stelle der betreffende Traktat zu analysieren, und im folgenden ist denn auch hauptsächlich von diesen beiden Präskriptionen die Rede.

Als erstes Bedenken gegen eine Übertragung der prozessualen praescriptio auf die Apologetik wurde eingangs der Umstand genannt, da $B$ für den Fall, wo der Beklagte die praescriptio erheben kann, der Streit der Parteien nicht auf seinen wahren Sachverhalt untersucht wird. Der Kläger mag seine Ansprüche oder das erlittene Unrecht noch so gut belegen, der Richter weist ihn trotzdem ab.

Wie wirkt sich diese Seite der praescriptio in ihrer Anwendung auf die Apologetik aus ? Die Häretiker behaupten, die wahre Lehre Christi zu besitzen. Tertullian erhebt gegen sie im Namen der apostolischen

1 Siehe oben S. $91 \mathrm{f}$.

3 Siehe oben S. $83 \mathrm{ff}$.
2 Siehe oben S. $89 \mathrm{ff}$.

4 Marc. 1, 1 (Kr. 292, 8). 
Gemeinden die zwei Prozeßeinreden, die auf ihre kürzeste Form gebracht, etwa so lauten :

Christus hat seine Lehre nur den Aposteln übergeben (1. praescr.). Von den Aposteln hat sie niemand erhalten als jene Gemeinden, die von den Aposteln persönlich gegründet wurden (2. praescr.).

Mit diesen beiden Präskriptionen ist der Streit zwischen den Katholiken und Häretikern entschieden. Es steht nun eindeutig fest, auf welcher Seite die wahre christliche Lehre sich findet. Es ist im Grunde überflüssig, sich mit dem Gegner hinsichtlich der verschiedenen größern und kleinern Differenzpunkte in Diskussionen einzulassen. Es ist ein für allemal der Beweis erbracht, da $\beta$ die Wahrheit auf Seiten der apostolischen Kirchen zu suchen ist. Das Gesetz des Handelns liegt also bei den Häretikern, sie haben die entsprechenden Konsequenzen zu ziehen und nachzugeben, nicht die Kirche.

Aber tun die Häretiker diesen Schritt ? Werden sie nicht vielmehr weiter behaupten, die Wahrheit sei auf ihrer Seite, und mit allen erdenklichen Sophismen die Gläubigen der Kirche abspenstig zu machen suchen?

Aber die Gläubigen werden sich nun der Angriffe der Häretiker mit Leichtigkeit erwehren, nachdem ihnen Tertullian in den beiden Präskriptionen eine derart schlagfertige Waffe geschmiedet hat ? Auch diese Erwartung wird sich kaum erfüllen. Es erhebt sich vielmehr die ernstliche Frage : kann der gewöhnliche Christ, der über keine tiefere Bildung verfügt, diese apologetische Waffe wirklich handhaben? Er mag dem Häretiker, der ihn belästigt, wohl erklären : wir haben die Wahrheit, sie war von allem Anfang an stets in unserm Besitz, ich brauche folglich gar nicht mit dir zu diskutieren. Aber wie will nun der gewöhnliche Mann sich verteidigen, wenn der Häretiker nach Art der in praescr. haer. behandelten drei Objektionen ${ }^{1}$ gerade auf diese Präskriptionen eingeht und nun diese zu entkräften sucht? Du berufst dich auf die Apostel; Christus hat ihnen ja lange nicht alles mitgeteilt. Du erklärst, die Apostel haben die ganze Offenbarung den von ihnen gegründeten Gemeinden anvertraut; der wahre Sachverhalt ist aber dieser : die Apostel haben, wenn sie überhaupt die ganze christliche Lehre besaßen, einiges öffentlich und allen, anderes im geheimen und nur wenigen, nämlich uns, gesagt. Ihr führt eure Lehre zurück

1 Siehe oben S. $57 \mathrm{ff}$. 
auf die Apostel; aber weißt du denn nicht, daß jene sog. apostolischen Urgemeinden die Apostel falsch verstanden, und daß eure heutige Lehre nichts als einen beharrlich und raffiniert überlieferten Irrtum darstellt ? Aus der Widerlegung der drei Objektionen ersehen wir ferner, wie die Häretiker ihre Behauptungen mit sehr verfänglichen Schriftstellen belegten.

Es ist nicht ausgeschlossen, daß ein Christ mit gründlicherer Bildung diese Einwände widerlegt und die Präskriptionen siegreich verteidigt. Aber wie erwehrt sich die große Schar der einfachen Gläubigen, die ohne tiefere apologetische Bildung und Kenntnis der Heiligen Schrift bleiben, denen aber Tertullian mit den beiden Präskriptionen zweifellos eine Waffe für den Kampf gegen die Häretiker liefern wollte ? Gerade die drei Objektionen in praescr. haer. lehren uns nämlich, daß die Häretiker ihre Angriffe nun erst recht gegen die Präskriptionen richten werden. Es kann aber auch keine Rede davon sein, daß die Häretiker von all den vielen andern Einwänden, die nicht Präskriptionen betreffen, ablassen. Besteht unter diesen Umständen nicht Gefahr, daß ein Christ, von der Sophistik der Häretiker geblendet, an der Wahrheit und dem Wert der beiden Präskriptionen zu zweifeln beginnt ?

In der Tat gab sich Tertullian in der Bewertung seiner beiden Präskriptionsargumente, besonders des zweiten, keiner Täuschung hin. Er ist wohl überzeugt, daß ihm in diesen beiden Präskriptionen in praescr. haer. 21, vor allem mit der zweiten, der praescriptio novitatis, ein einmaliger Wurf gelungen ist, sonst würde er in seinen übrigen Werken nicht so oft auf diese zweite Präskription verweisen ${ }^{1}$. Wobei allerdings daran erinnert sei, daß bei Tertullian nur die juristische For m, nicht aber der Inhalt des Argumentes neu ist. Irenäus hat vor Tertullian aus dem Alter und der zeitlichen Priorität der Kirche gegen die Häresien argumentiert ${ }^{2}$. Tertullian kennt die Grenzen dieser theologischen Prä-

1 Siehe oben S. 95.

2 Wir finden bei Irenäus deutliche Anklänge an die erste und zweite Präskription Tertullians. In Adv. haer. 3,3 (MIGNE PG 7, 851) finden wir den Gedanken der 1. Präskription: "Polycarpus autem ... ab apostolis edoctus et conversatus cum multis ex eis, qui dominum nostrum viderunt, ... haec docuit semper, quae ab apostolis didicerat, quae et ecclesiae tradidit et sola sunt vera. Testimonium his perhibent quae sunt in Asia ecclesiae omnes et qui usque adhuc successerunt Polycarpo ..." Die Lehre Polykarps ist die allein wahre, weil er sie von den Aposteln empfangen hat.

Den Gedanken der 2. Präskription spricht Irenäus deutlich aus, wenn er darlegt, wie die Apostel die christliche Lehre in ihrer ganzen Fülle (plenissime!) der Kirche übergeben haben. Deshalb seien in Meinungsverschiedenheiten die 
skriptionen. Er weiß zu gut, daß seine zwei Präskriptionen, sie mögen in ihrem juristischen Gewand noch so faszinieren, die mannigfachen Lehrdifferenzen zwischen Katholiken und Häretikern nur theoretisch beseitigen, dieselben aber praktisch bei weitem nicht aus der Welt schaffen. Irenäus hat sie mit demselben Argument, wenn auch in anspruchsloserer Aufmachung, ebensowenig überwunden. Hier macht sich der eingangs an der prozessualen praescriptio hervorgehobene schwache Punkt in seiner ganzen Tragweite bemerkbar. Der mit einer praescriptio abgewiesene Kläger hatte sich, er mochte de facto noch so im Recht sein, zu fügen. Der mit staatlicher Autorität bekleidete Richter verbot und versagte dem Kläger ein für allemal die gerichtliche Geltendmachung und Abklärung seines Anspruchs oder Streites, wenn er dem Beklagten die praescriptio gewährte. Mit welcher Autorität will Tertullian den Häretikern fortan das Klagen und Diskutieren

ältesten Gemeinden, in denen die Apostel geweilt haben, zuständig; adv. haer. 3, 4 (MIGNE PG 7, 855) : "Tantae igitur ostensiones cum sint, non oportet adhuc quaerere apud alios veritatem, quam facile est ab ecclesia sumere, cum apostoli, quasi in depositorium dives, plenissime in eam contulerint omnia, quae sint veritatis, uti omnis, quicumque velit, sumat ex ea potum vitae. Haec est enim vitae introitus, omnes autem reliqui fures sunt et latrones. Propter quod oportet devitare quidem illos, quae autem sunt ecclesiae, cum summa diligentia diligere et adprehendere veritatis traditionem. Quid enim ? Et si de aliqua modica quaestione disceptatio esset, nonne oporteret in antiquissimas recurrere ecclesias, in quibus apostoli conversati sunt, et ab eis de praesenti quaestione sumere, quod certum et re liquidum est ? Quid autem, si neque apostoli quidem scripturas reliquissent nobis, nonne oportebat ordinem sequi traditionis, quam tradiderunt iis, quibus committebant ecclesias ?"

Und wie Tertullian in praescr. haer. 30 seine 2. Präskription durch den geschichtlichen Nachweis erhärtet, daß alle zeitgenössischen Häresien neueren und neuesten Datums sind, und dies mit ganz konkreten Angaben belegt, so ganz ähnlich Irenäus, adv. haer. 3, \& (MIGNE PG 7, 856) : Ante Valentinum enim non fuerunt, qui sunt a Valentino; neque ante Marcionem erant, qui sunt a Marcione; neque omnino erant reliqui sensus maligni, quos supra enumeravimus, antequam initiatores et inventores perversitatis eorum fierent.

Valentinus enim venit Romam sub Hygino, increvit vero sub Pio et prorogavit tempus usque ad Anicetum. Cerdon autem qui ante Marcionem, et hic sub Hygino, qui fuit octavus episcopus, saepe in ecclesiam veniens et exhomologesin faciens sic consummavit, modo quidem latenter docens, modo vero exhomologesin faciens, modo vero ab aliquibus traductus in his quae docebat male, et abstentus est a religiosorum hominum conventu.

Marcionem autem illi succedens invaluit sub Aniceto, decimum locum episcopatus continente. Reliqui vero qui vocantur gnostici a Menandro Simonis discipulo, quemadmodum ostendimus, accipientes initia, unusquisque eorum, cuius participatus est sententiae, eius pater et antistes adparuit. Omnes autem hi multo posterius, mediantibus iam ecclesiae temporibus, in. surrexerunt in suam apostasim." 
verbieten ? Auch wenn er sie mit seinen Präskriptionen beeindrucken sollte, so werden sie sich dafür umso eifriger auf diese Präskriptionen selber stürzen, um sie nach dem Muster der drei Objektionen in praescr. haer. zu entkräften.

Tertullian rechnet in praescr. haer. mit all diesen Rückwirkungen von Seiten der Häretiker als mit fertigen Tatsachen. Daher erachtet er es für notwendig, die beiden Präskriptionen so ausführlich und gründlich gegen die drei Objektionen der Häretiker zu verteidigen. Vielleicht hatte er vor der Abfassung seines Traktates die Präskriptionen bereits im täglichen Kampf gegen die Häretiker angewendet und dabei nicht bessere Erfahrungen gemacht, als Angriffe gegen die Präskriptionen selber geholt. Nun verbindet er mit der Entwicklung der beiden Präskriptionen eine ebenso scharfsinnige Widerlegung der drei wesentlichen Einwürfe gegen dieselben, d. h. Tertullian gibt indirekt die Unzulänglichkeit seiner beiden Präskriptionsargumente im Kampf gegen die Häretiker zu. Er sieht voraus, vielleicht hat er es bereits erfahren, daß die Häretiker sich von diesen noch so genialen Argumenten nicht mundtot kriegen lassen, im Gegenteil, ihre Angriffe nun erst recht gegen die Präskriptionen selber richten werden, im Bewußtsein, daß sie hier einer gefährlichen Waffe gegenüberstehen, die es mit jeglichem Aufwand von Lüge und Sophistik zu vernichten gilt. Und deshalb begnügt sich der Apologet nicht damit, seine beiden Präskriptionen im betreffenden Traktat klar und zwingend zu entwickeln, er schützt sie im voraus gegen die Angriffe der Häretiker, indem er ihnen eine gründliche Widerlegung der drei Objektionen mit auf den Weg gibt. Nachdem er die beiden Präskriptionen und das anschließende Kriterium entwickelt hat, erklärt er in unverkennbarer Anspielung auf das Wesen der prozessualen praescriptio : " ... tam expedita probatio est, ut, si statim proferatur, nihil iam sit retractandum ${ }^{1}{ }^{1}$; der Beweis, gemeint ist der mittels der zwei Präskriptionen geführte Beweis für die Wahrheit der von den apostolischen Gemeinden gehüteten Lehre, sei so kurz, bündig, leicht, daß, prozeßtechnisch ausgedrückt, keine retractatio ${ }^{2}$, d. h. keine weitern Argumente mehr nötig seien, wenn der Beweis einmal vorgebracht worden sei. Gerade deshalb wolle er aber, "als ob der Beweis (d.h. die praescriptio) noch nicht vorgebracht wäre, inzwischen der Gegenpartei (d. h. den Häretikern) noch Gelegenheit geben für den Fall, daß sie glaubten, sie könnten etwas zur Ent-

1 Praescr. haer. 22 (Kr. 25, 6).

2 Siehe oben S. 56. 
kräftung dieser Präskriptionen unternehmen ") ${ }^{1}$. Darauf folgt die Widerlegung der drei Objektionen, die, wie die Analyse mehrmals hervorgehoben hat, die beiden Präskriptionen, statt sie zu erschüttern, erst recht bekräftigen helfen.

Werden sich vielleicht die Häretiker jetzt geschlagen geben ? Die beiden Präskriptionen halten doch, wie wir in der meisterhaften Widerlegung der drei Objektionen gesehen haben, den schärfsten Geschossen der Gegner stand. Muß aber der Häretiker die praescriptio, daß die apostolischen Gemeinden die Wahrheit von jeher besaßen, anerkennen, wird er doch gewiß, von der Irrtümlichkeit seiner Lehre überzeugt, von dieser lassen, oder doch die Kirche nicht mehr bekämpfen ? Mit andern Worten, Tertullian wäre der Mühe enthoben, die Häretiker noch besonders $\mathrm{zu}$ wiederlegen, $d . h$. eine retractatio vorzunehmen.

Auch diese Hoffnung wird sich als trügerisch erweisen. Der weltliche Richter untersagt mit der Anerkennung der prozessualen praescriptio dem Kläger jede weitere Belästigung des Beklagten mit seinen Ansprüchen und Behauptungen. Die Häretiker aber schweigen nicht, und wenn ihnen die überzeugendste praescriptio entgegengehalten wird. Auch angenommen, sie geben es auf, die beiden Präskriptionen weiter anzufechten, weil sie ihnen nach der zwingenden Widerlegung Tertullians nicht beizukommen vermögen, so werden sie dieselben einfach ignorieren, sie werden m. a. W. ihre Häresien mit einer Selbstverständlichkeit weiter verteidigen und die Kirche bekämpfen, als ob ein solch entscheidendes Argument gegen sie überhaupt nicht existierte.

Welches ist nun der Erfolg der beiden Präskriptionen? Es wird Tertullian nichts anderes bleiben, als sich nachträglich doch noch auf die einzelnen häretischen Ansichten und Beschuldigungen der Gegner einzulassen, um sie in mühsamer Einzeluntersuchung zu widerlegen, was ausgerechnet die Präskriptionen hätten ersparen sollen.

Tatsächlich tut dies Tertullian. Er widerlegt nachträglich ${ }^{2}$ noch in besondern, zum Teil sehr ausführlichen Abhandlungen alle bedeutenderen Häretiker bzw. ihre Anhänger, die wir bereits aus praescr. haer. kennen: Marcion, Hermogens, die Anhänger des Apelles, die Valentinianer. Der Apologet unterzieht sich also trotz praescriptio einer

1 Praescr. haer. 22 (Kr. 26, 8) : " ... locum interim demus diversae parti, si quid putant ad infirmandam hanc praesciptionem movere se posse."

2 Die Einzelwiderlegungen der Häretiker sind alle nach praescr. haer. entstanden. Vgl. die Chronologie der Schriften Tertullians bei P. Monceaux, Histoire littéraire de l'Afrique chrétienne, Bd. 1, 208/9. 
retractatio, was der Richter niemals tut, wenn er die praescriptio des Beklagten anerkannt hat. Und es ist aufschlußreich, daß Tertullian seine Retraktationen schon am Schluß von praescr. haer. ankündigt: "Sed nunc quidem generaliter actum est nobis adversus haereses omnes... De reliquo, si dei gratia adnuerit, etiam specialiter quibusdam respondebimus. " 1

Es scheint denn auch selbstverständlich, daß in den betreffenden Schriften, die die einzelnen Häretiker im besondern (specialiter !) widerlegen, auf obige Ankündung im letzten Kapitel von praescr. haer. klar Bezug genommen wird.

Im 2. Kapitel der Schrift De carne Christi, die den Doketismus der Gnostiker wiederlegt, wird Marcion vorgehalten, daß er ein abgefallener Christ sei, da $B$ er das verlassen habe, was von den Aposteln (quorum fuit tradere!) überliefert worden sei. Was aber überliefert worden sei, das sei die Wahrheit ${ }^{2}$; kurz, Tertullian wiederholt hier die beiden Präskriptionen, die er in praescr. haer. 21 entfaltet hat, was er auch anschließend ausdrücklich bezeugt : "Sed plenius eiusmodi praescriptionibus adversus omnes haereses (dieselben Worte wie am Schluß von praescr. haer.!) alibi iam usi sumus (nämlich in praescr. haer.). Post quas nunc ex abundanti retractamus, desiderantes rationem, qua non putaveris natum esse Christum. $)^{3}$

Marc. 4, $38^{4}$ erklärt der Apologet mit den fast gleichen Worten, er wolle sich nun nach der Präskription noch ausführlich mit den verschiedenen Argumenten Marcions befassen: "Ex abundanti nunc et post praescriptionem retractabo adversus argumentationes cohaerentes. ")

In den angekündigten Werken erfahren wir dann vom Autor weiter die klare Begründung, warum er es für nötig erachtet, nach seinem genialen Argument sich nun trotzdem noch in Retraktationen einzulassen.

Im ersten Buch gegen Marcion ${ }^{5}$ spricht er von den Neuerungen dieses Häresiarchen. Vor Marcion habe man von einem andern Gott neben dem Schöpfer nichts gewußt. Die erste Kunde von einem zweiten Gott habe Marcion gebracht. Man dürfe aber keinen Gott annehmen,

1 Praescr. haer. 44 (Kr. 58, 33).

2 Vgl. carne Chr. 2 (Kr. 192).

3 Carne Chr. 2 (Kr. 192, 32).

4 Marc. 4, 38 (Kr. 551, 1).

5 Vgl. Marc. 1, 22 (Kr. 318, 8). 
den sich ein Mensch nach seinem Sinn zurechtgelegt habe, außer er sei denn offenbar ein Prophet. Wenn Marcion dafür gelten wolle, so müsse er es beweisen. In weitere Verhandlungen müßte man sich hier gar nicht einlassen. - Es ist also hier ganz deutlich die Rede von einer praescriptio, und wenn Tertullian sie auch hier noch nicht nennt, so im folgenden. "Sed quomodo", ruft er anschließend aus, "funditus evertetur antichristus, nisi ceteris quoque iniectionibus eius elidendis locus detur, relaxata praescriptionum defensione? Accedamus igitur ... ${ }^{1}$ Eine gründliche Auseinandersetzung mit den einzelnen Irrtümern ist also trotz der Präskriptionen einmal notwendig, weil der Antichrist, der hinter der Häresie steckt, nur auf diese Weise endgültig gestürzt werden kann.

Einen andern, nicht weniger bedeutsamen Grund für die Retraktationen erfahren wir aus der Schrift gegen Praxeas, den Anhänger der Patripassianer. Der in einem Satz erwähnten Irrlehre des Praxeas stellt der Verfasser die Glaubensregel der Kirche gegenüber. Er hebt dabei hervor, da $\beta$ diese Glaubensregel aus der Entstehungszeit des Evangeliums stamme, früher sei als die frühesten Häretiker, von Praxeas, der erst von gestern sei, gar nicht zu reden. Und abschließend wird erklärt : "Dadurch ist in derselben Weise gegen sämtliche Häresien schon von diesem Standpunkt aus das Urteil im voraus gefällt : das Früheste ist immer das Richtige, das Spätere immer das Falsche. " ${ }^{2}$ Das ist aber nichts anderes als die bekannte zweite Präskription aus praescr. haer. 21, die hier vor allen andern Argumenten gegen Praxeas angerufen wird ${ }^{3}$. Doch schon im nächsten Satz verspricht der Autor, unbeschadet dieser Präskription, auch den Retraktationen Raum zu geben, d.h. er will es nicht bei der Präskription bewenden lassen, sondern mit dem Irrtum des Praexas sich gründlich auseinandersetzen : "Sed salva ista praescriptione ubique tamen propter instructionem et munitionem quorundam dandus est etiam retratatibus locus, vel ne videatur unaquaeque perversitas non examinata, sed praeiudicata damnari. » 4 Tertullian wird aus Erfahrung wissen, da $B$ die Einwände der Häretiker für viele Christen eine ernste Gefahr bedeuten ;

1 Marc. 1, 22 (Kr. 318, 18).

2 Prax. 2 (Kr. 229, 17): "Quo peraeque adversus universas haereses iam hinc praeiudicatum sit id esse verum, quodcumque primum, id esse adulterum, quod esse posterius."

${ }^{3}$ Siehe oben S. $64 \mathrm{ff}$.

4 Prax. 2 (Kr. 229, 20). 
es fehlt vielen die erforderliche apologetische Bildung, um den Häretikern Rede und Antwort zu stehen; und da sie auch bei sich selber mit den Behauptungen derselben nicht fertig werden, beginnen sie im Glauben schwach zu werden. Neben dem Präskriptionsargument ist daher aus praktischen Gründen nichtsdestoweniger eine einläßliche Widerlegung der einzelnen Irrtümer, prozeßrechtlich ausgedrückt, eine retractatio, notwendig, weil gewisse Christen sie zur Unterweisung und Festigung nötig haben, "oder - und dieser Grund kann sowohl für die Häretiker wie Christen gelten - damit es nicht den Anschein gewinne, als würden die einzelnen Irrtümer ohne Untersuchung auf eine vorgefaßte Meinung hin verurteilt». Dies könnte sowohl schwachen Christen zu Zweifeln wie den Häretikern zu Anschuldigungen Anlaß geben.

Eine ähnliche Begründung der Retraktationen wird im 1. Buch gegen Marcion gegeben. Der Autor beruft sich schon im 1. Kapitel auf die 2. Präskription in praescr. haer.: "In tantum enim haeresis deputabitur quod postea inducitur, in quantum veritas habebitur quod retro et a primordio traditum est. " Doch ist dieses Argument Gegenstand von praescr. haer. Daher : "Sed alius libellus (d. h. praescr. haer.) hunc gradum sustinebit adversus haereticos, etiam sine retractatu doctrinarum revincendos, quod hoc sint de praescriptione novitatis. " Anschließend folgt die Begründung, warum Marcion nun trotzdem noch im einzelnen widerlegt wird : "Nunc quatenus admittenda congressio est interdum, ne compendium praescriptionis ubique advocatum diffidentiae deputetur, regulam prius adversarii praetexam ... ${ }^{1}$ Der Apologet befürchtet demnach, das bei jeder Gelegenheit angerufene Abkürzungsverfahren der Präskription könnte Mißtrauen erregen.

Nach diesen Ausführungen steht fest, daß Tertullian von der Unzulänglichkeit einer Anwendung der prozessualen praescriptio auf die Apologetik und dementsprechend von der Notwendigkeit der Retraktationen überzeugt war. Diese Überzeugung kommt sogar in jenen Stellen zum Arusdruck, wo es sich mehr um eine Anspielung oder Skizzierung des Präskriptionsgedankens handelt ${ }^{2}$.

In der oben erwähnten Stelle von apol. 7 wird den heidnischen Richtern eine Präskription auf Grund ihrer Gleichgültigkeit entgegengehalten ${ }^{3}$. Deshalb hält sich aber Tertullian mitnichten der Mühe ent-

1 Marc. 1,1 (Kr. 292, 4).

2 Siehe oben S. $83 \mathrm{ff}$.

${ }^{3}$ Siehe oben S. 90. 
hoben, sich anschließend mit den Verleumdungen der Heiden gründlich auseinanderzusetzen.

Nichtsdestoweniger hält es Tertullian in nat. 2, 1 nach jener Präskription, die er auf Grund des eigenen Zugeständnisses der Heiden gegen den Götterglauben erheben möchte ${ }^{1}$, für notwendig, die perversitas des Götterglaubens mit ausführlichen Argumenten zu widerlegen. Er müsse, erklärt er, von dieser einmaligen Widerlegung mittels der Präskription absehen und den Kampf gegen all das unternehmen, was das Gewissen der Heiden verhärte, nämlich gegen die: institutiones maiorum, auctoritates receptorum, leges dominantium, argumentationes prudentium, vetustatem, consuetudinem etc. " ${ }^{2}$

Nach diesen Feststellungen erhebt sich die Frage, welcher a pologetische Wert der Präskription dennoch zukomme, wenn sie ja doch der Retraktation bedarf. Daß Tertullian der Präskription - wir meinen hauptsächlich die zwei Präskriptionen in praescr. haer. 21 trotz der Notwendigkeit der Retraktation einen besondern Wert beimißt, läßt er deutlich durchblicken. Aber diese Bewertung der Präskription hält sich, in kluger Berücksichtigung ihrer nur beschränkten Anwendungsmöglichkeit auf die Apologetik, in den angemessenen Grenzen. Für Tertullian ist die Präskription sozusagen ein argumentum generale. So äußert er sich am Schluß von praescr. haer. : "Sed nunc quidem generaliter actum est nobis adversus haereses omnes ... " ${ }^{3}$ Die zwei Präskriptionen in praescr. haer. 21 sind ein Schlag gegen alle Häresien zugleich. Trotzdem, oder gerade aus dem Grunde, weil die zwei Präskriptionen alle Häresien nur unter dem einen Gesichtspunkt der Priorität bzw. Posterität widerlegen, bleibt die Notwendigkeit bestehen, gewissen Häresien "quibusdam" (vorab wohl den gefährlicheren) auch noch im besondern, "specialiter " 4 , zu antworten.

So behält die Präskription als eine Art Gesamtwiderlegung ihren vollen Wert neben den Einzelwiderlegungen. Darum bemerkt der Apologet in Prax $2{ }^{5}$ zutreffend, "salva ista praescriptione", unbeschadet dieser Präskription, wolle er aber auch den Retraktationen Raum geben. Über den theologischen Beweiswert dieses argumentum generale wird im nächsten Abschnitt die Rede sein.

1 Siehe oben S. 91.

2 Nat. 2, 1 (RW. 94, 8).

3 Praescr. haer. 44 (Kr. 58, 33).

4 Praescr. haer. 44 (Kr. 58, 36).

5 Siehe oben S. 145. 
Zum Schlusse dieses Abschnittes sei noch auf eine Schwierigkeit hingewiesen, die gegen die Übertragung der prozessualen praescriptio auf die Apologetik vorgebracht werden könnte.

Es besteht nicht notwendig ein innerer Zusammenhang zwischen der praescriptio des Prozesses und dem Streitgegenstand, z. B. zwischen einem Verbrechen und der praescriptio, die eine Verfallsfrist geltend macht.

Diese Seite der prozessualen praescriptio könnte sich in ihrer Anwendung auf die Apologetik dahin auswirken, daß eine Streitfrage durch eine theologische Präskription abgewiesen würde, die zur Streitfrage in keinem innern Zusammenhang stände. Tertullian war aber ein zu tiefblickender Jurist und Theologe, als da $B$ ihm dieser Fehler unterlaufen wäre. Die beiden Präskriptionen, die er in praescr. haer. 21 formuliert, stehen mit der eigentlichen Streitfrage, die durch diese Präskriptionen entschieden werden soll, in einem innern Zusammenhang.

Die Häretiker behaupten, sie besitzen die unverfälschte Lehre Christi. Es wurde schon an früherer Stelle dieses Kapitels darauf aufmerksam gemacht, da $B$ die Katholiken und Häretiker sich wenigstens in diesem Punkte treffen, daß sie beide ihre Lehre von Christus herleiten.

Diese gemeinsame Basis, Christus, bildet nun für Tertullian den Ausgangspunkt zur Formulierung der zwei Präskriptionen : 1. Christus hat seine Lehre nur den Aposteln übergeben; auf dieser ersten Präskription baut die zweite weiter : 2. Die Apostel haben die ihnen anvertraute Lehre den apostolischen Urgemeinden übergeben; folglich können nur diese Gemeinden zuständig sein und erklären, was Lehre der Apostel bzw. Offenbarung Christi ist. Tertullian knüpft, wie wir sehen, an den Streit der Häretiker an, er geht von einer ge meinsamen Prämisse aus. Wollen die Häretiker dieselbe und damit ihre ganze Position nicht aufgeben, kann Tertullian anderseits seine Präskriptionen, die von dieser Prämisse ausgehen, stringent beweisen, was der Fall ist, dann müssen die Häretiker die Präskriptionen theoretisch, praktisch tun sie es ja doch nicht, anerkennen, und dies auf Grund der Einsicht in den ursächlichen Zusammenhang, der zwischen den Präskriptionen und der eigentlichen Streitfrage (genauer der gemeinsamen Basis in dieser Streitfrage) besteht. Die Häretiker müssen die Präskriptionen anerkennen auf Grund innerer Stringenz, während der Kläger im Prozeß, der mit einer praescriptio abgewiesen wird, diese auf den äußern Zwang des Gesetzgebers bzw. Richters hin anerkennen muß. Die prozessuale praescriptio weist den Streit, der zwischen 
Kläger und Beklagtem besteht, ab, ohne ihn zu lösen, das ist ja ausgerechnet der $Z$ weck der prozessualen praescriptio ; die beiden apologetischen praescriptiones in praescr. haer. 21 hingegen lösen den Streit, der zwischen den Katholiken und Häretikern besteht. Die theologische praescriptio ist ein Beweis, eine Widerlegung.

\section{Die 2. Präskription in praescr. haer. 21 theologisch nicht beweiskräftig}

Von den verschiedenen Präskriptionen, die Tertullian in seine Schriften einstreut, sind nur jene zwei in praescr. haer. 21 weiter ausgeführt und in den wohldurchdachten Plan eines ganzen Traktates eingefügt. Diese zwei Präskriptionen sind Gemeingut der Theologie geworden. Besonders die zweite, von Tertullian "praescriptio novitatis " genannt, mit der er den Hauptstoß gegen die Häretiker führt, hat den Namen des Apologeten berühmt gemacht ${ }^{1}$. Wir finden es daher angebracht, $\mathrm{da} B$ diese 2. Präskription nach ihrer theologischen Beweiskraft noch eigens untersucht werde.

Zwei geschichtliche Tatsachen und die zwangsläufig sich daraus ergebenden Folgerungen bilden den Inhalt der zwei Präskriptionen, die im Mittelpunkt des Traktates De praescriptione haereticorum stehen:

1. Präskr. : Christus hat die Apostel mit der Verkündigung seiner Lehre beauftragt, folglich sind diese die allein zuständigen Verkünder der Lehre.

2. Präskr.: Die Apostel wiederum haben Gemeinden gegründet; infolgedessen können nur diese Gemeinden über den wahren Inhalt der apostolischen Predigt Auskunft geben ${ }^{2}$.

Mit diesen beiden Präskriptionen, die untrennbar miteinander verknüpft sind, sollen die Häretiker ebenso kurz wie schlagend widerlegt, und der Nachweis erbracht werden, daß sich die Wahrheit auf Seiten Tertullians bzw. der von ihm verteidigten Kirche findet.

Die 1. Präskription ist theologisch unanfechtbar. Daß Christus die Apostel und sie allein mit der Verkündigung seiner Lehre betraut, die Kirche also gewissermaßen auf dem Fundamente der Apostel auferbaut hat, ist geschichtliche Tatsache. Die notwendige Folge davon ist, daß die Apostel nach Christus die ersten unumgänglichen Lehrer der Kirche sind.

1 Vgl. die Ausführungen oben S. 94 ff. 2 Vgl. oben S. 52. 
Anders verhält es sich mit der 2. Präskription. Die Erklärung, daß noch am Ende des 2. Jahrh. nur die von den Aposteln persönlich gegründeten Urgemeinden über den wahren Inhalt der Apostelpredigt befragt werden dürfen, wirkt verdächtig. Unmittelbar vorher (praescr. haer. 20) war noch die Rede von der ungetrübten Einheit der Lehre (eiusdem sacramenti una traditio), die die unmittelbar wie mittelbar apostolischen Gemeinden so eng miteinander verbinde, daß sie alle im Grunde eine einzige Gemeinde bildeten (una omnes). Aus welchem Grunde werden nun in der 2. Präskription die mittelbar apostolischen Gemeinden ausgeschlossen, und warum sollen die unmittelbaren d. i. die apostolischen Urgemeinden allein entscheiden können, was als apostolische Lehre zu gelten habe und was nicht, wenn sie doch anerkanntermaßen alle dieselbe Lehre teilen ? Tatsächlich liegt hier, in der 2. Präskription, der wunde Punkt in der theologischen Beweisführung Tertullians.

Wie Tertullian in der 1. Präskription von Christus und den Aposteln spricht, so würde er sich auch in der 2. Präskription präziser ausdrücken, wenn er, statt von den apostolischen Urgemeinden, von den Bischöfen der apostolischen Urgemeinden sprechen würde. Denn auch für Tertullian ist, wie wir noch sehen werden, der Bischof der von den Aposteln bestellte, amtliche und erste Lehrer der Gemeinde. Die 2. Präskription erklärt also, genauer ausgedrückt, nur die Bischöfe der von den Aposteln persönlich gegründeten Gemeinden für zuständig, um im "Prozeß " gegen die Häretiker zu erklären, welches der wahre Inhalt der Apostelpredigt sei. Daß Tertullian dabei nicht etwa an einen gemeinsamen Lehrentscheid dieser Urgemeinden, geschweige der apostolischen Urgemeinden und ihrer Tochtergemeinden zusammen, denkt, steht aus praescr. haer. 36 fest und wird uns im Verlaufe dieses Abschnittes noch beschäftigen.

Die Bevorzugung der apostolischen Mutterkirchen vor deren Tochterkirchen, wie sie die 2. Präskription ausspricht, ist von Tertullian her gesehen folgerichtig, wenn wir uns seine Auffassung von der bischöflichen Lehrgewalt vor Augen halten. K. ADAM äußert sich hierüber wie folgt:

"Tertullian sah in den Bischöfen nicht die Repräsentanten der Apostel und ihrer Gewalt, sondern lediglich amtliche Zeugen der Apostellehre. Unmittelbare Zeugen, insofern sie Apostelschüler oder deren Nachfolger waren; mittelbare, insofern sie ihre Lehre mit jener der Apostelbischöfe in Einklang zu setzen vermochten, also apostolisch 
erhielten. Diese Zeugenschaft hat rein menschlichen Charakter, bietet also auch nur rein menschliche Gewißheit. " ${ }^{1}$

"Anderseits aber entbehrt die Zeugenschaft der Bischöfe nicht jeglicher Autorität. Mit der doctrina Apostolorum verbindet Tertullian auch eine potestas docendi, nur trägt sie lediglich disziplinären Charakter. Sie erfließt ihm einerseits aus der besondern Eigenschaft der Bischöfe als Lehrzeugen, anderseits aus ihrer Stellung als Hirten der Kirche. ") ${ }^{2}$

Die Lehrgewalt des Bischofs ist, kurz zusammengefaßt, in der Vorstellung Tertullians von zwei Eigenschaften gekennzeichnet : einerseits ist der Bischof für ihn nicht mehr als ein historischer Zeuge der apostolischen Lehre - " apostolici seminis traduces " ${ }^{3}$-, dem jegliche Unfehlbarkeit abgeht; anderseits erscheint aber diese natürlich-historische Zeugenschaft doch wieder von einer gewissen disziplinären Autorität getragen, insofern der Bischof als der von den Aposteln bestellte oberste Lehrer und Hirte der Gemeinde dasteht. Das Lehramt der Bischöfe verbürgt die echte, unverfälschte, wenn auch nicht göttlich beglaubigte Gewißheit der Überlieferung: "porro quod traditum erat, id erat verum, ut ab eis traditum, quorum fuit tradere " 4 .

Tertullian war ein Geist, der seine Ideen zu Ende dachte. Das trifft erst recht zu bei seinem Irrtum über den Lehrberuf des Bischofs. Es war aber auch gar nicht anders möglich, als da $\beta$ dieser Irrtum, der die Fundamente der Kirche antastet, im theologischen Denken Tertullians die folgenschwersten Auswirkungen zeitigte.

Der Irrtum wirkt sich vorerst dahin aus, da $\mathrm{B}$ Tertullian in der $\mathrm{Zu}-$ verlässigkeit und Sicherheit der bischöflichen Lehrübermittlung eine Abstufung macht, auf die er sehr viel Gewicht legt. Wie schon in der Analyse dargelegt wurde, unterscheidet er in den Kap. 20-21 direkt und indirekt apostolische Gemeinden. Die direkt apostolischen Gemeinden erhalten als Mutter- und Urkirchen den Vorzug vor den indirekt apostolischen, denn sie haben die christliche Lehre von den Aposteln persönlich - " tam viva, quod aiunt voce, quam per epistolas postea $\|^{5}$ - empfangen und sollen daher nach der 2. Präskription allein zuständig sein, um über den wahren Inhalt der Predigt der Apostel Auskunft zu geben. Für die indirekt apostolischen Gemeinden ist die

1 Vgl. K. ADAM, Der Kirchenbegriff Tertullians 42.

2 A. a. O. 43.

3 Praescr. haer. 32 (Kr. 40, 13).

4 Carne Chr. 2 (Kr. 192, 29).

5 Praescr. haer. 21 (Kr. 25, 10). 
Übereinstimmung mit den direkt apostolischen Gemeinden das Kriterium der Rechtgläubigkeit. Diese Unterscheidung ist vom Standpunkt Tertullians nur logisch. Denn wenn das Lehramt des Bischofs sich in einer rein natürlich-historischen Funktion erschöpft, dann darf man den Bischöfen der von den Aposteln persönlich gegründeten Gemeinden dank ihrer zeitlich und örtlich besonders nahen Verbindung mit den Aposteln auch eine größere Treue und Zuverlässigkeit in der Weitergabe ihrer Lehre zutrauen.

Eine weitere Folge der historischen Auffassung Tertullians vom Bischof als Kirchenlehrer ist die Gleichsetzung der apostolischen Urgemeinden in bezug auf ihre Zuständigkeit und Zuverlässigkeit in der Verkündigung der christlichen Lehre. Tertullian kennt keinen Lehrprimat, so wenig wie einen Jurisdiktionsprimat. Warum sollte denn auch einer dieser apostolischen Urgemeinden, etwa Rom, hinsichtlich der Lehrautorität vor den übrigen ein Vorrang zukommen ? Sie stehen ja alle auf derselben Stufe einer bloß historischen Lehrübermittlung. Je nach Wohnsitz und Möglichkeit möge man daher, so praescr. haer. 36, gleicherweise entweder Korinth, Philippi, Thessalonich, Ephesus oder Rom aufsuchen, um die wahre Lehre kennen zu lernen ${ }^{1}$. Die Hauptpunkte des Symbolums werden nur deshalb im Anschluß an die Erwähnung Roms angeführt, weil Rom die Mutterkirche der karthagischen Christengemeinde ist. Weder Rom noch eine andere von diesen apostolischen Urgemeinden nimmt in den Augen Tertullians in der Lehrüberlieferung und Lehrautorität einen Vorrang vor den andern ein. $\mathrm{Er}$ erklärt vielmehr in unmißverständlichem Zusammenhang mit der Lehre, sowohl die direkt wie indirekt apostolischen Gemeinden seien alle erste "omnes primae" ", denn im Grunde seien diese zahlreichen und großen Gemeinden dank ihrer apostolischen Wurzeln und der Einheit in der Lehre nur eine einzige Kirche " una omnes " (scil. ecclesiae). Diese eindeutige Gleichstellung aller apostostolischen Gemeinden ist umso merkwürdiger, da Irenäus um dieselbe Zeit und sicher als Sprachrohr der allgemeinen Überzeugung der Kirche die "potentior principalitas" der römischen Kirche bzw. ihres Bischofs bezeugt ${ }^{3}$.

Nachdem wir die irrige Auffassung Tertullians von der bischöflichen

1 Vgl. oben S. 76.

2 Praescr. haer. 20 (Kr. 24, 24) : Omne genus ad originem suam censeatur necesse est. Itaque tot ac tantae ecclesiae una est illa ab apostolis prima, ex qua omnes. Sic omnes primae ct apostolicae, dum una omnes."

3 Adv. haer. 3, 3, 2 (Florilegium Patristicum Fasc. 4 (Bonn 1930) S. 42, 19). 
Lehrgewalt und deren folgenschweren Auswirkungen auf seinen Kirchenbegriff dargestellt haben, ist die Haltlosigkeit der 2. Präskription erwiesen. Diese Haltlosigkeit tritt noch viel klarer in Erscheinung, wenn wir jene Kapitel in praescr. haer. untersuchen, in denen Tertullian die 2. Präskription theologisch unterbaut und begründet und gegen die Einwände der Häretiker verteidigt.

Nach dem Zeugnis der Analyse entwickelt Tertullian die zwei Präskriptionen samt den dazugehörigen Argumenten nach einem bestimmten Plan ${ }^{1}$. Die ersten Grundlagen für die zwei Präskriptionen sind im 20. Kap. zu suchen, wo die historischen Tatsachen der Gründung und ersten Ausbreitung der Kirche angeführt werden. Die Hauptbeweise aber sind in Kap. 22-36 enthalten. Den prozeßrechtlichen Rahmen - die praescriptio ist ein Begriff des Prozeßrechts - seiner Streitschrift wahrend, verteidigt hier Tertullian die zwei Präskriptionen gegen die drei Einwände der Gegner. Am meisten Bedeutung kommt dem 3. Einwand, der die 2. Präskription angreift, bzw. der Widerlegung des 3. Einwandes zu. Dieser 3. Einwand behauptet, die apostolischen Urgemeinden hätten die Apostel falsch verstanden und daher einen Irrtum überliefert. Der Einwand wird vorerst abgewehrt mit dem Hinweis auf die wunderbare, vor aller Welt einzig dastehende Lehreinheit sowie mit dem unserem Autor geläufigen Prinzip von der Priorität der Wahrheit vor dem Irrtum, dem ein äußerst wirksamer Exkurs in die Geschichte folgt. Aber der entscheidende Schlag wird erst in den Kap. 32-34 geführt. Herausfordernd und siegesbewußt hält Tertullian den Häretikern die Tatsache entgegen, da $\beta$ die apostolischen Gemeinden allein Gründungen der Apostel seien, da $B$ die Apostel selber ihnen die ersten Bischöfe gaben, von denen her die apostolische Lehre in ununterbrochenen Bischofsreihen weitergegeben wurde bis in die unmittelbare Gegenwart. Tertullian läßt seine unbeirrte Überzeugung durchblicken, daß er mit dem Nachweis der Apostolizität des Ursprungs und der Sukzession die 2. Präskription endgültig und unwiderruflich gefestigt und damit die Wahrheit der von ihm verteidigten Lehre bewiesen habe. Dabei ist gerade dieses letzte Argument, das der ausgedehnten Beweisführung zugunsten der beiden Präskriptionen, besonders der zweiten, den entscheidenden Halt verleihen sollte, infolge der irrtümlichen Auffassung des Apologeten über die bischöfliche Lehrgewalt entwertet, wodurch auch die 2. Präskription ihre theologische Beweiskraft einbüßt.

1 Siehe oben S. $43 \mathrm{ff}$. 
Wir fragen unwillkürlich, wie es möglich war, daß ein so scharfblickender Geist, der zudem mit glühender - vir ardens - ja fanatischer Liebe an der Kirche hing, einem so verhängnisvollen Irrtum verfallen konnte. U. E. haben zum Entstehen dieses Irrtums zwei Ursachen zu sammengewirkt, die wir im folgenden kurz analysieren.

Einerseits war sich der Theologe Tertullian nie klar geworden über die Art und Weise des Beistandes des Heiligen Geistes in der Kirche. Die eigentliche Funktion und Würde des Bischofs, als Lehrer Organ des Heiligen Geistes zu sein, war ihm verborgen geblieben. Anderseits war Tertullians theologisches Denken von römisch-rechtlichen Vorstellungen und Elementen in geradezu bedrohlicher Weise durchsetzt.

$\mathrm{Da} B$ die vielbestaunte Einheit in der Lehre, um mit dem ersten Punkt zu beginnen, das Werk des Heiligen Geistes, daß also der Heilige Geist gewissermaßen der Lehrer der Kirche ist, hat Tertullian zwar nie angezweifelt. Im Gegenteil! Mit begeisterten Worten preist praescr. haer. 28 das Wirken des Heiligen Geistes in der Kirche. Eintretend auf die Behauptung der Häretiker, die apostolischen Urgemeinden hätten geirrt, ruft er aus : "Also gut, nehmen wir an, alle Gemeinden haben geirrt, auch der Apostel habe sich getäuscht, als er sein Zeugnis ausstellte, der Heilige Geist habe sich um keine Gemeinde bekümmert, um sie in die Wahrheit einzuführen, obwohl er von Christus dazu gesandt und vom Vater dazu erbeten war, Lehrer der Wahrheit zu sein. Nehmen wir an, er habe sein Amt als Gutsverwalter Gottes, als Stellvertreter Christi vernachlässigt und zugelassen, $\mathrm{da} B$ die Gemeinden das vorläufig anders verstanden, anders glaubten, was er selbst durch die Apostel verkündete. Ist es etwa wahrscheinlich, daß so viele und große Gemeinden sich zu dem einen Glauben verirrt haben ? "1

K. ADAm bemerkt zu dieser Stelle, daß Tertullian es liebe, selbstverständliche Grundwahrheiten in scheinbar flüchtig hingeworfene Floskeln zu kleiden. Tertullian wei $\beta$, daß solche zum Widerspruch reizende Formulierungen ihre Wirkung nicht verfehlen ${ }^{2}$. Einprägsamer könnte er seiner Überzeugung, daß der Heilige Geist, "Dei villicus" und

1 Praescr. haer. 28 (Kr. 34, $1 \mathrm{ff}$.) : "Age nunc omnes erraverint; cleceptus sit et apostolus dei testimonium reddendo quibusclam; nullam respexerit spiritus sanctus, ut eam in veritatem deduceret, ad hoc missus a Christo, ad hoc postulatus de patre, ut esset doctor veritatis; neglexerit, ut aiunt, officium dei villicus, Christi vicarius, sinens ecclesias aliter interim intellegere, aliter credere quod ipse per apostolos praedicabat; ecquid verisimile est, ut tot ac tantae in unam fidem erraverint ?"

2 Vgl. K. AdAM, Kirchenbegriff 35. 
"Christi vicarius ", für die vielbewunderte Einheit der Kirche die allein hinreichende Erklärung sei, nicht Ausdruck verleihen. DaB letztlich der Heilige Geist die Kirche regiert und in ihrer Einheit erhält, davon ist der Apologet felsenfest überzeugt, aber über das Wie dieses göttlichen Beistandes hat er sich nie Rechenschaft gegeben. Für ihn wirkt der Heilige Geist einfach in der Kirche. Er denkt nicht im entferntesten daran, diesen göttlichen Beistand auf den Episkopat als sein Organ zu lokalisieren, durch das er die Kirche führen und vor Irrtum bewahren soll ${ }^{1}$. Wenn aber Tertullian in einer so zentralen Frage der Theologie dermaßen verschwommene Begriffe hatte, wie leicht gewannen da bewußte und unbewußte Vorstellungen des römischen Rechts, dem er mit seinem ganzen Denken und Vorstellungsvermögen so sehr verpflichtet war, Spielraum! Mochte Tertullian vom apostolischen Ursprung des Bischofsamtes auch überzeugt sein und dem Bischof als Hirt und Lehrer in der Gemeinde eine unumschränkte Stellung zugestehen, der Bischof blieb in seinen Augen trotzdem nur ein menschlicher Lehrer und Beamter. Hat Tertullian vielleicht den Bischof, der in der christlichen Gemeinde die Stelle eines ersten Lehrers einnimmt, den angesehenen und einflußreichen Vorstehern der römischen Rechtsschule gleichgestellt?

Welche von beiden Ursachen die frühere war oder zum Entstehen des Irrtums über das bischöfliche Lehramt mehr beigetragen hat, das verschwommene Denken in einer so zentralen theologischen Frage oder römisch-rechtliche Vorstellungen, läßt sich nicht entscheiden. Es ist ebenso denkbar, daß durch den Mangel klarer theologischer Begriffe der Spielraum geschaffen wurde für juristische Vorstellungen, wie es möglich ist, daß Tertullians juristische Betrachtungsweise so ausschließlich war, da $B$ er sich von Anfang an über das Amt des Bischofs seine eigenen Vorstellungen machte.

Gerade den letzten Punkt dürfen wir nicht unterschätzen. Es ist eine allgemeine Erscheinung, daß Beruf und Lebensaufgabe den Menschen formen und in seinem Denken zutiefst beeinflussen. Die Schriften des Kirchenlehrers von Hippo verraten den Philosophen ebenso wie die Hirtenschreiben Cyprians den ehemaligen Rhetor. So tragen auch die Schriften Tertullians das unverkennbare Gepräge ihres Verfassers. Jede Seite, oft jeder Satz weist mit seinen juristischen Fachausdrücken und Vergleichen auf den gewiegten Juristen. Tertullian sieht alles und jedes

1 Vgl. K. ADAM, Kirchenbegriff 42. 
vom juristischen Standpunkt aus. Für jeden Gegenstand der christlichen Lehre hat er einen juristischen Terminus oder Vergleich zur Stelle. Mußte nicht hinter dieser einseitigen Betrachtungsweise, die alles in eine juristische Schablone preßt, die Gefahr des Irrtums lauern? Diese Gefahr drohte Tertullian umso mehr, da er erst in reifen Jahren Christ wurde, wo ihm seine juristische Denkweise, wie seine Schriften hinlänglich beweisen, zur zweiten Natur geworden war und er erst anfing, sich in den Reichtum der christlichen Wahrheiten allmählich einzuleben. Nun zählen aber die Präskriptionsschrift und die erste Fassung der 5 Bücher gegen Marcion, aus denen wir über den Irrtum Tertullians den wesentlichen Aufschluß erhalten, gerade zu den frühesten Erzeugnissen seiner apologetischen Wirksamkeit.

Umso naheliegender ist daher der Verdacht, Tertullian sei in seinem folgenschweren Irrtum über das bischöfliche Lehramt von römischrechtlichen Vorstellungen beeinflußt, und umso berechtigter die Absicht, im römischen Recht nach einer möglichen Erklärung zu fahnden. Wir schicken für die folgende Untersuchung einige orientierende Gedanken voraus.

Wir hatten in der bischöflichen Lehrgewalt, so wie sie Tertullian sieht, zwei Momente unterschieden : einerseits die rein natürlich-historische Lehrübermittlung, anderseits die natürlich-disziplinäre Lehrautorität, mit der der Bischof als Kirchenlehrer bekleidet ist. Für diese beiden Komponenten suchen wir im römischen Recht, von dessen Geist und Stil Tertullian so stark beeinflußt ist, eine Parallele. Wir vermuten diese Parallele in der römischen Rechtsschule. Unsere Untersuchung gliedert sich in drei Abschnitte. Zuerst unterziehen wir die maßgeblichen Texte Tertullians einer gründlichen Prüfung, geben anschließend eine gedrängte Darstellung der römischen Rechtsschule mit ihrer successio, um endlich an dritter Stelle die Gründe vorzulegen, die für den Einfluß der Rechtsschule auf Tertullians Irrtum sprechen.

a) In den uns erhalten gebliebenen Schriften Tertullians findet sich leider nur eine ausführlicherere Stelle, die uns über seine Auffassung vom Lehrberuf des Bischofs nähern Aufschluß gibt : praescr. haer. 32 (Kr. 39 ff.). Ihr Wortlaut ist folgender :

"Ceterum si quae (scil. haereses) audent interserere se aetati apostolicae, ut ideo videantur ab apostolis traditae, quia sub apostolis fuerunt, possumus dicere : edant ergo origines ecclesiarum, suarum, evolvant ordinem episcoporum suorum, ita per succes- 
sionem ab initio decurrentem, ut primus ille episcopus aliquem ex apostolis vel apostolicis viris, qui tamen cum apostolis perseveraverit, habuerit auctorem et antecessorem. Hoc enim modo ecclesiae apostolicae census suos deferunt, sicut Smyrnaeorum ecclesia Polycarpum ab Johanne collocatum refert, sicut Romanorum Clementem a Petro ordinatum edit. Perinde utique et ceterae exhibent, quos ab apostolis in episcopatum constitutos apostolici seminis traduces habeant."

Der möglichen Behauptung der Häretiker, sie stammten ebenfalls aus apostolischer Zeit, zuvorkommend, fordert Tertullian diese auf, sich über die Anfänge ihrer Gemeinden auszuweisen und die Reihenfolge ihrer Bischöfe $\mathrm{zu}$ entrollen, d. h. den Nachweis der Apostolizität des Ursprungs und der Sukzession zu liefern. Der Satz, der mit "evolvant ordinem " beginnt und mit "antecessorem " schließt, bildet als Kernstück des zitierten Textabschnittes den Gegenstand unseres besonderen Interesses.

"Ordo" und "successio" sind die beiden Begriffe, von denen die Deutung des Satzes hauptsächlich abhängt. Aus dem Zusammenhang ergibt sich eindeutig, da $\beta$ " ordo " hier mit Reihenfolge zu übersetzen ist. Ganz entsprechend bezeichnet auch Irenäus die Liste der von ihm auf-

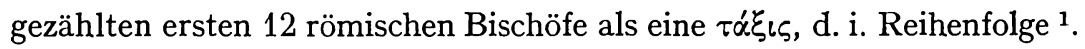
Tertullian fordert die Häretiker auf, "ordinem episcoporum ab initio decurrentem", die "Reihenfolge der Bischöfe in ihrem Verlauf von Anfang an " zu entrollen (evolvant ... denkt Tertullian an das Entrollen der Papyrusrolle, die die Bischofsliste enthält?). Wenn wir "per successionem " vorläufig einklammern, lautet der Satz in der Übersetzung wie folgt :

"Sie (die Häretiker) mögen die Reihenfolge ihrer Bischöfe entrollen, die in der Weise von Anfang an verläuft (die so beginnt), da $B$ jener erste Bischof einen von den Aposteln oder apostolischen Männern, der jedoch bei den Aposteln ausharrte, zum Lehrer und Vorgänger hatte. Auf diese Art weisen nämlich die apostolischen Gemeinden ihren Ursprung nach. ")

Der "ordo episcoporum", auf den die Häretiker sich eventuell berufen, muß mit einem Apostel oder einem von den aposteltreuen apostolischen Männern beginnen. "Denn auf diese Art weisen sich die

1 Vgl. adv. haer. 3, 3, 3 (Flor. Patr., Fasc. 4 S. 4' , 8). 
apostolischen Gemeinden über ihre (apostolischen) Anfänge aus; so berichtet die Gemeinde von Smyrna, daß Polykarp von Johannes (zum Bischof) bestellt, so die römische, daß Klemens von Petrus eingesetzt worden sei. Gerade so geben natürlich auch die übrigen (Gemeinden) die Männer an, die, von den Aposteln ins Bischofsamt eingesetzt, ihnen als Überleiter des apostolischen Samens dienten."

Noch an anderer Stelle - Marc. 4, 5 (Kr. 430, 11 ff.) - beruft sich Tertullian gegenüber den Häretikern auf den "ordo episcoporum". Marcion hat die Kühnheit, für das von ihm zurechtgestutzte Lukasevangelium und die gleicherweise zerpflückten ersten 10 Paulusbriefe die Echtheit zu beanspruchen. Tertullian widerlegt ihn zunächst mit dem uns schon aus praescr. haer. bekannten Nachweis, da $B$ das von der Kirche vorgelegte Lukasevangelium sowie die übrigen kanonischen Bücher älter seien als die Fälschungen Marcions. So bezeuge schon allein der Nachweis des höhern Alters die alleinige Echtheit und den alleinigen apostolischen Ursprung der von den apostolischen Gemeinden überlieferten Schriften. "Kurz, wenn feststeht, daß das wahrer, was früher, das früher, was von Anfang, das von Anfang, was von den Aposteln stammt, dann wird natürlich gleicherweise feststehen, daß das von den Aposteln überliefert ist, was in den Gemeinden der Apostel für heilig und unantastbar galt. " ${ }^{1}$ Was aber in den betreffenden apostolischen Urgemeinden als Evangelium und Schrift der Apostel und als solche für unantastbar galt, kann man auch heute noch, am Ende des 2. Jahrh., in den gleichen Gemeinden - der Apologet nennt Korinth, Galatien, Philippi, Tessalonich, Ephesus und Rom - erfahren 2. Aber welches ist für Tertullian das Kriterium und die Garantie, da $\beta$ diese Gemeinden die Lehre und die Schriften der Apostel noch heute in jener ursprünglichen, unverfälschten Fassung besitzen, in der die Apostel sie ihnen vor mehr als 100 Jahren übergeben haben? Die Antwort gibt uns Tertullian selber : der ordo episcoporum. Nachdem er nämlich die Tochtergemeinden des Apostels Paulus und Rom als gemeinsame Grün-

1 Narc. 4, 5 (Kr. 430, 11) : "In summa: si constat id verius quod prius, id prius quod ab initio, id ab initio quod ab apostolis, pariter utique constabit id esse ab apostolis traditum, quod apud ecclesias apostolorum fuerit sacrasanctum. Videamus, quod lac a Paulo Corinthii hauserint, ad quam regulam Galatae sint recorrecti, quid legant Philippenses, Thessalonicenses, Ephesii, quid etiam Romani de proximo sonent, quibus evangelium et Petrus et Paulus sanguine quoque suo signatum reliquerunt."

2 Ebd. 
dung der beiden Fürstapostel aufgezählt hat, kommt er auf die Tochtergemeinden des Johannes zu sprechen :

Marc. 4, 5 (Kr. 430, 18) : “ Habemus et Johannis alumnas ecclesias. Nam etsi Apocalypsin eius Marcion respuit, ordo tamen episcoporum ad originem recensus in Johannem stabit auctorem. Sic et ceterarum (litterarum, epistolarum ?) generositas recognoscitur."
"Wir haben auch von Johannes Tochterkirchen. Denn obgleich Marcion seine Apokalypse verwirft, so wird die Reihenfolge der Bischöfe - diese Reihenfolge bis zu ihrem Ursprung durchgangen - trotzdem für Johannes als Verfasser einstehen. So wird auch bei den übrigen (Heiligen Schriften) die edle Abkunft (von den Aposteln) erkannt. " (Es folgt die Anwendung auf das Lukasevangelium.)

Sowohl praescr. haer. 32 wie adv. Marc. 4, 5 sprechen vom "ordo episcoporum ", der Reihenfolge der Bischöfe, im Zusammenhang mit der bischöflichen Lehrgewalt, jedoch mit dem Unterschied, daß praescr. haer. 32 die Lehrübermittlung im Vordergrund steht, Marc. 4, 5 aber die Lehrentscheidung. Der "ordo episcoporum", die Bischofsreihe, ist nach praescr. haer. 32 die Brücke, über die die apostolische Lehre zu jeder noch so fernen Generation gelangt. Den gleichen

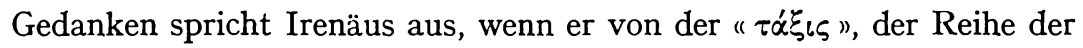
ersten 12 römischen Bischöfe sagt, durch sie sei die Lehre und Tradition der Apostel unversehrt bis auf die Gegenwart weitergegeben worden ${ }^{1}$. Die Lehrübermittlung ist Grundlage für die Lehrentscheidung. Eine zuverlässige Lehrübermittlung ermöglicht auch eine sichere Lehrentscheidung. Während aber Irenäus überzeugt ist, da $B$ letztlich der Heilige Geist durch den "ordo episcoporum " wirkt und ihn im Überliefern und Entscheiden vor Irrtum bewahrt, stellt Tertullian den " ordo episcoporum " ganz auf sich selbst, d. i. auf eine natürliche Ebene. Die Lehrübermittlung ist für ihn nur eine historische Funktion, die Lehrentscheidung nur ein disziplinärer Akt. Man empfindet es daher fast als selbstverständlich und wartet darauf, da $B$ Tertullian gegenüber den Häretikern die Struktur und den innern Verlauf dieses "ordo

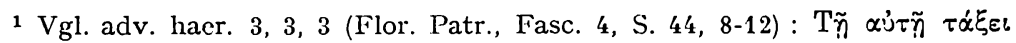

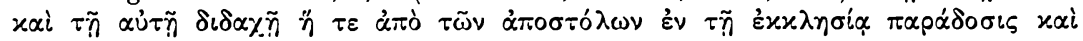

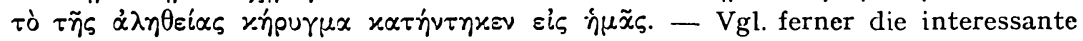
Stelle des Ambrosiaster, Comment. in 2. Tim. 1, 1-2 (Migne PL 17, S. 511): "Quod ideo huic (scil. Timotheo) quasi carissimo filio scribit, ut huius rei imitator exsistat, eadem caeteris tradens, ut per traducem successionum indeficiens sit idoneus doctor, per quem asserta veritas multos acquirat ad vitam promissam." 
episcoporum ", von dem so viel abhängt, noch genauer festlegt, damit er ein nach seiner Vorstellung historisch wirklich zuverlässiger Träger der apostolischen Überlieferung sei. Dies geschieht in praescr. haer. 32. Während nämlich adv. Marc. 4, 5 nur vom " ordo episcoporum " spricht, ist praescr. haer. 32 die Rede vom "ordo episcoporum per successionem decurrens". Mit diesem "per successionem", das wir eingangs dieser Textanalyse vorläufig eingeklammert hatten, wollen wir uns nun im folgenden eingehend befassen.

Der "ordo episcoporum" der apostolischen Gemeinden ist nach Tertullians Worten zunächst ein " ordo ita ab initio decurrens, ut primus ille episcopus aliquem ex apostolis vel apostolicis viris ... habuerit auctorem et antecessorem ". Die Bischofsreihe muß ihren Anfang bei einem Apostel oder einem der sog. apostolischen Männer genommen haben. Weiter präzisiert Tertullian die Art und Weise oder, wenn man will, die innere Struktur im Verlauf der Bischofsreihe, er spricht von einem "ordo episcoporum per successionem decurrens". Grammatikalisch ist "per successionem " adverbiale Bestimmung $\mathrm{zu}$ " decurrere ". Wir erfahren Näheres über die Art und Weise, wie die Bischofsreihe verläuft, sich fortbewegt. Es ist ein "decurrere per successionem ", ein Verlauf durch Nachfolge. Ein Bischof folgt dem andern nach. Der " ordo " ist also genauer ausgedrückt " successio ", die Reihenfolge ist Nachfolge, Aufeinanderfolge. Mit dem Zusatz "per successionem" wird also zunächst einmal die Lückenlosigkeit in der Bischofsreihe angedeutet ${ }^{1}$.

Enthält "per successionem " aber nicht mehr ?

Suc-cedere, suc-cessio heißt in seiner allgemeinsten Bedeutung nachfolgen, nach-rücken an die Stelle eines andern. Succedere, successio ist aber recht eigentlich ein Rechtsbegriff und dieser Charakter haftet dem Ausdruck auch in seiner allgemeinsten Bedeutung immer irgendwie an ${ }^{2}$.

Succedere, successio, successor begegnet in der Sprache des römischen Rechts hauptsächlich in einem zweifachen Sinn : einer Person nachfolgen in bezug auf ein Amt (z. B. successor proconsulis, successor praefecti Aegypti, praesidis) und : einer Person nachfolgen in bezug auf ein Rechtsverhältnis (als Gläubiger, Schuldner und besonders Erbe) ${ }^{3}$.

1 Vgl. S. Augustinus, De nuptiis et concupiscentia 1, 11 : parentes Christi connexione successionis commemorantur.

2 Vgl. Heumann-Seckel, Handlexikon zu den Quellen des röm. Rechts 565.

3 Ebd. 
Wie will Tertullian sein "per successionem " verstanden wissen, im streng juristischen Sinn oder vielleicht nur allgemein ?

Auf den ersten Blick möchte man das letztere annehmen. Der Zusatz " per successionem " scheint auch gar flüchtig hingeworfen. Aber ist dem wirklich so ? Wir führen im folgenden einige Gründe an, die für die streng juristische Deutung des "per successionem" sprechen.

Tertullian drückt sich mit Vorliebe juristisch aus. Wenn man auch nicht jeden Ausdruck ernst zu nehmen hat, so wird man den juristischen Charakter des tertullianischen Stils doch immer berücksichtigen müssen. Nun ist aber successio vornehmlich ein Ausdruck der Rechtssprache, und unsere Stelle, wo Tertullian den Ausdruck verwendet, gehört zu den grundlegenden des ganzen Traktates, wird doch hier, in Kap. 32, der Hauptschlag geführt gegen die Häretiker. Wie wohl abgewogen aber der Apologet Tertullian solche Stellen formuliert, hat die Analyse der Kap. 15-37 gezeigt, wir erinnern nur an Kap. 21, wo die beiden Präskriptionen entfaltet werden.

Wie schon bemerkt, bezeichnet successio im römischen Recht die Nachfolge einer Person auf eine andere in bezug auf ein Amt oder in bezug auf ein Rechtsverhältnis. In unserm Fall kann es sich nur um Nachfolge in ein Amt, eben das Bischofsamt, handeln. Christus hat das Bischofsamt, diesen Inbegriff bestimmter Rechte und Pflichten in der Kirche, geschaffen und die Apostel zu seinen ersten Trägern berufen. Die Apostel wiederum haben ihr Bischofsamt Nachfolgern anvertraut und seither wird dasselbe von Bischof zu Bischof in ununterbrochener Reihenfolge weitergegeben. Jeder Bischof tritt nur an die Stelle seines Vorgängers, er übernimmt dessen bischöfliche Rechte und Pflichten. Jeder ist in bezug auf seinen Vorgänger dessen successor im Bischofsamt. Tertullian darf also mit Fug und Recht sagen, der "ordo episcoporum ", die Reihenfolge der Bischöfe verlaufe von ihrem Anfang, d. h. vom ersten Bischof an, der ein Apostel oder apostolischer Mann war, "per successionem", d. i. durch Amtsnachfolge.

Jeder successor hat einen antecessor, jeder Amtsnachfolger hat einen Amtsvorgänger ${ }^{1}$. Jeder Bischof innerhalb der Kette ist in bezug auf seinen Vorgänger successor, in bezug auf seinen Nachfolger antecessor. Sehen wir uns nun den fraglichen Satz näher an, so machen wir die Feststellung, da $B$ darin sowohl vom antecessor wie successor

1 Vgl. Paulus dig. 5, 1, 55: Edictum, quod ab antecessore datum est... Plane licet omnis ab antecessore numerus finitus sit, solet successor unum edictum dare. 
die Rede ist. Tertullian bezeichnet die Bischofsreihe als "ordo per successionem decurrens ", d. h. jeder Bischof innerhalb der Reihe ist im Hinblick auf seinen Vorgänger successor, Rechtsnachfolger in dessen bischöflichen Rechten und Pflichten. Umgekehrt bezeichnet er den Vorgänger des (hier ersten) Bischofs, der diesem das Bischofsamt erstmals übertrug und so die Bischofsreihe mit ihrer stets sich wiederholenden successio eröffnet, in der Sprache des römischen Rechts korrekt als antecessor : "ut primus ille episcopus aliquem ex apostolis vel apostolicis viris ... habuerit auctorem et antecessorem ". Als Beispiele solcher "antecessores" führt Tertullian Johannes und Petrus an, die Polykarp bzw. Klemens zu ihren Nachfolgern, "successores", bestimmten.

"Auctor » ist im vorliegenden Satz nicht mehr als eine Verstärkung von "antecessor ». Tertullian liebt es, sinnverwandte Wörter zu häufen. "Auctor " kann in unserm Fall Rechtsvorgänger bedeuten : der Apostel oder apostolische Mann ist der (Rechts)-Vorgänger, von dem der erste Bischof der Gemeinde (primus ille episcopus!) die bischöflichen Rechte empfangen mußte. So gedeutet hat "auctor" dieselbe Bedeutung wie " antecessor ". Es besteht auch keine Schwierigkeit, " auctor " mit Lehrer wiederzugeben. In dieser Bedeutung findet sich das Wort in den römischen Rechtsquellen sehr häufig ${ }^{1}$ und ist auch Tertullian nicht unbekannt ${ }^{2}$.

Alle diese Gründe sprechen dafür, daß der uns interessierende Satz juristisches Gepräge hat. Die drei Hauptbegriffe des Satzes sind juristischer Natur, sie gehören zusammen und sind aufeinander abgestimmt : " per successionem " und " antecessor " gehören zusammen, das eine ruft dem andern, " auctor " ergänzt und verstärkt "antecessor ». Es wäre zudem - um ein letztes Argument für den juristischen Grundcharakter des Satzes bzw. des "per successionem" zu geben - in unserem Fall, wo jedes Wort wohl überlegt ist, eine unverständliche Tautologie, wenn "successio" nur in seiner allgemeinsten Bedeutung als zeitliche Aufeinanderfolge, als Nacheinander zu verstehen wäre, denn diese allge-

1 Ulpianus dig. 44, 4, 4, 14: constitutionibus et sententiis auctorum cavetur. Codex $7,32,3$ : auctorum sententiae dissentientes.

Gaius, Institutiones 4, 79: nostrae scholae auctores.

2 Vgl. praescr. haer. 6 (Kr. 8, 13) : Apostolos domini habemus auctores, qui nec ipsi quicquam ex suo arbitrio quod inducerent elegerunt, sed acceptam a Christo disciplinam fideliter nationibus assignaverunt.

Apol. 19 (H. 48, 20) nennt die Philosophen "a u ctores sapientiae". Apol. 21 (H. 53, 17) nennt die Patriarchen "a uctores originales". 
meinste Vorstellung ist schon im "ordo episcoporum" enthalten, der doch auch ein zeitliches und lückenloses Nacheinander ausdrückt. Wenn aber Tertullian wie mit "ordo" so auch mit "successio " nicht mehr aussagen wollte als ein zeitliches Nacheinander, dann hätte es keinen Sinn, den " ordo episcoporum " mittels der "successio " zu präzisieren als einen "ordo episcoporum per successionem decurrens".

Als erster bedeutender kirchlicher Schriftsteller lateinischer Sprache ist Tertullian jedenfalls auch der erste, der die Aufeinanderfolge der Bischöfe im juristischen Sinn als eine "successio" d. i. Amtsnachfolge bezeichnet. Es ist daher nicht ausgeschlossen, daß die successio als Fachausdruck für die Nachfolge der Bischöfe, gleich andern zahlreichen Rechtsbegriffen, durch Tertullian in der Sprache der Theologie Eingang gefunden hat. Wir haben schon früher darauf hingewiesen, und es bestätigt sich hier von neuem: Tertullian versteht es meisterhaft, noch zu wenig scharf formulierte Wahrheiten in die festen Konturen eines in der Esse der Jahrhunderte geschmiedeten Rechtsbegriffs zu zwingen. Irenäus gebraucht in seiner Bischofsliste nebst dem vereinzelten " $\tau \dot{\alpha} \xi$ เ५ "1, was dem tertullianischen "ordo " entspricht, regelmäßig den umstrittenen Ausdruck $\delta \iota \alpha \delta \circ \chi \dot{\eta}, \delta \iota \alpha \delta \varepsilon^{\prime} \chi \varepsilon \sigma \theta \alpha$ ! ${ }^{2}$, was nach den Untersuchungen von ERICH CASPAR nicht die Aufeinanderfolge von gleichgearteten Personen, hier der Bischöfe, bedeutet, sondern das "Weiterempfangen von Hand zu Hand"; " $\delta(\alpha \delta \circ \chi \eta$ " " hätte etwa die gleiche Bedeutung wie $\pi \alpha \alpha_{\alpha} \delta 0 \sigma \iota \varsigma^{3}$. Gegenüber dieser etwas unbestimmten Ausdrucksweise bedeutet Tertullians "successio" einen Fortschritt insofern sie den Rechtscharakter der bischöflichen Amtsnachfolge zum Ausdruck bringt und so auch dem angeborenen Rechtsempfinden des Römers entgegenkommt.

Aber ist diese juristische Betrachtungsweise, die die Wahrheiten und Einrichtungen der Kirche mit Vorliebe mit solchen des römischen Rechts vergleicht und in die Sprache des Rechts kleidet, nicht ein gefährliches Unterfangen? Ist am Ende die Ursache für Tertullians Irrtum in der Frage des bischöflichen Lehramtes hier zu suchen ? Wir haben dargelegt, wie Tertullian im Bischof nicht mehr sieht als einen zuverlässigen historischen Übermittler der apostolischen Lehre, ausgestattet

2 Vgl. adv. haer. 3, 3, 3 (Flor. Patr., Fasc. 4, S. 44, 8).

2 Vgl. adv. haer. 3, 3, 3 (Flor. Patr., Fasc. 4, S. 43).

3 Vgl. E. Caspar, Die älteste röm. Bischofsliste ; Krit. Studien zum Formenproblem des Eusebian. Kanons, in Schriften d. Königsb. gel. Ges., Geisteswiss. Kl. II 4 (Berlin 1926) $233 \mathrm{ff}$. u. $443 \mathrm{ff}$. 
mit einer bloß disziplinären Lehrautorität. Können in diesem Irrtum römisch-rechtliche Vorstellungen mitgespielt haben ?

Wenn Tertullian die Bischofsreihe in der Terminologie des Rechts einen "ordo " nennt, der sich "per successionem " weiterpflanzt, dann ist die Möglichkeit nicht ohne weiteres von der Hand zu weisen, Tertullian habe als gründlicher Kenner des römischen Rechts dabei ein Parallelinstitut des römischen Rechts vor Augen gehabt. Aber welches ist das Rechtsinstitut, das Tertullian bei der "successio " der Bischöfe vorschwebte oder vorschweben konnte ? Vielleicht die "successio auctorum ", die Nachfolge der Rechtsgelehrten, die als Häupter der römischen Rechtsschulen und damit in der Rechtsgeschichte des 1. und 2. nachchristlichen Jahrhunderts eine beherrschende Stellung einnahmen? Es liegen tatsächlich eine Reihe von Gründen vor, die für eine Gleichsetzung der Bischofsreihe mit der Juristenreihe der römischen Rechtsschule durch Tertullian sprechen.

b) Es folgt nun vorerst eine gedrängte Darstellung der "successio auctorum " in den römischen Rechtsschulen. Die einzige Quelle, die uns hierüber Aufschluß gibt, ist ein Abschnitt aus den fast vollständig verlorenen Schriften des römischen Juristen und Rechtshistorikers Sextus Pomponius ( $\dagger$ unter Mark Aurel 161-180). Der betreffende Abschnitt ist überliefert unter dem 2. Titel des 1. Buches der Digesten : De origine iuris et omnium magistratuum et successione prudentium. Nachdem Pomponius, der dreiteiligen Überschrift entsprechend, eine Übersicht über Ursprung und Fortbildung des römischen Rechts und der staatlichen Ämter gegeben hat, zählt er in einem 3. Abschnitt (35-53) die berühmtesten Vertreter der römischen Rechtswissenschaft auf. Die Liste beginnt mit der Zeit der Könige und endigt mit Salvius Julianus (unter Hadrian 117-138 und Antonius Pius 138-161), einem der größten Juristen Roms. Die Kontinuität der römischen Rechtsentwicklung könnte nicht wirksamer in Erscheinung treten als durch diesen lückenlosen geistigen Stammbaum. Er ist der sinnenfällige Beweis dafür, da $B$ es keine Rechtstradition gibt ohne Rechtstradenten. Was uns jedoch an dieser beinahe ein halbes Jahrtausend umfassenden Juristenliste vor allem interessiert, ist der Abschnitt, der zeitlich mit Augustus beginnt und bis in die Mitte des 2. Jahrhunderts reicht, wo die Liste mit Salvius Julianus, dem Zeitgenossen des Verfassers, abbricht. Es ist dies die Zeit der sich bekämpfenden zwei Rechtsschulen der Sabinianer und Prokulianer, deren Gegensatz zurückgeführt wird auf die zwei 
großen Juristen der augusteischen Zeit : C. Ateius Capito und M. Antistius Labeo. Von diesen zwei sagt Pomponius, sie hätten zuerst zwei verschiedene (Rechts-) Schulen - sectae - begründet. Die Sabinianische Schule erhielt ihren Namen von Massurius Sabinus, dem ersten Nachfolger des Capito in der Leitung der Schule, die Prokulianische von Proculus, dem zweiten Nachfolger des Labeo. Worin der Gegensatz der beiden Schulen bestand, läßt sich nicht mehr sicher feststellen, diese Frage ist für uns auch nicht von Belang. Was uns hier interessiert, ist die merkwürdige Tatsache, $\mathrm{da} B$ Pomponius für die Zeit der beiden Rechtsschulen auch zwei selbständige, einander entgegengesetzte Juristenlisten überliefert. Die lange Juristenlinie der republikanischen Zeit spaltet sich mit dem Entstehen der beiden Rechtsschulen gleichsam in zwei Nebenlinien. Der geistige Stammvater der einen Linie ist Capito, der andern Labeo. Anschließend an Capito und Labeo, die auch ihrerseits fest in der Vergangenheit wurzeln - "Ateius Capito, qui Ofilium secutus est, et Antistius Labeo, qui omnes hos audivit ..." werden in genauer Reihenfolge die Juristen aufgezählt, die den beiden Gründern in der Leitung der Schule nachfolgten und deren Ideen bis gegen die Mitte des 2. Jahrhunderts weitergaben. Mit Salvius Julianus, der den Sabinianern zum Siege verhalf und so den Gegensatz der beiden Schulen überwand, beschließt Pomponius die geistige Ahnenreihe der römischen Rechtstradenten.

Weil uns die Juristenlisten der beiden Rechtsschulen besonders interessieren, geben wir nun vorerst unter Weglassung des Unwesentlichen den betr. Abschnitt des Pomponius wieder :

Dig. 1, 2, 2, 47-53. "Post hunc (scil. Tuberonem) maximae auctoritatis fuerunt Ateius Capito, qui Ofilium secutus est, et Antistius Labeo, qui omnes hos audivit, institutus est autem a Trebatio. ... Hi duo primum veluti diversas sectas fecerunt; nam Ateius Capito in his, quae ei tradita fuerant, perseverabat ; Labeo ingenii qualitate et fiducia doctrinae, qui et ceteris operis sapientiae operam dederat, plurima innovare instituit. Et ita Ateio Capitoni Massurius Sabinus successit, Labeoni Nerva qui adhuc eas dissensiones auxerunt. Hic etiam Nerva Caesari familiarissimus fuit. Massurius Sabinus in equestri ordine fuit et publice primus respondit ... Ergo Sabino concessum est a Tiberio Caesare, ut populo responderet; qui in equestri ordine iam grandis natu et fere annorum quinquaginta receptus est. Huic nec amplae facultates fuerunt, sed plurimum a suis audi- 
toribus sustentatus est. Huic (scil. Sabino) successit Gaius Cassius Longinus natus ex filia Tuberonis, quae fuit neptis Servii Sulpicii ... Nervae successit Proculus. Fuit eodem tempore et Nerva filius ; fuit et alius Longinus ex equestri quidem ordine, qui postea ad praeturam usque pervenit. Sed Proculi auctoritas maior fuit, nam etiam plurimum potuit ; appellatique sunt partim Cassiani, partim Proculiani, quae origo a Capitone et Labeone coeperat. Cassio Caelius Sabinus successit, qui plurimum temporibus Vespasiani potuit ; Proculo Pegasus, qui temporibus Vespasiani praefectus urbi fuit; Caelio Sabino Priscus Iavolenus; Pegaso Celsus; patri Celso Celsus filius et Priscus Neratius, qui utrique consules fuerunt, Celsus quidem et iterum; Iavoleno Prisco Aburnius Valens et Tuscianus, item Salvius Iulianus."

Die beiden Juristenreihen ergeben, in ein Schema gefaßt, folgendes Bild :

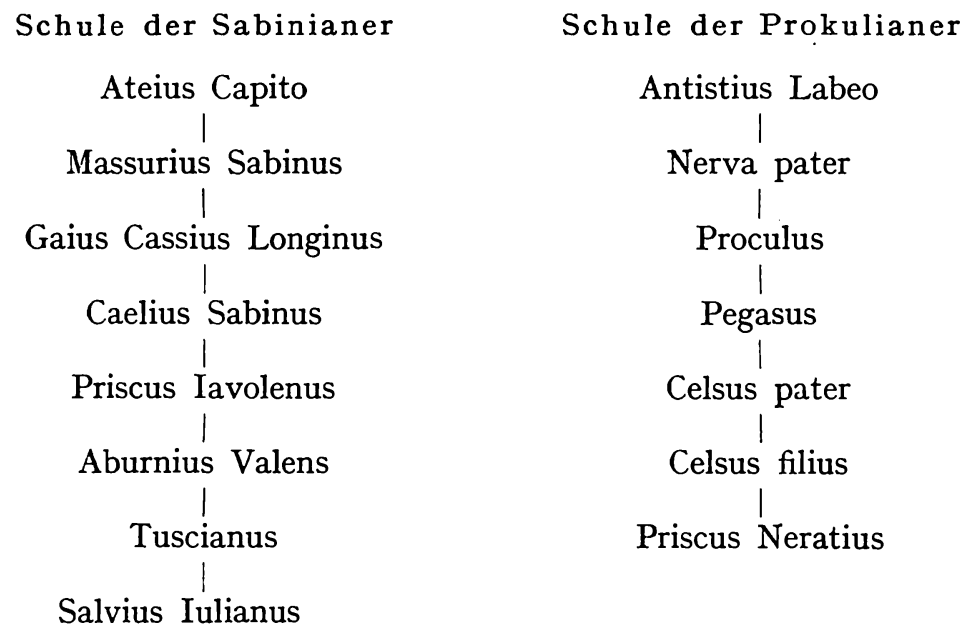

An dieser doppelten Juristenreihe verdienen zwei Momente besonders hervorgehoben zu werden : erstens die betont lückenlose, zeitliche Geschlossenheit, mit der Pomponius die Vertreter der beiden Schulen einander folgen läßt; zweitens die regelmäßige, ausschließliche Verwendung des Ausdruckes "successit " in der Aufzählung der beidseitigen Schulhäupter; in der Aufzählung der republikanischen Juristen begegnet dieser Ausdruck kein einziges Mal ; es wird dort blo $B$ auf das zeitliche Nacheinander (post hunc ...) oder die geistige Abhängigkeit (ab hoc profecerunt) hingewiesen. 
Daß Pomponius bei der Aufzählung der Sabinianischen und Prokulianischen Schulhäupter regelmäßig von einem "Successit " spricht, - Dig. 1, 2, 2, 13 ist sogar ausdrücklich die Rede von der "successio auctorum" und in der Überschrift desselben Titels "de successione prudentium " - während er diesen Ausdruck bei der Aufzählung der republikanischen Juristen vermeidet, ist längst aufgefallen und wurde von kompetentesten Kennern des römischen Rechts als Hinweis auf eine körperschaftliche Organisation der Rechtsschulen gedeutet, deren Vorsteher, meist berühmte Rechtsgelehrte, einander durch "successio " d. i. Rechtsnachfolge ablösten ${ }^{1}$. "Es liegt in jenem Ausdruck (successit), daß es sich bei den Sabinianern und Prokulianern wirklich um eine Rechtsnachfolge, nämlich in die Vorstandschaft der Schule, handelte. " 2

Es kann kein $Z$ weifel darüber bestehen, daß Tertullian die römischen Rechtsschulen mit der in ihnen üblichen Sukzession der Schulhäupter kannte. Die Rechtsschulen hatten seit Beginn der Kaiserzeit bis zur

1 Vgl. C. G. Bruns, Geschichte und Quellen des röm. Rechts; neu bearb. von O. Lenel (Enzyklopädie der Rechtswissenschaften, 1. Bd. 1915) S. 362 : "Die Art, wie Pomponius dic Schulhäupter aufeinander folgen läßt ("succedere ") - und diesem Bericht zu mißtrauen haben wir keinerlei Anlaß - deutet en t schieden auf eine Organisation, die wir uns sehr verschieden von der der Philosophenschulen und so frei vorstellen mögen wie wir wollen, die aber immerhin fest genug gewesen sein muß, um die Wahl eines Vorstandes zu ermöglichen."

Im gleichen Sinne äußert sich R. Soнм. Er sieht in den Beiträgen, die sich Massurius Sabinus von seinen Schülern entrichten läßt, und besonders im Ausdruck "successit" die Belege dafür, da $\beta$ die Rechtsschulen eine den griechischen Philosophenschulen ähnliche korporative Organisation aufwiesen. Vgl. R. SoHм, Institutionen, Geschichte und System des röm. Privatrechts, 17. Aufl. bearb. von L. Mitreis, herausg. von L. Wenger (München u. Leipzig 1923) S. 97 Anm. 15. Was die Beiträge an M. Sabinus betrifft, zitiert R. Soнm ebd. eine Stelle aus Ulpian (Dig. 50, 13, 1, 5), wo dieser in bezug auf das dem Rechtslehrer zu entrichtende Honorar vom "honor, qui in ingressu sacramenti offerri debuit " spricht. Sонм weist darauf hin, daß "sacramentum " im Vulgärlatein für das griechische $\mu \nu \sigma \tau \eta \dot{p} \iota v$ steht, die Mysterien aber Privatkorporationen waren, die von jedem Neueintretenden ein Eintrittsgeld verlangten. - Vgl. zur Frage auch F. P. BREMER, Die Rechtslehrer und Rechtsschulen im röm. Kaiserreich (Berlin 1868) 69 f. : "Ein bestimmter Jurist erscheint als successor eines bestimmten andern, und zwar wiederholt sich diese Erscheinung auf beiden Seiten, auf der der Prokulianer wie der der Sabinianer. Es ist keine bloß wissenschaftliche Nachfolge, sondern auch eine zeitliche Aufeinanderfolge, bei der außer dem Verhältnis des Schülers zum Lehrer noch ein anderes zu Grunde liegen muß. Meines Erachtens kann es nicht wohl einem Zweifel unterliegen, daß Pomponius in jener Darstellung die Juristen angeben will, die in der einen oder andern statio nacheinander als Rechtslehrer aufgetreten sind."

2 R. Sонм, Institutionen 97 Anm. 15. 
Mitte des 2. Jahrhunderts einen zu großen Einfluß auf die Entwicklung des römischen Rechts ausgeübt, ja diese recht eigentlich entschieden und deshalb auch in der gesamten Rechtsliteratur und außerhalb derselben tiefe Spuren zurückgelassen. Wie hätte dies Tertullian, der sich eine gründliche Kenntnis des römischen Rechts angeeignet hatte, der, vermutlich längere Zeit, in Rom ${ }^{1}$, dem Sitz der Rechtsschulen und dies in der Glanzzeit des klassischen Rechts gelebt hatte, entgehen können! Es sei ferner daran erinnert, daß das Wissen um das Bestehen der Rechtsschulen untrennbar mit den Namen der berühmtesten Vertreter der römischen Rechtswissenschaft verknüpft ist, wir erinnern nur an Massurius Sabinus, nach dem sich die Sabinianische Schule benannte, oder an den großen Salvius Julianus, an dessen Namen sich der Sieg der Sabinianer über die Prokulianer knüpft. Es ist übrigens nicht ausgeschlossen, daß Tertullian, der Sohn eines Centurio der Africa proconsularis und selber gewandter Rechtsgelehrter, seinen berühmten Landsmann Salvius Julianus persönlich gekannt hat; denn dieser stammte wie jener aus Latein-Afrika und wurde noch unter Mark Aurel zum Prokonsul von Afrika ernannt.

c) Nach diesen Feststellungen wägen wir die Möglichkeiten und Gründe $a b$, die für einen Einfluß der römischen Rechtsschule auf Tertullians Irrtum hinsichtlich der bischöflichen Lehrgewalt geltend gemacht werden könnten.

Wir sehen in der römischen Rechtsschule zwei Parallelen, die zur Bischofskirche hinführen und die für eine Persönlichkeit, die vom römischen Recht herkommt und erst in reifen Jahren und plötzlich Christ wird, wie dies bei Tertullian der Fall ist, zur Gefahr werden konnten. Diese zwei Parallelen der Rechtsschule sind das Vorsteheramt der Schulhäupter und deren Sukzession d. h. Amtsnachfolge. Diesen beiden Parallelen entsprechen in den christlichen Gemeinden das Vorsteher- und Lehramt der Bischöfe mit ihrer Sukzession.

Die eigentümliche und wichtigste Funktion des Schulhauptes - um mit der ersten Parallele zu beginnen - war sicher die des Lehrers. Das Schulhaupt wachte über die Reinerhaltung und unversehrte Weitergabe der von der betr. Schule vertretenen Rechtsgrundsätze. Nur die

1 Nach H. Kellners überzeugenden Argumenten weilte Tertullian bereits im Jahre 166 in Rom, d. i. zu einer Zeit, wo die Erinnerung an die Rechtsschulen noch frisch war. Vgl. H. Kellner, Tertullians ausgewählte Schriften ins Deutsche übersetzt 1. Bd., Bibl. d. Kirchenväter Bd. 7, S. xxxırv. 
angesehensten Rechtsgelehrten wurden zu Vorstehern der Rechtsschulen bestellt, wie ein Blick auf die Listen des Pomponius beweist. Es geht in den Rechtsschulen in erster Linie um die Pflege eines geistigen Gutes, eben der von der Schule gehüteten Rechtstradition, nicht aber, wenigstens nicht im Wesen, um die Verwaltung eines Vermögens oder um materielle Ziele. Beide Rechtsschulen kämpfen für ihre Grundsätze und suchen diesen zum Durchbruch zu verhelfen. Der Rechtsgelehrte, der der Rechtsschule vorsteht, muß, infolge seiner Stellung als Haupt der Schule, als der Exponent und verantwortliche Führer in diesem geistigen Ringen angesehen werden. Worin der Gegensatz der beiden Schulen bestand, darin ist sich die Wissenschaft nicht einig. Nach O. LENEL ist es "überflüssig, darauf hinzuweisen, daß sehr viele der zwischen den Schulen bestehenden Kontroversen sich um Fragen drehen, die mit wissenschaftlichen Gründen überhaupt nicht entschieden werden können, sondern nur mit Autorität "1. In diese Richtung weist die "auctoritas ", von der in den römischen Rechtsquellen so viel die Rede ist, und mit der die einzelnen Juristen gegeneinander ausgespielt werden. Man beruft sich zur Begründung eines Rechtsentscheides oder einer persönlichen Ansicht auf die " auctoritas", das wissenschaftliche Ansehen eines großen Rechtsgelehrten oder mehrerer. So erwähnt Pomponius in der Aufzählung der Prokulianischen Schulhäupter für denselben Zeitabschnitt einmal drei bekannte Juristennamen miteinander: Proculus als Vorsteher der nach ihm benannten Schule, daneben Nerva filius und einen Longinus, bemerkt aber inbezug auf ihr juristisches Ansehen : "sed Proculi auctoritas maior fuit, nam etiam plurimum potuit ». Weil Prokulus als Jurist eine größere " auctoritas " genoß als die andern, wird er auch zum Vorsteher der Schule prädestiniert gewesen sein, daher : "Nervae successit Proculus ». Dasselbe wird für C. Cassius Longinus, den Nachfolger des großen Sabinus zutreffen, von dem Pomponius ebenfalls berichtet : "plurimum in civitate auctoritatis habuit ", oder für Cassius Caelius Sabinus, "qui plurimum temporibus Vespasiani potuit".

Führt von hier eine Parallele zur Bischofskirche ? Doch wohl die, da $B$ der Lehrberuf, ähnlich wie beim Vorsteher der Rechtsschule, eine der dem Bischofsamt wesentlichen Funktionen darstellt. Gleich Irenäus weist auch Tertullian dem Bischof im Lehrorganismus der Kirche eine besondere Stellung zu. Der Bischof ist ihm von den Aposteln eingesetzt

1 C. G. BRuns, Gesch. u. Quellen des röm. Rechts 362. 
und deshalb der erstqualifizierte Zeuge der Apostellehre : " sicut apostoli non diversa inter se docuissent, ita et apostolici non contraria apostolis edidissent "1. Der Bischof ist der oberste Lehrer der Gemeinde und als solcher der erstberufene Wächter für die Reinerhaltung und Verteidigung der christlichen Lehre im beständigen Kampf mit den Häresien. Aber wenn auch von den Aposteln begründet, so ist die bischöfliche Lehrgewalt, wie schon früher dargelegt wurde, für Tertullian trotzdem keine unfehlbare, göttlich beglaubigte, sondern bloß eine historisch empfohlene und zuverlässige Zeugenschaft. So wird das "magisterium" des Episkopats zu einer rein natürlichen, menschlichen "auctoritas " erniedrigt. Es fällt auf, wie oft Tertullian im Zusammenhang mit der Lehrgewalt der Apostel und Bischöfe das Wort "auctoritas" im Munde führt.

So erklärt er in seiner Polemik gegen die Evangelienfälschung des Marcion, die ersten berufenen Verfasser der Evangelien seien die Apostel ; jene Evangelisten aber, die nicht Apostel seien, könnten sich auf die Autorität der Apostel berufen : "... praedicatio discipulorum suspecta fieri posset de gloriae studio, si non adsistat illi a uctoritas magistrorum, immo Christi, quae magistros apostolos fecit. " ${ }^{2}$

Von Rom wird gesagt, dieses habe über die Tochtergemeinde Karthago in Fragen der kirchlichen Lehre die " auctoritas " : " habes Romam, unde nobis quoque auctoritas praesto est ". Dem Patripassianer Praxeas wird der Vorwurf gemacht, er sei beim römischen Bischof für die " auctoritates praedecessorum ", wobei " auctoritas " wohl am besten mit Gutachten, autoritärer Entscheid wiedergegeben wird, eingetreten, um ihn gegen die montanistische Bewegung umzustimmen ${ }^{4}$. An Nigidius und Hermogenes richtet der Apologet die Aufforderung : "Cupio ostendant mihi ex qua auctoritate prodierint. " 5

Gegen Marcion spricht der Apologet von der "auctoritas ecclesiarum apostolicarum ", die für die Echtheit der Evangelien zeuge ${ }^{6}$.

Als zweite Parallele führen wir die der römischen Rechtsschule und Bischofskirche gemeinsame "successio" an. Die Schulhäupter

1 Praescr. haer. 32 (Kr. 40, 18).

2 Marc. 4, 2 (Kr. 426, 10).

3 Praescr. haer. 36 (Kr. 45, 9).

4 Prax. 1 (Kr. 228, 9).

5 Praescr. haer. 30 (Kr. 38, 40).

6 Marc. 4, 5 (Kr. 431, 4). 
folgen einander in ununterbrochener Reihenfolge. Nachdem einmal eine Rechtsschule organisiert und in ihr das Amt eines Vorstehers geschaffen ist, muß mit dem Ausscheiden eines Vorstehers stets ein neuer seine Stelle einnehmen, soll das Amt nicht untergehen, die Organisation zerfallen und damit auch eine geregelte Weitergabe der Tradition aufhören. Und so folgt denn auch den Begründern der beiden Rechtsschulen beiderseits durch einen Zeitraum von etwa 150 Jahren eine ununterbrochene Reihe von Schulhäuptern, wie die zwei parallel verlaufenden Listen des Pomponius zeigen. Jeder Nachfolger übernimmt die Pflichten und Befugnisse seines Vorgängers, es handelt sich folglich um eine stete juristische "successio ", weshalb denn auch Pomponius bei der Aufzählung der Schulhäupter mit Recht und zweifelsohne mit Absicht regelmäßig von einem "successit " spricht.

Wie in den beiden Rechtsschulen die Schulhäupter, so lösen sich . auch in den christlichen Gemeinden die Bischöfe in ununterbrochener Reihenfolge ab. Dabei handelt es sich, wie wir zu Beginn dieses Abschnittes darlegten, im Vollsinn des Wortes um eine Rechtsnachfolge, indem jeder neue Bischof die Rechte und Pflichten seines Vorgängers übernimmt, so daß es nicht überrascht, wenn der Jurist Tertullian von der "successio " der Bischöfe spricht. Wir stellen weiter fest, daß man sowohl in den Rechtsschulen wie in den christlichen Gemeinden die Reihenfolge dieser Vorsteher sorgfältig registrierte. In den christlichen Gemeinden wurden nach dem Zeugnis des Irenäus die Bischofslisten seit frühester Zeit geführt. Ob dasselbe für die Rechtsschulen zutrifft, ergibt sich aus der Aufzählung des Pomponius nicht, wenn es auch große Wahrscheinlichkeit für sich hat. Denn es ist zu bedenken, da sich die Rechtsschulen über einen Zeitraum von etwa 150 Jahren erstrecken und daß Pomponius seine Doppelliste erst am Ende dieses Zeitraums aufstellt, was die Benutzung vorhandener Listen nahelegt. Aber es kommt schließlich in unserer Frage nicht auf die schriftliche Fixierung der Sukzessionsreihen, sei es der Schulhäupter oder Bischöfe, an, sondern auf die Tatsache, da $B$ diese einander in lückenloser Reihenfolge ablösen und daß diese lückenlose Aufeinanderfolge da wie dort den $Z$ weck hat, die Tradition zu sichern. Denn es gibt keine Tradition ohne Tradenten. Schulhaupt wie Bischof stehen an der Spitze einer Organisation, deren wesentliche Aufgabe es ist, das ihr anvertraute juristische bzw. religiöse Traditionsgut gegen Angriffe zu verteidigen und unverfälscht weiterzugeben. Schulhaupt und Bischof erscheinen als die verantwortlichen und bestandsichernden Exponenten dieser Auf- 
gabe. Eine ununterbrochene Kette solcher Exponenten sichert den Fortbestand der Tradition.

Soweit die zwei Parallelen, die sich, immer und hauptsächlich von Tertullian her gesehen und ohne einem der beiden Vergleichsglieder Gewalt anzutun, zwischen der Rechtsschule und der Bischofskirche ziehen lassen. Wir sind uns wohl bewußt, daß wir nur einen sehr unvollkommenen Deutungsversuch vorlegen. Für einen sichern Schluß in dieser heiklen Frage erweisen sich wohl die Vergleichsglieder mit ihren zur Verfügung stehenden Quellenunterlagen als zu knapp. Dazu wären noch manche Probleme des tertullianischen Stils zu lösen und über gewisse für eine solche Untersuchung entscheidende Termini gründliche Untersuchungen anzustellen ${ }^{1}$.

Die 2. Präskription in praescr. haer. 21, die wir als das Präskrip- tionsargument Tertullians ansprechen, ist, von Tertullian her gesehen, theologisch nicht schlüssig. Das heißt aber nicht, daß das Argument nicht für uns beweiskräftig sei, da wir im Lehramt des Bischofs nicht nur eine historisch-disziplinäre Funktion sehen. Damit fallen auch die Abstufungen dahin, die Tertullian hinsichtlich der Zuverlässigkeit in der Lehrübermittlung macht, und die einzige Korrektur, die an der 2. Präskription in praescr. haer. 21 anzubringen ist, besteht darin, daß alle apostolischen Gemeinden, seien sie in der Sprache Tertullians direkt oder indirekt apostolisch, bzw. deren Bischöfe, über den Inhalt der Apostelpredigt Auskunft geben können, sofern sie nur in Frieden und Gemeinschaft mit dem römischen Bischof leben, dessen Apostolizität des Ursprungs und der ununterbrochenen Sukzession von Petrus her feststeht.

1 Die gründliche Arbeit von V. Morel über Disciplina - siehe Literaturverzeichnis! - liefert den Beweis dafür, wie notwendig und förderlich solche Wort-Untersuchungen für das Verständnis und die Klärung mancher Begriffe Tertullians sind. 


\section{SCHLUSSWORT}

Unsere Arbeit teilt sich in einen juristischen und einen theologischen Teil.

I. Der erste, juristische Teil hat für das 2. Jahrhundert, in welchem Tertullian lebte, eine dreifache prozeßrechtliche praescriptio festgestellt : a) die praescriptio pro actore, ein außerordentlicher Bestandteil der Formel im Formularproze $\beta$ und dazu bestimmt, den in der intentio formulierten klägerischen Anspruch abzugrenzen ; $b$ ) eine praescriptio, insofern damit die exceptio, d. i. der Einwand oder die Einrede gemeint ist, die der Beklagte im Formularprozeß vor dem Prätor geltend macht; die exceptio wird in der Regel in Form eines negativen Bedingungssatzes in die Formel eingefügt ; $c$ ) eine praescriptio des Kognitionsprozesses, der Prozeßform der Kaiserzeit. Unter dieser praescriptio ist eine ohne feste Form geschehende Berufung des Beklagten auf eine dem Prozeß entgegenstehende Vorschrift, meist eine Verjährungs- oder Ausschlußfrist, zu verstehen, die, wenn sie bewiesen werden kann, den Kläger abweist. Wir haben den Nachweis erbracht, da $\beta$ die Präskriptionen Tertullians diese letztere zum Vorbild haben.

II. Der zweite, theologische Teil gibt im 1. Kap. eine ausführliche Analyse von praescr. haer. 15-37. Die Analyse deckt den planvollen Gedankengang dieses Hauptabschnittes von praescr. haer. auf. Im Mittelpunkt desselben stehen die zwei Präskriptionen in Kap. 21, die, etwas freier gefaßt, folgendermaßen wiedergegeben werden können :

1. Präskr.: Christus hat die Apostel mit der Verkündigung seines Evangeliums beauftragt. Also darf man nicht auf andere Prediger hören.

2. Präskr.: Die Apostel wiederum haben die von ihnen gegründeten Gemeinden mit der Verkündigung des Evangeliums betraut. Also darf auf keine andere Weise als durch eben diese Gemeinden erklärt werden, was Lehre der Apostel, d. h. Offenbarung Christi ist. 
Wenn Tertullian die Berufung der Apostel durch Christus und die Berufung der apostolischen Gemeinden durch die Apostel und die aus diesen beiden Tatsachen sich ergebenden Folgerungen den Häretikern als zwei Präskriptionen entgegenhält, so will er damit zum Ausdruck bringen, da $B$ die Häretiker durch diese zwei Tatsachen samt den daraus sich ergebenden Folgerungen so zwingend abgewiesen, d. h. widerlegt werden, daß ein Eingehen auf die verschiedenen Lehrstreitigkeiten streng genommen nicht mehr nötig sei, geradeso wie der Kläger im Prozeß durch die praescriptio des Beklagten abgewiesen wird, so daß ein Eingehen auf den Streit nicht mehr in Frage kommt.

Es liegt in der Natur der Sache, wenn Tertullian zwei Präskriptionen erhebt. Die erste Präskription umschreibt das Fundament (die Apostel), auf dem die wahre Kirche aufgebaut ist. Die erste Präskription bzw. die darin ausgesprochene Wahrheit bildet die Grundlage für die zweite Präskription. Durch die zweite Präskription wird festgestellt, wer die nächsten $\mathrm{Nachfolger} \mathrm{der} \mathrm{Apostel} \mathrm{sind} \mathrm{:} \mathrm{die} \mathrm{von}$ diesen persönlich gegründeten Gemeinden. Aus der Tatsache, daß die apostolischen Urgemeinden die einzigen sind, die mit den Aposteln in Kontakt kamen und von ihnen die Offenbarung empfingen, ergibt sich, $\mathrm{da} B$ die von diesen Gemeinden verteidigte Lehre die älteste ist. $\mathrm{Da} B$ diese Gemeinden, entgegen dem Einwand der Häretiker, die Apostel richtig verstanden und nicht einen Irrtum überliefert haben, wird von Tertullian erhärtet durch die Berufung auf das Prinzip von der Priorität der Wahrheit vor dem Irrtum und den geschichtlichen Nachweis, daß alle bestehenden Häresien aus nachapostolischer Zeit stammen. So werden die Häretiker durch den alleinigen Nachweis ihres spätern Auftretens, ihrer Neuheit gegenüber der katholischen Lehre, des Irrtums überwiesen. Deshalb nennt Tertullian diese zweite Präskription einmal praescriptio novitatis (Marc. 1,1). Während die erste Präskription mehr im Hintergrund bleibt und die zweite stützt, führt diese den Hauptstoß gegen die Häretiker und weist sie endgültig ab.

Das Präskriptionsargument des Tertullian setzt sich also aus zwei Präskriptionen zusammen. Statt vom Präskriptionsargument, würde man daher zutreffender von den (zwei) Prozeßeinreden oder Einwänden des Tertullian gegenüber den Häretikern sprechen. Dies noch aus dem andern Grunde, weil sich heute mit "praescriptio" meistens die Vorstellung der Verjährung verbindet.

Aus dem Gesagten ergibt sich klar, daß Tertullian gegenüber den Häretikern nicht eine Verjährung geltend macht, wie in zahlreichen 
Handbüchern der Apostologetik oder Patristik zu lesen steht. Die praescriptio des römischen Kognitionsprozesses bezeichnet kurz die Berufung des Beklagten auf eine den Prozeß ausschließende Verordnung. Weil es sich dabei in den meisten Fällen um eine Verjährungs- oder Ausschlußfrist handelt, wurde "praescriptio " allmählich und dies schon vor Justinian gleichbedeutend mit "Verjährung". Unsere Arbeit hat den Beweis erbracht, da $\beta$ "praescriptio" im Munde Tertullians noch den bei den zeitgenössischen Juristen gebräuchlichen und ursprünglichen Sinn von Prozeßeinrede, Berufung auf eine dem Prozeß entgegenstehende Vorschrift bedeutet. Die Präskriptionen Tertullians machen gegenüber den Häretikern nicht eine Verjährung geltend, sei es am Besitz der Heiligen Schrift oder der christlichen Wahrheit im allgemeinen, derzufolge die Kirche den rechtmäßigen Besitz derselben oder die Wahrheit ihrer Lehre nicht mehr beweisen müßte, sondern sie verweisen auf die zwei Tatsachen, daß Christus, auf den sich Katholiken und Häretiker berufen, die Apostel und sonst niemand zu Verkündern seiner Lehre bestellt hat (1. Präskription), die Apostel aber die Lehre niemandem als den von ihnen persönlich gegründeten Gemeinden übergeben haben (2. Präskription), wodurch das höhere Alter der apostolischen Gemeinden und ihrer Lehre vor den Häresien erwiesen und so die Häresien allein auf Grund ihres spätern Entstehens des Irrtums überführt werden.

Ein einläßlicher Vergleich zwischen der tertullianischen praescriptio und jener des Kognitionsprozesses auf Grund der beidseitigen Terminologie und Funktion ergibt, daß sich die praescriptio Tertullians mit der prozessualen praescriptio insofern deckt, als sie ein Einwand ist, der, wie die prozessuale praescriptio den Prozeß, einen Streit der Katholiken mit den Häretikern oder Heiden abweist. Die praescriptio Tertullians unterscheidet sich von der des Prozesses, insofern sie mit theologischem Inhalt erfüllt ist.

Die Untersuchung der in praescr. haer. 21 enthaltenen zwei Präskriptionen auf ihre Formulierung beweist für beide eine bestimmte Struktur, die mit dem innern Aufbau der Kap. 15-37 planvoll verkettet ist.

Sehr wahrscheinlich enthält praescr. haer. 37 eine Anspielung auf die longi temporis praescriptio, die vermutlich im letzten Jahrzehnt des 2. Jahrh. n. Chr. eingeführt wurde.

Die zwei in Kap. 21 entwickelten Präskriptionen sind die einzigen in praescr. haer. enthaltenen Präskriptionen.

Zuletzt prüften wir die tertullianische praescriptio vom theologischapologetischen Standpunkt aus. Wir unterschieden dabei die rein äußere 
Funktion der theologischen Präskription Tertullians von ihrem theologischen Inhalt.

So meisterhaft Tertullian die prozessuale praescriptio auf die Apologetik anwendet, so ist er sich nichtsdestoweniger der Unzulänglichkeiten seiner theologischen Präskriptionen bewußt: sie lösen die eigentliche Streitfrage und die Einwände der Häretiker nicht, sondern weisen sie bloß ab. Deshalb sieht Tertullian in den beiden in praescr. haer. 21 formulierten Präskriptionen nur ein argumentum generale, das nach seiner Erklärung noch eine einläßliche Einzelwiderlegung - in der Rechtssprache retractatio genannt - der verschiedenen Häresien notwendig macht.

Was den theologischen Inhalt der beiden Präskriptionen betrifft, wurde festgestellt, daß die erste Präskription theologisch unanfechtbar ist, nicht aber die zweite, wenn wir sie von Tertullian her sehen. Die zweite Präskription erklärt, daß die von den Aposteln persönlich gegründeten Gemeinden allein über den Inhalt der Apostelpredigt Auskunft geben dürften, und in der Verteidigung dieser Präskription gegen die Behauptung der Häresien, sie reichten auch in die apostolische Zeit zurück, beruft sich Tertullian auf die ununterbrochene, auf die Apostel zurückreichende Sukzession der Bischöfe in den apostolischen Gemeinden. So stellt also die 2. Präskription in ihrem tiefsten Kern die Berufung auf die von der Sukzession getragene Lehrübermittlung und Lehrentscheidung der Bischöfe dar. Da jedoch Tertullian im Bischof nur einen mit disziplinärer Autorität ausgestatteten historischen Zeugen der apostolischen Lehre sieht, verliert die 2. Präskription, von Tertullian aus gesehen, ihre theologische Beweiskraft. Dieser Mangel verhindert jedoch nicht, daß die Apologetik, da sie die richtige Auffassung hat von der bischöflichen Lehrgewalt, die 2. Präskription zu ihrer Verteidigung handhabt, wie dies tatsächlich seit den Tagen Tertullians bis heute der Fall war. 


\section{STELLENREGISTER}

Digesten 1, 2, 2, 47-53 . . . 165 f. Tertullian, carne Chr. 4 . . 85

$-5,1,52,3$. . . . . 88 一, -6 . . . . . . . . 85

$-5,1,55$. . . . . . . 161

,--15 . . . . . . . 85

$-5,2,12$ pr. . . . . . 24

- 8,1,4 pr. . . . . 88

-, Hermog. 1 . . 848890

- 29,3,12...... . 77

-, $-7 . . . . . . . .84$

- 38,10,10, 3 . . 106 Anm. 1

一, -39 . . . . . . . . 84

- 44,1,10..... . 88

一, ieiun. 17 . . . . . 65

- 44,4,4,14..... . 162

一, Iud. 13 . . . . . . 8488

- 47, 15,3,1... . . 88

—, Marc. 1, 1 . 65839095147

- 48,5,16,6... . $2287 / 8$

一, $-1,6$. . . . . . . 83

- 48,5,16,7..... . 87

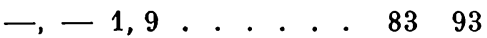

- 48,16,7 pr. . . . . . . 88

一, $-1,11$. . . . 8393

- 49, 1, 3 pr.-2... . . . 23

-, $-1,22 \quad$. . . $\quad 83 \quad 88145$

$-49,16,13,1$. . . . . . 22

$-50,5,1,1$... . 87

一, $-2,24$. . . . . . . 83

一, $-3,1$. . . . . . 8392

-, $-3,16$. . . . . . 83

Codex Justinianus $7,32,3 \quad$. 162

一, $-4,1$. . . . . . 8388

- 7, 32,7 . . . . . . 117

-, $-4,2$. . . . . . 170

-, $-4,4$. . . . . . . 84

- 7,33,1 . . . . . . . 32

-, $-4,5$. . . . . . . 84

$-7,33,5$. . . . . . . 88

一, $-4,6$. . . . . . . . 84

$-7,34,1$. . . . . . . 88

一, $-4,10$. . . . . . . 84

$-7,34,3$. . . . . . 24

$-,-4,25$. . . . . . 84

$-7,34,5$. . . . . . 88

一, $-4,38$. . . . . . . 144

- 7,36,2 . . . . . . . 88

-, $-4,5$. . . . . . $158 / 9$

- 8,13,15 . . . . . . . . . 89

$-8,14,5$. . . . . . . 24

- 9,9,32 . . . . . . 88

-, $-5,1$. . . . . . . . 84

-, $-5,6 . . . . . . .884$

-, $-5,19 \quad$. . . 8490131

- $-5,38$. . . . . . 82

Tertullian, apol. 1 .... $137 \quad-$ mart. 1....... . 2

- -4 . . . . . . . . . 82

-, nat. 1,3 . . . . . . 83

一, - 7 . . . . . 8390137

-, $-1,20$. . . . . . . 83

-, -44 . . . . . . . . 137

-, $-2,1$. . . . 83147

一, -47 . . . . . . . . 83

一, bapt. 3 ..... . . . 82

-, $-2,12$. . . . . . 8391

-, carne Chr. $2 \quad . \quad 85144151$

一, paenit. 5 . . . . . 1826

-, pat. 4 . . . . . 8492 
Tertullian, praescr. haer. 15-37 siehe Analyse 39-80

一, Prax. 11 . . . . . . . 85

-, resurr. 2 . . . . . . 85

-, -19 . . . . . . . . 82

-, Scorp. 10 . . . . 8588
Tertullian, Valent. 1. . . 7

—, Virg. vel. 1 . . . 8488

Eusebius, hist. eccl. 2. 2, 4. . 3

一, $-7,19$. . . . . . . . 78

Irenäus, adv. haer. 3, 3140152159

\section{PERSONEN- UND SACHREGISTER}

$$
\text { T. }=\text { Tertullian pr. }=\text { praescriptio }
$$

abdicatio, der Häretiker 121.

Adam K. 63, 150 f., $154 \mathrm{f}$.

adiudicatio 15 .

Allie J.-L. 41, $133 \mathrm{f}$.

Amtsnachfolge, der Bischöfe $161 \mathrm{f}$. antecessor, für Apostel 110, $161 \mathrm{f}$. Apelles, Gnostiker 7, 58, 108.

Apostel : von Christus gesandt 48 ; gründen Gemeinden 49 ; besitzen die ganze Lehre Christi 58 ff. u. teilen sie allen ganz mit $60 \mathrm{ff}$., verbieten Disputationen mit Häretikern 44 ; ihre autographa 76 ff.; cathedrae apostolorum $76 \mathrm{ff}$. ; Auctores und antecessores in bezug auf ihre Nachfolger $160 \mathrm{ff}$.

Apostolische Gemeinden : von den Aposteln gegr. 49 f., 73 ; haben Apostel richtig verstanden $62 \mathrm{ff}$. ; Gemeinschaft mit ihnen Kriterium der Wahrheit 54 ff. ; mittelbar und unmittelbar apostolische G. 49 f., $149 \mathrm{ff}$; Vorrang der unmittelbar apostolischen G. 150 ff. ; nach T. kein Primat Roms 152. auctor, für Apostel 110, 162.

auctoritas, der Apostel 71, der Bischöfe 170.

Bardenhewer O. 1.

Beamtenprozeß s. Kognitionsprozeß. Besitz : an Heiliger Schrift $112 \mathrm{ff}$; Störung durch Häretiker $106 \mathrm{ff}$.
Bischof: amtlicher Lehrzeuge mit disziplinärer Autorität $150 \mathrm{ff}$. ;

Lehrgewalt 156 ff., 168 f. ; " Ordo episcoporum " $157 \mathrm{ff}$. ; apostolische Sukzession $159 \mathrm{ff}$.

bona fides s. Gutgläubigkeit.

Bremer F. P. 167 Anm. 1.

capere, erwerben 105.

Caspar E. 163.

cavere, testamento 118.

cognitio extraordinaria s. Kognitionsprozeß.

condemnatio, im Formularprozeß 15.

Darlehensklage 14 .

demonstratio, im Formularprozeß 15. $\delta 1 \alpha \delta 0 \%$ '́ 163.

disciplina 46 .

Einheit, des Glaubens 55, 64. ; Werk des Heiligen Geistes $62 \mathrm{f}$.

Ersitzung, im röm. Recht 28 ff. ; der Heiligen Schrift ? 125.

Ersitzungsfrist, Unterbrechung derselben 34 ; für longi temporis pr. 34 ; für Heilige Schrift $114 \mathrm{f}$.

Erwerbsgrund (iustum initium), für longi temporis pr. 33 ; für Besitz der Heiligen Schrift $115 \mathrm{ff}$.

exceptio, im Formularprozeß 17 ; ausnahmsweise pr. genannt 19. exheredatio, der Häretiker $120 \mathrm{f}$. 
Felder H. 130 Anm. 1.

Fideikommiß, auf der Heiligen Schrift $118 \mathrm{f}$.

fides $46 \mathrm{f}$.

Formel, im Formularprozeß $14 \mathrm{ff}$.

Formularprozeß $12 \mathrm{ff}$.

Gnostische Sekten 6 ff., $107 \mathrm{f}$.

Gutgläubigkeit (bona fides), für longi temporis pr. $33 \mathrm{f}$; ; für Besitz der Heiligen Schrift $123 \mathrm{f}$.

Häretiker : ihre Waffe die Heilige Schrift 43 f., 100 ff. ; ihre Einwände gegen die Lehre der Kirche $57 \mathrm{ff}$; ; widerlegt durch ihr späteres Auftreten 70, 74 und ihre Werke $70 \mathrm{f}$. ; nicht apostolischen Ursprungs 73, von den Aposteln verurteilt 74 und enterbt $120 \mathrm{f}$. und verstoßen 121.

Heiliger Geist : Garant der Wahrheit $62 \mathrm{f}$. ; unklare Begriffe T.s $154 \mathrm{f}$.

Heilige Schrift: Mißbrauch durch Häretiker $43 \mathrm{f}$. ; Verhältnis zur Tradition $45 \mathrm{ff}$., $100 \mathrm{ff}$; Disput auf Grund der Heiligen Schrift $43 \mathrm{f}$. ; Verfälschung durch Häretiker 107 f. ; Eigentum der Kirche $79 \mathrm{f}$; ; Kirche besitzt sie von jeher und früher als Häretiker 109, weil ihr von Aposteln testamentarisch vermacht $117 \mathrm{f}$., mit Fideikommiß 118.; keine Ersitzung durch Kirche 125.

heres, apostolorum 117, extraneus u. domesticus 122 .

Hermogenes, Gnostiker 71 f., 170. Hüntemann U. 3, 41, 48, $67 \mathrm{ff}$, $127 \mathrm{ff}$.

intentio, im Formularprozeß 15.

Irenäus 152, 163.

iustum initium s. Erwerbsgrund.

Koch H. 4.

Kognitionsprozeß $20 \mathrm{ff}$.
Labriolle P. de 2, 4.

Lenel O. 169.

litterae pacis 56 .

longi temporis pr.: im röm. Recht $28 \mathrm{ff}$; angewendet auf Heilige Schrift $99 \mathrm{ff}$.

Marcion 6, 107.

Möhler J. A. 1.

Monceaux P. 99.

Montanus 56.

Morel V. 46 Anm. 5.

Moricca U. 99.

Mutterkirchen s. (unmittelbar) apostolische Gemeinden.

Nigidius, Gnostiker 71 f., 170.

Norden Ed. 40, 68.

ordo episcoporum $157 \mathrm{ff}$., Garant für unverfälschte Weitergabe der Lehre der Apostel $158 \mathrm{f}$.

$\pi \alpha \rho \alpha y \rho \alpha \varphi \emptyset n$. 24.

Partsch J. 24, 27 Anm. 2, 31, 87, 99.

Pomponius, röm. Rechtshistoriker $164 \mathrm{ff}$.

possessio, an der Heiligen Schrift $112 \mathrm{ff}$.

Praxeas, Patripassianer 56, 170.

praescriptio: im Formularprozeß : pr. pro actore 16,25 ; pr. pro reo 16. - im Kognitionsprozeß 21 ff., 27. ; Pr. des Kognitionsprozesses von $T$. auf Theologie übertragen 27, $86 \mathrm{ff}$; - - longi temporis pr. $28 \mathrm{ff}$., ihr Wesen $28 \mathrm{ff}$., älteste Quellen $32 \mathrm{f}$,, Voraussetzungen $33 \mathrm{ff}$; Z Zur Zeit T.s noch nicht Ersitzungsinstitut 35. Prozessuale Gestalt $35 \mathrm{f}$; ; - in T.s Schriften $83 \mathrm{ff}$; Einwand $87 \mathrm{ff}$. und abgekürztes Beweisverfahren $89 \mathrm{ff}$.; T. gibt der pr. theologischen Inhalt $92 \mathrm{ff}$; ; nur die pr. novitatis Gemeingut der Apologetik geworden $94 \mathrm{f}$.; theologische Be- 
denken $135 \mathrm{ff}$. Einzelwiderlegung (s. retractatio) der Häretiker trotzdem notwendig $143 \mathrm{ff}$. ; nur argumentum generale 147.

Primat 152.

Prokulianer $164 \mathrm{ff}$.

Prozeßurkunde 14.

Rechtsschulen, römische $164 \mathrm{ff}$.

replicatio : im röm. Recht 18 , bei $\mathrm{T}$. $74 \mathrm{ff}$.

res, für christliche Lehre 124.

retractatio $56,142 \mathrm{ff}$.

Rom : Gemeinschaft mit Karthago 55. ; Mutterkirche Karthagos 152. ; Auctoritas über Karthago 170.; kein Lehrprimat 152.

Sabinianer 164.

Schloßmann S. 3.

Septimius Severus 4, 31, 32.

Sohm R. 167 Anm. 1.

successio: der röm. Rechtsschulen 164 ff., der Bischöfe 159 ff., 170 ff. Symbolum, römisches $76 \mathrm{ff}$.

Terminologie, juristische, bei T. 93 f., $155 \mathrm{f}$.
Tertullian : Apologet $1 \mathrm{ff}$; juristische Bildung $3 \mathrm{f}$., 82. Pandektenjurist ? 4. ; führt juristische Termini in Theologie ein $93 \mathrm{f}$.; Gefahren $154 \mathrm{f}$.

testamentum s. Heilige Schrift.

Tochterkirchen s. (mittelbar) apostolische Gemeinden.

Tradition, christliche 45 ; Verhältnis zur Heiligen Schrift $45 \mathrm{f}$.; juristische $164 \mathrm{ff}$.

usucapio 30 .

Valentin, Gnostiker 7, 107.

Verjährungsfrist : im Kognitionsprozeß $21 \mathrm{ff}$; für Besitz der Heiligen Schrift $114 \mathrm{f}$.

Wahrheit, christliche: Kriterium $54 \mathrm{ff.}$; Priorität vor Irrtum $64 \mathrm{ff.}$, 75.

Wallenburch A. u. P. $133 \mathrm{f}$.

Wenger L. $11 \mathrm{ff}$.

Zivilprozeß, römischer $11 \mathrm{ff}$. 
In der gleichen Sammlung sind erschienen :

I.

LEONHARD WEBER :

Hauptfragen der Moraltheologie Gregors des Großen

Ein Bild altchristlicher Lebensführung

xII + 288 Seiten (1947) Fr. 9.-

II.

P. ANDREAS SCHMID:

Die Christologie Isidors von Pelusium

XII + 114 Seiten (1948) Fr. 5.-

III.

Joseph KaSPAR STIRNIMANN :

Die Praescriptio Tertullians im Lichte des römischen Rechts und der Theologie

xII + 180 Seiten (1949) Fr. 6.50 
Printed in Switzerland 